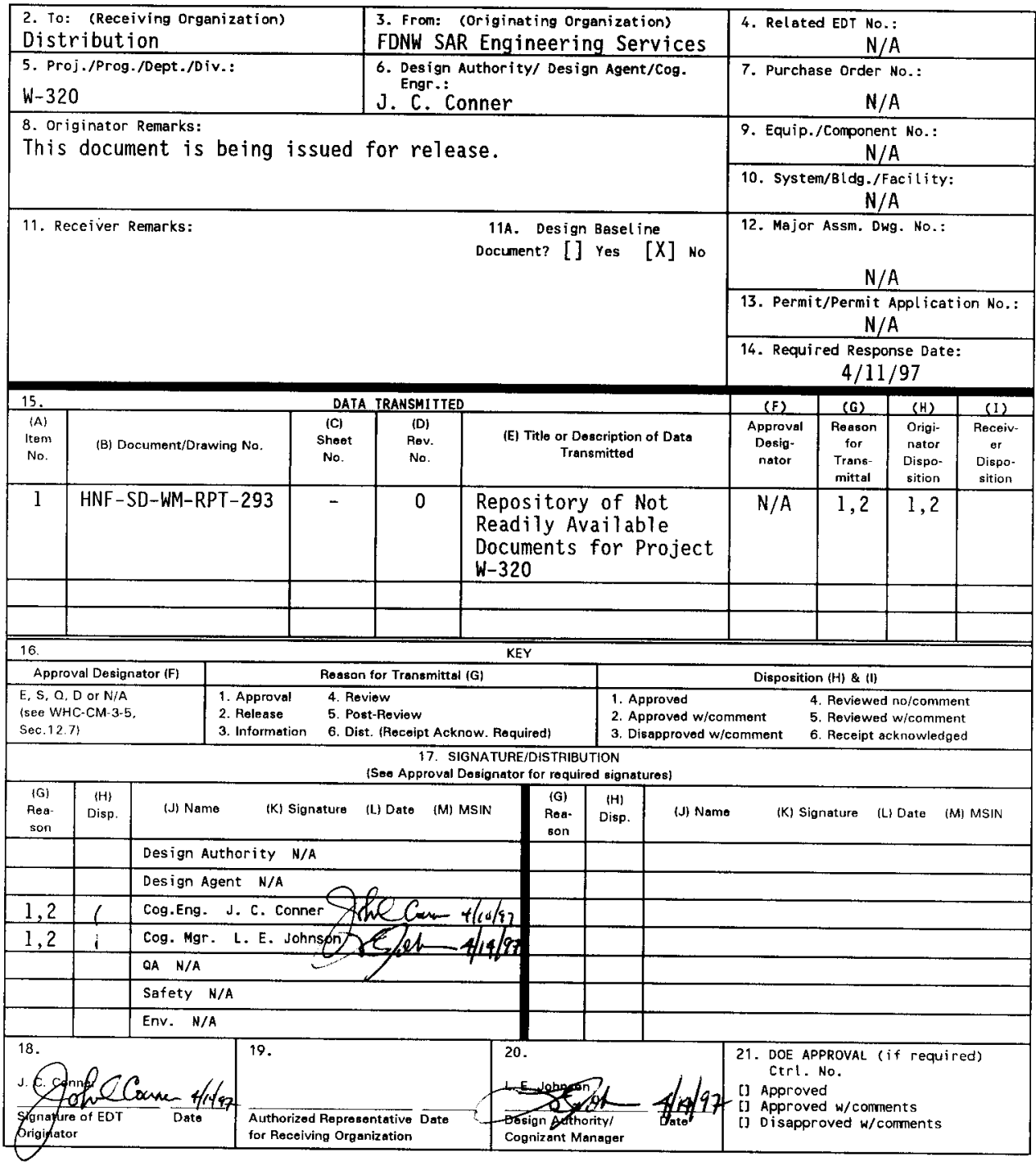

BD-7400-172-2 (05/96) GEF097 


\section{Repository of Not Readily Available Documents For Project W-320}

J. C. Conner

Fluor Daniel Northwest, Richland, WA 99352

U.S. Department of Energy Contract DE-ACO6-96RL13200
EDT/ECN: 616290
Org Code: 403
B\&R Code: EW 3130010
UC: 510
Charge Code: E09120
Total Pages: 339

Key Words: WRSS, S1uicing, Tank 241-C-106

Abstract: This document provides a readily available source of technical reports for the development of the safety documentation provided for the waste retrieval sluicing system (WRSS), designed to remove the radioactive and chemical sludge from tank 241-C-106, and transport that material to double-shell tank 241-AY-102 via a new, temporary, shielded, encased transfer line.

IRADEMARK DISCLAIMER. Reference herein to any specific commercial product, process, or service by trade name, trademark, manufacturer, or otherwise, does not necessarily constitute or imply its endorsement, recommendation, or favoring by the United states Government or any agency thereof or its contractors or subcontractors.

Printed in the United States of America. To obtain copies of this document, contact: Document Control Services, P.O. Box 950, Mailstop H6-08, Richland WA 99352, Phone (50́9) 372-2420; Fax (509) 376-4989.

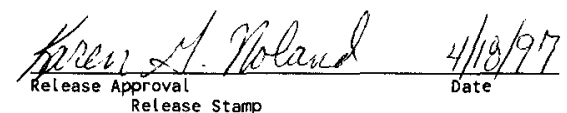

Rel ease Stamp

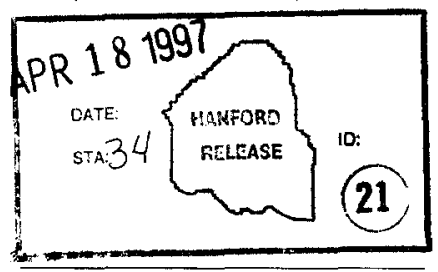

\section{Approved for Public Release}


HNF-SD-WM-RPT-293 REV 0

\section{REPOSITORY OF NOT READILY AVAILABLE DOCUMENTS}

FOR PROJECT $W-320$

FLUOR DANIEL NORTHWEST

Apri1 1997

For the U.S. Department of Energy

Contract DE-AC06-87RL10930 
HNF-SD-WM-RPT-293 REV 0

This page intentionally left blank 


\section{CONTENTS}

Agnew, S. F., 1994, (untitled letter CST-14:94-sta202a to C. 0'De11, July 21), Los Alamos National Laboratory, LoS Alamos, New Mexico . . 3

Agnew, S. F., 1994, (untitled letter CST-14:94-sta209a to C. O'De11, July 28), Los Alamos National Laboratory, Los Alamos, New Mexico . . 13

Bander, T. 3., 1993b, Tota7 Heat Source in Tank C-106, internal memo 23210-TJB-93-048, dated January 22, Westinghouse Hanford Company, Richland, Washington ....................

Bander, T. J., B. Crea, and D. M. Ogden, 1996, Recommendation for C-106 sluicing, (internal Memorandum 74A50-96-DM0-006, dated July 12) Westinghouse Hanford Company, Richland, Washington . . . . . . . .

Claybrook, S. W., 1995, Gothic Model for Tanks C-104, C-105, and C-106 to Evaluate Hydrogen Gas Concentration Data (internal memorandum 74220-95-SWC-001 to D. M. Ogden, August 28), Westinghouse Hanford Company, Richland, Washington

Conner, J. C., 1995b, Official Project Files Record of Revision to WHC-SD-WM-SEL-033, Rev. I, Interim Safety Equipment List for 241-C-106 Waste Retrieval, Project W-320: Cover Blocks Supplied by Project W320 (internal memorandum JCC-8M200-005A to J. W. Bailey, August 17), Westinghouse Hanford Company, Richland, Washington . . . 21

Conner, J. C., 1995c, Source Term for Safety Analysis Support of the Waste Retrieval of Tank 241-C-106, (internal memo 8M110-JCC-95002 to J. W. Bailey, February 6), Westinghouse Hanford Company, Richland, Washington .................. 25

DOE/EA-0933, 1995, Environmental Assessment, Tank 241-C-106 Past-Practice Sluicing Waste Retrieval, Hanford Site, Richland, Washington, D0E/EA-0933, U. S. Department of Energy, Richland, Washington

Estey, S. D., 1994, Project W-320 Revised Headspace Characterization (internal memo 71320-94-056 to J. W. Bailey, December 6), Westinghouse Hanford Company, Richland, Washington.

Estey, S. D., 1995, Tank 241-C-106 Headspace Organic Concentration During Project $W-320$ sluicing Operations (internal memo 75510-95-027 to J.P. Harris, May 9), Westinghouse Hanford Company, Richland, Washington....................

Estey, S. D., 1995, Tank 241-C-106 Headspace Organic Concentration During Project $W-320$ Sluicing Operations (internal memo 75510-95-040 to J.P. Harris, June 23), Westinghouse Hanford Company, Richland, Washington

Estey, S. D., 1995, Waste Compatibility Evaluation for Inhibited Propylene G7ycol, (internal memo 75510-95-031 to J. D. Minteer, May 25), Westinghouse Hanford Company, Richland, Washington 
Estey, S. D., 1996, Tank 241-C-106 Retrieva7 Induced Flammable Gas Plume Analysis, (internal memo 74A10-96-082 to J. P. Harris, dated June 10), Westinghouse Hanford Company, Richland, Washington . . . . . . . 249

Fox, J. V., 1994, Project W-320, Tank 241-C-106 Sluicing, (internal memo A-94-001 to D. J. Shrimpton, January 10), ICF Kaiser Engineers Company, Richland, Washington ............

Goldberg, H. J., 1994, Tanks 106-C and 102-AY Equipment Packaging Dose Consequence Analysis for Safety Class Assignment, (internal memo 22570-HJG-94-005 to D. B. Calmus, January 6), Westinghouse Hanford Company, Richland, Washington ... . . . . . .

Grumbly, T. P., and T. O'Toole, 1993, Delegation of Approval Authority to Streamline Tank Waste Remediation System (TWRS) Documentation (memorandum to Manager, DOE Richland Operations office, December 9), U.S. Department of Energy, Washington, D.C . . . . . . . . . .

Harris, J. P., 1995, Project W-320, Tank 241-C-106 Sluicing/Pit Compliance and Ventilation Duct Containment Issues, meeting minutes to Scott McKinney dated June 27, Westinghouse Hanford Company, Richland, Washington . . . . . . . . . . . . .

Herborn, D. I., 1996, Consistency Review of WHC-SD-WM-SAD-024, Rev. O "Safety Assessment for Tank 241-C-106 Waste Retrieval Project W-320, ", (internal memorandum to J. P. Harris dated August 1), Westinghouse Hanford Company, Richland, Washington

Hey, B. E., 1995, Estimated Dose to Onsite Individual from Tank C-106 Transfer Pool Spi77, (internal memo 8M400-BEH-95015 to J. C. Conner, October 19), Westinghouse Hanford Company, Richland, Washington.

Kinzer, J. E., 1995, Preliminary Safety Evaluation Report (memorandum 95-PRI-086 to J. D. Wagoner, February 17), U.S. Department of Energy, Richland Operations office, Richland, Washington.

Kinzer, J. E., 1996, Direction for Risk Evaluation Guidelines and off site Maximum Exposed Individual (MEI) Location, (Letter 96-WSD-062 to President, Westinghouse Hanford Company, dated May 31), U.S. Department of Energy, Richland Operations Office, Richland, Washington.

Meyer, G. A., 1996, Project 93E-EWW-320, "Tank 241-C-106 Sluicing," Modification of Sluicing Fluid Selection, (letter 9652542 to B. L. Nicoll, U.S. Department of Energy, Richland Operations Office, Richland, Washington, dated June 10), Westinghouse Hanford Company, Richland, Washington

Nelson, J. L., 1996, Evaluation of Corrosion Status of 241-AY-102, (internal memorandum 75A40-96-JLN-006 to $L$. A. Tusler, dated April 16), Westinghouse Hanford Company, Richland, Washington

Nguyen, D. T., 1996, W-320 Pressure Pulse, (internal DSI to J. P. Bailey dated June 25) Westinghouse Hanford Company, Richland, Washington 
Ogden, D. M., T. J. Bander, and B. A. Crea, 1996, Tank C-106 Heat Distribution and Post Sluicing Temperatures, (internal memorandum 74A50-96-BAC-006 to R. J. Cash dated February 27), Westinghouse Hanford Company, Richland, Washington . . . . . . . 207

Ogden, D. M., T. J. Bander, and B. A. Crea, 1996, Resolution of Project W-320 Tier 2 Review Comments, (internal memorandum 74A50-96-BAC-003 to R. J. Cash dated February 27), Westinghouse Hanford Company, Richland, Washington ..............

Plys, M. G., 1996, C-106 Power Distribution, (memorandum to J. P. Harris, Westinghouse Hanford Company, dated January 12),

Fauske \& Associates, Inc., Burr Ridge, I1linois

Plys, M. G., 1996, C-106 "Leading Edge Question" Response, (memorandum to J. P. Harris, Westinghouse Hanford Company, dated February 6), Fauske \& Associates, Inc., Burr Ridge, Illinois . . . 223

Plys, M. G., 1996, Responsce to C-106 "Trailer Edge" Question, (memorandum to J. P. Harris and R. J. Cash, Westinghouse Hanford Company, dated February 8), Fauske \& Associates, Inc., Burr Ridge, 111 inois .....................

Plys, M. G., 1996, C-106 3-Phase Flow, (memorandum to J. P. Harris, Westinghouse Hanford Company, dated February 28), Fauske \& Associates, Inc., Burr Ridge, I1 linois

Plys, M. G., 1996, Hypothetical AY-102 Burn Analysis, (letter to J. P. Harris, Westinghouse Hanford Company, dated July 9), Fauske \& Associates, Inc., Burr Ridge, I11 inois

Plys, M. G., 1996, Hypothetical AY-102 Burn Analysis, (revised letter to J. P. Harris, Westinghouse Hanford Company, dated July 23), Fauske \& Associates, Inc., Burr Ridge, Illinois

Plys, M. G. and B. Malinovac, 1996, Incomplete Combustion Model, (letter to J. P. Harris and J. C. Conner, Westinghouse Hanford Company, dated August 9), Fauske \& Associates, Inc., Burr Ridge, Illinois . . . .

Sanders, G. H., 1995, Project 93L-EWW-320, Tank 241-C-106 Sluicing Sluicing Fluid Baseline Change to Corrosion Inhibited Water (letter 95-RTI-065 to President, Westinghouse Hanford Company, July 19), U.S. Department of Energy, Richland Operations Office, Richland, Washington.....................

Sathyanarayana, K., 1995, Current Status of Thermal Hydraulic Analysis and Results in Support of the Safety Documentation for Project W-320 (internal memo 74010-95-PSSB-KS-036 to J. C. Conner, September 20), Westinghouse Hanford Company, Richland, Washington

Sathyanarayana, K., 1996, W-320 and W-030 Design Integration, (interna1 memorandum 74A50-96-KS-018 to J. P. Harris, July 12), Westinghouse Hanford Company, Richland, Washington 
Sidpara, A. B., 1995, Risk Acceptance Criteria for Tank Farm Operation (letter 95-TOP-063 to President, Westinghouse Hanford Company, June 14), U.S. Department of Energy, Richland Operations Office, Richland, Washington. .................. 197

Tseng, J. C., 1993, Safety Documentation for Tank 241-C-106 Retrieva] operations (memorandum to J. Anttonen, DOE Richland Operations Office, July 13), U.S. Department of Energy, Washington, D.C... . 201

Van Vleet, R. J., 1994, Safety Classification of the Standard Hydrogen Monitoring System for Flammable Gas Watch List Tanks, (internal memorandum 29140-94-001 to R. E. Clayton, January 11), Westinghouse Hanford Company, Richland, Washington ............. 


\section{HNF-SD-WM-RPT-293 REV 0}

\subsection{PURPOSE}

The purpose of this document is to provide a readily available source of the technical reports needed for the development of the safety documentation provided for the waste retrieval sluicing system (WRSS), designed to remove the radioactive and chemical sludge from tank 241-C-106, and transport that material to double-shell tank 241-AY-102 via a new, temporary, shielded, encased transfer line. 
HNF-SD-WM-RPT-293 REV 0

This page intentionally left blank. 
HNF-SD-WM-RPT-293 REV 0

\section{LosAlamos \\ Stegnen F. Agnew \\ Groue CSi-i4, Mail Sics \$5a6 \\ Los Alinos Natienal Liooratory \\ Los Alanos. New Mexies 37545}

To: Chartie Q'Dell, DCS.E.M32

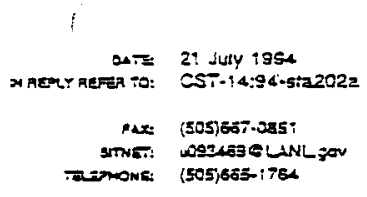

Copies to: Harsid Sullivan, TSA- $1 \uparrow$ Harry Eabad. WHC

Oliver Wans, WH:C

Dear Charila:

As per your request. I have reviewed the inicmation that you farec the on the thermal prociems with $C$-iOE and here are my thougitts and analysis.

Criticaity is definitely no! an issue. Not only are the P.y levels well celow any lavel of enncem, the very large amount of iron (a neutren poison) in the siucge (i-2 moln) acsolutely practuces any criticality within the sludge. The measurec leveis of Pu in a cemcosite oi the stucge are $3.1 \mathrm{HCHg}$, and the historical estimates ior any layer within the iank ars in the ange 0.7 to 6.0 uCig. Citicality would occus in an infinite yclume of pura water at abcur $250 \mu \mathrm{CVg} P=$, but thera woulc have io ba much ilcher soncantzations whan neutron peisons, such as irch, are presant. Thereicre, this is a ysry large non-issue.

To say the least, it was not a gooc ifea to let this :anx dry out. Stzan expansion frem siudese hot spets has jeen a tracticnal probiem at fiantord in the past, (i. J. :ank burncing) and wo will be dazing more with this problem in the turure with other ianks. Tnis iank's prosiem staried when it unexpectedly becan to boil in 1971. Much work was perismed io get the bolling under control, which it has been until now: The secand ic-iree r14 was gut inte the tank in order to bether deramine the stuç̧e temparatures lor this tank.

Histerically, there has always baen a jiscrepancy betwaen the ive themoceuole trees in iank C-106, :e-tree $t \mathrm{t}$ and tc tree 14 . The mystery has been that the tree inat was placed into iser $i \perp$ in $19 \pi 7$ ajways showed coldar waste iemperatures than the original tree in iser $g$, although the come space temperatures berween the irses agreed guite well.

Although there inve baen many different explanations for this anomaly, it now appears that the chimney hypothesisi has now been proven. This hypothesis was that thera was the sluiced pit or hole dug that was dug into the sludge layer in 1977 when the rese wes oriçinaly inserted persisted sven atter installation. This hole or "thimney' allowed te-tree it 4 :o esol by cenvection of the liquid areund it, even though the bulk wasie in the vicisity was always at much higiner temperatures. The inal iest ot this hypothesis would have been to elesa yo the enimney semenow and watch ine temperature tisa for te-tre 794 . I suggest that this is exactly what has now hapoenes in C-10द.

The seenario gces scmething like this. Evaporation st all cocling water iemoved significant sonduction and zonvecion paths for woling the uoper sludge. thereoy allowing upper portions of the siudgs to dry out. Onca the siudgs had tried

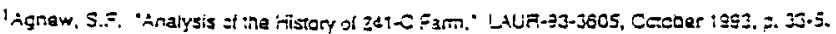


out, a hot seot seyelops and becomes a suestantial steain sourea, nuch hake new exists uncer iank A- 105 . This staam seure drives stean tnio the surrouncing waste, eausing the wase to heave and icw therecy seaing up the fissures that have developed over the past-ineluding the gimney around te-tree $r 4$.

Cnes the issures ars saaled up. eniy purg sencuerion patins ean esol that "hot spot', and the hot spet will heat to its enducton timit. (We can estimate the size of the hot soet by knewing the exace details of the zxperiment) At any rate, water adjition into the driac not spot will evenualy scen uo new fissures and csol the he: spot to below the boiling point. However, during this period. thepe will be steam surges as the water trickes back into the hot soot. which I beliave is rasponsible for the level ifucsuations that are now oceiring. This effest is mucin akin ic the geysers that oceur in the earti's mantile.

The geod news is that ie+iree it is now 'packed" into the siudge and we will finally se gerting reailsic :emeorarures ic the lank esnter fer C-106. The bac nows is that it mignt :axe some months icr this lank to sertie down. Last time C-iOG was bciling, remencer, it teck acout a year and a half for it to "saule cown". Eur it was a lot hotter sack then.

Atached find an themal aralysis (that is completely unoficial and my own) for the dome space tamperz:ure of C. 1 Ce uncer vatious scenarics. Please take these astimates with a very large grain of salt. Jut they afs based on a tank heat load of 38,000 3tuhr, my besi astiriare basec on the dome tertperature and the evacoration rate. If I ienovg the evascrative heat loss out kasp ventilation, I precici the dorns seace ternearature would incteasa trom aroune $80^{\circ} 9$ to $145^{\circ} 5$, or acout $a$ 6."F rise in dorne spece tenceraiure. The wasta iamperature, on the other hand, - will go up at-least that anount, and procabiy mueit more. If it went uo oy the sane amouns, it wevid incrazse irem $i 60^{\circ}, 5$ is $225^{\circ}, 5$. Of osurse, once the rasta went: above $212^{\circ}$. it would dry ati and the !emperatura would in iach incizase even more, sines watar shanneis wouid so sopiaced by sieam and gas.

In slosing, I suggest that there are otiar anks of similar eoncern for staam prodems with iturire water actitions. and we sinould look careitully at these ianks before adding water. They inciude $A-i 0 \Sigma, 0-104$, and a series of tertks in SX iarm.

Suggestad action: Believe ie-tree $M 4$ readings-there is nothing wrong with that tree: It has been acaurate all along. $\lambda$ bertor thing to do than verity that tree would be to lest the waste temperature in a completeiy different spot, ier =xample the other side of the tanix. in risers $1,2,3,4, i 0$, sr $1 i$. That would tell us more abours the waste iemperature.

The steam surgirg ghencmenen should setile down arter a iew months, as fissures open and allow water evnvecton cooling. Until then, wa have inte io do. If the tank penetroneter were ccerating, we could star punching holes in the waste to faciiltate the process, but that devics is not yet operating. (Another pusin for an intank penetrometer, pardon the pun.)

$\Leftrightarrow \operatorname{cic}-00, \operatorname{csi}-14$

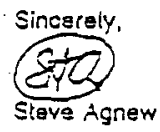

900

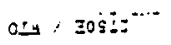

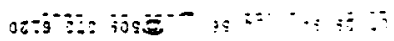


HNF-SD-WM-RPT-293 REV 0

fial themal mocol exar?

1

\section{Tank C-106 Thermal Mede}

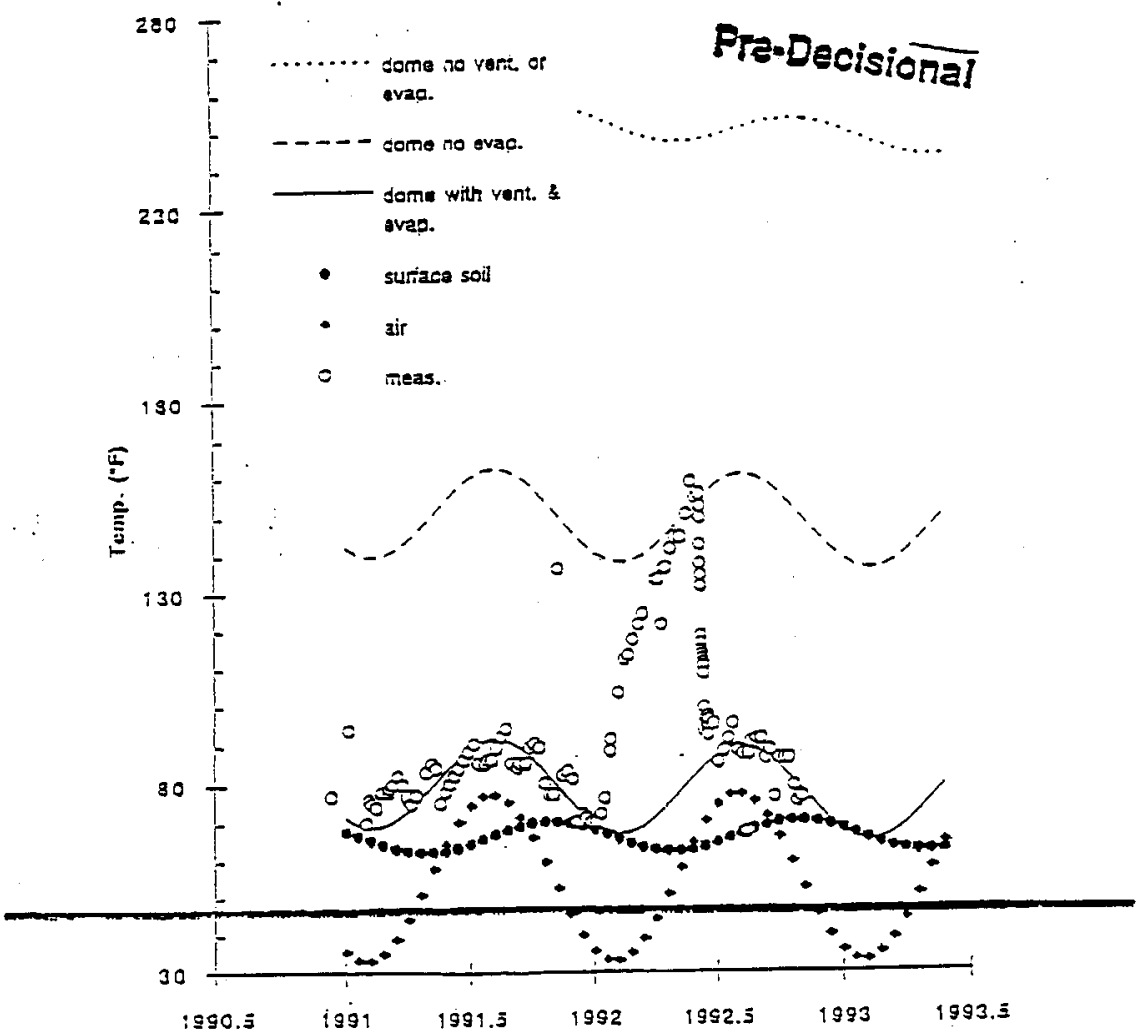

$= \pm 591$ 


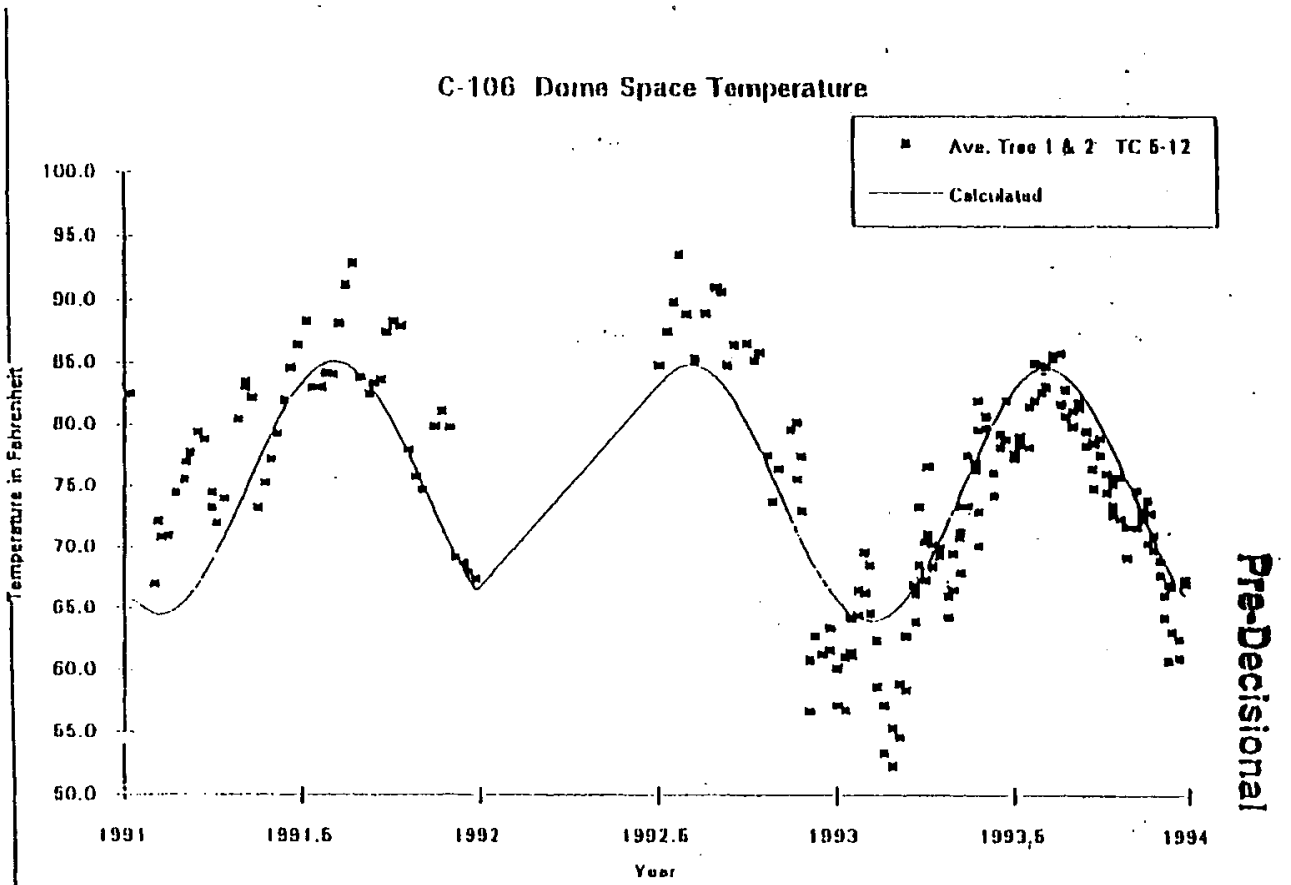

Yuar 


\begin{tabular}{|c|c|c|c|c|c|c|c|c|c|c|}
\hline & & & & & & $\ldots$ & [ & & & \\
\hline & & & & & & & - & Dome $A y_{n}$ & 72.4 & \\
\hline- & & & & & $\bar{T}$ & - & - & & & \\
\hline & Noles: & & & & & & - & Suret of Squesias & 5210.94 & \\
\hline & Almpdlitso!s & Coslouteled ai wophos & 301011 & & & & 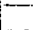 & Davlation & 0.30 & \\
\hline & Innperoluies & Apilo lolwoon 1982. & 992.6 & & & & $一$ & & & \\
\hline-1 & Mun Sullace & Lovd ond15 ol $0^{\circ}$ & & & & & - & Viluo & $\overline{Y_{Y e}}$ & Conimzonite \\
\hline & Mex PonkIn & Nalo: $6 / 6192$ 100 & IF Tous & $11 T 11$ & & - & $\ldots$ & in.4 & aypol. & F enasound minpl. \\
\hline - & $\ldots$ & & -1 & & $\ldots$ & $\ldots$ & - & & tiat. & Yuceoloul \\
\hline$\ldots \ldots$ & & & & & & & $\cdots$ & 0.59 & phase & Inno. Yu. \\
\hline$\ldots$ & !!en!looed (01 & 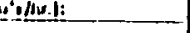 & 34530 & & & -.. & $\ldots$ & 31.31 & entent & Focosenel aye: \\
\hline 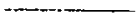 & & - & & 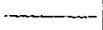 & $-\ldots$ & $\ldots$ & $\ldots$ & 0.39 & dious & 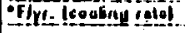 \\
\hline
\end{tabular}


HNF-SD-WM-RPT-293 REV 0

$$
\because
$$

Titfe: Analysis of the Hisicry of 24i. Fam

\author{
Authar: Stephen F. Agnew
}

Submitzed io: as Tecinical Repor to DCE HO EM-AS

Date: Cetocer 1993 


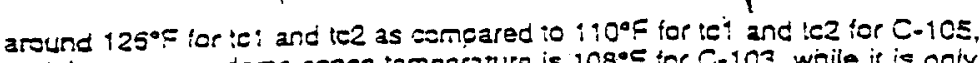
and the average dome space temperantra is $108^{\circ} \%$ for $0-103$, while if is onily $7 \leftarrow \circ 5$ for $C-105$. These measurements are consistent with the moderate heat lead icr C-10S. as shown in Tades $i$ and $\vec{z}$, and the fact that it is somewhat ventilated by sannections to C.iOQ.

The plutcrium assay was repored as 0.85 ".CVG, which suggests a $P$.

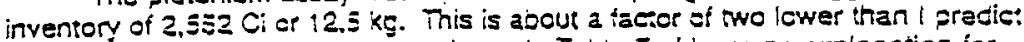
based on the layers of wasie type snown in Table 7. I have no explanation ior this dir̈erence.

C-106

Soijds layering

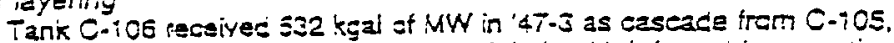
was sluiced in iSS3. and were is acperently litle heel lett from this operation (sae Fic. ;0). Thereupon, C-i06 recsived S38 kģal UR in ' $54.3,420 \mathrm{keal}$ CWF

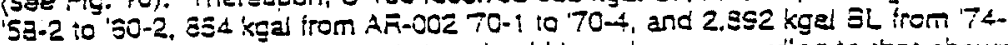
3 to $T E-1$. The siucge accumulation sinculd have been acoording to that shown in the Tacie $\mathrm{B}$.

\begin{tabular}{|c|c|c|c|c|c|c|c|}
\hline sabe & 9 & $\begin{array}{l}m=25 . \\
s 0 l l d s\end{array}$ & $\begin{array}{c}\text { sollds } \\
g a \ln / i 0 s s\end{array}$ & $\begin{array}{l}\text { pred. } \\
\text { leyoi }\end{array}$ & $\begin{array}{l}\text { leyer } \\
\text { type }\end{array}$ & 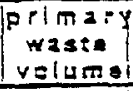 & comments \\
\hline 1953 & 121 & & 3 & 0 & $1 \mathrm{HW} / \mathrm{cas} .1$ & 1532 & - \\
\hline 19.54 & 13 & & $2 \overrightarrow{1}$ & 27 & UI & 538 & $1:$ \\
\hline 1957 & $1 \div$ & 29 & 2 & 2 & neas: & 1 & I gain irom?? \\
\hline 1960 & 131 & & 34 & & ONP & 420 & 1 \\
\hline$? ?$ & 11 & & $-\hat{\jmath}$ & 23 & ENP & 1 & loss to ?? \\
\hline 1963 & 14 & 57 & 1 & & 1 meas. & 1 & 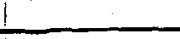 \\
\hline 1970 & 14 & & 93 & & $1+3.002$ & 354 & 1 \\
\hline 1371 & 11 & & .24 & 59 & $1 \pm A-002$ & & llass ic C.103 \\
\hline 1975 & 12 & & $\vec{i} 1$ & $7 i$ & $3 L$ & 2892 & I 2.5 vol\% \\
\hline 1985 & $|2|$ & 197 & & $;$ & meas. & & \\
\hline
\end{tabular}

The solids layering in C-106 would then be 29 kgal UF, $28 \mathrm{kgal}$ CWF, 69 $\mathrm{kgal}$ AR -02 solids, $71 \mathrm{kgal}$ EL. and $32 \mathrm{kgal}$ of supsmatant (which veries since water is added periodicajly ic replace that lest by evaperation.

The only unrecorced loss or solids is the $24 \mathrm{kgal}$ of AF-DO2 soinds lost 10 C-103 in ' $71-1$. Thasa high sirentium solids (temed AR-002) ara actualy $P$ solid's (stusce from Purez wasta) that were being washed in AF-002. a :ark in AR vault. The selics mestly eriginatad from A-106, which was a primary raceiver for $F$ waste irom 'so- 10 ' $\$ 3-1$, afthougn $\lambda+106$ acsimulated soiids from A-iO4 as well. Acproxinately $184 \mathrm{kggal}$ of selicis werg sluiesd from A-iOe 
starting in Feb. 1970 thrcugh Jun. 1972. with $93 \mathrm{kga}$ or these ssiics ending up in C-106.

Padionudice inventory sstimate

Sased on the solics layering and the care cemcosite iniomation, 47 ine srontum concantration in the sore composite is $2 \mathrm{a} C \mathrm{Ch}$, which would be 8.0 CUL if it were all coneentrated in the oe Xoal Af soiicis layer. A previous recor. by Wakker' derives much larger inventones of Sr-90 in C-105. This autnor uses a siudge anajysis ${ }^{49}$ that is $i 8.9 \mathrm{CiJ}$ Sr.90, and a total siudge volume ot $140 \mathrm{kgal}$, and states that the :etal $\mathrm{S}-\mathrm{GC}$ is then $\$-10 \mathrm{MCi}$. However, this author does not difierentiats berwesn $\mathrm{BL}$ and AfF-DC2 studges. The fomar has very little Sr-so, wrille the larar has Sr-gC en the orcer of $3.0 \mathrm{CV}$ L Thus, Waiker derives a much largar total Se-90 inan I do. bur l belleve inat his strontium concentrations wara nct represeniative oi this waste type-Walker did not ake into ac=ount the absence of Si-9o in BL wasta. My estimates ior Sr-90 are tied to a tank corz analysis as cecesad to some grab sample, and are sonsistant with the wasis type.

The rapored dose readincs an the csra sagments as they are broughi to the suriace are unusually high ior the loo wo secments sonsidering the low radic nucide sontent expected for SL (E-Flant low-ievei) wasie. These dosa measurements are not consistent with iow radio nuclice contents anc l can't explain ise discrepansy.

The plutonium osncantration ior C-i0s tron the core analysis was 3.1 -CVig. wrich leads to an inventory of $3 \pm . ; \mathrm{kg}$. My astination of the plutonium content of is lank is $63.7 \mathrm{Kg}$, wnich is concerable to thet estimejed irom the anajysis.

Temperalure anomaly in C-ios

The inadvertent addition of high sirontium sludge :0 C-i06 in 1970 has been noted beiore in several reports. 30.51 .52 Temcerziures in azcess of boiling occurrad shorty aiter the adcition of the high Sr siudge. In 1978; a second themocouple tree was installed in risar 14 of $C$-106 (ses Fig. 1) :o help monitcr the temperature of this tank. The temperante readings iron themocouples at the same level beween the two trees agres within the dome space, but have never agreed within the waste, and there are differences on the order of 35 $45^{\circ} \mathrm{F}$ between the te2's of eact tree. For example, in January 1993, ic 1 -r8 (themocouple 1 , iser 3 ) was isjoF, while ic $1-714$ was $115^{\circ} \mathrm{F}$. Likewise, the

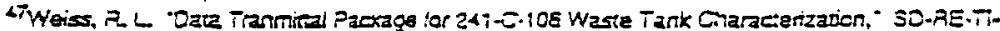
205. January 1988.

ispid Walker.

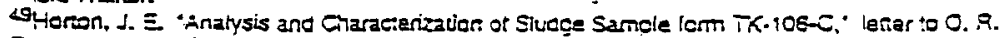

Rasmussan, Lan: 9, 1975.

soibid Walker.

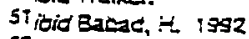

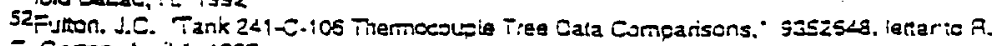

E Geron, Aerit 1. 1993.
} 
1

1

1

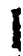

I

I

I

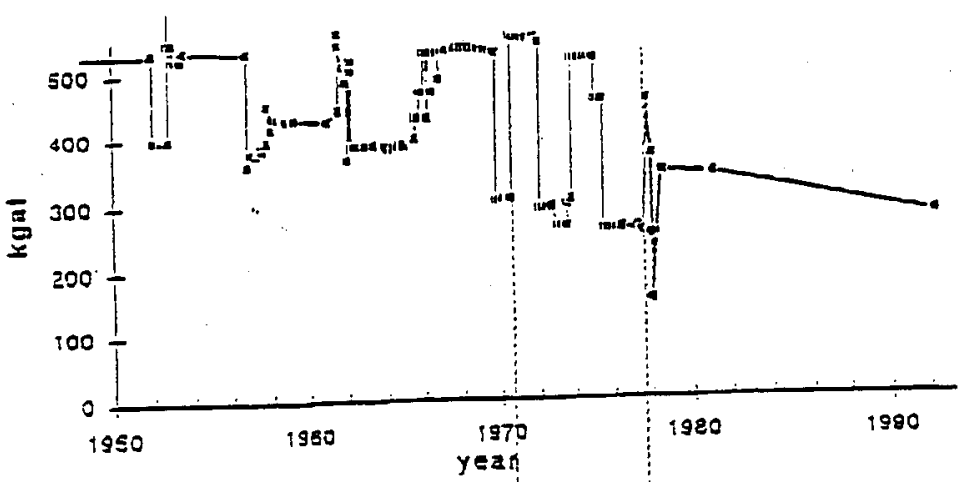

1
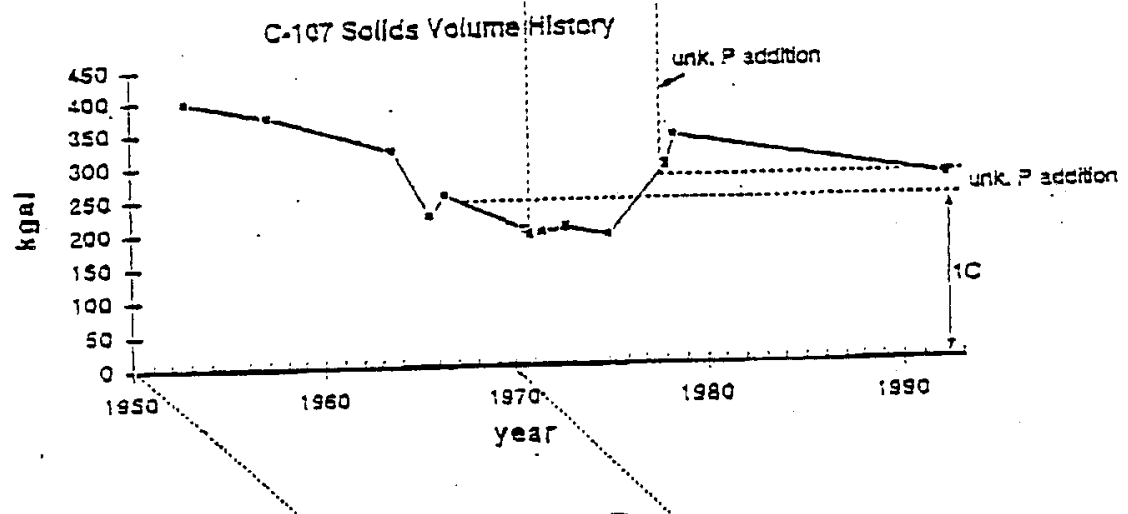

1

!

I

?

E
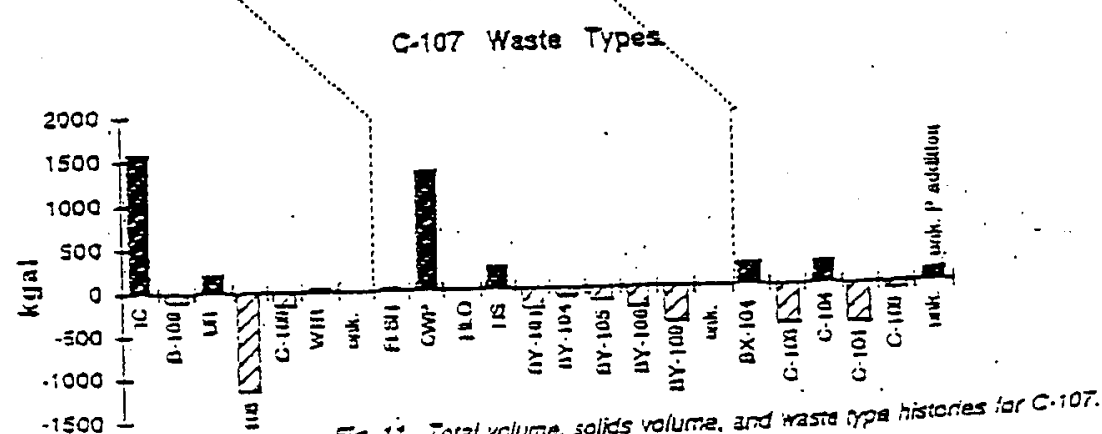

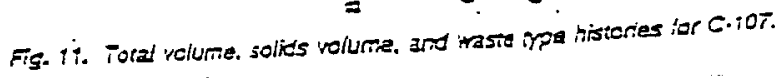


te2's were at 131 and $87^{\circ} \%$, respectively. Riser 9 and Fiser 14 are cocur $30^{\prime}$ apart. and it saems counter-intuitive to have the higher iemperature on the ourside of the tarik wasie. In other words. I would expect the lemcerature near the iank outer wall to be iower at the sarma laval as compared to the iermperature si the weste near the center of the lank.

I suggesi that this explanation for this ancmaly is a chinney eifect. Tha: is, the itser-i4 tree was likaly inserted with a water lancing oceration that effectively drilled a nole or chimney within the wasie sludge. It this situdge chimrey did not collapse following the insarion of the themocouple tree, it would allow the irae convecilen of liquid within inat shimney and ihereiore the cooling of the waste around the to tres. This localized convecion would prooucs a cold soot that would not so rapresenrative of the temperature of the studge. in all likelihood, then, the actual peak siudge temperatures at the center, of the iank are actually hicner inan sithar themcesufle ires is now neasuring.

An experiment to tost ihis chimney iypothesis would be very simple and invelve amping the sludge around the is tree in iser 14 in order to collapse the sludge around the iree. It is very important io have an accurate representation of the temperature of the sivoge in C-106 and that wiil only be possible if the is tres is packed into the sludge so as not :o allow any tree convection around the ic iree.

Another hypothesis that has been suggested is the presence of a 'doughnut of sircntium studge around ine outer wail of the tank, concentrating the heal scurca near the wall.

C-107

Tank C. 107 iecsived ic (first cycle decontaminatlon) waste itom the BiFO process, whici was a minture of the ec:ual wasia irom this cycle and the decladding wasia (sae Fig. $1 i$ ). iC westa had the hignesi soijds irection of any wasto strean ai Haniord, being on average 25 vol\% sciids.

\begin{tabular}{|c|c|c|c|c|c|c|c|}
\hline & & & Estimates of & $\begin{array}{l}\text { Dle } 9 . \\
\text { Solids for }\end{array}$ & $\mathrm{c}-107$. & & \\
\hline$d z t=$ & 9 & $\begin{array}{l}\text { moas. } \\
\text { solles }\end{array}$ & $\begin{array}{l}\text { sollds } \\
\text { gaindlass }\end{array}$ & $\begin{array}{l}\text { prod. } \\
\text { layer }\end{array}$ & $\begin{array}{l}\text { layer } \\
\text { type }\end{array}$ & $\left|\begin{array}{c}p r i m a r y \\
w a s t e \\
\text { varume }\end{array}\right|$ & comments \\
\hline 1948 & 3 & & 395 & 1 & 10 & $11,58 \mathrm{~g}$ & $24.3 \times 01 \%$ \\
\hline$? ?$ & 1 & & $d$ & & unk gajn & 1 & \\
\hline 1952 & 13 & 399 & $T$ & 1 & ineas. & $i$ & \\
\hline 1953 & 13 & & 11 & 1 & G & $2 i 1$ & \\
\hline 1962 & 12 & & 109 & I & ONP & 11.364 & \\
\hline 19.63 & 12 & 321 & .193 & $i$ & nows. & 1 & loss 10?? \\
\hline$? ?$ & 1 & & .72 & 243 & 10 & 1 & unk. loss \\
\hline 1977 & 12 & 249 & 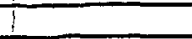 & 1 & moas. & ! & \\
\hline 1977 & 3 & & 23 & & Si solics & & $\begin{array}{c}\text { repored in } \\
\text { walty }\end{array}$ \\
\hline 1992 & 11 & $.2 \bar{T}$ & -3 & 25 & Se soticis & & unk less \\
\hline
\end{tabular}




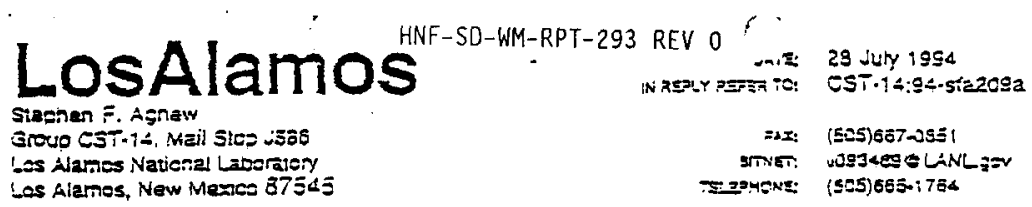

To: Charlie O'Ceil, LOE-E.VI2

Copies te: Harcld Sullivan, TSA-11 Harry Bacad. WH:C

Olivar Wang. WhiC

Dear Charlie:

1 net with Oliver Weng and his :ean on 25 July 1984 at hiariord and tiscussed $\equiv$ some lengih the issues surrounding the C-106 heatu that followed the process axperment tha: Was periornad in April-June ise4.

It is clear that we so nct yer have a full understancing of the siructure of the siudga layer in C.i06. anc jnereiore wa de nol uncersiand all oi the meciarisms by which the siudga coolso. The previous nodel or paracigm ior the slucgs cooling has been a sure concuction model for sooling the lower sludge layers. It is apparont now, however, that a sacond nechanism, periacs the more inportant mechenism, was one in which "iumaroies" or conveeven chimnevs that had greviousiy iomed in the siuoge provicsd onnection channals jy. whish the lower siudge layer sould coci sy corvecting hot fults to the suraca layer. in this model, the upper sluzgs layer woulc je a "Swiss eheesa" of iumaroles ianging in size iron 2-10 ivet in ziameter. Any shanges in the configuration of bis ieyer, as uncioubtedly occuried during the experiment, sculd eicse sone of these fumaroles, peitheps permanently.

It is siear that there ars two prinary esnesms associaied with 0.106 at this tine. First, the continued heatuo of the lower lavel of the ank, as indicated by ic i di

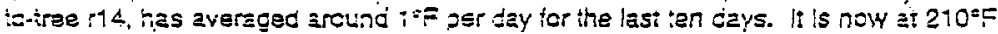
and is snowing no sign oi stabilizing. The zoiling point of pure water at that level in the tank is around $202 \%$ (105\%), but the salt content should raise it io around $230^{\circ} \mathrm{F}$ or so. I Ixpecr stean producion at be lower layer of ute iank once this amparaiure is iacaned, which would result in sweiling of the lower iayer and scre kind of venting or andetion oi the lower siudge layer. Thus, l sxpeci someining io happen in welve to wenty days. Of course, wo may not be messuring the hotesi part of the tank at riser 14, but until there is significant level incressa and/or fluctuations, the level data would suggest that the layer is nct yet boiling.

The second issue is the zpoarent change in the stucture ci the siudge that is trapping more heat in the lowar slucge layer. This heat trapoing is indicated by a marked reciuction in the evapcration rate of suriace watar, and is evidently the cause ior ine temperature rise. Apparently, the ank level has not chanceo at all since the last water adcition on Juty $3 r$. This is very distressing since the grevious lank coollng rate involved $\equiv 22^{2}$ loss oi suriace water per month, which would suggest a $1.2 *$ ioss siculd have ocaurred by July isth. Since this water eveporation acoounted for about 70.000 Buhr heat ramoval tiom the tank, lts loss means thet the heat is going somewinere eise, i.e. it is heating to the sludge above ractitional iavsis to soma new value. Until the tan'x's behavior becornes steacy, that 


$$
\text { HNF-SD-WM-RPT-293 REV } 0
$$

new value could exceed ... boiling point of the tank liquid at! , ieval in the wasie and some kind of steam striven eriction is likely.

This anction sould ranga all the way frem a "glug-giug" localized event to seme more deleterious gicial iank "bump." At this soint, it is very ditileult :o predict which of the two axtremes will oceur. I suggesi based on pasi history inat a "gituglug^ event is most likely, but l can not rule out a mors subsianial iank bume.

All of these notions are limited by the fact that we do not have anough anaivsis of bounding conditions is: the heat sourse distribution, there is no tank leval behavior on an hour by hour tesis beiare, during. and atter this process experiment, or any model of convective diven 'iumarole" sludge cooiing.

\section{Recommendations:}

1) Start immediate plans to cool ank. This could involve an air conditicner, acied ico directly to :ank, or soma other hezt exchange prsesss. We nesd ic get that tank back to a heat removal rate of ecout $30-70,000$ stwhr as 500 n 25 possible. We will not be out oi the woods with this tarik untll we can siow that the heat !esses with ventilztion are sack is the previets levels.

2) Immediately star :aking level data. at lesst once ger hour, preiarably at least four tasa points for eaci joriccic snange that is noted. For examole, if tiere is a fitheen minute variation in leval, then we need daia every six minutes. Afeumulaie level intomation trom beiore the expariment up until the present ime and into the foreseeable iutura. I carit overamphasize how imcorant it is to trave as mus:iniomation as pessible for this tank ovsir the nexi tew nonths.

Level data wiil show us if there is any steam vapor acoumulation, tank levei changes due to thermal expension of the yaste will bound the size of the hoi seot. and geyser senayior due to periocic steem venting sinould provice soms incication of how unstadie that iank wasta is becoming.

3) The immeciats hezarc is not high :ennoeratures gei se but ather tank bumping due to steam vapor production and venting, we need immedlaie help tron the ociing weste "grey jeards" ter this prodiem. There is a histery of this problem at Hantord and we should tje intc that experise.

4) Siart an intensive zitort on analysis si the betavior of C-iOE. We need better bounding estimates of tank behavior, inclucing lecalization of heat scurca into a layer that is zonsistent with historical fill recorcs, Si-so concentrations in the siudoe layer as high $\equiv 20 \mathrm{CW}$, with total inventories in the range $\$-s \mathrm{MCl}$ ( $1 \mathrm{MCl}=$ ies $\mathrm{Ci}$ ), better understanding of saasonal evaporation rates and seasonal benavior of level and iemperaturs, more psychrometric data on tha oudst vacors, continuous measured pressure of the iank come space and ventilaticn raie, and any other data that we can gat our hands on.

se: Cicico, CST.i4

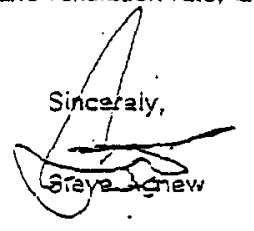




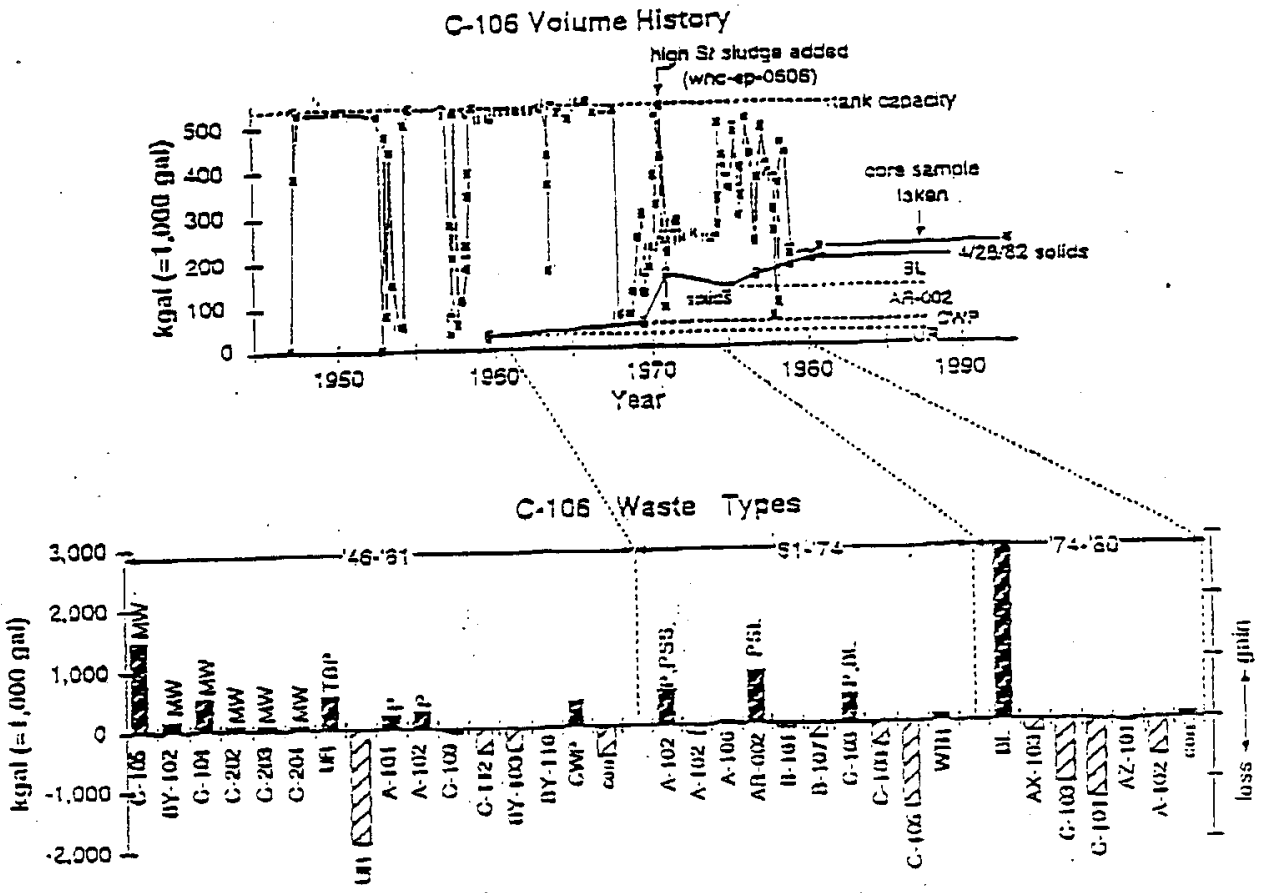

Fig. F. Total volune, solies volume, and wasie type inistores for C-i ice. 
HNF-SD-WM-RPT-293 REV 0

This page intentionally left blank. 
From: $\quad$ Safety Fluid Mechanics

74220-95-SWC-001

Phone: $\quad 376-0438$ HO-34

Date: $\quad$ August 28, 1995

Subject: GOTHIC MODEL FOR TANKS C-104, C-105, AND C-106 TO EVALUATE HYDROGEN GAS CONCENTRATION DATA

To:

D. M. Ogden

HO-34

cc:

R. J. Cash

S7-15

J. C. Conner

H4-68

J. P. Harris, III

S2-48

J. D. Hopkins

R2-11

G. D. Johnson

\$7-15

SWC File/LB

An evaluation of $\mathrm{fl}$ ammable gas concentrations in $\mathrm{C}$ Farm has been performed.

A GOTHIC model has been constructed for tanks C-104, C-105, and C-106 to evaluate hydrogen gas concentration data for those tanks. A schematic of the mode1 is shown in Figure 1.

Volumes 1,2 , and 3 represent tanks $C-105, C-104$, and $C-106$, respectively. Each tank volume contains a thermal conductor to maintain internal tank temperatures at measured levels. Ventilation system ducts are modeled by volume 4 and flow paths 1,2 , and 6 . Pressure boundary $3 \mathrm{P}$ represents the ventilation outlet. Inlet risers are modeled by flow paths 3,4 , and 8 , which are also attached to pressure boundary conditions. Underground cascade lines are represented by flow paths 5 and 7 . A hydrogen source is introduced into each tank by flow boundaries $5 F, 6 F$, and $7 F$ through flow paths 9 , 10 , and 11 .

The model was calibrated by setting the inlet pressure boundary conditions to atmospheric pressure and adjusting the inlet riser loss coefficients and the outlet pressure until internal flows and pressures matched measurements taken during ventilation system flow balancing operations. After the flow balancing calibration was complete, the hydrogen source rates were adjusted to try to match measured hydrogen concentrations for each of the tanks.

Table 1 shows a comparison of GOTHIC model results and measured data for each of the three tanks. The GOTHIC results were obtained with a hydrogen source rate of $0.00000051 \mathrm{bm} / \mathrm{s}$ in each tank. This comparison suggests that the hydrogen concentration levels measured in 
D. M. Ogden

Page 2

August 28, 1995

tanks $\mathrm{C}-104, \mathrm{C}-105$, and $\mathrm{C}-106$ are consistent with approximately equal hydrogen generation rates in all three tanks and are consistent with the measured and predicted tank ventilation flows.

Table 1. Hydrogen Concentration Comparison for C-104, 105, and 106.

\begin{tabular}{|c|c|c|}
\hline Tank & $\begin{array}{c}\text { Measurement } \\
(\mathrm{ppm})\end{array}$ & $\begin{array}{c}\text { GOTHIC mode } 1 \\
\text { (ppm) }\end{array}$ \\
\hline \hline $\mathrm{C}-104$ & 68 & 69 \\
\hline $\mathrm{C}-105$ & 22 & 24 \\
\hline $\mathrm{C}-106$ & 10 & 13 \\
\hline
\end{tabular}

S.W. Caybrok

S. W. Claybrook

Consuitant

bab

Attachment 
Figure 1. GOTHIC Model for C-104, C-105, and C-106.

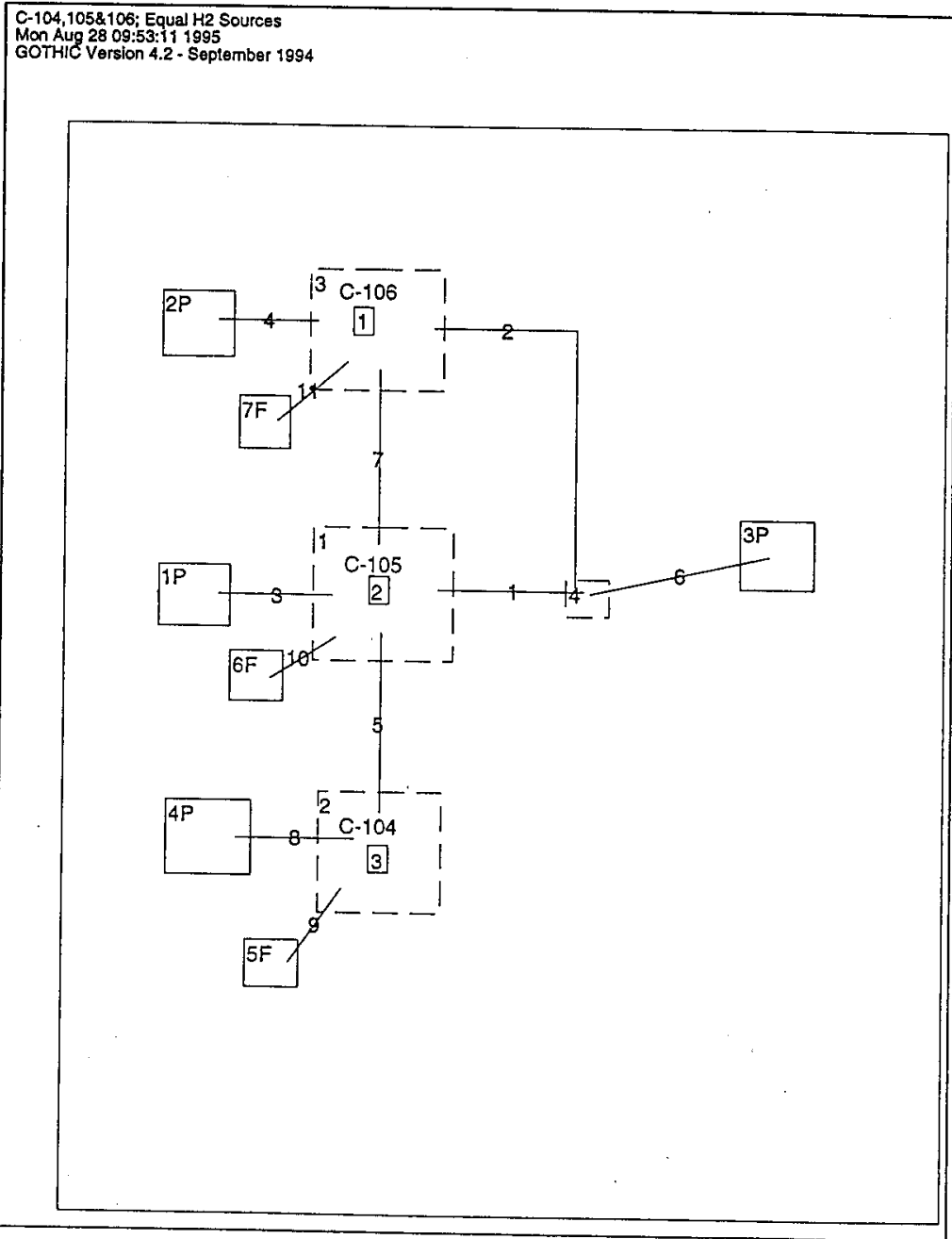


HNF-SD-WM-RPT-293 REV 0

This page intentionally left blank 
From: $\quad$ Projects SAR Engineering

Phone: $\quad 376-2058$

Date: August 17, 1995

Subject: OFFICIAL PROJECT FILES RECORD OF REVISION TO WHC-SD-WM-SEL-033, REV 1, INTERIM SAFETY EQUIPMENT LIST FOR 241-C-106 WASTE

RETRIEVAL, PROJECT W-320: COVER BLOCKS SUPPLIED BY PROJECT $W-320$

To:

J. W. Bailey

J. P. Harris III

K. W. Leliefeld

cc: F. W. Bradshaw

R. W. Davidson

D. L. Evans

K. B. Ferlan
$56-12$

$52-48$

$52-48$

$J C C-8 M 200-005 A$

J. J. Huston

56-12

L. E. Johnson

H4-68

Official Project files R1-28

$52-47$

$52-47$

$52-47$

$52-48$

Official Projer

References: 1) Internal Memo, J. C. Conner to J. W. Bailey, et al., "Official Project Files Record of Revision to WHC-SD-WM-SEL-033, Rev 1, Interim Safety Equipment List for 241-C-106 Waste Retrieva1, Project W-320: Cover BTocks Supplied By Project W-320

2) Internal Memo, J. C. Conner to J. W. Bailey, et al., "Official Project Files Record of Revision to $W H C-S D-W M-S E L-033$, Rev I, Interim Safety. Equipment List for 24I-C-106 Waste Retrieval, Project $W-320$

3) WHC-CM-4-46, Safety Analys is Manual, Section 9, Table 1 , Revision 1, "Safety Classification Criteria and Components, " Dated May 17, 1995

4) WHC-CM-4-3, Volume 1, Industrial Safety Manual, Section G-1, Revision 3, Change 1, "Operations Lock and Tag Program," Dated Apri广 28, 1995

5) WHC-SD-WM-0SR-005, Single-She11 Rank Interim Operational Safety Requirements, Section 3.6.1 Revision 0-A, "Transfer System Cover, " Dated April 3, 1995

6) WHC-SD-WM-SEL-033, Interim Safety Equipment List (SEL) for 241-C-106 Waste Retrieval, Revision 1, Dated November 15, 1994

7) WHC-SD-WM-SEL -020, Acing Waste Facility Interim Safety Equipment List (SEL), Revision 2, Dated June 9, 1993

8) WHC-SD-PSE-010, Prel iminary Safety Evaluation (PSE) for 24]-C-106 Waste Retrieva?, Revision 2, Oated October 19, 1994 
This revision represents slight editorial changes and clarification of the evaluation of the Waste Retrieval Sluicing System design and the EDE dose consequences caused by a postulated break of both supply and return transfer lines during a seismic event. This memo supersedes Internal Memo number JCC-8M200-004 dated August 16, 1995 (Reference 2).

Interim Safety Equipment list Safety (SEL) for 24]-C-106 Waste Retrieval, (Reference 5), has been produced in support of the Preliminary Safety Evaluation (PSE) for 24l-C-106 Waste Retrieval, (Reference 7), for Project W-320. The Interim Safety Equipment List (Reference 5) is presentiy being revised to reflect further progress made in the design of Project $W-320$ and subsequent safety analyses of this design. This memo serves as the official project file record of an additional revision made to the Interim Safety Equipment List (Reference 5) and supersedes Internal Memo number JCC-8M200-004 dated August 8, 1995 (Reference 2).

In the Interim Safety Equipment List (Reference 5), the waste transfer pits for AY-102 have been classified as Safety Class (SC)-1 according to the Aqing Waste Facility Interim Safety Equioment List (SEL), (Reference 6). The pit/box structure (cover block) performs $S C-1$ functions based on the analysis in Reference 6 . The safety function of the pit/box structure is to contain any spill and confine resulting aerosols. If the cover biock is properly instalied, the pit/box will perform its safety function.

During waste transfer or recirculation of Tiquid waste within C-106 pits, a spray leak scenario could be postulated that would lead to SC-1 consequences. Such an accident scenario could consist of the following events:

a. An initiating event where a spray leak occurs in a pit due to failure of jumpers, connection or flange

b. A single failure where a pit cover biock is left off

c. The spray is oriented such that it sprays out of the opening in the pit

d. The leak detectors may not activate because of most of the spray is out of the pit, and also, not enough liquid is lost that could be detected by material balance discrepancy (MBD) analysis.

Calculations were performed for the above scenario, and the resulting offsite Effective Dose Equivalent (EDE) value for a connector failure, with the pit cover block off, exceeds the risk acceptance guideline and is unacceptable. 
Page 3

August 17,1995

Based on evaluation of the Waste Retrieval Sluicing System design and the EDE dose consequences caused by a postulated break of both supply and return transfer lines during a seismic event, redundant seismic switches will be installed to shut down the sluicing transfer system. With the operation of the seismic switches and a postulated release of waste for approximately 10 seconds (the seismic switches will terminate operation of the pumps, and the liquid release to the environment will stop within 10 seconds allowing for pump coast down), the calculated EDE offsite and onsite dose consequence values are reduced to $1.0 \mathrm{E}-3 \mathrm{mSV}$ and $1.0 \mathrm{E}-3 \mathrm{~Sv}$, respectively. A connector break inside the pit with the cover block on, with all openings closed, and a release time of 8 hours, the offsite EDE dose value of $3.8 E-6$ mSv. is well within the allowable limit of $5 \mathrm{mSv}$, and the onsite dose value of $3.6 \mathrm{E}-6 \mathrm{~Sv}$ is well within the allowable limit of 50 SV based on Section 9 of WHC-CM-446 (Reference 2). Therefore, if the pit covers are installed before any transfer operation via the jumpers/connectors within the pit, there is no impact to health and safety of personnel or to the environment. The pit covers are required to be installed and remain in place while performing the transfer per Section 3.6.1 of the Sinale-Shel1 Rank interim Operational Safety Requirements (Reference 4). In addition, Reference 3, WHC-CM-4-3, Industrial Safety Manual Section G-1, Revision 3, Change 1, "Operations Lock and Tag Program" wil] be implemented to ensure safety of the personnel and the environment.

The seismic switches have been classified as SC-1 per the safety function they perform and WHC-CM-4-46, Criterion 2 of Table 1, Section 9, (Reference 2). The standalone seismic switch enclosures are located outside the C-106 and $A Y-102$ facilities, and have two independent compartments housings for each of the redundant switches. A barrier wall is provided between the two compartments, designed for missile protection in accordance with the SC-1 requirements of Hanford Plant Standards SC 4.1 .

The safety function of the cover blocks to be provided by Project $W-320$ is to confine any spill and resulting aerosols, which are evaluated to have SC3 consequences if the cover blocks are properly installed, and based on the safety function that the seismic switches perform. Therefore, the cover blocks to be provided by Project $W-320$ will perform a safety class three function and are classified as a SC-3.

If you have any further questions please call me at 376-2058.

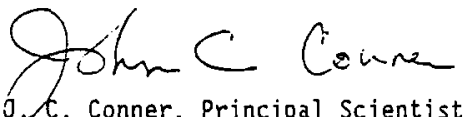

Project SAR Engineering

jwh 
HNF-SD-WM-RPT-293 REV 0

This page intentionally left blank. 
From: $\quad$ TWRS Safety Engineering

Phone: $\quad 376-2058$ H4-61

$8 M 110-J C C-95002$

Date: February 6, 1995

Subject: SOURCE TERM FOR SAFETY ANALYSIS SUPPORT OF THE WASTE RETRIEVAL OF TANK 241-C-106

To:
J. W. Bajley
$56-12$
J. P. Harris III
$56-12$
D. J. Shrimpton
S3-10
Official Field File S6-12
Official Project Files RI-28
CC: C. A. Augustine $\mathrm{S} 6-12$
K. D. Gibson H4-61
JCC LB/File

The initial sample data used to develop the radiological and toxicological unit doses in support of the safety documentation for the waste retrieval of Tank 241-C-106 was obtained from WHC-SD-WM-TI-565, Radionuclide and Chemical Inventories for the Single Shell Tanks (SSTs). This document lists the highest concentrations of radionuclide and chemicals found in a survey conducted by WASTREN of sample data maintained by Tank Waste Remediation System (TWRS) engineers and by the Westinghouse Hanford Company (WHC) Tank Characterization program. The reported analyses were, in general, from the most recent waste tank samples up to approximately 1990 . This data was believed to give a reasonable indication of the radionuclide and chemicat concentrations for use in safety analysis. This data does not represent the entire universe of sample data available at Hanford.

The data for this document was collected, entered into a data base, and plots were prepared by Kaiser Engineers Hanford (ICF KEH). Sample or calculated results were obtained from:

I. WHC-SD-WM-TI-565, Radionuclide and Chemical Inventories For the Single Shell Tanks (SSTs).

2. The Tank Sample Analysis Data Base prepared by Westinghouse Hanford Company's (WHC) Risk Assessment Technology group (Braun Database).

3. The files of sample data collected by the Tank Characterization Program.

4. Tank Characterization Reports (TCRs).

5. The Tank Characterization Database (TCD) maintained by Pacific Northwest Laboratories for WHC. 
6. The Track Radioactive Components (TRAC) database. This document does not contain actual sample results but gives calculated concentrations of radionuclides derived from production records and waste process flowsheets.

7. WHC-SD-WM-TI-628, Estimated Chemical and Radiochemical Inventories Spreadsheet: NE Quadrant, A, AX, B, BX, C Farms. This document does not contain actual sample results. It gives calculated concentrations of radionuclides and chemicals derived from process flowsheets and historical data on transfers in and out of the Hanford tanks.

Eleven radionuclides and 25 chemicals were identified for review using the scatter plots. For radionuclides, the 11 radionuclides were plotted for C106 , in both the liquid and solid phases. For the chemicals, the 25 chemicals were plotted in both the liquid and solid phases.

On each plot, a concentration line was drawn that corresponded to the concentration originally obtained from WHC-SD-WM-TI-565, Radionuclide and Chemical Inventories For the Single Shell Tanks (SSTs). Since the purpose of the review was to ensure that the unit doses calculated from this data was an upper bound, sample points that were higher than the concentration line was reviewed by a panel to determine if the higher points should be used for calculating the unit doses.

The review panel consisted of experienced personnel from the analytical laboratory, process chemistry, TWRS engineering, waste tank operations and safety analysis. Data base support was provided by ICF KEH. The review panel used their cumulative knowledge of the Hanford Chemical Separations processes, references on the history of the Hanford tank farms, and files of Taboratory sample reports to evaluate the sample points. If the panel determined that ali the points on the plot which were above the concentration line were not applicable, then the concentration represented by the line continued to be the concentration used for unit dose calculations. If the panel found a point above the concentration line that could not be eliminated, then that point became the basis for a new, higher concentration for unit dose calculations.

The panel documented their rational for rejecting or accepting sample points on the scatter plots and on separate Concentration Data Evaluation forms which were filed with the scatter plots. As the review has been completed the recommended concentrations for each radionuclide was provided to Criticality and Radiological Analyses for calculation of unit doses. 
J. W. Bailey, et al

Page 3

$8 M 110-J C C-95002$

February 6, 1995

The following listed data represents the maximum sample activity concentration for use in the safety analysis effort to support the waste retrieval of Tank 241-C-106:

$$
\text { C-106 Solids }
$$

\section{Radionuclide}

$\mathrm{Am}_{241}$
$\mathrm{Cm}_{244}$
$\mathrm{CO}_{60}$
$\mathrm{Cs}_{137}$
$\mathrm{Eu}_{154}$
$\mathrm{~Np}_{237}$
$\mathrm{Pu}_{238}$
$\mathrm{Pu}_{239 / 240}$
$\mathrm{Pu}_{241}$
$\mathrm{Y}_{90}$
$\mathrm{Sr}_{90}$

Concentration

$5.48 \mathrm{E} 7 \mathrm{~Bq} / \mathrm{L}$ (decayed) ${ }^{9}$

No $\operatorname{data}^{2}$

$3.0 \mathrm{E7} \mathrm{Bq} / \mathrm{L}$ (decayed) $^{3}$

2.67 El0 Bq/L (decayed) ${ }^{4}$

$5.04 \mathrm{E} 4 \mu \mathrm{Ci} / \mathrm{kg}$ (not decayed)

No datas

No data

3.27 E8 (decayed) ${ }^{7}$

Calculate from $\mathrm{Pu}_{240}$

Equal to $\mathrm{Sr}_{90}$

$9.75 \mathrm{E} 10 \mathrm{~Bq} / \mathrm{L}$ (decayed) $^{8}$

1 Decayed to December 1994

2 Data appears in WHC-SD-WM-SARR-016, Iank Farm HLW Compositions and Atmospheric Dispersion Coefficients for Use IN ASA Consequence Assessments

3 Decayed to December 1994

4 Decayed to December 1994

5 Data appears in WHC-SD-WM-SARR-016, Tank Farm HLW Compositions and Atmospheric Dispersion Coefficients for Use IN ASA Consequence Assessments

' Data appears in WHC-SD-WM-SARR-016, Tank Farm HLW Compositions and Atmospheric Dispersion Coefficients for Use IN ASA Consequence Assessments

7 Decayed to December 1994

8 Decayed to December 1994 
Page 4

February 6, 1995

Composite 100 Percentile

\begin{tabular}{|c|c|c|c|c|c|c|c|c|c|}
\hline Nucl ide & $\begin{array}{l}\text { Volum. } \\
\text { Activ. } \\
\text { SBg/L) }\end{array}$ & $\begin{array}{l}\text { CEDE } \\
\text { DOSe } \\
(S \vee / L)\end{array}$ & $\begin{array}{c}\text { Cont. } \\
(x)\end{array}$ & $\begin{array}{l}\text { Heat } \\
\text { Load } \\
(U / L)\end{array}$ & $\begin{array}{c}\text { Cont. } \\
\text { (x) }\end{array}$ & $\begin{array}{c}\text { Lung } \\
\text { Dose } \\
\text { (SV/L) }\end{array}$ & $\begin{array}{l}\text { Cont. } \\
(\boldsymbol{x})=\end{array}$ & $\begin{array}{c}\text { Bone sur } \\
\text { Dose } \\
\text { (SV/L) }\end{array}$ & $\begin{array}{c}\text { Cont. } \\
(\mathbf{z})\end{array}$ \\
\hline C 14 & $1.2 E \quad 06$ & $6.9 E-06$ & 0.0 & $0.0 E+00$ & 0.0 & $6.9 \mathrm{E}-06$ & 0.0 & $6.9 E-06$ & 0.0 \\
\hline $\cos 0$ & $3.0 \mathrm{E}+07$ & $1.8 E+00$ & 0.0 & $1.2 E-05$ & 0.1 & $1.0 E+01$ & 0.1 & 4.1E-01 & 0.0 \\
\hline SE79 & $0.0 E+00$ & $0.0 \mathrm{E}+00$ & 0.0 & $0.0 \mathrm{E}+00$ & 0.0 & $0.0 E+00$ & 0.0 & $\cdot 0.0 E+00$ & 0.0 \\
\hline SR90 & $9.7 E+10$ & $6.3 E+03$ & 8.8 & $3.05-03$ & 14.0 & $3.6 E+02$ & 3.3 & $7.1 \mathrm{E}+04$ & 5.7 \\
\hline Y 90 & $9.7 E+10$ & $2.2 E+02$ & 0.3 & $1.5 E-02$ & 67.0 & $9.1 E+02$ & 8.4 & $1.5 E+00$ & 0.0 \\
\hline 2R95 & $0.05+00$ & $0.0 E+00$ & 0.0 & $0.0 E+00$ & 0.0 & $0.0 E+00$ & 0.0 & $0.0 E+00$ & 0.0 \\
\hline regs & $1.2 E+07$ & 3.2E-03 & 0.0 & 1.6E-07 & 0.0 & $4.18-03$ & 0.0 & $5.2 E-04$ & 0.0 \\
\hline RU106 & $0.0 E+00$ & $0.0 E+00$ & 0.0 & $0.0 \mathrm{E}+00$ & 0.0 & $0.0 E+00$ & 0.0 & $0.0 \mathrm{E}+00$ & 0.0 \\
\hline SB125 & $0.0 E+00$ & $0.0 E+00$ & 0.0 & $0.0 \mathrm{E}+00$ & 0.0 & $0.0 \mathrm{E}+00$ & 0.0 & $0.0 \mathrm{E}+00$ & 0.0 \\
\hline 1129 & $4.3 E+03$ & $2.0 E-4$ & 0.0 & $5.4 E-11$ & 0.0 & $1.3 E-06$ & 0.0 & $5.9 \mathrm{E}-07$ & 0.0 \\
\hline $\operatorname{cs} 134$ & $0.0 E+00$ & $0.0 \mathrm{E}+00$ & 0.0 & $0.0 E+00$ & 0.0 & $0.0 E+00$ & 0.0 & $0.0 E+00$ & 0.0 \\
\hline $\operatorname{cs} 137$ & $2.7 E+10$ & $2.3 \mathrm{E}+02$ & 0.3 & $3.4 E-03$ & 15.7 & $2.4 E+02$ & 2.2 & 2. $1 \mathrm{E}+02$ & 0.0 \\
\hline CE 144 & $0.0 E+00$ & $0.0 E+00$ & 0.0 & $0.0 E+00$ & 0.0 & $0.0 E+00$ & 0.0 & $0.0 \mathrm{E}+00$ & 0.0 \\
\hline PM147 & $0.05+00$ & $0.0 E+00$ & 0.0 & $0.0 E+00$ & 0.0 & $0.0 \mathrm{E}+00$ & 0.0 & $0.0 E+00$ & 0.0 \\
\hline EU154 & $1.1 E+09$ & $8.8 E+01$ & 0.1 & $2.8 E-04$ & 1.3 & $9.0 \mathrm{E}+01$ & 0.8 & $6.0 E+02$ & 0.0 \\
\hline NP237 & $0.0 E+00$ & $0.0 E+00$ & 0.0 & $0.0 E+00$ & 0.0 & $0.0 E+00$ & 0.0 & $0.0 E=00$ & 0.0 \\
\hline PU238 & $1.4 E+08$ & $1.5 E+04$ & 20.5 & $1.2 E-4$ & 0.6 & $2.5 E+03$ & 23.5 & $2.6 \mathrm{E}+05$ & 29.0 \\
\hline PU239 & $3.3 E+08$ & $3.8 \mathrm{E}+04$ & 52.9 & $2.7 \mathrm{E}-04$ & 1.2 & $5.7 E+03$ & 52.2 & $6.9 \mathrm{E}+05$ & 55.2 \\
\hline PU240 & $0.0 \mathrm{E}+00$ & $0.0 \mathrm{E}+00$ & 0.0 & $0.0 E+00$ & 0.0 & $0.0 E+00$ & 0.0 & $0.0 E+00$ & 0.0 \\
\hline PU241 & $2.6 \mathrm{E}+09$ & $5.7 E+03$ & 7.9 & $2.1 \mathrm{E}-6$ & 0.0 & $1.9 E+01$ & 0.2 & $1.1 E+05$ & 8.6 \\
\hline AM241 & $5.5 E+07$ & $6.6 \mathrm{E}+03$ & 9.2 & $4.9 E-05$ & 0.2 & $1.0 E+03$ & 9.3 & $1.2 E+05$ & 9.5 \\
\hline AM242M & $0.0 \varepsilon+00$ & $0.0 E+00$ & 0.0 & $0.0 \mathrm{E}+00$ & 0.0 & $0.0 E+00$ & 0.0 & $0.0 E+00$ & 0.0 \\
\hline AM243 & $0.0 E+00$ & $0.0 E+00$ & 0.0 & $0.0 E+00$ & 0.0 & $0.0 \varepsilon+00$ & 0.0 & $0.0 E+00$ & 0.0 \\
\hline $\operatorname{cm} 262$ & $0.0 E+00$ & $0.0 \mathrm{E}+00$ & 0.0 & $0.0 \mathrm{E}+00$ & 0.0 & $0.0 \mathrm{E}+00$ & 0.0 & $0.0 E+00$ & 0.0 \\
\hline CM244 & $0.0 E+00$ & $0.0 \mathrm{E}+00$ & 0.0 & $0.0 E+00$ & 0.0 & $0.0 E+00$ & 0.0 & $0.0 \mathrm{E}+00$ & 0.0 \\
\hline EU155 & $0.0 E+00$ & $0.0 E+00$ & 0.0 & $0.05+00$ & 0.0 & $0.0 E+00$ & 0.0 & $0.0 E+00$ & 0.0 \\
\hline Total & $2.3 E+11$ & $7.2 \mathrm{E}+04$ & & $2.2 \mathrm{E}-2$ & & 1.1E+04 & & $1.3 E+06^{*}$ & \\
\hline
\end{tabular}

* Indicates whole body or organ limited. 
HNF-SD-WM-RPT-293 REV 0

J. W. Bailey, et al

Page 5

February 6, 1995

8M110-JCC-95002

The listed data of the 25 chemicals will be provided at a future date. If you have any questions, please contact me at 376-2058.

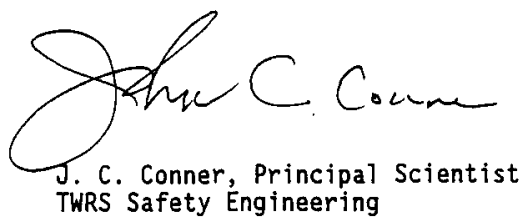

TWRS Safety Engineering

29 
HNF-SD-WM-RPT-293 REV 0

This page intentionaliy left blank. 
DOE/EA-0933

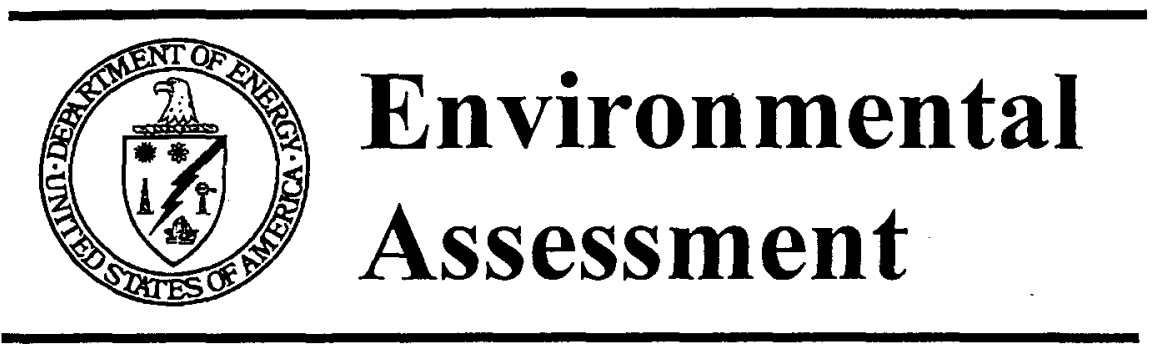

Tank 241-C-106 Past-Practice Sluicing Waste Retrieval, Hanford Site, Richland, Washington

Richland, Washington

February 1995 
HNF-SD-WM-RPT-293 REV 0

This page intentionally left blank 
DOE/EA - 0933

ENVIRONMENTAL ASSESSMENT

TANK 241-C-106

PAST-PRACTICE SLUICING

WASTE RETRIEVAL

HANFORD SITE, RICHLAND, WASHINGTON

U.S. DEPARTMENT OF ENERGY

February 1995 
HNF-SD-WM-RPT-293 REV 0

This page intentionally left blank. 


\section{Glossary}

\section{Acronyms and Initialisms}

$\begin{array}{ll}\text { ALARA } & \text { As Low As Reasonably Achievable } \\ \text { Btu } & \text { British thermal unit } \\ \text { CAA } & \text { Clean Air Act of 1970 } \\ \text { CPS } & \text { Criticality Prevention Specification } \\ \text { CRR } & \text { Cultural Resources Review } \\ \text { CY } & \text { Calendar Year } \\ \text { DBE } & \text { Design Basis Earthquake } \\ \text { DOE } & \text { U.S. Department of Energy } \\ \text { DOH } & \text { State of Washington Department of Health } \\ \text { DST } & \text { double-shell tank } \\ \text { EA } & \text { Environmental Assessment } \\ \text { Ecology } & \text { State of Washington Department of Ecology } \\ \text { EDE } & \text { Effective Dose Equivalent } \\ \text { EPA } & \text { U.S. Environmental Protection Agency } \\ \text { HEPA } & \text { High-Efficiency Particulate Air } \\ \text { HVAC } & \text { heating, ventilation, and air conditioning } \\ \text { kW } & \text { kilowatts } \\ \text { LCF } & \text { latent cancer fatality } \\ \text { MEI } & \text { maximally exposed individual } \\ \text { NRC } & \text { Nuclear Regulatory Commission } \\ \text { RCRA } & \text { Resource Conservarion and Recovery Act of 1976 } \\ \text { rem } & \text { roentgen equivalent man } \\ \text { SST } & \text { single-shell tank } \\ \text { Tri-Party Agreement } & \text { Hanford Federal Facility Agreement and Consent Order } \\ \text { TRU } & \text { transuranic } \\ \text { WAC } & \text { Washington Administrative Code } \\ \end{array}$

\section{Definition of Terms}

As Low As Reasonably Achievable (ALARA). An approach to radiation protection to : control or manage exposures (both individual and collective to the workforce and general public) as low as social, technical, economic, practical, and public policy considerations permit.

Double-shell tank. A reinforced concrete underground vessel with two inner steel liners to provide containment and backup containment of liquid waste; annulus is instrumented to permit detection of leaks from the inner liner. 


\section{Definition of Terms (cont.)}

Effective Dose Equivalent. A value used for estimating the total risk of potential health effects from radiation exposure. This estimate is the sum of the committed effective dose equivalent from internal deposition of radionuclides in the body and the effective dose equivalent from external radiation received during a year.

High-heat waste. Liquid radioactive waste which has the potential to generate sufficient fission product decay heat to cause self-boiling and self-concentration.

High-level waste. The highly radioactive waste material that results from the processing of spent nuclear fuel, including liquid waste produced directly in reprocessing that contains a combination of transuranic waste and fission products in concentrations requiring permanent isolation.

Latent cancer fatality. The additional cancer fatalities in a population due to exposure to a carcinogen.

Low-level waste. Waste that contains radioactivity and is not classified as high-level waste, transuranic waste, or spent nuclear fuel or byproduct material where the concentration of transuranic radionuclides is less than $100 \mathrm{nCi} / \mathrm{g}$.

Maximally exposed individual. A hypothetical member of the public residing near the Hanford Site who, by virtue of location and living habits, could receive the highest possible radiation dose from radioactive effluents released from the Hanford Site.

Person-rem. A population dose based on the number of persons multiplied by the radiation dose.

rem. Acronym for roentgen equivalent man; a unit of dose equivalent that indicates the potential for impact on human cells.

Single-shell tank. Older style Hanford Site high-level waste underground tank composed of a single carbon steel liner surrounded by concrete.

Sluicing. A method of waste retrieval which utilizes a high-volume, low-pressure stream of liquid to mobilize the waste prior to pumping.

Supernatant. The relatively clear liquid which is located over material deposited by settling or precipitation.

Transuranic waste. Without regard to source or form, radioactive waste that at the end of institutional control periods is contaminated with alpha-emitting transuranic radionuclides with half-lives greater than 20 years and concentrations greater than $100 \mathrm{nCi} / \mathrm{g}$. 


\section{Definition of Terms (cont.)}

Watch List tanks. These tanks have been identified as Watch List Tanks in accordance with Public Law 101-510, Section 3137, Safery Measures for Waste Tanks at Hanford Nuclear Reservation, 1990. These tanks have been identified as the Priority 1 Hanford Site Tank Farm Safety Issues: "Issues/situations that contain most necessary conditions that could lead to worker (onsite) or offsite radiation exposure through an uncontrolled release of fission
products, e.g., Tank SY-101." 


\section{Metric Conversion Chart}

\begin{tabular}{|c|c|c|}
\hline If you know & Multiply by & To get \\
\hline \multicolumn{3}{|c|}{ Length } \\
\hline cectimetors & 0.39 & inches \\
\hline meter & 3.28 & foet \\
\hline kilometers & 0.62 & miles \\
\hline \multicolumn{3}{|c|}{ Area } \\
\hline squrro kilometers & 0.39 & equare miles \\
\hline equare certimeten & 0.16 & equere inch \\
\hline \multicolumn{3}{|c|}{ Mass (weight) } \\
\hline grams & 0.035 & ounces \\
\hline kilogtems & 2.20 & pounds \\
\hline milligrams & $2.20 \times 10^{4}$ & pounds \\
\hline \multicolumn{3}{|c|}{ Volume } \\
\hline liters & 0.26 & gallons \\
\hline cubic meters & 35.3 & cubic feet \\
\hline \multicolumn{3}{|c|}{ Temperature } \\
\hline Celsius & multiply by $9 / 5$ tht, then add 32 & Fohreaheit \\
\hline kilowatts & 3412.14 & British thermal unit \\
\hline \multicolumn{3}{|c|}{ Preasure } \\
\hline kilograms per-aquare-centimeter & 14.22 & pounds per-square-inch \\
\hline
\end{tabular}
Floride.

Source: CRC Handbook of Chemismy and Physics, Robert C. Weast, Pt.D., 70th Ed., 1989-1990, CRC Press, Inc., Boca Raton,

\section{Scientific Notation Conversion Chart}

\begin{tabular}{|c|c|}
\hline Multiplier & Equiralent \\
\hline $10^{-1}$ & 0.1 \\
\hline $10^{-7}$ & .01 \\
\hline $10^{-4}$ & .001 \\
\hline $10^{-4}$ & .0001 \\
\hline $10^{-5}$ & .00001 \\
\hline $10^{-5}$ & .000001 \\
\hline $10^{-4}$ & .0000001 \\
\hline $10^{-4}$ & .00000001 \\
\hline
\end{tabular}




\section{Executive Summary}

The U.S. Department of Energy (DOE) needs to take action to eliminate safety concerns with storage of the high-heat waste in Tank 241-C-106 (Tank C-106), and demonstrate a tank waste retrieval technology. This Environmental Assessment (EA) was prepared to analyze the potential impacts associated with the proposed action, past-practice sluicing of Tank C-106, an underground single-shell tank (SST). Past-practice sluicing is defined as the mode of waste retrieval used extensively in the past at the Hanford Site on the large underground waste tanks, and involves introducing a high-volume, low-pressure stream of liquid to mobilize sludge waste prior to pumping. This EA describes the proposed action, the affected environment, reasonable alternatives to the proposed action, and provides an analysis of the potential environmental impacts.

It is proposed to retrieve the waste from Tank C-106 because this waste is classified not only as transuranic and high-level, but also as high-heat, which is caused by the radioactive decay of strontium. This waste characteristic has led DOE to place Tank C-106 on the safety "Watchlist." Historically, water has been added to the tank to provide evaporative cooling of the waste and to prevent the sludge from drying out. In the absence of these water additions, the heat load in Tank C-106 might exceed allowable temperature limits with the potential for structural damage to the tank. The tank is currently classified as sound, but there is a concem that should the tank start leaking, continued water additions could result in an increased amount of waste released to the environment.

Specifically, this action would accomplish the following:

- Remove at least 75 percent of the high-heat waste, which would reduce the tank heat load to less than 11.72 kilowatts $(\mathrm{kW})(40,000$ British thermal units [Btu] per hour). Water additions could then be stopped, and the tank removed from the safety "Watchlist" 
- Demonstrate one form of SST retrieval by October 1997 as called for in Hanford Federal Facility Agreement and Consent Order (Tri-Party Agreement) milestone M-45-03a, "Initiate Sluicing Retrieval of C-106." DOE has committed to resolving the safety concerns of the waste tanks at the Hanford Site in a more expedient timeframe. Consequently, the accelerated schedule calls for an October 1996 date for the waste retrieval demonstration.

Past-practice sluicing would be accomplished by transferring waste from Tank C-106 to the receiver tank, Tank 241-AY-102 (Tank AY-102), an underground double-shell tank (DST). Two transfer lines would connect the tanks. One line would carry the slurry (the sluiced waste) to the DST, and the other would carry the supernatant liquid from the DST, which would be used to mobilize the waste in Tank C-106 to facilitate pumping and waste transfer. The primary equipment necessary for this action would include pumps in each of the tanks; sluicer(s) to remotely aim the sluice streams in Tank C-106; a slurry distributor in the DST; an air ventilation system on Tank C-106; and additional monitoring devices. To provide adequate receiving space in Tank AY-102, its supernatant would be pumped out prior to sluicing. It is proposed that supernatant from Tank 241-AY-101 (Tank AY-101) or other appropriate sluicing fluid would be used as the sluicing agent. This sluicing fluid, which may consist of chemically treated water, would be pumped to Tank AY-102 prior to sluicing. Chemicals may be added, as necessary, to prevent potentially undesirable waste characteristics or to control corrosion. include:

Several alternatives to the proposed action are discussed briefly in this document. They

- Batch Transfer. This alternative would use an accumulation tank of 189,000 liters $(50,000$ gallons) that would alternately hold the supernatant from Tank AY-102, and the slurry from Tank C-106. The transfers would occur when this accumulation tank was full, and not simultaneously. 
- Once Through-No Recycle. This altemative would use a tanker truck to supply the sluicing medium instead of using the supematant from Tank AY-102.

- Limited Mixer Pump. A tanker truck would provide the sluicing fluid which would utilize sluicers, and a combined mixer and transfer pump, to create a slurry which would be sent to the receiver tank in batches.

- Recirculate Within a SST Via Mixer Pump. Two mixer pumps would use the sluicing fluid, introduced by a tanker truck, to mobilize all the solids in Tank C-106. The tank contents would be transferred to the receiver tank.

- Internal Recirculation. In this altemative, the sluicing fluid from a tanker truck would be routed through a loop in the sluicing system. After the waste has formed a slurry, some of this waste would be sent to the receiver tank, while the rest would be reused as a sluicing fluid.

- Eydraulic Mining. A crane would lower a mining tool into the waste in Tank C-106, and shoot a high-pressure stream of liquid laterally. As the waste is pumped, a cavity forms in the layer of waste desired.

- Center Pivot Dredge. This alternative would retrieve the waste in Tank C-106 by mechanical dredging equipment which would access the tank by a new 1.5-meter (5-foot) opening.

- No-Action. This alternative would involve leaving the high-heat waste in Tank C-106, and continuing to add cooling water periodically.

These altermatives were examined and found to either pose a greater threat to the cnvironment than the proposed action, or failed to meet one of the two requirements of this project. These requirements consist of reducing the heat load in Tank C-106 to below $11.72 \mathrm{~kW}$ (40,000 Btu per hour), and being able to start retrieval by October of 1996 . 
Impacts from the proposed action were found to be small in comparison to Hanford Site operations as a whole. Environmental impacts to the air and water would be within all applicable standards. The proposed action would not lead to a substantial increase in human health effects and would be in compliance with all standards pertaining to public health. No impact is expected to any threatened or endangered plant or animal species, critical or sensitive habitat, or cultural or historical resources.

Impacts from accidents were examined and evaluated. The worst-case scenario, for both onsite and offsite populations, would involve an unfiltered release through a breach in the recirculation duct of the ventilation system using Tank AY-101's supernatant as a sluicing fluid. The likely mechanism for this accident is a vehicular collision, however it is possible that a Design Basis Earthquake (DBE) could lead to similar results. It is assumed that one hour elapses before the leak is detected. This duration can be considered conservative due to the presence of design features which would shut off the sluicing operation, and identify a release, well before one hour. The offsite maximally exposed individual (MEN) has been calculated to receive a dose of $5.2 \times 10^{-4}$ roentgen equivalent man (rem) Effective Dose Equivalent (EDE), which would represent a probability of $3.0 \times 10^{-7}$ that the individual would develop a latent cancer fatality (LCF). The onsite MEI was calculated to receive $5.0 \times 10^{-1}$ rem EDE. This dose would represent a probability of $2.0 \times 10^{-4}$ that the onsite individual would develop an LCF. The effect to offsite and onsite populations from this scenario would be a calculated 0.0 and 0.02 LCFs, respectively. 


\section{Table of Contents}

1.0 Purpose and Need for Agency Action $\ldots \ldots \ldots \ldots \ldots \ldots \ldots \ldots$

2.0 Description of the Proposed Action $\ldots \ldots \ldots \ldots \ldots \ldots \ldots \ldots \ldots \ldots \ldots \ldots \ldots$

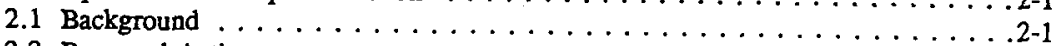

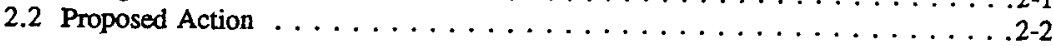

3.0 Alternatives to the Proposed Action $\ldots \ldots \ldots \ldots \ldots \ldots \ldots \ldots$

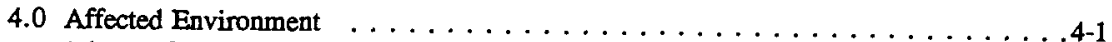

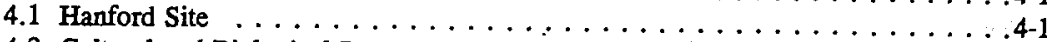

4.2 Cultural and Biological Resources $\ldots \ldots \ldots \ldots \ldots \ldots \ldots \ldots \ldots \ldots \ldots$

5.0 Environmental Impacts $\ldots \ldots \ldots \ldots \ldots \ldots \ldots \ldots \ldots$. $\ldots \ldots \ldots$

5.1 Analysis of Past-Practice Sluicing of Tank $241-\mathrm{C}-106 \ldots \ldots \ldots \ldots \ldots$. $\ldots \ldots$.

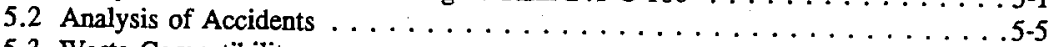

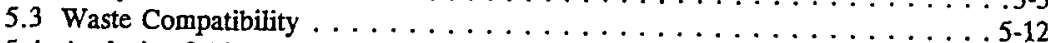

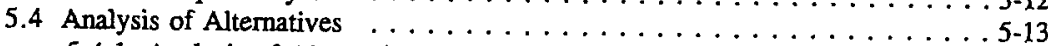

5.4.1 Analysis of Alternative Waste Retrieval Methods . . . . . . .

5.4.2 Analysis of the No-Action Alternative $\ldots \ldots \ldots \ldots \ldots \ldots \ldots$ 5-15

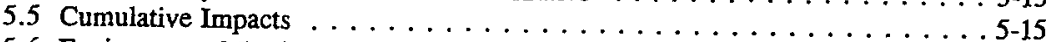

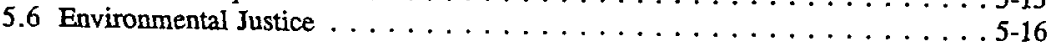

6.0 Permits and Regulatory Requirements $\ldots \ldots \ldots \ldots \ldots \ldots$ 6-1

7.0 Agencies Consulted $\ldots \ldots \ldots \ldots \ldots \ldots \ldots \ldots \ldots \ldots \ldots \ldots \ldots$

8.0 References $\ldots \ldots \ldots \ldots \ldots \ldots \ldots \ldots \ldots \ldots \ldots \ldots \ldots$ 8-1 


\section{List of Tables}

1. Reasonably Foreseeable Accident Scenarios $\ldots \ldots \ldots \ldots \ldots \ldots \ldots$ 5-6

2. Accident Assumptions and Consequence Reduction Features $\ldots \ldots \ldots \ldots$. . . . .

\section{List of Figures}

1. Hanford Site Showing Tank 241-C-106 Location.. . . . . . . . . . . . . F-1

2. Tank 241-C-106 and Tank 241-AY-102 Configuration. . . . . . . . . . F-2

3. Tank $241-\mathrm{C}-106$ Volume History $\ldots \ldots \ldots \ldots \ldots \ldots \ldots \ldots \ldots$ F-3

4. Tank $241-\mathrm{C}-106$ Heat Generation by Layer $\ldots \ldots \ldots \ldots \ldots \ldots \ldots \ldots$ F-4

5. Tank-To-Tank Sluicing $\ldots \ldots \ldots \ldots \ldots \ldots \ldots \ldots \ldots$ F-5

6. Proposed Location of Waste Transfer Lines. . . . . . . . . . . . F-6

7. Proposed Pipeline Configuration $\ldots \ldots \ldots \ldots \ldots \ldots \ldots \ldots$ F-7

8. Typical Sluicer Configuration $\ldots \ldots \ldots \ldots \ldots \ldots \ldots \ldots$ F-8

9. Tank 241-C-106 Sluicing Features $\ldots \ldots \ldots \ldots \ldots \ldots \ldots \ldots \ldots$ F-9

Appendices

A. Cultural Resources Review (HCRL $\# 93-200-111) \ldots \ldots \ldots \ldots \ldots$. . . . . . A A-1

B. Ecological Survey $(\$ 93-200-40) \ldots \ldots \ldots \ldots \ldots \ldots \ldots \ldots$. . . . . . .

C. Yakama Indian Nation's Comments and DOE Responses $\ldots \ldots \ldots \ldots$. . . . C-1 


\subsection{Purpose and Need for Agency Action}

The U.S. Department of Energy (DOE) needs to take action to eliminate safety concerns with the storage of high-heat waste in Tank 241-C-106 (Tank C-106), and demonstrate a tank waste retrieval technology. The action would address the following concerns:

- The heat generation for Tank C-106 is estimated to be 32.24 plus or minus 5.86 kilowatts $(\mathrm{kW})(110,000$ plus or minus 20,000 British thermal units [Btu] per hour) (WHC 1993a). The heat is produced from the radioactive decay of radionuclides present in the waste, principally strontium-90. This decay heat is currently being removed by evaporative cooling. Approximately 22,700 liters (6,000 gallons) of water are added to the tank each month for this purpose. It is believed that without active cooling, temperatures in the tank would exceed established limits and eventually affect the structural integrity of the tank with a possible breach of containment.

- The continued addition of cooling water to the tank increases the amount of waste that could disperse into the soil column if Tank C-106 starts to leak. Even with the continued additions of cooling water, Tank C-106's integrity could still fail due to the fact that it is storing waste beyond its design life. In addition to the possibility of a tank leak occurring due to the age of the tank, a natural occurrence (i.e., an earthquake) also could lead to a release of the tank's contents to the environment. It is, therefore, advantageous to remove the waste from this tank as soon as possible to protect the environment against an accidental release.

- Hanford Federal Facility Agreement and Consent Order (Tri-Party Agreement) Milestone M-45-03-T01, "Complete SST Waste Retrieval Demonstration," calls for the completion of a waste retrieval demonstration by 2003 . Tank C-106 has been selected by DOE as the demonstration tank for this milestone. The State of Washington Department of Ecology (Ecology) has concurred in this selection and the Tri-Party Agreement names Tank C-106 as the retrieval demonstration tank. Sluicing has been identified as a reference retrieval technology for single-shell tank (SST) waste. While past-practice sluicing has been practiced extensively at the Hanford Site, it is identified as a demonstration technology because it has to be proven effective under the current regulatory framework which is much more stringent than past requirements. Sluicing will be evaluated as a method of waste retrieval for all SSTs. Tri-Party Agreement Milestone M-45-03a, "Initiate Sluicing Retrieval of C-106," also calls for the initiation of sluicing retrieval of Tank C-106 by October of 1997 to resolve the high-heat issue. This project has been identified by DOE as a Secretary of Energy Safety Initiative, and its schedule has been accelerated by one year over the date committed to in the Tri-Party Agreement. This reflects DOE's desire to resolve the safety issues surrounding specific waste tanks at the Hanford Site in a more expedient manner. The new, accelerated date proposed for initiation of the retrieval of the heat-generating waste from Tank C-106 is October 1996. Construction activities required prior to sluicing operations would last approximately two years, while the actual waste retrieval activities would take between six months and one year. 
This page intentionally left blank. 


\subsection{Description of the Proposed Action}

\subsection{Background}

The National Defense Authorization Act for Fiscal Year 1991, Public Law 101-510, Section 3137, "Safety Measures for Waste Tanks at Hanford Nuclear Reservation," mandates that DOE develop plans to respond to safety issues associated with underground waste storage tanks on the Hanford Site, and report the progress of implementation of these plans to the U.S. Congress. The tanks identified as having safety issues associated with them belong to the safety "Watchlist." The report containing the response plans has been prepared as Status Report on Resolution of Waste Tank Safety Issues at the Hanford Site (WHC 1993b), which identifies Tank C-106 as one of the "Priority 1," safety issues at the Hanford Site.

The proposed action would involve sluicing the waste from Tank C-106, a SST, and transferring the waste to Tank 241-AY-102 (Tank AY-102), a double-shell tank (DST), through one of the two proposed double encased (pipe-in-pipe design), bermed lines. Past-practice sluicing involves introducing a high-volume, low-pressure stream of liquid to mobilize sludge waste prior to pumping. Tank C-106 is located in the 200 East Area (Figure 1). Tank C-106 is 23 meters ( 75 feet) in diameter, and is constructed of reinforced concrete with a carbon-steel liner on the tank bottom and sides. The tank has a 31-centimeter (12-inch) thick dished bottom, and a useable waste depth of approximately 4.8 meters (16 feet) at the sidewall. The dome of the tank is constructed of 38-centimeter (15-inch) thick reinforced concrete. Tank C-106 was constructed between 1943 and 1944, and has the capacity of approximately 1.9 million liters $(500,000$ gallons). Figure 2 shows the proposed configuration of Tank C-106.

In 1992, the ventilation system failed on the tank, and the practice of adding cooling water was halted for a period of six months while the ventilation system was being repaired. The tank was continuously monitored for waste level decreases that might indicate that there was a loss of confinement in the tank. During this period, the waste level in the tank did not decrease, but actually rose as a result of themal expansion due to the increased temperature, which supported DOE's classification of the tank as sound.

The waste in Tank C-106 consists of 746,000 liters (197,000 gallons) of sludge. The waste is stratified into two layers. The top layer consists of 655,000 liters $(173,000$ gallons) of sludge, containing a sufficient amount of strontium to be considered high-heat waste (WHC 1993a). This layer generates approximately $32 \mathrm{~kW}$ (110,000 Btu per hour). The bottom layer consists of 91,000 liters $(24,000$ gallons) of low-heat producing hardened material. Approximately 121,000 liters $(32,000$ gallons) of supernatant exists above the sludge layers, and would be pumped to Tank AY-102 as part of this project, just prior to sluicing operations. In order to resolve the heat issue associated with this tank, sluicing would need to remove approximately 75 percent of the high-heat waste to lower the heat output of the remaining waste to less than $11.72 \mathrm{~kW}(40,000$ Btu per hour). Before the 
addition of the strontium bearing waste in the 1970s, Tank C-106 did not exhibit a heat problem. There was also an observable hardened layer at the bottom of the tank. After the sluicing operation which introduced the strontium waste was completed, the level of solids in Tank C-106 was observed to increase. At the same time, the waste started generating excess amounts of heat. Figures 3 and 4 show Tank C-106's volume history and heat generation, by layer, respectively.

A core sample taken from Tank C-106 in 1986 showed that stratification of the waste layers persisted. The bottom layer was observed to remain as a hardened layer while the upper layer still remained a soft sludge. It was concluded that since the layers did not commingle, the constituents generating heat remained in this upper soft layer.

In addition to producing significant quantities of heat, the waste in Tank C-106 has greater than 100 nanocuries per gram transuranic (TRU) content (WHC 1994a). This qualifies the sludge as both a high-heat and TRU waste (WHC 1993a). The chemical composition of the sludge also classifies the contents of the tank as a "listed waste" in accordance with Washington Administrative Code (WAC) 173-303, "Dangerous Waste Regulations." The heat generation rate for this sludge is estimated to be 32.24 plus or minus $5.86 \mathrm{~kW}$ (110,000 plus or minus 20,000 Btu per hour) (Bander 1993).

Tank AY-102, which also is located in the 200 East Area, was built between 1968 and 1970 , and has an operational capacity of 3.7 million liters $(980,000$ gallons). Tank AY-102 is currently near its operational capacity, but would undergo a waste transfer operation prior to sluicing to provide receiving space for Tank C-106's waste. The tank is currently classified as sound (WHC 1993a), and was built with a design life of 50 years. Tank AY-102's waste comes from a variety of sources and is considered TRU and of a noncomplexed organic nature, which poses no criticality issues with the waste from Tank C-106 (WHC 1994a). Tank AY-102 was chosen as the receiver tank because it is a DST, which provides an additional barrier against the release of the waste to the environment; has a newer, larger capacity ventilation system which can dissipate much larger amounts of heat; and has a sufficient amount of space available for waste storage. The transfer of the waste to this DST would eliminate the high-heat problem associated with the waste because Tank AY-102's ventilation system (which serves four DSTs) is capable of handling 1,173 kW (4 million Btu per hour). Tank AY-102 would store the waste until final treatment options become available (currently scheduled for the Year 2009). Figure 2 shows the proposed configuration of Tank AY-102.

\subsection{Proposed Action}

The proposed action would remove the high-heat solids in Tank C-106 by a closed-loop, continuous sluicing process. Specifically, this would entail introducing a high-volume, low-pressure stream of liquid (supernatant or treated water) to mobilize the sludge waste in Tank C-106 and prepare it for pumping. Up to two remotely aimed "sluicers" would be installed in Tank C-106 at separate locations to ensure full sluicing coverage of the waste. As soon as the sludge is broken up by the sluicers, and a slurry formed, a slurry transfer pump would remove the mixture for transfer to the receiver tank at approximately the same 
rate that the supernatant is being introduced to Tank $C-106$. The waste would be transferred to Tank AY-102 through one of two proposed, double encased pipelines, which would be installed to support this waste retrieval project. These pipelines, which would connect the two tanks, would measure approximately 0.4 kilometer $(0.25$ miles) in length. Figure 5 depicts tank-to-tank sluicing while Figure 6 shows the location of the proposed waste transfer lines. The slurry would be deposited in Tank AY-102 through a slurry distributor (located below the liquid level), which would greatly diminish the flow velocity and allow the heavier, sludge particles in the slurry to settle under the force of gravity. The liquid portion of the slurry would remain on top to be recycled to Tank C-106 as the liquid sluicing agent (supernatant). A sluice pump would simultaneously transfer the supernatant from Tank AY-102 to Tank C-106 through one of the two, newly installed, pipelines to the sluicers where it would be used to mobilize additional sludge in Tank C-106. The pipelines would be partially buried and covered with an earthen berm to limit personnel dose exposure to tank farm workers (Figure 7).

At the beginning of the sluicing operation, the 120,000 liters $(32,000$ gallons) of supernatant presently in Tank C-106 would be pumped to the receiver tank (which would be approximately half full at the time of sluicing) to allow improved sluicing efficiency in Tank C-106. The valves on the slumy transfer pump in Tank C-106 then would be set to allow the slumy to recirculate directly to the sluicers. This process would allow the mixture recirculating within Tank C-106 to be monitored for waste consistency. Once the slurry has the desired characteristics (mainly for percentage of solids), the valves on the slurry transfer pump would be switched to allow the slumy to pump through the transfer line to Tank AY-102. At this point, the maximum amount of supernatant pumped from Tank AY-102 would be roughly 19,000 liters (5,000 gallons). The sluice pump would send the supernatant simultaneously from Tank AY-102 to the sluicers, creating a continuous process.

During this process, the sluice pump in Tank AY-102 would deliver 1,324 liters (350 gallons) per minute of supernatant to the sluicing nozzles in Tank C-106, with a pressure of 12.5 kilograms per-square-centimeter (180 pounds per-square-inch), and a temperature between 24 and $29^{\circ} \mathrm{C}$ (75 to $85^{\circ} \mathrm{F}$ ). This pump maintains enough agitation to prevent any solids from settling in the transfer lines. Up to two sluicers (Figure 8) would be installed in Tank C-106, and would use the supernatant from Tank AY-102 to break up the sludge waste. One sluicer would operate in the existing sluice pit, while the other would operate in the existing pump pit, if needed. During most of the waste retrieval operations, only one sluicer would operate at any given time.

An in-tank imaging system would be used to monitor the operation of the sluicers by locating sludge concentrations, and determining the effectiveness of the sluicers. This imaging system would allow for sluicing operations to proceed with a minimal volume of liquid in Tank C-106, which is desirable for safety (tank leakage) considerations and proper jositioning of the sluicers for maximum solids removal efficiency. The sluicers would be directed with the aid of this imaging system to cut troughs in the waste during the initial stages of waste removal. These troughs, which would produce channels in the waste leading to the slurry pump, would increase sluicing efficiency (Figure 9). 
A new submersible pump would be installed in Tank C-106 to transfer the slurry (i.e., the sluiced waste) to Tank AY-102. To allow for slurry elevation changes, the slurry transfer pump would be manually adjusted to maintain sufficient suction-head pressure. The sluicing operations would start from the center of the tank, and work to the outside, by remotely adjusting the angle of the sluicers. The waste solids located along the tank walls would not be removed until the end of sluicing operations (Figure 9). This would minimize the potential for the sluicing stream to cause a leak by impinging upon a weak point in the tank wall or by opening a pre-existing corrosion induced or sludge-plugged leak site.

The slurry would be pumped into the transfer line and deposited into Tank AY-102. A slurry distributor would evenly spread the Tank C-106 waste solids in Tank AY-102. This would provide a more uniform heat source in Tank AY-102. The distributor also would provide a siphon break for the transfer line back to Tank C-106.

Various techniques exist for determining the amount of sludge the sluicing operation has transferred from Tank C-106. Two of these techniques include direct observation by the in-tank imaging system and the use of process instrumentation. Instrumentation included in the transfer lines would offer a direct measurement of the quantity of waste transferred. In addition to assessing the amount of sludge transferred, the sluicing system proposed for this operation, combined with the level indicator located in Tank AY-102, could be used to determine whether Tank C-106 has developed a leak. A running material balance inventory would be maintained to assure that all liquids (within the accuracies of the Tank AY-102's liquid level instrument and the transfer lines' flow meters) remain accounted for. The presence of flow meters on the transfer lines and material balance controls on Tank AY-102 would detect a leak when approximately 30,000 liters $(8,000$ gallons) are removed from the sluicing process by means of a leak somewhere in the closed-loop system.

Determination of the end point for the sluicing operation would depend on the results of an in-field evaluation to determine the heat balance of Tank C-106. When the majority (at least 75 percent) of the high-heat waste has been transferred, the evaluation may be considered, although the evaluation may be conducted at other times if other situations arise. If this evaluation confirms that the heat load in the tank is below $11.72 \mathrm{~kW}(40,000 \mathrm{Btu}$ per hour), the sluicing operation could end; however, additional waste might be sluiced to demonstrate the effectiveness of this waste retrieval technology.

Chemical additions of sodium hydroxide and sodium nitrite (to maintain the waste within the DST operating specifications for corrosion control), would be distributed through an existing riser in Tank AY-102, as needed. In addition, caustic solution (namely sodium hydroxide) would be added, as necessary, to the supernatant prior to and during sluicing to promote waste compatibility.

The project would be designed to incorporate features that would protect workers. The waste transfer lines would be partially buried and bermed for radiation shielding. The proposed new ventilation system for Tank $\mathrm{C}-106$ would be designed to reduce the time workers would spend changing filters. Workers in the 241-C Tank Farm would wear all of the appropriate protective clothing, and may use respiratory equipment (e.g., face masks and bottled 'fresh' air). 
Prior to the actual sluicing operations, several actions would be required to prepare the tanks for the insertion of the pumps and/or equipment. Some of the existing equipment in the pump and sluice pits of Tank C-106 must be removed and stored at the Hanford Site for subsequent treatment and disposal. This removal would be accomplished by hoisting the equipment through existing risers into flexible receiver containers. These containers would be lowered into specially constructed crates positioned on a trailer, and sent to the Hanford Central Waste Complex. During the actual sluicing operation, it may be necessary to remove additional equipment if it is determined that this remaining, obsolete equipment impairs sluicing efficiency. The same method of equipment removal described above likely would be utilized for these removals as well. The inside of the pump and sluice pits would require cleaning, and the application of paint or fiber to the surface, to provide a surface that can be more easily decontaminated. Equipment removal and pit decontamination are routine tank farm activities, as previously considered in the preparation of the Final Environmental Impact Statement: Disposal of Hanford Defense High-Level, Transuranic and Tank Wastes, Hanford Site, Richland, Washington (HDW-EIS) (DOE 1987), and the Environmental Assessment: Waste Tank Safety Program, Hanford Site, Richland, Washington (DOE 1994).

It is proposed that the initial sluicing fluid used to sluice Tank C-106's waste would be Tank 241-AY-101's (Tank AY-101) supernatant or other appropriate fluid. Alternative sluicing agents may consist of supernatant, or fluid, from another waste tank (or waste stream at the Hanford Site) or "buffered" water (water which has been chemically treated for corrosion control). The decision on which fluid to use as the sluicing agent would consider factors such as waste compatibility, cost effectiveness, waste minimization guidelines, and coordination with ongoing tank farm operations. Prior to the transfer of the sluicing fluid into Tank AY-102, the supematant currently in Tank AY-102 would be sent to the Evaporator Bottoms System or another DST because of potential waste compatibility concerns with the sludge in Tank C-106. This type of transfer is performed frequently at the Hanford Site, and is considered to be a routine action required for proper waste storage and treatment. The removal of Tank AY-102's supernatant, even with the introduction of the new sluicing fluid, would create approximately 1.9 million liters $(500,000$ gallons) of space in the receiver tank for this transfer and would eliminate the potential for overflow as a result of the proposed sluicing operation.

To minimize releases to the atmosphere from the ventilation system on Tank C-106, the proposed action would install a High-Efficiency Particulate Air (HEPA) filtration system for Tank C-106. Additional filtration elements (which could include mist eliminators and gas filtration units) would be included in this system as required to meet regulatory release requirements, such as Best Available Control Technology for both toxic and radionuclide emissions. These additional elements would be added before sluicing operations commence if ongoing air emission studies demand their inclusion. New exhaust ductwork would be designed and installed to discharge through the new filtration system. The old ventilation system and ductwork would remain in place and operational for Tank 241-C-105 and Tank C-106 major maintenance operations. During these infrequent major maintenance operations, an air flow of approximately 75 cubic meters $(2,500$ cubic feet $)$ per minute would 
be discharged through this ventilation system. The new filtration system would discharge a maximum of approximately 9.9 cubic meters ( 350 cubic feet) per minute during normal operations. Section 5.1 presents a description of emissions from sluicing operations.

A metal filtration unit would be installed upstream from the HEPA filtration units, which would catch the majority of the contaminants before they reach the HEPA filters. This would negate the need to change these HEPA filters during the operational life of this project. This metal filtration unit would be included to meet As Low As Reasonably Achievable (ALARA) requirements, which are designed to minimize worker exposure to radioactive air emissions. Since the metal filtration unit is flushable, little or no solid waste is expected to be generated by the entire air filtration system. At the conclusion of these waste retrieval activities, the disposable part of these filter units would be disposed of properly at the Hanford Site.

To control the temperature and humidity of the Tank C-106 vapor space during sluicing, the proposed action would install a recirculation line in the ventilation system. This recirculation line would consist of a condenser, a dehumidification coil, and a recirculation fan. The proposed action would include a supplemental cooling system, if necessary, to provide a means of removing excess heat from the tank and to preclude steam generation from within the waste. A supplemental cooling system would allow sluicing to proceed safely and more efficiently. This cooling may be accomplished by modifying the piping on the ventilation system to allow the use of the proposed recirculation duct air chiller with the existing tank ventilation system or may involve the addition of cooling liquid (e.g., water), either prior to, or as part of, the sluicing process.

Additional instrumentation would be required in both tanks (Tanks C-106 and AY-102), and in the transfer lines between the tanks. Tank $\mathrm{C}-106$ would receive instrumentation that would monitor tank pressure to ensure confinement. Temperature monitoring would be provided by using a thermocouple tree. Sluicing pump control and status instrumentation also would be provided. A double-wide trailer would be installed outside the 241-C Tank Farm, and would serve to bouse centralized monitoring and control instrumentation. Additional monitoring devices would be installed in Tank AY-102, as needed. Leak detection would be provided for the new transfer lines and the pump pits, and a seismic switch would be added to reduce the volume of a spill from a rupture of the transfer lines that could be caused by a Design Basis Earthquake (DBE).

Support services in the form of raw water, sanitary water, electrical power, telecommunications, and hoisting hardware, would be provided. The use of existing septic systems or portable facilities for sanitary sewage would be considered for the personnel using the control trailer. A sanitary catch tank, sized for one week of operation, may be provided should it be determined that existing facilities are inadequate. This catch tank would be emptied periodically (weekly) to a properly sited facility for treatment in accordance with approved Hanford Site procedures. Standby power and/or uninterruptable power supplies would be provided, as required. 
The project has a maximum design life of two years, although actual sluicing operations should take approximately six months to complete. After the retrieval operation is complete, the used equipment and waste transfer lines would be decontaminated and stored for future treatment and disposal. Other project waste would be disposed of in a properly sited landfill in accordance with all applicable state and federal guidelines.

This project is designed to, at a minimum, remove 75 percent of the high-heat waste, which would lower the heat output of the remaining waste to less than $11.72 \mathrm{~kW}$ (40,000 Btu per hour). Sluicing would attempt to remove as much waste as possible beyond this 75 percent to demonstrate a waste retrieval technology. At the end of sluicing operations, however, a 0.3 - to 0.6 -meter (1- to 2-foot) layer of hardened waste may remain. This hardened layer, if not removed during the sluicing operation, would be removed by a different technology which is under development as part of a separate project, and will be addressed by future National Environmensal Policy Act of 1969 documentation. In the interim period, between the conclusion of the proposed action and the initiation of this future retrieval action, the hardened layer would be monitored and treated (e.g., removing any potential excess heat by utilizing air chillers, and sprinkler systems), if necessary, to prevent this waste from drying out and potentially developing undesirable characteristics. The waste in Tank AY-102 also would be monitored to ensure that the storage of waste is within the tank's operating specifications. Proper measures would be taken, which may include the use of airlift recirculators, to prevent the waste from forming potentially hazardous physical properties. 
This page intentionally left blank. 


\subsection{Alternatives to the Proposed Action}

Sluicing alternatives to the proposed action were identified and described in Appendix $F$ of the Tank 106-C Sluicing Letter Report (WHC 1993c). The sluicing alternatives mentioned, including the No-Action Alternative, are listed below. Section 5.3.1 contains a discussion of the impacts from these alternatives.

- Batch Transfer. This option would utilize a 189,000-liter (50,000-gallon) accumulation tank, which would hold both the supernatant from Tank AY-102, and the slurry from Tank C-106, alternately. This supernatant would be used as the sluicer fluid for Tank C-106 waste. When enough solids were pumped to the accumulation tank, the material would be batch transferred to Tank AY-102. The accumulation tank then would be refilled with supernatant from Tank AY-102, and the cycle repeated. While definitive design for this alternative has not been completed, it is anticipated that the accumulation tank would be located within the 241-C Tank Farm boundaries. This alternative has been used at the Hanford Site as a proven technology used to retrieve waste.

- Once Through-No Recycle. This altemative would use a tank truck to supply the sluicing medium to mobilize the solids in Tank C-106, which are then pumped to the receiver tank. With no recycling, the amount of liquid, most likely raw water (chemically adjusted for corrosion control), pumped to the receiver tank would be larger, relative to the amount of liquid pumped from the proposed action. Some of this excess liquid would be pumped from the DST for additional treatment or storage (i.e., sent to an evaporator or another DST with more available space). This alternative, one of several which would use a tank truck, would allow for continuous operation.

- Limited Mixer Pump. This altemative is similar to the Once Through--No Recycle described above in that it would utilize a tank truck to provide the sluicing agent. This alternative, however, would use sluicers and a specially designed combined mixer and transfer pump to mobilize a portion of the solids in Tank C-106 in a bowl-shaped depression (utilizing the remaining solids as an additional barrier to tank leakage). The homogenized slurry then would be transferred to the receiver tank in batches to reduce the amount of extra liquid waste produced. While this alternative is not expected to produce as much additional waste as the Once Through--No Recycle Alternative, it still would require more storage space than the proposed action or the Batch Transfer Alternative.

- Recirculate Within a SST Via Mixer Pump. Again, a tank truck would be used to supply the waste mobilizing agent. However, sluicers would not be used in this option. Instead, two mixer pumps would use the introduced liquid to mobilize all of the solids in Tank C-106 into a homogenous slurry before transfer. This option would have roughly the same waste space requirements as the proposed action; however, there are several drawbacks that make this option unattractive. These 
drawbacks include higher heat input to the waste due to additional mixing and agitation; increased environmental risk due to possible damage to the tank from the mixing pump outlet spray impinging on the tank walls and a much higher liquid inventory maintained in Tank C-106 during the retrieval operation; the need for an additional 107-centimeter (42-inch) riser; and a longer design and testing period.

- Internal Recirculation. The last alternative examined using a tank truck, internal Recirculation, would use a portion of the slurry (i.e., the already-sluiced waste) as an additional mobilization agent. Some of the slurry would be pumped to the receiver tank, and some would be fed back into the sluicers. This would limit the amount of mobilization agent needed from the tank truck. As with the other alternatives that use a tank truck, the amount of slurry waste would be somewhat greater than that of the proposed action.

- Bydraulic Mining. This alternative would use a variation of a technique used in the mining industry. A crane would lower a mining tool that would penetrate the waste and shoot a high-pressure stream of water laterally. A slurry inlet port would pump the slurry out to the receiver tank, creating a waste cavity in the section of waste desired. More complex than the proposed action, this unproven alternative would have the potential for the greatest waste minimization of any of the altematives. However, the amount of time required to develop and test the method would be much greater than any of the other alternatives.

- Center Pivot Dredge. Dredging involves utilizing a 1.5-meter (5-foot) opening to allow mechanical dredging equipment to access the tank. This option involves the highest cost and complexity, and yet provides the lowest probability of success because of the technical difficulty of dredging around obstructions (i.e., failed equipment and instrumentation), which extend from the risers. In addition, the amount of time needed to test and develop appears to be prohibitive. The exposure to workers is anticipated to be higher due to the 1.5-meter (5-foot) opening. Concerns on exceeding tank dome weight limits also exist with this option. The potential for worker exposure is greater, and the amount of equipment to be decontaminated and decommissioned is larger.

- No-Action. This altemative would involve leaving the high-heat waste in Tank C-106 and continuing to add cooling water.

Of the sluicing alternatives presented above, only the proposed action and the Batch Transfer Alternative meet the two requirements considered essential to addressing the concerns mentioned in Section 1.0. These requirements consist of reducing the heat load in Tank C-106 to less than $11.72 \mathrm{~kW}(40,000 \mathrm{Btu}$ per hour), and choosing a sluicing method that would be capable of starting retrieval by October of 1996 . The other alternatives were not capable of meeting one or both of these requirements and, therefore, were not examined further. The Batch Transfer Alternative, while it meets the two requirements, would entail more design, procurement and construction costs, and would be less likely to meet the start date. 
The No-Action Alternative would result in maintaining Tank C-106 in its present condition. No waste transfer operations would be performed, and the high-heat producing waste would continue to generate excessive thermal loads. In order to maintain the temperature of the tank to levels below the point where the tank structural integrity would not be affected by excessive heat, cooling water would continue to be added. Alternative means of cooling the waste, such as using a sprinkler system, an air chiller (which would introduce cooled air into the tank), or a combination of the two, are currently being examined. These cooling methods are designed to be used as a contingency plan should the tank start to leak. Because Tank C-106 has reached the end of its design life, the possibility of a tank leak is fairly high and will increase over time. The continued addition of cooling water, which would likely proceed under the No-Action Alternative, would increase the total amount of possible contamination which could leak into the soil column. No matter which cooling method is used (either the addition of cooling water or the development and use of an air chiller), the problem of high-heat producing waste would persist, and the Tri-Party Agreement milestone (M-45-03-T01) for the demonstration of a waste retrieval technology would not be met.

Alternatives to the use of Tank AY-102 as the receiver tank were examined at the inception of this project. All DSTs in the 200 East Area were examined as potential receiver tanks. The SSTs were excluded due to fact that most, if not all, of the SSTs are beyond their design life and do not meet double containment requirements. Of the DSTs examined, only the Aging Waste Facility (including two tanks in the AY Tank Farm and two tanks in the AZ Tank Farm) contained a ventilation system capable of handling the additional heat load of Tank C-106's waste. Only the two tanks within the AY Tank Farm were found to have sufficient storage space. Later analyses examined the waste forms from both of the AY tanks for compatibility, and found the best waste compatibility aspects in terms of storage to be with the Tank AY-102. As was mentioned earlier, it has been determined that the supernatant from Tank AY-101 would be used as the initial sluicing agent.

No other reasonable alternatives to past-practice sluicing have been identified. 


\section{This page intentionally left blank.}




\subsection{Affected Environment}

\subsection{Hanford Site}

Tanks C-106 and AY-102, are located in the 200 East Area of the approximately 1,450 square kilometer ( 560 square mile) semi-arid Hanford Site in Southeastern Washington State (Figure 1). The 200 East Area is approximately 10 kilometers (6 miles) west of the Columbia River, the nearest natural watercourse. The nearest population center is the City of Richland, approximately 32 kilometers $(20$ miles) to the south. The City of Richland has a population of 32,315 , while the population within an 80 -kilometer $(50$-mile) radius of the 200 Areas is approximately 380,000 . Roughly 2,800 employees are working in the 200 East Area, and an estimated 20 workers would be directly involved with the sluicing operations. The 200 East Area is not located within or adjacent to a wetland, or in a 100-or 500-year floodplain.

The geology of the site where the proposed action would take place is typical of the 200 Areas. The surface is covered with loess and sand dunes of varying thickness, although the tank farms and the majority of the area between them is composed of a disturbed gravel layer. Under the surface layer, in ascending order, are basement rocks of undetermined origin, the Columbia River Basalt Group with intercalated sediments of the Ellensburg Formation, the Ringold Formation, the Plio-Pleistocene unit, and the Hanford Formation. The depth to groundwater in the 200 East Area is 75 meters (246 feet). Groundwater flow is generally in an easterly and southeasterly direction, toward the Columbia River (PNL 1994a).

The Hanford Site has a mild climate with 15 to 18 centimeters ( 6 to 7 inches) of annual precipitation, and infrequent periods of high winds of up to 128-kilometers (80-miles) per hour. Tornadoes are extremely rare; no destructive tornadoes have occurred in the region surrounding the Hanford Site. The probability of a tornado hitting any given waste management unit on the Hanford Site is estimated at 1 chance in 100,000 during any given year.

The region containing the Hanford Site is categorized as one of low to moderate seismicity. The annual probability (frequency) of a DBE has been determined to be $7.0 \times 10^{-4}$. The DBE determines the structural standards which a facility must meet.

Additional information regarding the Hanford Site can be found in characterization documents (PNL 1994a and PNL 1994b).

\subsection{Cultural and Biological Resources}

The Hanford Site is known to be rich in cultural resources, and contains many well-preserved archaeological sites dating back to both prehistoric and historical periods. 
Over 10,000 years of human activity have left extensive archaeological deposits along the Columbia River shoreline and at well-watered inland sites. By virtue of their inclusion in the controlled Hanford Site, archaeological deposits bave been spared some of the severe disturbances that have befallen unprotected sites in the area.

The proposed activities, past-practice sluicing and waste transfer operations, would not occur in a known environmentally sensitive area. The tank farms affected by the sluicing and waste transfer actions have been reviewed, and have not been found to contain any cultural resources. Appendix A contains the Cultural Resources Review (CRR) for the impacted area and states that, "due to the highly disturbed nature of the area, no cultural resources are expected." If the work being proposed uncovered any items of significance (e.g., bones and artifacts), work would be halted until proper mitigation measures are taken. Additional information regarding the Hanford Site's cultural and biological resources can be found in characterization documents (PNL 1994a).

No plants or animals on the federal list of "Endangered and Threatened Wildlife and Plants" (50 Code of Federal Regulations 17) are found in the immediate vicinity of the proposed action. Consequently, there is no need for formal consultation with the U.S. Fish and Wildlife Service. In addition, none of the several species of plants and animals, which are under consideration for formal listing by either the Federal Government or the State of Washington, would be adversely impacted by the proposed waste retrieval activities. In fact, there are relatively few species of either plants or animals found in the proximity of the proposed action due to the highly disturbed nature of the area. Appendix B contains the Ecological Survey for the impacted area, and states that no state or federal threatened, endangered, or candidate species would be adversely impacted. 


\subsection{Environmental Impacts}

This section presents information on those potential environmental impacts that have been identified as a result of the proposed activities for past-practice sluicing of waste from Tank C-106 to Tank AY-102. Also, environmental impacts are presented for reasonably foreseeable accident scenarios, impacts from the reasonable altematives to the proposed action, and cumulative impacts.

\subsection{Analysis of Past-Practice Sluicing of Tank 241-C-106}

It is expected that proper controls on the tank ventilation systems would operate in accordance with Clean Air ACt of 1970 (CAA) requirements for gaseous and particulate discharges to the atmosphere. The tank ventilation system would maintain a negative pressure inside of Tank C-106. This would keep the gaseous and particulate contents inside the tank in the event of planned or unforeseen openings of the tank risers. The HEPA filtration units would be employed at the Tank C-106 exhaust stack, which would satisfy ALARA principles, and meet state and federal regulatory requirements. These requirements would limit emissions from both tanks, Tanks C-106 and AY-102. Emissions from Tank C-106 as a result of sluicing operations, which are expected to be slightly higher than current levels, would represent only a small fraction of total Hanford Site tank farm emissions. In 1992, the average dose to the offsite maximally exposed individual (MEI), based on measured emissions, from the combined filtration stack which services Tanks C-106 and 241-C-105, was $6.23 \times 10^{-7}$ millirems (DOE-RL 1993). The average dose to the offsite MEI from the operation of the AY and AZ Tank Farms for 1992 was $4.4 \times 10^{-5}$ millirems (DOE-RL 1993). Since the four tanks which comprise the AY and AZ Tank Farms all release through a common ventilation stack, individual release data from Tank AY-102 is not available. This number is not expected to increase either during or after the waste transfer operation. The proposed action would not result in a greater impact from emissions to either on- or offsite populations than the status quo.

Most of the liquid necessary for the sluicing operations would be obtained from, and returned to, Tank AY-102. The overall amount of liquid in Tank C-106 would not increase substantially during sluicing operations because the amount of material being sluiced is approximately equal to the amount of supernatant added. During the initial stage of retrieval operations, the total amount of waste in Tank C-106 would be increased by roughly 19,000 liters (5,000 gallons) of supematant from Tank AY-102. Additional liquid, which would consist primarily of clean water, might be required for sluicing-line cleanout, but would not be a significant increase in total volume used, and would be within the receiving tank's storage capacity.

Sanitary services for the support trailer would consist of either a buried catch tank designed to collect sanitary waste, which would need to be emptied weekly for the duration of the project, or portable facilities. The waste from the catch tank would be pumped to a trailer truck and sent to a properly sited facility for treatment in accordance with approved 
Hanford Site procedures. A permit for this catch tank would be required from the State of Washington Department of Health $(\mathrm{DOH})$ if this option is chosen.

The sluicing and slurry transfer lines would comply with Resource Conservation and Recovery Act of 1976 (RCRA) requirements, and include full pipe-in-pipe containment with leak detection capability. The sluicing line valve box would be designed to have a drain system capable of handling a worst-case spill scenario. This drain system also would serve to prevent releases to the environment. Initially, sluicers would direct the diluted supernatant toward the center of the tank. As the retrieval operation proceeds, the sluicers would be directed outward. This would minimize the time that the tank liner is directly exposed to the sluice stream, and minimize the potential for a sluicing-induced tank leak.

During normal sluicing operations, no releases of tank contents would be expected. During jumper change operations (which is defined as the replacement of the hoses which connect the transfer lines to the various pumps, and sluicers), small residual amounts of radioactive material would be available for release. Leaks within the pump and sluice pits would be detected by special instrumentation which might include conductivity probes. Pit drains would return leaked wastes to either Tank C-106 or Tank AY-102 for compatible waste storage. Leaks resulting in measurable accumulation of solution on the floor of the pits would be detected, and the waste returned to the tank. For smaller leaks, detection would be accomplished by visual inspections or engineered features. The pits would maintain slightly negative pressures, maintained by the tank ventilation system, to prevent release of any airtorne radioactivity from the pit to the atmosphere during retrieval activities. Administrative controls, such as lock and tag procedures, would require that all pit covers be in place before any transfer. The transfer pumps would be locked and tagged-out while the pit covers are off. The removal of the pump lock and tag requires that the pit covers be in place. Only after the lock and tagout requirements are met, would the pumps be allowed to operate. Spray and washdown systems would be incorporated into the design to reduce any contamination in the pits before they are opened for any maintenance activities.

Leaks in the primary piping system of the transfer lines would be controlled by the secondary containment system (the outer encasement pipe). This secondary containment system would be designed to collect released waste at a common point for detection and removal. Leaks from the DST would be controlled by the secondary containment shell, which is designed to collect and transmit released waste to a common point for detection and transfer. Inspection for potential leaks and waste transfer would be possible through a number of risers located on the DST.

There would be some radiological exposure to workers involved in the proposed activities. However, the anticipated exposure would be no greater than other routine tank farm activities. Average occupational external exposure to workers in the Hanford Site tank farms (as measured by individual dosimetry records) is approximately 14 millirem per year per worker (WHC 1994b), which is substantially less than the maximum allowable exposure of 5,000 millirem per year as set by DOE guidelines. For comparison purposes, the national average dose to the public from natural sources is 300 millirem per year (PNL 1994b). 
Some additional exposure might occur to workers involved in decontamination of excess equipment at the conclusion of sluicing operations. Decontamination is considered a routine action at the Hanford Site. Engineering controls would be in place prior to decontamination activities to prevent any excess radiological exposure. Further, the workers are trained and would be attired in appropriate protective gear. Therefore, workers would not be expected to receive more than the allowable 5,000 millirem per year set by DOE guidelines. Also, decontamination activities could lead to exposure of hazardous chemicals used in the decontamination process. Proper training, equipment, and procedures would prevent adverse human health effects from the bandling of these hazardous chemicals.

Workers involved with the sluicing operation would use proper respiratory equipment as required, (which may include masks and bottled 'fresh' air) while in the 241-C Tank Farm for the duration of the project, to avoid the possibility of inhalation of toxic vapors, which may emanate from other tanks (notably Tank 241-C-103). Tank C-106 is not expected to produce toxic vapors in detectable quantities and no threat to worker safety is predicted. Toxic air pollutants from routine operations would be within acceptable source impact levels at the Hanford Site boundary, and would pose no threat to the public.

Based on a dose-to-risk conversion factor of $4.0 \times 10^{-4}$ (onsite) latent cancer fatality (LCF) per person-rem (56 Federal Register [FR] 23363), the average tank farm worker with the previously mentioned dose rate of 14 millirem per year would have an estimated annual probability of an LCF induced by the radiation of $5.6 \times 10^{6}$. The estimated probability of the worker dying from cancer induced by such radiation doses over the worker's projected exposure period (2 years) is approximately $1.1 \times 10^{3}$ (or 1 chance in 100,000). Further, assuming that annually 20 tank farm workers are directly involved with operations associated with the proposed actions, and those workers are exposed to the average annual dose rate for tank farm operations (i.e., 14 millirem), a total of $2.2 \times 10^{4}$ LCFs over the two year projected exposure period would be expected.

No public exposure above that currently experienced from Hanford Site operations would be anticipated as a result of these actions. As reported in the Hanford Site Environmental Report 1993 (PNL 1994b), the potential dose to the hypothetical offsite MEI during Calendar Year (CY) 1993 from Hanford Site operations was $3.0 \times 10^{-2}$ millirem. The potential dose to the 380,000 persons which constitute the affected population (defined as the number of people living within 80 kilometers [50 miles] of the source) from 1993 operations; was 0.4 person-rem. The 1993 average dose to the population was $1.0 \times 10^{-3}$ millirem per person. The current DOE radiation limit for an individual member of the public is 100 millirem per year.

The proposed action would result in the generation of solid waste during the life of the project. Such waste would be surveyed and disposed of in the Hanford Site Solid Waste Landfill if uncontaminated, or another applicable, permitted location if found to be contaminated with hazardous or radioactive constituents. Transportation of hazardous and/or radioactive waste is considered a routine activity at the Hanford Site. Proper administrative controls and operating procedures would minimize the impact of transporting this waste. At the completion of activities, noncontaminated equipment would be excessed where applicable, 
while contaminated materials and components would be packaged and stored in an onsite permitted facility as is the current practice.

Trenching would be required for the installation of the transfer lines, power and instrumentation control cable lines, and for the tie-down operations required to install a double-wide trailer (two single, modular trailers combined into one facility). This facility would be located between the 241-C and the 241-AY Tank Farms. An Excavation Permit would be required for the trenching required for the power and instrumentation control cable lines, the buried waste transfer lines, and the tie-down operations needed for the double-wide trailer. Appendix A of this document is the CRR for this project, which states that no cultural resources are expected to be disturbed.

The area where the work is to be performed (i.e., the 241-C and 241-AY Tank Farms) is a developed, highly disturbed area, and is currently under vegetation management. The pipelines would be partially buried and covered with an earthen berm for shielding. Neither the pipelines nor the support facility would have a negative impact on plant or animal species of concern. The work would not disturb any sensitive or critical habitat. There are no animal species of special concem that are known to use the area exclusively. The 200 East Area is not located in a floodplain, and the tank farms are not located on land that could be considered wetlands. Appendix B consists of the Ecological Survey, which states that no adverse impacts are expected to any plant or animal species of concern because the proposed action takes place in such a highly disturbed location.

The proposed action likely would result in a minor release of particulates from construction activities needed to prepare the tanks for sluicing. These particulates, which consist chiefly of dust, would be mitigated by proper dust controls whenever necessary. Thermal discharges to the environment would be generated by equipment and vehicle exhaust, but can be considered minor when compared to sitewide thermal releases. Noise levels would rise in the vicinity of the 241-C and 241-AY Tank Farms during the sluicing operations, but would retum to present levels when the project is finished. The equipment to be used (e.g., steel and other metals for piping and enclosures that are necessary for sluicing operations) represents a long-term commitment of nonrenewable resources. A Hanford Site Radiation Work Permit would be required for work within the tank farms.

Protective clothing requirements would be prescribed in the Hanford Site Radiation Work Permit and would be selected based upon the contamination level in the work area, the anticipated work activity, worker health considerations, and regard for any nonradiological hazards that may be present. The Tank Farm Health and Safety Plan (WHC 1994c) lists controls and procedures which are in place to protect tank farm workers. This document specifies clothing requirements (including respiratory equipment), monitoring procedures, tank farm access restrictions, and standard operating controls. In addition, workers would have completed all proper procedural and safety training prior to commencement of sluicing activities. This would result in having trained personnel present during all phases of the project, especially during the duration that the pumps are operating.

Construction activities would not generate any substantial risk to the existing operating facilities in the 200 East Area located near the waste transfer site. Routine construction 
hazards would exist both before and during the retrieval operations. Field and construction operations would be conducted to ensure a safe working environment in accordance with both federal and state standards. The project would be designed to minimize the amount of hazardous and nonhazardous waste generated.

There would be no substantial effect to the work force at the Hanford Site, from either construction activities or during the actual sluicing operations. The 50 construction workers needed for work on the tank farms prior to sluicing would be taken from the existing local work force. As there would be no need for additional employees to be hired, there would be little effect on the local economy.

Neither the use of Tank AY-102 as the receiver tank nor the two preliminary supernatant transfers (from Tank AY-102 to the evaporator or another DST and from Tank AY-101 to Tank AY-102, if that is the sluicing agent chosen) would cause an adverse impact to the overall waste management strategy at the Hanford Site. The supernatant from Tank AY-102 would be sent to an evaporator for volumetric reduction before its subsequent storage in another DST. Such transfers at the Hanford Site occur routinely and are part of normal waste tank storage activities as described in the HDW-EIS (DOE 1987). For each of these routine transfers, a specific procedure, work plan, and/or work procedure would be written in accordance with approved DOE contractor procedures. Finally, these transfers would be evaluated to ensure that the DST storage criteria fall within an acceptable range for waste storage (i.e., temperature, chemical compatibility, organic material, and liquid level). No additional impact to human health or the environment would occur as a result of these transfers. Capabilities of DSTs other than Tank AY-102, either in existence or proposed, would exist to handle planned waste transfers in the future.

\subsection{Analysis of Accidents}

Table 1 displays the accident scenarios relevant to the proposed action. In addition, this section analyzes the issue of waste compatibility. For each accident scenario in the table, the probability of the accident occurring and the accident's potential impacts are provided. The consequences are conservatively presented assuming that Tank AY-101's supernatant is used as the sluicing agent. If another sluicing fluid is chosen that has a lower source term than Tank AY-101's supernatant, these doses likely would be lower. The probability for many of the accident scenarios is dependent on the probability of a DBE occurring at the Hanford Site. In fact, the worst case scenario for this sluicing operation would consist of a combination of the three accident scenarios discussed individually in this section. These scenarios consist of a DBE leading to an unfiltered release through a breach in the recirculation duct (which is not the only mechanism for this accident), a break in the waste transfer lines, and the rupture of Tank C-106. The presence of a DBE does not necessarily mean that all, or even some, of these accidents would happen, only that the mechanism exists which might lead to their occurrence. These accident scenarios were addressed in the Preliminary Safety Evaluation for 241-C-106 Waste Retrieval (WHC 1994a), an engineering study on leaks from Tank C-106 as a result of hydraulic retrieval (WHC 1993d), and a waste compatibility study (1994d). The range of reasonably foreseeable accident scenarios 
associated with the proposed action, which could result in a release of radioactive materials to the environment, are discussed in detail following the table.

Table 1.

Reasonably Foreseeable Accident Scenarios.

\begin{tabular}{|c|c|c|c|}
\hline Accident Scenario & Accident Consequences & Annual Probability & $\begin{array}{c}\text { Reference } \\
\text { Documentation }\end{array}$ \\
\hline $\begin{array}{l}\text { (1) Wasto leak from jumper } \\
\text { or connector }\end{array}$ & $\begin{array}{l}\text { Offrite MEI dove of } 1.6 \times 10^{-4} \mathrm{rem} \text { EDE. } \\
\text { Onsite dow of } 1.5 \times 10^{-1} \mathrm{rem} \text { EDE. }\end{array}$ & $2.6 \times 10^{-2}$ & WHC 1994. \\
\hline (2) Waste trander line leak & $\begin{array}{l}\text { Offrite MEI dove of } 1.0 \times 10^{-4} \mathrm{rem} \text { EDE. } \\
\text { Onsite done of } 1.9 \times 10^{-1} \mathrm{rem} \text { EDE. }\end{array}$ & $7.0 \times 10^{-4}$ & WHC 1994a \\
\hline (3) Tank ruprure due to DBE & $\begin{array}{l}\text { Potentindly large rcale envirosmentsl } \\
\text { conturaination of woil end groundwater. }\end{array}$ & $7.0 \times 10^{-4}$ & N/A (10e text) \\
\hline $\begin{array}{l}\text { (4) Tank C-106 leak from } \\
\text { sluicing }\end{array}$ & $\begin{array}{l}\text { Release of nubreatial amounts of liquid werre } \\
\text { to the environment (coil and possibly } \\
\text { groundwater). }\end{array}$ & Usdetermined (soe text) & WHC 1993d \\
\hline (5) Recireuletion line breech & $\begin{array}{l}\text { Offrite MEI dose of } 5.2 \times 10^{-1} \mathrm{rem} \text { EDE. } \\
\text { Onsite dose of } 5.0 \times 10^{-1} \mathrm{rem} \text { EDE. }\end{array}$ & Undetermined** & WHC 1994a \\
\hline
\end{tabular}

- The probsbility ahown for these scenarios in the occurrence of a DBE, however, the presence of a DBE does not necesenrily menn the accident would occur. The worat case kenario involves a DBE triggering these two nccidenth as well as rupturing the HVAC rexirculation duct. While it is not accurate to add the human health effects from each ecentrio, the coneeguences would be fairly similar to those discussed for the breach of the recircuintion duct.

** In the abrenco of afety fentures, the most common mechanism for this accident is bumen ertor (e.g., vehicular collision). It is also possible that $a \mathrm{DBE}$ might reault in a breach.

Accidents occurring during sluicing operations involving environmental releases of the tank waste to the atmosphere or soil column would result in the greatest impacts. An atmospheric accident would involve either a spray leak in a valve pit, an unfiltered release through a breach in the recirculation duct of the heating, ventilation, and air conditioning (HVAC) system leading to a radioactive release, or a transfer line break. A soil column accident would involve a breach of containment in the tank, leading to a spill of the liquid component of Tank C-106, which is not held up in either the sludge or hardened waste.

Many of the accident scenarios assume that releases occur for a prolonged duration. During the sluicing phase of the project, when the pumps are running and the waste is being retrieved, trained personnel would be present. The presence of these workers would minimize the duration of a release and restrict access to the release site. Additional precautions would be taken to protect on and offsite personnel in the event of an accident (such as stopping the pumps immediately, stabilizing and containing the release and evacuating onsite personnel as needed). Table 2 presents the accident scenarios, consequences, assumptions used, and administrative and design features in place which could lower the consequences of these accidents further. 


\begin{tabular}{|c|c|c|c|}
\hline \multicolumn{4}{|c|}{ Accident Assumptions and Consequence Reduction Features. } \\
\hline $\begin{array}{l}\text { (1) Wante bal from junger } \\
\text { of oocnetor }\end{array}$ & $\begin{array}{l}1.6 \times 10^{4} \mathrm{mem} \\
\text { EDE ofthile } \\
1.5 \times 10^{1} \mathrm{ncm} \\
\text { EDE atoile }\end{array}$ & 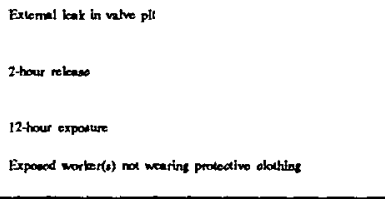 & 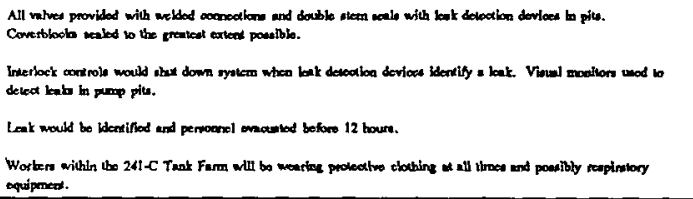 \\
\hline (I) Wono innoter line bet & $\begin{array}{l}1.0 \times 10^{-1} \\
\text { EDE oflsite } \\
1.9 \times 10^{1} \\
\text { EDE onstito }\end{array}$ & 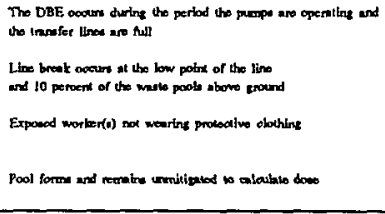 & 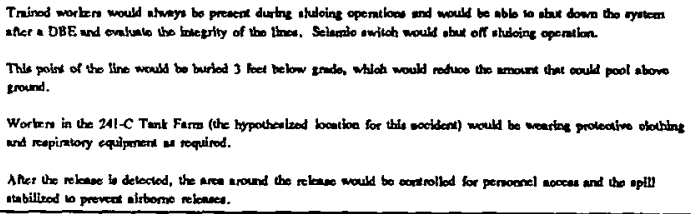 \\
\hline $\begin{array}{l}\text { (3) Tunt nupture dise lo: } \\
\text { DBE }\end{array}$ & 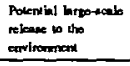 & 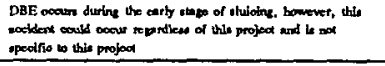 & 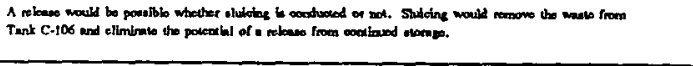 \\
\hline 19 Tent ket from elludedne & $\begin{array}{l}\text { 150,000 liven } \\
(+0,000 \text { pllions) } \\
\text { rkeased }\end{array}$ & 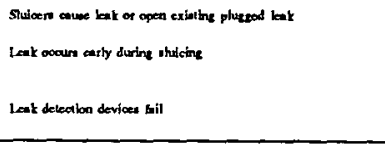 & 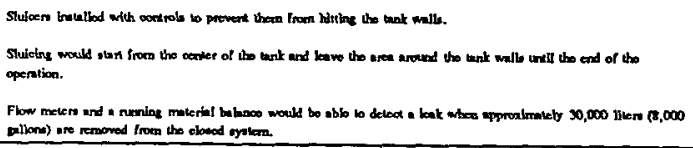 \\
\hline (9) Recisulation line brech & $\begin{array}{l}5.2 \times 10^{-4} \mathrm{rem} \\
\text { EDE offalto } \\
5.0 \times 10^{1} \mathrm{rmm} \\
\text { EDE ordile }\end{array}$ & 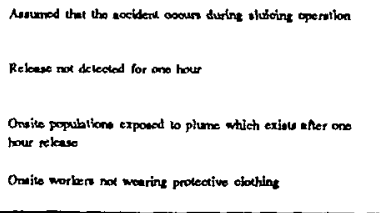 & 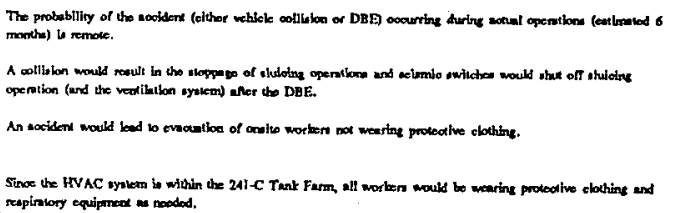 \\
\hline
\end{tabular}


For the accident scenarios, the offsite population is defined as the 115,000 people located within 80 kilometers ( 50 miles) of the release point in a southwesterly direction. The uninvolved workers (numbered at 1,630 ) are defined as personnel in the area greater than 100 meters ( 328 feet) to the south of the release point. Onsite bealth effects in terms of LCFs are presented for the uninvolved worker only. The risk to the directly involved worker (those workers directly involved with the proposed action, which may or may not be within the 100 meters [328 feet]) is highly dependant upon the worker's specific location, meteorological conditions, and nature of the accident. All of these circumstances could either increase or mitigate the severity of the consequences. Therefore, no quantification of risk to the directly involved worker is available; however, it is assumed that the directly involved worker could receive a substantially higher dose given the proper conditions.

Accident consequences are evaluated in terms of human health effects from radiological exposure. Nonradiological hazards, during normal sluicing operations, would be controlled by strict adherence to the contractor guidelines dealing with industrial safety (WHC-CM-4-3). Potential nonradiological hazards encountered during postulated accidental releases would be controlled by adherence to emergency procedures to be written prior to the initiation of the sluicing operation. These emergency procedures would be based upon analyses to be performed as part of future safety documentation. The Preliminary Safety Evaluation (WHC 1994a) examined the chemical constituents in Tank C-106, and indicate that toxic chemicals would not be available for release from the various accident scenarios in large quantities.

Waste Leak From Jumper or Connector. The first scenario considered was a waste leak from a jumper or a connector in a pump pit. Equipment in a pump pit would include valves that were provided with welded connections and double stem seals. Although the system would have been leak tested before operation, it is postulated for this scenario that an external leak could develop in the valve pit. Leakage, in the form of a spray in a valve pit, may result in an atomizing (spray) leak and release of waste material from improperly sealed openings in the pit covers which allow monitoring equipment to access the pump pit. From such a leak at 12.7 kilograms per-square-centimeter (180 pounds per-square-inch) and for a duration of two hours, an aerosol capacity of 10 milligrams per cubic meter $\left(1.0 \times 10^{-3}\right.$ pounds per cubic feet) of transportable, respirable liquid aerosol equivalent to $3.0 \times 10^{2}$ liters (2.1 $\times 10^{2}$ gallons) would be generated (WHC 1994a).

The mitigating feature of administrative controls (i.e., lock and tag procedures), which would ensure that the pit covers are always in place during waste transfer operations would reduce the consequences of a spray leak to the atmosphere to much lower levels than might occur in the absence of pit covers in the pump pits (WHC 1994a). With pit covers in place, the dose to the offsite MEI is calculated to be $1.6 \times 10^{-4} \mathrm{rem}$ Effective Dose Equivalent (EDE), which is within the "low" category of radiological dose consequences (WHC-CM-4-46). Uninvolved workers could be exposed to $1.5 \times 10^{-1} \mathrm{rem} \mathrm{EDE}$, also in the "low" category. Additional administrative controls which would include sealing the pit cover openings and edges could lower these numbers substantially. While there is no accurate method for calculating the dose received to the directly involved worker, it is conceivable that the dose could be somewhat greater. All doses in this section are considered to be a 
50-year committed dose. With pit covers in place the chance of either the offsite or onsite MEI developing an LCF, which is calculated by multiplying the dose with the conversion factors of $4.0 \times 10^{4}$ (onsite) and $5.0 \times 10^{-4}$ (offsite) (56 FR 23363), could be considered nonexistent $\left(8.0 \times 10^{-8}\right.$ and $6.0 \times 10^{-5}$ respectively). Even assuming that the directly involved worker receives a dose several orders of magnitude greater than that of the uninvolved worker (which can be considered extremely conservative), it is not likely that any adverse health effects would occur.

Waste Transfer Line Leak. This scenario assumes that both transfer lines (and both pipes comprising double containment) fail and the waste leaks at a rate of 1,324 liters ( 350 gallons) per minute from each line. It is further assumed that seismic switches located on the transfer lines would be activated and would shut down the pumps immediately. A duration of 10 seconds is used to estimate the time required for the pumps to stop completely and cease adding fluid to the transfer lines. Based upon this 10 second duration, an estimated 10,500 liters (2,800 gallons) could be released to the soil column. Due to the fact that the release is below grade and covered by an earthen berm, only a small amount of this total spill volume would pool above ground and affect human health. The majority of the waste would migrate downward and laterally from point of origin. Only a small percentage of the waste that pools on the surface would be in a condition to be considered as a possible source term which might impact human health. The mechanism for this accident has been determined to be a DBE, which has an annual probability of occurring (frequency) of $7.0 \times 10^{-4}$.

For the accident scenario dealing with a leak in the transfer line, the dose to the offsite MEI has been calculated to be $1.0 \times 10^{-4} \mathrm{Tem}$ EDE, which is within the "low" criteria range for offsite populations. The onsite MEI has been calculated to receive a dose of $1.9 \times 10^{-1}$ rem EDE, which also is within the "low" criteria range for uninvolved workers (WHC-CM-4-46). Based on the above numbers, the accident scenario dealing with a waste transfer line leak would result in a probability of $5.0 \times 10^{-8}$ that the offsite MEI would develop an LCF and a probability of $7.6 \times 10^{4}$ for the onsite uninvolved worker. The total number of LCFs for the affected offsite population, determined to be the 115,000 persons residing within 80 kilometers (50 miles) southeast of the release site, has been determined to be $5.3 \times 10^{-5}$. This number was calculated by multiplying the offsite probability by a conversion factor of 2,500 (which can be calculated by dividing the collective dose to the affected offsite population by the dose to the offsite MEN) (Leach 1993). The uninvolved worker population $(1,630)$ was calculated to have approximately 0.2 LCFs. This number was calculated by multiplying the volume of waste available on the surface as the source term, 1.0 liters ( 0.27 gallons), by the conversion factor of 0.16 LCFs per liter $(0.6$ LCFs per gallon). Given the proper conditions (i.e., the directly involved worker is in the immediate vicinity of the spill and the wind carries contamination toward that worker), the possibility exists for the directly involved worker to experience an adverse health effect, which might include genetic effects or even the occurrence of a fatal cancer. 
Based upon the 10-second spill duration, and the soil characteristics of the area, it can be assumed that less than 28.3 cubic meters (1,000 cubic feet) of soil around the ruptured pipe would be contaminated and would need to be cleaned up. Radiation cleanup workers would wear proper clothing and respiratory protection when performing the remediation for this accident scenario. It is further assumed that five radiation cleanup workers would be employed for a period of one week. The absence of these seismic switches in the transfer lines could increase the amount of waste released into the environment by several orders of magnitude. The higher cost of eventual cleanup of a two hour spill duration, and the increased exposure likely to the cleanup workers, further justifies the presence of these switches.

For CY 1992, the average dose to radiation cleanup workers was 8 millirem per year (WHC 1993e). This number yields a collective dose to the five workers involved in the cleanup of the 10-second release scenario for a period of 1 week of $7.7 \times 10^{-4}$ person-rem. The number of LCFs expected from this dose is $3.0 \times 10^{-7}$. In other words, an individual worker has less than one chance in one million of contracting an LCF as a result of cleanup activities.

The contaminated soil would be transported to existing onsite disposal or storage facilities. After the contaminated spill area is cleaned up, the spill area would be properly posted. Overall site remediation at and around the spill area would be included as a part of a Hanford Site operable unit cleanup.

Tank Rupture Due to a DBE. Another soil column accident would be the result of a seismic event which ruptures the tank. This accident scenario would be possible at any time and regardless of this specific waste transfer operation. Subsequently, a detailed discussion of this accident is not presented. The annual probability (frequency) of a DBE at the Hanford Site is $7.0 \times 10^{-4}$ per year. While human health effects would probably not be a factor, the accident could involve the contamination of a large volume of soil depending upon when the accident occurs during the sluicing operation, which would require a significant cleanup operation. The total amount of waste in all forms in Tank C-106 is not expected to be greater than 750,000 liters $(200,000$ gallons) at any time, however, only that portion of the waste in a liquid form would contribute to the amount of waste released.

An accident of this magnitude could result in long-term health effects to the public if the contamination reached the groundwater and the groundwater was accessible to the public. However, the chance of contamination reaching the groundwater is remote since the most conservative release from Tank C-106 is estimated to be less than 662,000 liters (175,000 gallons), and the majority of radionuclides would be trapped in the top portion of the soil column. Cleanup of a leak of more than 375,000 liters $(100,000$ gallons) would likely be performed with the eventual cleanup of the tank farms and would be completed well before the waste reaches the groundwater. As bas been mentioned, this scenario is possible for normal waste storage activities and is not exclusive to this action. In fact, this waste retrieval operation would reduce the risk of a DBE induced leak from Tank C-106 by removing the waste and storing it in a DST. 
Tank Leak From Sluicing. Sluicing operations have the possibility of releasing liquid waste from the tank to the soil column. The probability of this happening is undetermined because of the lack of information concerning the condition of Tank C-106's bottom and sides. The most probable occurrence would involve the sluicers opening a plugged leak in the tank wall. The leak source term during sluicing would be any free-standing liquid present in the tank during the sluicing operation, the drainable interstitial liquid above the level of the leak point, and the sluicing stream as it impacts the tank wall. Based on historical leak rates of other SSTs, the actual leaked volume is expected to be on the order of a few cubic meters (several thousand gallons). However, the most conservative estimate has a release of up to 150,000 liters (40,000 gallons) (WHC 1993d). This estimate assumes that the leak occurs early in the sluicing operation, that leak detection devices and controls fail, sluicing operations proceed without these leak detection devices, the leak(s) occur at the bottom of the tank, and the remaining sludge does not plug these leaks. The size of any leaks would be limited by: (1) the ability to detect leaks, (2) administrative controls on liquid inventories, (3) the tendency of solids in the sludge to plug any leaks, and (4) the free liquid in the Tank C-106, is limited, and could be pumped out in a short time. The presence of flow meters on the transfer lines and material balance controls on Tank AY-102 would detect a leak when approximately 30,000 liters $(8,000$ gallons) are removed from the sluicing process by means of a leak somewhere in the closed-loop system.

Any postulated waste leak, upon reaching the soil, would be driven downward by the moisture recharge, rainfall and runoff, from the tank dome. Travel time for the first of the radioactive constituents in the waste to reach the aquifer is calculated to be about 60 years (WHC 1993d) (though most of the constituents would be held up in the top portion of the soil column and would take significantly longer to reach the aquifer), provided the amount leaked was small compared to the rate of recharge, and no preventative measures were taken to halt the migration. It has been shown that surface barriers are effective in limiting the migration of any tank leaks. Any contaminated soil could be recovered or treated after sluicing, if required, as part of the overall site closure activities under the Tri-Party Agreement milestone M-45-06. No immediate human bealth effects are anticipated from this accident; however, if left unchecked, the release would have the potential to contaminate a relatively small section of groundwater.

Recirculation Line Breach. It has been postulated that a mechanical accident (e.g., a vehicular collision) or a DBE (with a probability [frequency] of $7.0 \times 10^{-4}$ per year) could result in a breach in the recirculation line of the ventilation system, leading to a release of radioactive air emissions. A DBE would pose a threat to normal tank waste storage activities; however, in this scenario, the DBE would damage the recirculation line installed by this project. Therefore, this DBE accident is specific to this project, and is evaluated in this section. For this scenario it is assumed that the recirculation duct has been breached and unfiltered ventilation flow passes through the stack, and that the failure is not detected for one hour (it should be emphasized that this duration is extremely conservative since engineered features would be designed to shut off HVAC system when a break occurs to any of its piping). Based on a vapor space capacity of 100 milligrams per cubic meter $\left(1.3 \times 10^{-2}\right.$ pounds per cubic feet), approximately 0.146 liters (0.04 gallons) are released, leading to an 
offsite dose calculation of $5.2 \times 10^{-4}$ rem EDE to the MEI, which is within the "low" category, and an onsite dose of $5.0 \times 10^{-1} \mathrm{rem}$ EDE, which is within the "high" category (WHC 1994a). These numbers represent a probability of $2.6 \times 10^{-7}$ that the offsite individual would develop an LCF, and $2.0 \times 10^{-1}$ for the onsite population. Using the conversion factor mentioned in the transfer line leak scenario, an anticipated $2.0 \times 10^{-4}$ LCFs would occur to the entire affected offsite population (identified as the 115,000 persons residing to the southeast) (Leach 1993). Based upon 0.146 liters (0.04 gallons) release volume, and the onsite population conversion factor of 0.16 LCFs per liter ( 0.6 LCFs per gallon), no LCFs to the uninvolved workers would be expected (the actual number being 0.02 LCFs for the uninvolved worker population of 1,630 ). It is not likely that any adverse health effects would occur to the directly involved workers.

This scenario is considered the worst case accident when examined separately. It is possible that a DBE could trigger not only a recirculation duct break, but also a rupture of the waste transfer lines and a breach of tank confinement in Tank C-106. If this were to occur, the bealth consequences to on- and offsite populations would be close to, but somewhat higher than, the health effects presented for this scenario. In addition, the potential for large scale soil contamination, and possibly groundwater contamination, would exist. As noted earlier, however, the impacts from a DBE-initiated leak are not specific to this proposed action, but could occur for normal waste storage operations.

\subsection{Waste Compatibility}

The transfer of waste from Tank C-106 to Tank AY-102 raises the issue of waste compatibility. The Chemical Compatibility of Tank Waste in 241-C-106, 24I-AY-101 and 241-AY-102 (WHC 1994d) evaluated waste compatibility (WHC 1994a), and stated that using Tank AY-102 would not result in potentially dangerous situations. This document verifies that no chemical compatibility safety issue currently understood or perceived to exist would be adversely impacted by the proposed waste transfer operation. Additionally, the waste in Tank AY-102, after sluicing, would not be in a condition that precludes future treatment options.

Specifically, the compatibility safety issues addressed in this waste compatibility evaluation are criticality, energetics, corrosivity, and flammable gas accumulation. It was determined that criticality was not an issue based on analytical data. A criticality is defined as a self-sustaining or divergent neutron chain-reaction that has the potential to release large amounts of energy. Plutonium concentrations were determined to be so minimal as to be impossible to support a criticality prior to, or as a result of, waste transfers. Transfer of the fissile material contents, namely plutonium, from Tank $\mathrm{C}-106$ to the receiving tank fully complies with, and does not exceed current criticality safety evaluation report limits. A waste characterization report (WHC 1988) provided analysis of a core sample

from Tank C-106. The plutonium concentration is given as $7.1 \times 10^{-2}$ grams per liter ( $9.0 \times 10^{-3}$ ounces per gallon), a value less than 8 percent of the Criticality Prevention Specification (CPS) limit. The transfer of this waste to Tank AY-102 would satisfy limits provided by the applicable CPS. Further analysis of this criticality issue, which supports the 
above conclusion, is addressed in the Criticality Safery of Single Shell Waste Storage Tanks (WHC 1994e).

The analytical data also indicated that there is minimal organic carbon contained in the wastes of Tanks C-106, AY-102, and AY-101. Furthermore, if the organic carbon is conservatively assumed to be entirely in the form of Sodium Acetate, then there is still greater than twice the needed water to suppress the limiting exothermic reaction that might be postulated. This provides assurance that no propagating exothermic reaction is sustainable before, during, or after combining these wastes as described in the proposed action. Further, the concentrations of hydroxide, nitrate and nitrite, as well as the average temperature (all parameters affecting corrosion of the tank walls) would continue to be well within acceptable limits.

Finally, the existing and resultant specific gravities of the wastes would not result in exceeding specifications for placing the tank(s) on the flammable gas "Watchlist." The specific gravity provides an indication of the capability for retention of flammable gases (e.g., hydrogen) within the waste. While the waste compatibility evaluation indicates that hydrogen buildup would not be a problem, further safety analysis will evaluate this issue. It is possible that the initial shicing fluid to be used may be supplemented with a caustic solution (sodium hydroxide) to ensure that flammable gas generation is not a problem. It is proposed to utilize the existing airlift recirculators in Tank AY-102 to agitate the waste after the sluicing operation is completed, if needed. This agitation would result in the constant release of potentially flammable gases, and the prevention of a surface layer in the waste that could trap these gases. If the possibility arises for hydrogen accumulation, hydrogen monitoring equipment may be installed. In addition, the introduction of the initial sluicing fluid to Tank C-106 would maintain a large margin of safety, and would not result in compromise of chemical compatibility between the sluicing fluid and the waste in Tank C-106 (WHC 1994a).

Certain accidents that were not analyzed in this Environmental Assessment have been analyzed by other tank farm facilities. These accidents include tank dome failure due to exceeded weight limits, tank bottom penetration by dropped equipment, and riser damage due to excavation and/or construction activities. These accidents were found to have a smaller risk, where risk equals the product of probability and consequence, than the analyzed accidents. In other words, either the probability of the event occurring was outside the realm of reasonableness or the consequences were not considered substantial enough to warrant discussion.

\subsection{Analysis of Alternatives}

\subsubsection{Analysis of Alternative Waste Retrieval Methods}

While all of the alternatives presented in Section 3.0 were designed to retrieve the waste in Tank C-106, they often involved additional environmental impacts. Several of these 
alternatives had greater impacts than the proposed action, while others posed less of a threat to the environment, but involved substantially more design or construction costs which likely would mean failure to meet the October 1996 targeted start time.

The Once Through--No Recycle, Limited Mixer Pump, and Internal Recirculation Altemative would utilize a tanker truck to provide the sluicing medium to mobilize the solids in Tank C-106. Since none of the slurry deposited in the receiver tank would be recycled, the space requirements for Tank C-106's waste would be greater than the proposed action or the Batch Transfer Alternative. This additional waste would add to the total amount of waste which would eventually have to be treated, and does not support the waste minimization policy practiced at the Hanford Site.

Two of the alternatives, the Recirculate Within a SST Via Mixer Pump, and the Center Pivot Dredge Alternatives, both pose greater environmental risks than the proposed action. The Recirculate Within a SST Via Mixer Pump Alternative would introduce potentially more heat than the proposed action from the increased mixing and agitation of Tank C-106's waste. This alternative also would increase the environmental risk, relative to the proposed action, due to possible damage to the tank from the mixing pump outlet spray impinging on the tank walls, and maintain a much higher liquid inventory in the tank. In addition, this alternative would involve installing a new riser to the tank, and would require a longer design and testing period. The Center Pivot Dredge Alternative raises issues on worker safety due to the need for the construction of a 1.5-meter (5-foot) opening necessary to allow the dredging equipment access to the waste. This would lead to the possibility of a higher exposure to workers both during the creation of this opening and during operation of the dredging equipment. There also are concerns on exceeding tank dome weight limits with this alternative. Other negative factors include a high cost to implement; greatest design complexity compared to alternatives; and the amount of equipment to be decontaminated and decommissioned is larger than the other alternative.

The Hydraulic Mining Alternative would have the potential for the greatest waste minimization of the alternatives, but would be much more complex than the proposed actions. As this is an unproven technology, unlike the proposed action which has been used extensively in the past at the Hanford Site, the time required to develop and test this method would probably lead to failure in meeting the accelerated or Tri-Party Agreement timeframe. While the waste minimization aspects make this alternative attractive, the time required to design and implement this alternative makes this method unacceptable.

The Batch Transfer Alternative would utilize a temporary receiver tank which would require additional ventilation systems, and more waste transfer line jumpers, which would increase the probability of a waste leak from a failed jumper. The temporary receiver tank would be an additional source term that would have the possibility for release in the event of an accident. Due to this alternative's increased complexity created by the additional engineering requirements of the accumulation tank, an agitation system, and the additional pumps required to pump waste from the accumulation tank to Tank AY-102 and supematant from the accumulation tank to Tank C-106, it is estimated to extend the project duration by 2 to 3 years and would mean the probable failure of the October 1996 start date. Further, this waste retrieval operation is estimated to entail a higher cost (as much as $\$ 10$ million) 
than the proposed action, and may require more detailed and extensive environmental permitting due to the construction of the new accumulation tank.

\subsubsection{Analysis of the No-Action Alternative}

Under this alternative, the high-heat waste would remain in Tank C-106 and continue to generate sufficient heat to require active cooling. The primary cooling method would be the continued addition of cooling water, however, alternative means might be available, such as an air chiller or a combination of an air chiller and a sprinkler system. Regardless of the method used to cool the waste, the threat of a structural failure of the tank would remain, and increase over time. The probability of the DBE, which could lead to a breach in tank confinement, would continue to exist. The waste would continue to be stored in a tank which is considered past its design life and more susceptible to release than if it were stored in the newer DST.

Using the same conservative assumptions which were presented in the accident scenario dealing with a tank leak created by sluicing operations (i.e., leak detection devices and controls fail, the leaks occur at the bottom of the tank, and the remaining sludge does not plug the leak sites), the possibility exists for a large leak to develop. If Tank C-106's waste is not retrieved and remains in the tank for an extended duration, the likelihood of the tank failing, and a leak occurring, becomes greater. The presence of leaks in other SSTs at the Hanford Site indicate that it is only a matter of time before these tanks lose their integrity.

Tank C-106 would continue to remain on the safety "Watchlist," and continue to pose a risk to the environment. In addition, the Tri-Party Agreement milestones for the retrieval of Tank C-106's waste, and demonstration of a waste retrieval technology, would not be met.

\subsection{Cumulative Impacts}

The potential impacts from the proposed action are not expected to contribute substantially to the cumulative impacts of tank farm operations. In fact, because the high-heat waste would be removed from Tank C-106, which is at the end of its design life, it is expected that there would be a decrease in the overall risk to the environment.

Radioactive materials and nonradioactive chemicals are handled routinely on a daily basis throughout the Hanford Site. Standard Operating Procedures, and administrative controls, would provide sufficient personnel protection such that exposure to radiological and chemical materials would be kept below DOE guidelines, and within the policy of ALARA. The sluicing and waste transfer operations would not have a substantial cumulative effect on day-to-day operations on the Hanford Site with respect to worker exposure. The incremental impact from handling radioactive or nonradioactive materials that would result from the proposed action would be very small, and when added to the impacts from existing day-to-day operations on the Hanford Site and surrounding community, the total impact would remain small. 
While sluicing operations would release some radionuclides, the proposed action is not expected to substantially increase the amount of radioactivity released from total Hanford Site operations. DOE limits the dose received to an individual worker to 5,000 millirem per year. In 1992, the offsite MEI was exposed to $3.7 \times 10^{-3}$ millinem EDE from total air emissions (DOE-RL 1993), well below allowable limits (10 millirem to the public from airbome sources) set by state and federal regulations (WAC 246-247). The potential dose to the hypothetical offsite MEI during CY 1993 from Hanford Site operations were $3.0 \times 10^{-2}$ millirem (PNL 1994b). The potential dose to the population within 80 kilometers (50 miles), established at 380,000 persons, from 1993 operations was 0.4 person-rem. The 1993 average dose to the population was $1.0 \times 10^{-3}$ millirem per person.

Waste generation resulting from the proposed activity is not expected to be a substantial quantity compared to annual Hanford Site waste generation. For example, small quantities of low-concentration hazardous waste (e.g., solvents, cleaning agents) could be generated as a result of performing the proposed activities. These materials would be managed and disposed of in accordance with applicable federal and state regulations. Liquid waste generated from decontamination of equipment and the transfer lines is expected to be less than 26,000 liters (7,000 gallons), which could be easily stored in Tank AY-102. This project could potentially result in the creation of approximately $2,000,000$ liters ( 500,000 gallons) of additional liquid waste if an uncontaminated fluid is used as the sluicing agent. While this would represent an increase in the amount of waste to be stored and treated at the Hanford Site, it is within current tank farm capabilities and in accordance with current waste management strategies (i.e., it could be sent to the evaporator for volumetric reduction). Radioactive waste, radioactively contaminated equipment, and mixed waste would be appropriately packaged, stored, and/or disposed of at existing treatment, storage, and/or disposal units on the Hanford Site. It is estimated that this project would produce an average of 62 cubic meters (2,200 cubic feet) of low-level and low-level mixed waste per year. This waste would be sent to either the Hanford Central Waste Storage Facility or the low-level burial grounds. This number represents only a minor amount of waste received at these facilities in the course of a year and would not substantially impact their operation or design life. The recorded total volume of waste received in the 200 Areas for storage in CY 1991 was approximately 6,028 cubic meters (213,000 cubic feet) (PNL 1992).

\subsection{Environmental Justice}

Executive Order 12898, Federal Actions to Address Environmental Justice in Minority Populations and Low-Income Populations, requires that Federal agencies identify and address, as appropriate, disproportionately high and adverse human health or environmental effects of their programs and activities on minority and low-income populations. DOE is in the process of developing official guidance on the implementation of the Executive Order. However, the analysis in this EA indicates that there would be minimal impacts to both the offsite population and potential workforce during the proposed action, under both routine and accident conditions. Therefore, it is not expected that there would be any disproportionate impacts to any minority or low-income portion of the community. 


\subsection{Permits and Regulatory Requirements}

It is the policy of DOE to cany out its operations in compliance with all applicable federal and state laws and regulations, Presidential Executive Orders, and DOE orders. Environmental regulatory authority over the Hanford Site is vested both in federal agencies, primarily the U.S. Environmental Protection Agency (EPA), and in State of Washington agencies, primarily Ecology.

The SSTs are being operated under interim status as treatment and storage units under WAC 173-303. A dangerous waste closure/postclosure plan would be submitted to Ecology for closure of the SSTs (Ecology et al. 1993). Specific requirements under RCRA include revisions to the Part A permits for both the SST and DST Systems, and revisions to the Part B permit for the DST System (WHC 1993f).

Notification and approval from the $\mathrm{DOH}$ would be required because of the potential increase in radionuclide air emissions. Additionally, a National Emissions Standards for Hazardous Air Pollutants Permit is required by the EPA ( 40 CFR 61), and an approval for Toxic Air Pollutants is required by Ecology. All of these approvals would be obtained before the start of construction for this activity. Phase I and Phase II CAA Permit Applications would have to be prepared and submitted to Ecology, the DOH, and the EPA. Phase I applications deal with non-HVAC systems, while Phase II applications deal specifically with HVAC systems.

The project would not be subject to the "National Primary and Secondary Ambient Air Quality Standards" (40 CFR 50), the federal new source review program, or emission limitations in an air quality control region. The project would conform to the State Implementation Plan for air quality.

A permit would be required from the DOH for the installation of the sanitary catch tank to be buried at the control trailer if this option is chosen. 
This page intentionally left blank. 


\subsection{Organizations Consulted}

Prior to approval of this document, a draft version was sent to Ecology, the Yakama Indian Nation, the Confederated Tribes of the Umatilla Indian Reservation, the Nez Perce Tribe, and the Wanapum. Comments were received from the Yakama Indian Nation and were considered in the preparation of this document. Appendix $C$ contains the Yakama Indian Nation's comments and the DOE responses. 


\section{This page intentionally left blank.}




\subsection{References}

40 CFR 50, 1992, "National Primary and Secondary Ambient Air Quality Standards, Code of Federal Regularions, as amended.

40 CFR 61, 1992, "National Emission Standards for Hazardous Air Pollutants," Code of Federal Regulations, as amended.

50 CFR 17, 1992, "Endangered and Threatened Wildlife and Plants," Code of Federal Regulations, as amended.

56 FR 23363, 1991, "Nuclear Regulatory Commission, Preamble to Standards for Protection Against Radiation," Federal Register, May 21.

Bander, T. J., 1993, "Total Heat Source in Tank C-106," (Intemal Memo TJB-93-048, T. J. Bander to J. P. Harris, January 25), Westinghouse Hanford Company, Richland, Washington.

Clean Air Act, 1970, as amended, 42 U.S.C. 7401 et seq.

DOE, 1987, Final Environmental Impact Statement: Disposal of Hanford Defense High-Level, Transuranic and Tank Wastes, Hanford Site, Richland, Washington, 5 vols, DOE/EIS-0113, U.S. Department of Energy, Washington, D.C.

DOE, 1994, Environmental Assessment: Waste Tank Safety Program, Hanford Site, Richland, Washington, DOE/EA-0915, U.S. Department of Energy, Washington, D.C.

DOE-RL, 1993, Radionuclide Air Emissions Report for the Hanford Site, Calendar Year 1992, DOE/RL-93-36, U.S. Department of Energy, Richland Operations Office, Richland, Washington.

Ecology, EPA, and DOE, 1993, Hanford Federal Facility Agreement and Consent Order, as amended, Washington State Department of Ecology, U.S. Environmental Protection Agency, and U.S. Department of Energy, Olympia, Washington.

Leach, C. E., Stahl, S. M., 1993, Hanford Site Tank Farm Facilities Interim Safety Basis," WHC-SD-WM-ISB-001, Westinghouse Hanford Company, Richland, Washington.

National Environmental Policy Act of 1969, as amended, 42 U.S.C. 4321 et seq.

PNL, 1994a, Hanford Site National Environmental Policy Act (NEPA) Characterization, PNL-6415, Rev. 6, Pacific Northwest Laboratory, Richland, Washington.

PNL, 1994b, Hanford Site Environmental Report 1992, PNL-8682, Pacific Northwest Laboratory, Richland, Washington. 
Public Law 101-510, "Safety Measures for Waste Tanks at Hanford Nuclear Reservation," Section 3137 of Narional Defense Aurhorization Act for Fiscal Year 1991, 42 U.S.C 7274, et seq., November 5, 1990.

Resource Conservation and Recovery Act of 1976, as amended, 42 U.S.C. 6901 et seq.

WAC 173-303, 1990, "Dangerous Waste Regulations," Washington Administrative Code, as amended.

WAC 246-247, 1994, "Radiation Protection - Air Emissions," Washington Administrative Code, as amended.

WHC, 1988, Data Transmittal Package for 241-C-106 Waste Tank Characterization, WHC-SD-RE-TI-205, Westinghouse Hanford Company, Richland, Washington

WHC, 1993a, Project W-320, Tank 241-C-106 Sluicing, Functional Design Criteria, WHC-SD-W320-FDC-001, Rev. 2, Westinghouse Hanford Company, Richland, Washington.

WHC, 1993b, Status Report on Resolution of Waste Tank Safety Issues at the Hanford Site, WHC-EP-0600, Westinghouse Hanford Company, Richland, Washington.

WHC, 1993c, Tank 106-C Sluicing Letter Report, WHC-SD-WM-ES-234, Rev. 0, Westinghouse Hanford Company, Richland, Washington.

WHC, 1993d, Engineering Study of Tank Leaks Related to Hydraulic Retrieval of Sludge From Tank 241-C-106, WHC-SD-WM-ES-218, Rev. 1, Westinghouse Hanford Company, Richland, Washington.

WHC, 1993e, Westinghouse Hanford Company Health and Safety Performance Report, Fourth Quarter 1992, WHC-SP-0564-28, Westinghouse Hanford Company, Richland, Washington.

WHC, 1993f, Work Plan-Permitting Support for Tank 241-C-106 Waste Retrieval, WHC-SD-W320-WP-001, Westinghouse Hanford Company, Richland, Washington.

WHC, 1994a, Preliminary Safety Evaluation for 241-C-106 Waste Retrieval, WHC-SD-WM-PSE-010, Rev. 2, Westinghouse Hanford Company, Richland, Washington.

WHC, 1994b, Westinghouse Hanford Company Health and Safety Performance Report. Fourth Quarter Calendar Year 1993, WHC-SP-0564-32, Westinghouse Hanford Company, Richland, Washington.

WHC, 1994c, Tank Farm Health and Safety Plan, WHC-SD-HSP-002, Rev. 1, Westinghouse Hanford Company, Richland, Washington. 
WHC, 1994d, Chemical Compatibility of Tank Waste in 241-C-106, 241-AY-101 and 241-AY-102, WHC-SD-WM-ES-290, Rev. 2, Westinghouse Hanford Company, Richland, Washington

WHC, 1994e, CSER 94-001: Criticality Safety of Single Shell Waste Storage Tanks, WHC-SD-SQA-CSA-20363, Rev. 0, Westinghouse Hanford Company, Richland, Washington.

WHC-CM-4-3, Industrial Safery Manual, Westinghouse Hanford Company, Richland, Washington.

WHC-CM-4-46, Nonreactor Facility Safety Analysis Manual, Westinghouse Hanford Company, Richland, Washington. 
This page intentionally left blank. 


\section{Figures}


This page intentionally left blank. 


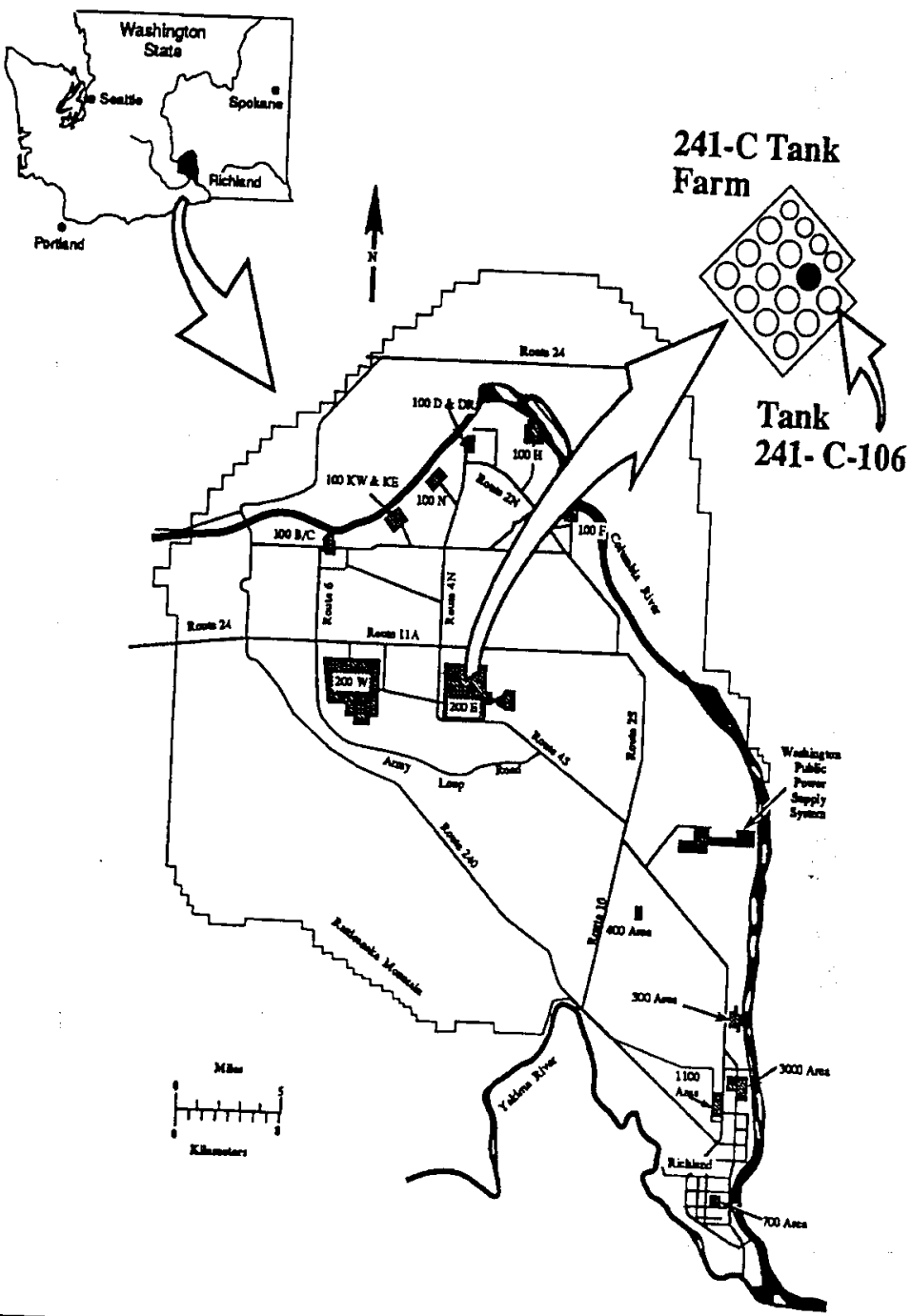

Figure 1.

Hanford Site Showing Tank 241-C-106 Location. 


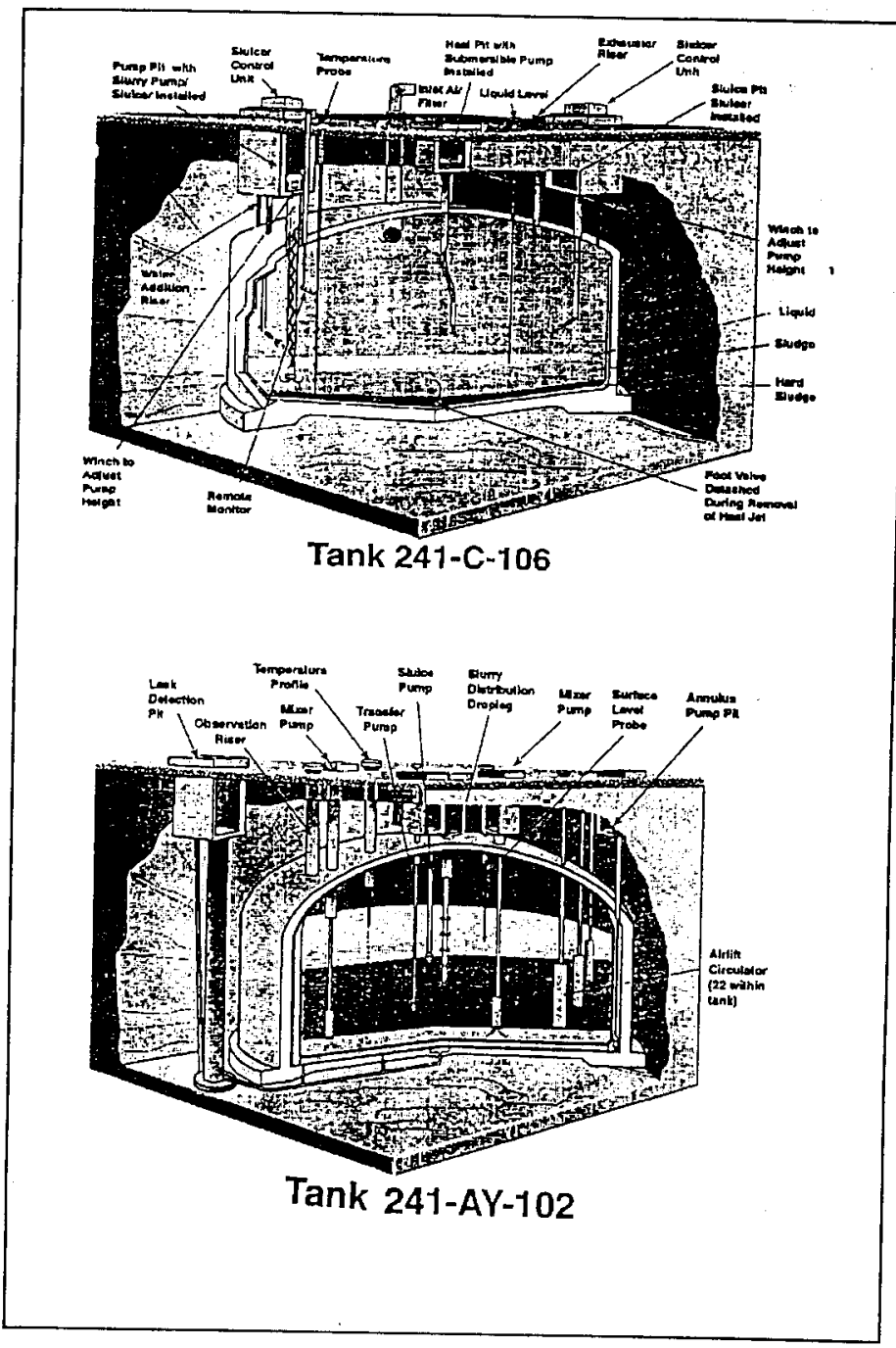

Figure 2.

\section{Tank 241-C-106 and Tank 241-AY-102 Configuration.}




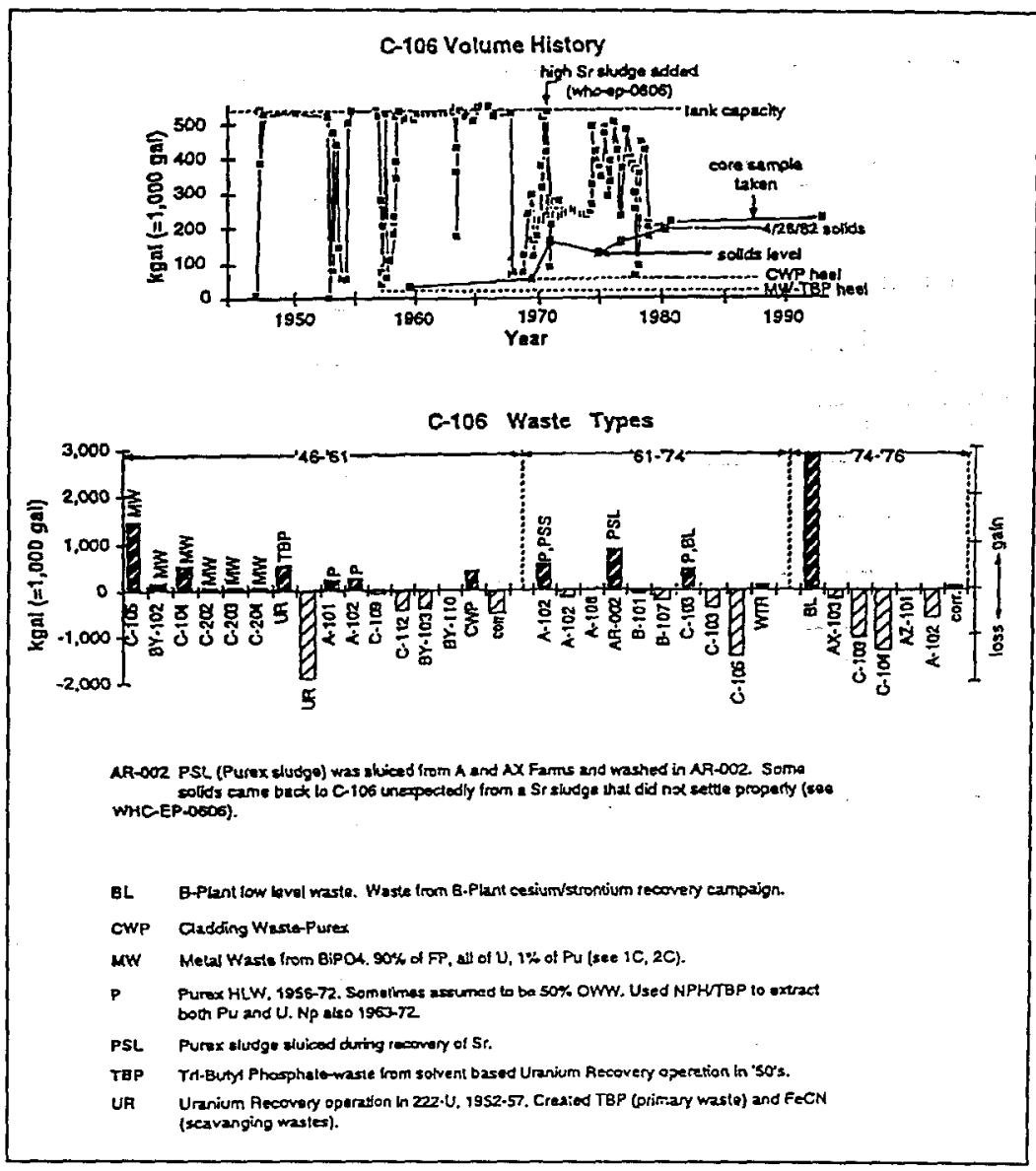

Figure 3. Tank 241-C-106 Volume History. 


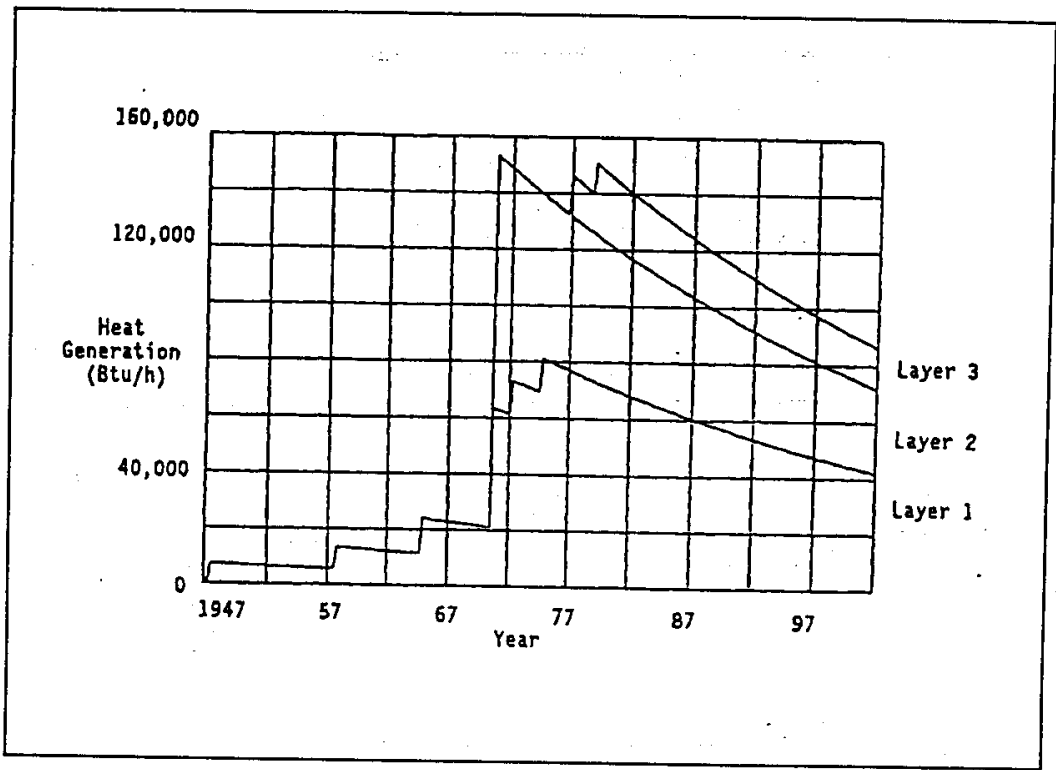

Figure 4. Tank 241-C-106 Heat Generation by Layer. 


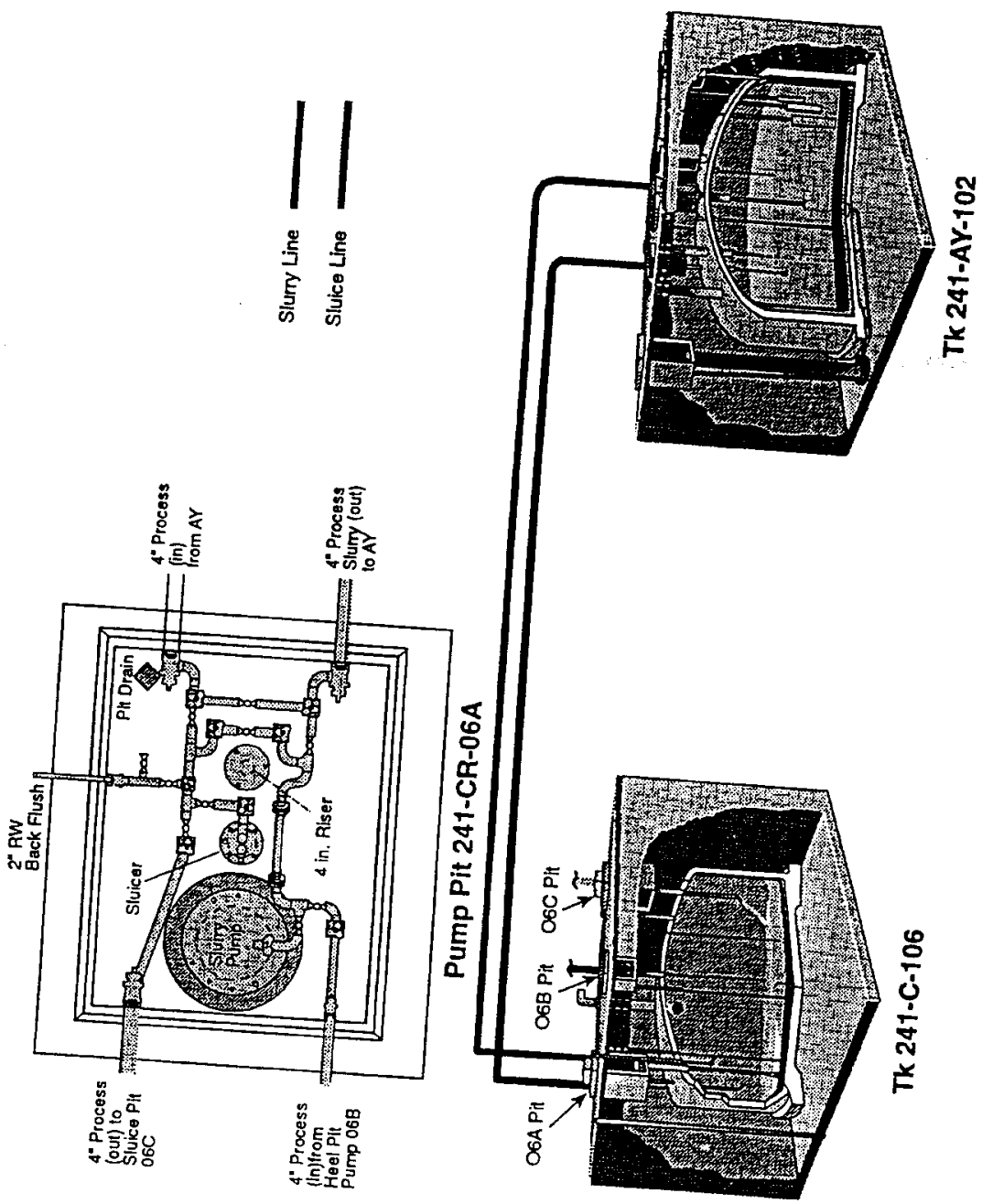

Figure 5. Tank-To-Tank Sluicing. 


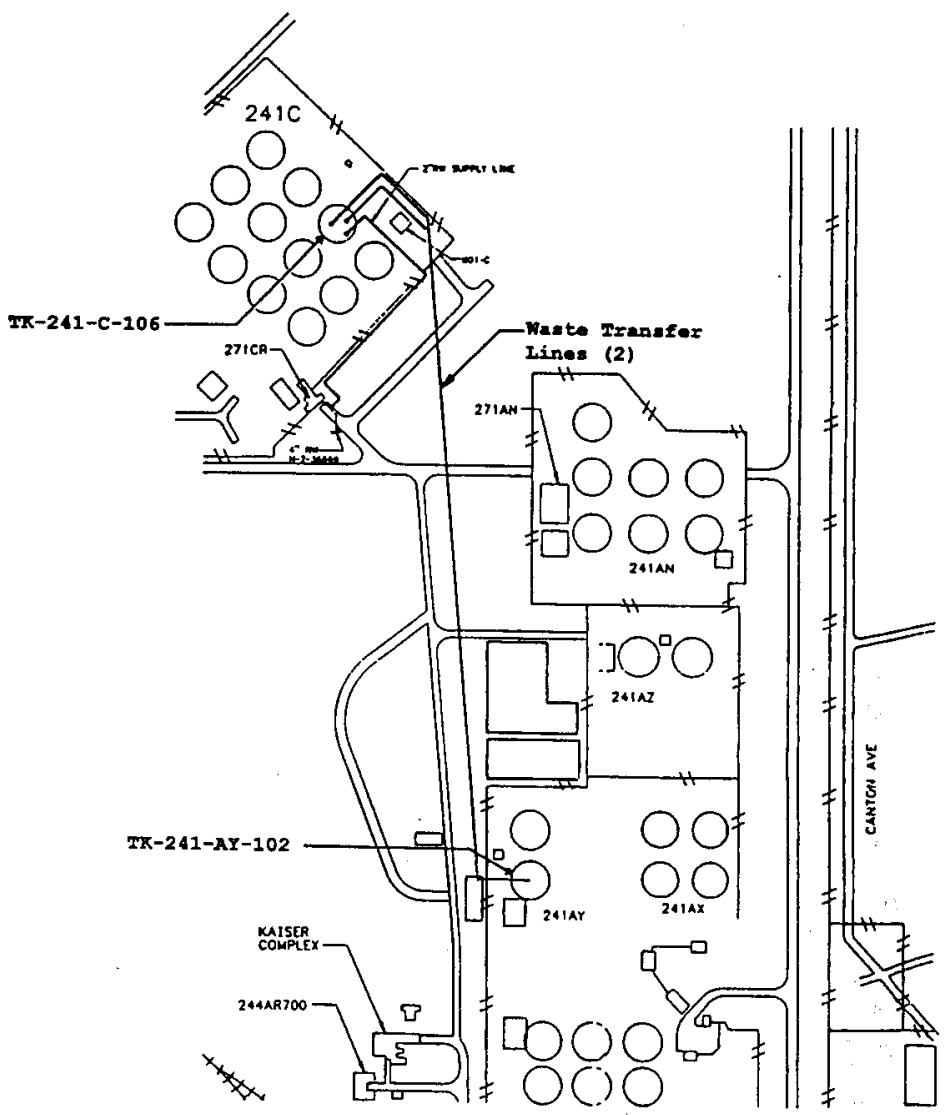

Figure 6.

Proposed Location of Waste Transfer Lines. 


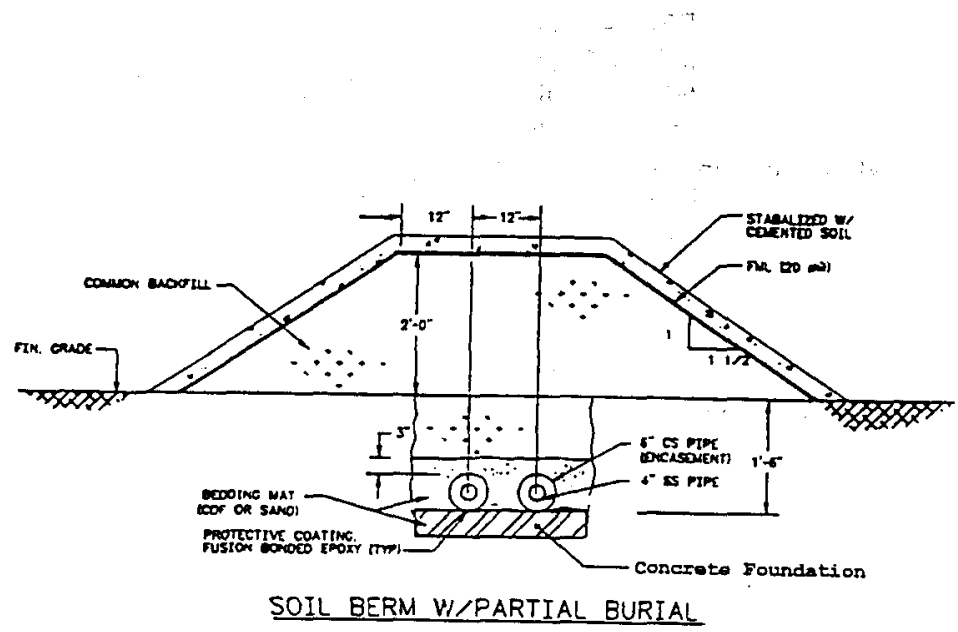

Figure 7.

Proposed Pipeline Configuration. 


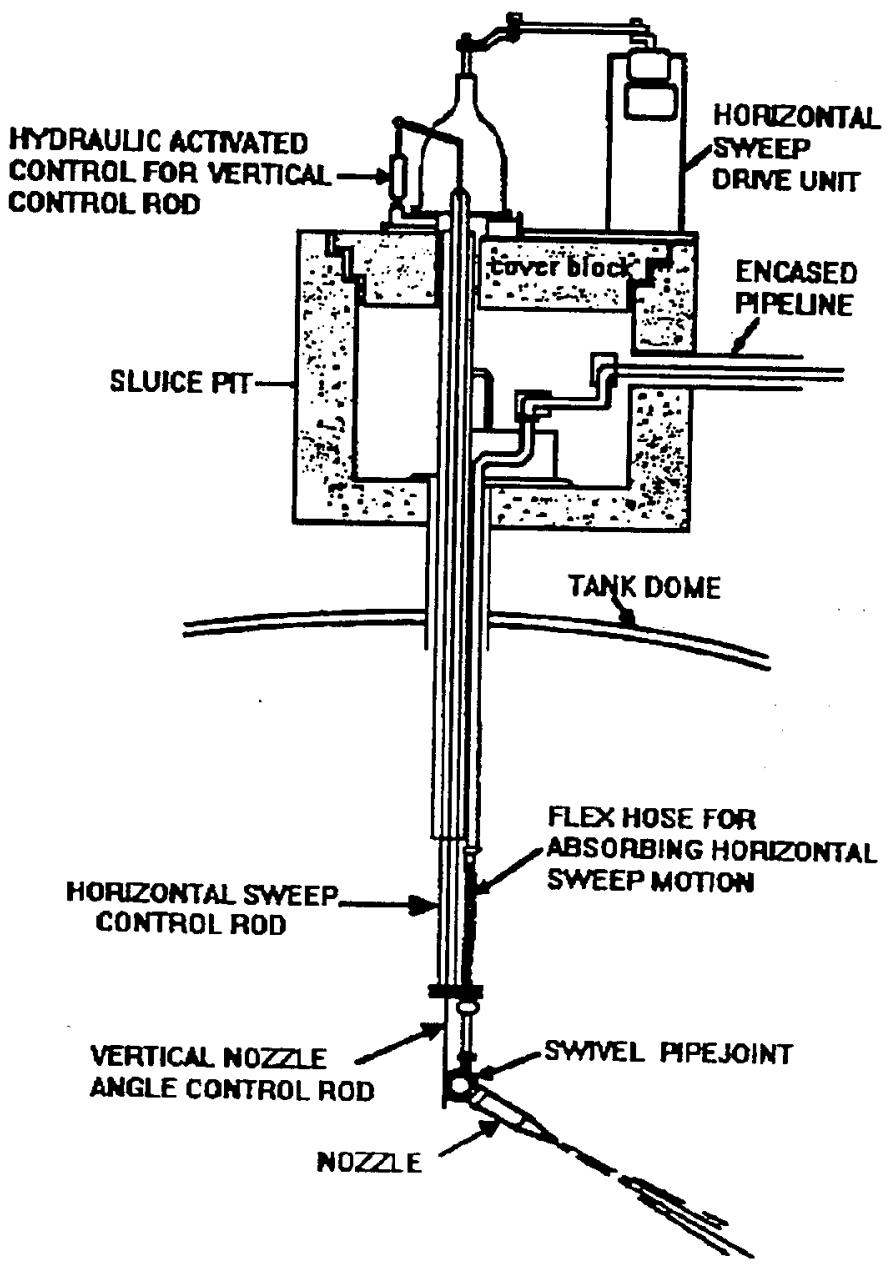

Figure 8.

Typical Sluicer Configuration. 


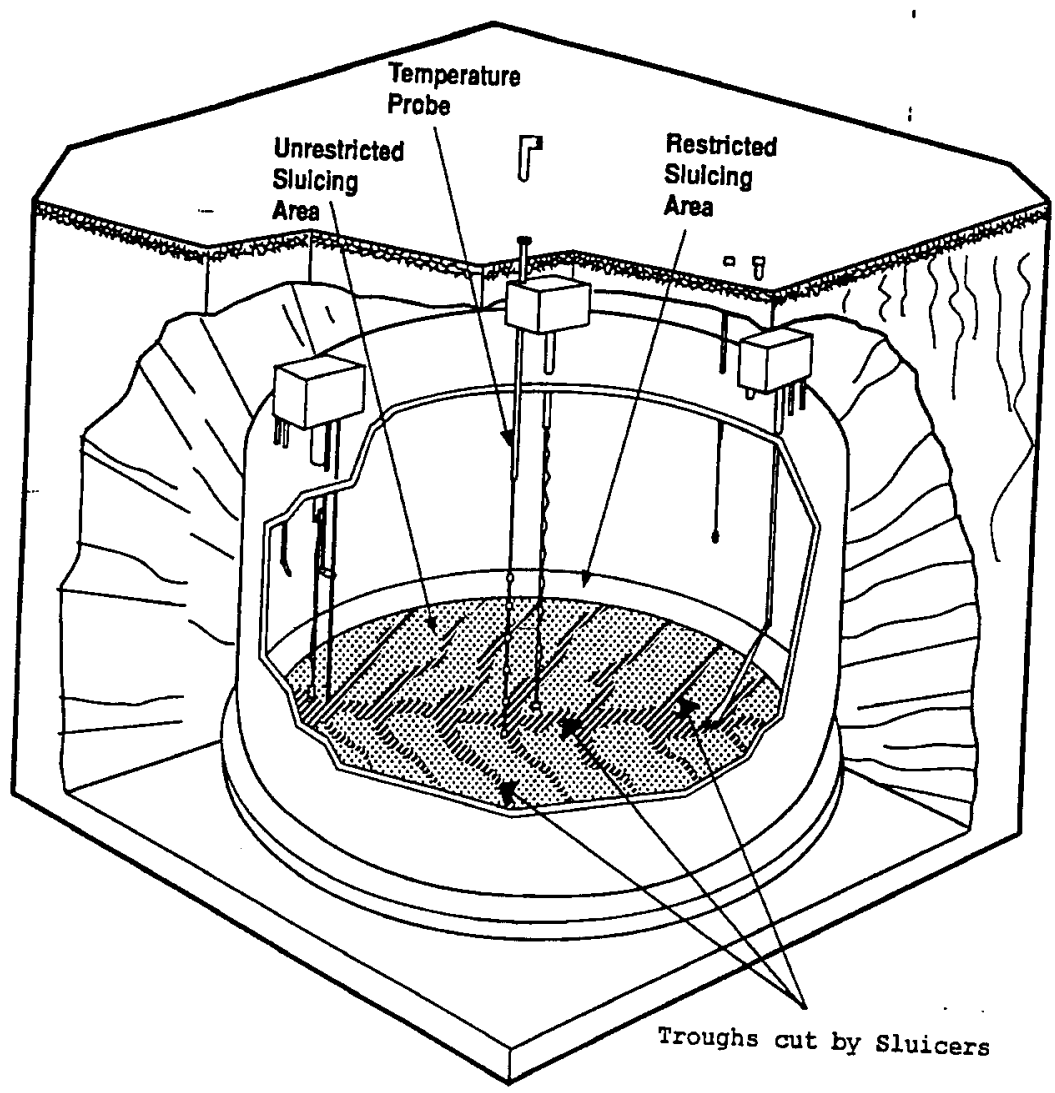

Figure 9.

Tank 241-C-106 Sluicing Features. 
This page intentionally left blank. 


\section{Appendix A \\ Cultural Resources Review (HCRL \#93-200-111)}


This page intentionally left blank. 


\section{* Battelle}

Pacific Northwest Laboratories

Battelle Boulevard

P.O. Box 999

Richland, Washington 99352

Telephone (509)

372-1791

August 9, 1993

Mr. Warren Rued

No Known Cutural Resources

Westinghouse Hantord Company

Restoration and Remediation

P. O. Box 1970/16-26

Richland, WA 99352

CULTURAL RESOURCES REVIEW OF PROJECT W-320, TANK 241-C-106 SLUICING. HCRC *93-200-111.

Dear Warren:

In response to your request received August 4, 1993, staff of the Hantord Cultural Resources Laboratory (HCRL) conducted a cultural resources review of the subject project, located in the 200 Area of the Hantord Site. According to the information that you supplied, the project entails sluicing Tank 241-C-106 to remove solid waste and transierring the wasto to Tank 241-AY-102. The sluicing and transter will require two transfer pipes to be installed above ground between the two tanks, except where the pipes meet existing roadways when the depth of burial will not exceed six th, and the instaliation of a double-wide trailer.

Our literature and records review shows that project is located in an area that has been highly disturbed by previous constnuction. It is very unlkely that any intact cultural materials would exist in such disturbed ground. Survey and monitoring by an archaeologist are not necessary.

It is the finding of the HCRL staff that there are no known cultural resources or historic properties within the project area. The workers, however, must be directed to watch for cuhural materials (e.g., bones, antitacts) during excavations. If any are encountered, work in the vicinity of the discovery must stop until an HCRL archaeologist has been notified, assessed the significance of the find, and, if necessary, arranged for mitigation of the impacts to the find. This is a Class III case, defined as a project that imvolves new constnction in a disturbed, low-sensitivity area. Please notify us if changes to the project beation or dimensions are anticipated.

A copy of this letter has been sert to Charles Pasternak, DOE, Richiand Operations Office, as ofticial documentation. If you have any questions, please call Beth Crist, AScl Corporation, at 372-1791. Please use the HCRC\# above for any future correspondence concerning this project.

Very truly yours,

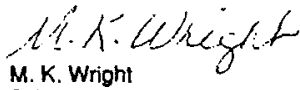

M.K. Wright

Scientist

Cultural Resources Project

c: C. R. Pastemak, RL (2)

File/LB 
This page intentionally left blank. 


\section{Appendix B}

\section{Ecological Survey \\ (\#93-200-40)}


This page intentionally left blank. 
Westinghouse

Hanford Company

Internal

Memo

From: Environmental Technology and Assessment

Phone: $\quad 376-9956$ H4-14

Date: August 16, 1993

Subject: SURVEY NUMBER 93-200-40

25320-93-126

To: W. J. Rued

H6-26

cc: L. L. Cadwell

K. A. Gano

A. R. Johnson

D. S. Landeen

M. R. Sackschewsky

J. C. Sonnichsen

S. W. Seiler

R. S. Weeks

$S$. Weiss

DSL File/LB

P7-54

$X 0-21$

H6-30

H4-14

H4-14

$\mathrm{H} 4-14$

B4-64

H6-26

$\mathrm{H} 6-02$

This letter is in response to the request for a biological assessment in support of the transfer line between $241-C$ tank farm Siuicing of Tank 241-C-105. "Althoughect W-320, "Past Practice been conducted in the $C-106$. "Although no biological surveys have impacts to any plant or animal species of concen no adverse occur because the proposed routing ies of concern are expected to adjacent to established roadways and through transfer line is areas. Most of this area is current through highly disturbed management.

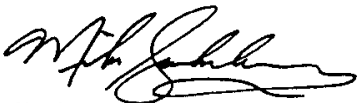

M. R. Sackschewsky

Biological Sciences Team Senior Scientist

mjm

CONCURRENCE:

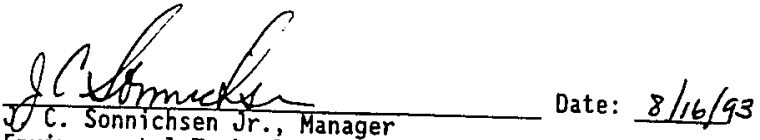

Environmental Technology and Assessment 
This page intentionally left blank. 


\section{Appendix C}

\section{Yakama Indian Nation's Comments and DOE Responses}

NOTE: Finalization of the EA may have resulted in changes to the specific pages/paragraphs referred to in the DOE response letter to the Yakama Indian Nation. 
This page intentionally left blank. 
Mr. John Wagoner, Manager

Richland Operations office

Department of Energy

P.O. Box 550 A7-50

Richland, WA 99352

Subject: ENVIRONMENTAL ASSESSMENT FOR TANK 241-C-106 PAST-PRACTICE SLUICING WASTE RETRIEVAL; COMIDNTS ON--

Dear Mr. Wagoner:

Department of Energy Richland operations letter 94-PRJ-006 from Mr. Dunigan of your staff requested comments on the subject environmental assessment (EA).

We support the action to expedite the remediation of Tank $\mathrm{C}-105$; however, we are concerned with the potential environmental impacts associated with the evolution and recomend that thorough engineering evaluations be accomplished and reported by means of the subject EA.

We consider that, in general, EA's should be used more consistently as a project controlifing document to assure comprehensive engineering evaluations for projects are accomplished and potential impacts properly identified and quantified.

This type of information is necessary to rationally reach conclusions about the conceptual design of a project and impact mitigation measures. It is consistent with Mr. Grumbly's recent initiative to improve the front-end planning as a means of reducing project costs.

Comments concerning the subject EA for Tank C-106 reflecting this consideration are contained in the Attachment to this letter.

Sincerely,

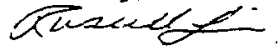

Russell Jim, Manager

Environmental Restoration/Waste Management Program

Yakama Indian Nation

P. O. Bō 151

Toppenish, WA 98948

ATTACHMENT: Componts on Invirommental Asessament rank 241-6-106 Past-practice Bluicing waste Retrieval pot/EA/XOXX (see next page for distribution) -HCUEIYEL

$\because$ AR 021994

$$
\text { ACE } 9496826 \text { InF-RL/COC }
$$

Post Office Bax 151. For Road. Toppenish. WA 98948 (s09) R65.512:

Bh Coumitment Contol

HAR 01.1374

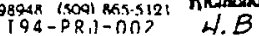


cc: R. Clarke, DOE/RL

M. Riveland, WA Ecol.

G. Emison, U.S. EPA Reg. 10

T. GrUmbly, DOE/EM

Washington Gov. M. Lowry

U. S. Congressman J. Inslee

U. S. Senator P. Murray 


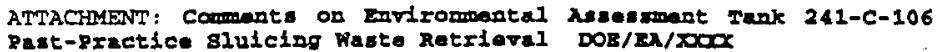

Commonts prepared by J.R. Brodaur, R.E.

General Corment:

USE OF EA'S TO IDENTIFY ENGINEERING SCOPE AND ENVIRONMENTAL ISSUES-

We consider that Environmental Assessments (EAs), including the subject EA, provide a primary means of identifying issues and concerns about technical aspects of a project. However, the subject (EA) does not adequately address engineering concerns associated with potential environnental impacts of the subject project.

our concerns reflect a potential for significant environmental impacts, such as leaks or spills resulting from the sluicing operation, and we consider these concerns should be addressed and resolved. Resolution of some of those concerns may be the responsibility of the various engineering functions of the project and may not necessarily be resolved in the EA; but the EA should provide the formal vehicle to commit to addressing the concerns and should respectively identify or reference the appropriate engineering documents that are planned or completed.

It appears that there is inadequate prelininary engineering assessment of the subject sluicing project to comprehensively scope technical issues and establish conceptual designs. We note that Mr. Grumbly, in connection with the recent stand down, identified the need to perform more comprehensive engineering at the initial stages of major projects such as this one. We agree that comprehensive engineering in the initial stages of various DOE projects has been a root cause of cost over-runs and inefficient operations. In it's current form, the EA falls short of providing a true assessment of the impacts to the environment. Furthermore, it appears to be based on a collection of aisorganized, uncoordinated documents that use inconsistent design and operational criteria. The EA should be revised to correct the deficiencies identified below.

\section{SPECIFIC COMMENTS:}

1. LEAK EVALUATION, OVER-FILIING TANK-AY-102--Page 2-1, 3rd par.-This paragraph 5 tates that $\mathrm{C}-106$ contains $173,000 \mathrm{gal}$. of top layer sludge of which at least $75 \%$ is to be removed $(129,750 \mathrm{gal}$.$) to AY-$ 102 in the sluicing operation. However, according to WHC-EP-018264 (TF Surveillance and waste status). Tank AY-102 only has 131,000 gal. of space available. This leaves only a 1250 gal. difference. Additionally, both the $E A$ and the functional design criteria (FDC) (WHC-SD-W320-FDC-001 Rev.1) indicate that the transfer lines will be flushed after completion of the sluicing operation. 
We assumed from the description of operations in the aA that pumping of liquid from $C-106$ will be accomplished at the sane rate at which sluicing liquid is pumped into C-106 (350 gpm). Therefore, after pumping 758 of the Iiquid from C-106 there would only be a maximum of 3.5 minutes before the pump nust be turned off to assure AY-102 is not filled beyond its capacity.

This will require careful monitoring with adequate instrumentation and operational controls to prevent spills and overfilling tank AY102. In this regard monitoring criteria should be specified in the EA, and the EA should assess the environmental impact of leak of spill considering the capabilities of the instrumentation.

In sumary, our concern is that tank AY-102 may be filled beyond design capacity, resulting in an environmental impact tue to a release from the first shell of the double shell tank. We consider that additional engineering is required to address and prevent this scenario.

The EA should consider the realistic impact of overfilling AY-102, and such a risk should be minimized by adequate process design. instrumentation and automatic pump controls.

2. OPERATIONAL CONTROLS TO PREVENT LEARS/SPILIS-

The EA is not clear about the amount of liquid that will be in Tank C-106 at any time during the sluicing operacion. The functional design criteria (FDC), described in WHC-SD-W320-FDC-001, provide an upper linit of liquid in the tank at 79 inches (217,000 gal). However, this document a) does not indicate how the amount of liquid in the $\mathrm{C}-106$ will be minimized; b) does not state what criteria will be used to decide when punping from C-106 will occur; or c) does not indicate, if there will be any additional controls to minimize the liquid. Also, there is no explanation of the sequence of events relative to the pumping and sluicing operations in the EA, in the FDC, or in the procedural report (WHC-SD-WM-ES234).

The following additional questions should be resolved by the engineering documents justifying the subject operation: a) will the existing liquid in the tank be pumped prior to introduction of the sluicing liquid? b) Will the sluicing liquid be pumped from C106 during the sluicing operation? c) Will there be a significant fluctuation in the licuid level? Appropriate operational limits should be specified in the procedures.

The EA should provide a clear statement as to the maximum volume of liquid to be placed in tank C-106 at any time, and it should clearly indicate the sequence of the pumping and sluicing operations. These process design data should be used as input parameters in the tank leak engineering study (WHC-SD-WM-ES-218). Currently, that study assesses tank volume criteria that are inconsistent with the FDC. 
A primary concern is that leaving a large amount of liquid in c-106 during the sluicing operations could promote a leak from the tank and result in an environmental impact. The EA should consider such an impact and assess this impact. The significant cooling anticipated by the removal of the sludge will cause thermal contraction of the tank that could lead to tank failure.)

3a. LEAK DETECTION CAPABILITY--

As suggested by the comments above, questions remain about the curfent ability to detect leaks and the resulting environmental impacts from undetected leaks. The tank leak engineering assessment (WHC-SD-WM-ES-218) postulates a low volume leak, even though, as a result of poor precision leak detection instrumentation, a high volume leak may go undetected,

Therefore, an engineering assessment of the Hanford single shell waste tank leak detection systems to be used in the sluicing operations should be completed and those data should be used to provide input to the tank leak engineering stucy. This, in tura should be referenced and used in the EA. Engineering evaluations of the leak detection systems that exist should be made public as background information.

The EA should provide a credible assessment of the maximum leak volume to compare with our estimate of $200.000 \mathrm{gal}$. (See comment 3b below) that could be released in the sluicing operation, and an evaluation should be made of various sluicing methods so as to minimize the chances of a leak from $c-106$.

3b. TANK INTEGRITY WITH SLUICING--Section 5, DD 5-7\&5-8--

We have a major concern about the current integrity of Tank C-106; about the possibility that the sluicing operation will induce further leaks from the tark; about the inadequacy of the leak detection instrurentation; and about the inadecuacy of the $E A$ in assessing the impacts resulting from a leak.

The question about the current integrity of the tank has not been addressed in the EA. However, documents describing studies about possible tank leaks in the C-farm, specifically adaressing possible leaks from C-106, have not been reviewed or referenced in the EA. Studies about the integrity of $C-106$ have not been completed (see recomendations section of WHC-SD-EN-TI-185). Specifically, there is contamination in the unsaturated zone on the north-west and east sides of this tark that is of unknown origin. Some of that contamination is deep in the unsaturated zone and is probably not from downward rigration of surface contamination. Additional studies are required to identify the sources of that contamination. Such studies, together with a comprehensive assessment of the origin of the unsaturated zone contamination and the tank integrity should be completed. This study should inciude a review and analysis of all bistorical tark leak detection data. 
We consider that the sluicing operation should not proceed without knowing if the tank is currently sound, if it has leaked in the past, if the operation will induce another leak, or if the siuicing operation could be performed with a minimal amount of free liquid in the tank to mitigate such a potential leak.

To evaluate the worst case scenario, the EA should assess the impacts resulting from a large leak (over 200,000 gal). In any case, adequate tank integrity characterization should be performed and sluicing operational controls should be put into place to minimize the possibility of a large leak.

4. IEAR DETECTION FOR TRANSFER LINES AND PUMP PITS--PAge 2-3-The last sentence states "Leak detection would be provided for the new transfer lines and purp pits." Since leak detection is critical to prevention of spills, considering the spill history at $C$ farm, more detail concerning this issue is warranted in the EA. A more rigorous assessment of the possibility of a spill is needed. Such an assessment should identify the instrumentation required to assess a spill and evaluate the probability of a spill. This was not accomplished in the referenced Hazard Classification (WHC-SDWR-HC-007). As a result, the real hazard associated with a spill is not determined, and the potential enviromental inpacts were not assessed.

5. FACILITY DECONTAMINATION AND WASTE DISPOSITION--Pg 2-4, Par. 2This paragraph discusses decontamination of the transfer lines and equipment. This decontamination process will generate both liquid and solid waste. Estimates of the nature of this decontamination waste and its environmental impact should be provided, as well as, a description of how the decontamination waste will be handled, including facilities needed to accomplish the decontamination and plans for disposal.

6. INCORRECT TRANSFER LINE FLOW RATES--Section 5, p 5-6, par. 1-The transfer line leak scenario appears to incorrectly use a transfer Iine flow rate of $105 \mathrm{gpm}$, which is inconsistent with the sluicing pump output which would pump liquid from $A Y-102$ at a rate of $350 \mathrm{gpm}$ (pg. 2-2, par 3). The scenario should be re-evaluated to include the highest possible flow rate. Adaitionally, the probability that has been "determined" may not be correct. The EA should incorporate the probability calculations or a proper scientific reference.

7. WORKER PROTECTION FROM TANK C-103 TOXIC VAPORS--

There is nothing in the environmental assessment which addresses the problem of worker protection from organic vapors arising from Tank $C \rightarrow 03$. The assessment of a vapor release from $\mathrm{C}-103$ during the sluicing operations is critical to the health and safety of the workers. Heasures appropriate to mitigate the impact on workers from such releases should be identified. 
8. RECOVERY FROM A LEAK FROM TANK C-106--Page 5-7, par 2.-This paragraph implies that a surface barrier will be constructed over C-106 if a leak occurs. Further, It alludes to an action of recovering or treating any contaminated soils. These statements do not constitute an assessment of the impact of a release on the groundwater or unsaturated zone ervironment and remediation associated with these natural resources. As noted above, a proper and comprehensive assessment of these potential impacts, together with possible remediation, should be completed in the $E A$. 


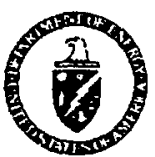

\section{Department of Energy \\ Richland Operations Office \\ P.O. Box 550 \\ Richland. Wasnington 99352}

14it $1:$ :

94-TWP-104

Mr. Russell Jim, Manager

Confederated Tribes and

Bands of the Yakama Mation

P.0. Box 151

Toppenish, WA 98948

Dear Mr, Jim:

RESPONSES TO COMDENTS ON THE ENVIRONMENTAL ASSESSMENT (EA) FOR

TANK 241-C-106 PAST-PRACTICE SLUICING WASTE RETRIEVAL

The Department of Energy, Richland Operations office (RL), appreciates your efforts in reviewing and commenting on the EA for Tank 24l-C-106 Past-Practice sluicing Waste Retrieval. Enclosed are RL's responses to your coorments on this $E A$ and one copy of the revised Prel iminary Safety Evaluation for 241-Cjo5 Waste Retrieval, Project $\mathbf{W}-320$, which includes the revised Chenical Compat fbility of Tank Wastes in Tanks 241-C-106, 241-AY-101, and 241-AY-102 Report as an attachment. The EA is being revised to incorporate changes in response to your comments. He will send you a copy when it is finished.

If you or your staff wish to receive further information about this activity, please contact Mr. S. D. Bradley, of the Tank Haste Projects Division, on (509) 376-7333. If you desire further information about the Mationa? Environmental Policy Act (NEPA) process, please contact me on (509) 376-6667.

Sincerely,

PJR:SO8

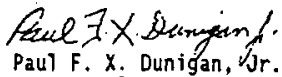

Enclosures

cc w/o encis:

M. D. McKinney, PNL

H. R. Cook, YIN

R. Tulee, YIN

W. RueK, AHE 


\section{Department of Energy Richland Operations Office}

Subject:Responses to the Yakama Indian Nation Coments on the Environmental Assessment (EA) for Tank 241- -105 Past-Practice Slucing Waste Retrieva7, letter dated February 24, 1994.

1. According to WHC-EP-0182-64 (TF Surveillance and Waste Status). Tank AY102 onty has 131,000 gallons of space available. This leaves only 1,250 gallons difference between space available and the 129,750 gallons of waste needed to be sluiced. Additionally, the transfer lines will be flushed which will produce more liquid waste. Towards the end of the sluicing operation (after 75\% of the waste has already been transferred) there will only be 3.5 ninutes before the pumps rust be shut off to prevent Tank $A Y-102$ fron being filled to capacity (based upon the 1,250 gallons of space mentioned above). The EA should specify the nonitoring criterla which would prevent tank overfilling and the environoental impact from a spill or leak given the instrumentation capabilities.

Disposition of Coistent 1: Section 2.2 has been expanded to include a discussion on the preliminary activities needed to Tank AY-102 to prepare it for sluicing operations. The 2nd paragraph (on page 2-5) explains that the supernatant currently in Fank AY-102 would be pumped out and sent to the Evaporator Bottoms System or another double shell tank (DST). Either Tank AY10l's supernatant or treated water would be pumped into Tank AY-102 to provide the initial sluicing agent. This would be done because both AY-jol's supernatant and treated water have better compatibility characteristics with waste in Tank C-106 than the supernatant in Tank AY-102. The paragraph states, "...The removal of Tank AY-102's supernatant, even with the introduction of Tank AY-10l's supernatant, would allow for sufficient space requirements for the receiver tank and would eliminate the potential for overflow as a result of the proposed siuicing operation".

2a. The EA does not indicate how the amount of liquid in $C-106$ will be minimized; what criteria will be used to decide when pumping from C-106 will occur, what additional controls (if any) will be installed to minimize the 1fquid. An explanatioit is needed in the EA on the sequence of events relative to pumping and sivicing.

Dispostition of Copment 2a: The EA describes the process that would be involved in sluicing in Section 2.2 (which has been modified). The description emphasizes that the process would be a closed loop and would not introduce additional liquid to Tank $[-106$.

A paragraph has been added (page 2-3) whtch explains that at the start of sluicing, the slurry transfer pump in $6-106$ would be configured to run the slurry internally through the sluicers. This closed loop would be monitored to ensure that the proper consistency is reached before the slurry is transported to AY-102. This section (Section 2.2) has been modified to provide a more detailed description of the overali sluicing process, and indicates that this is a continuous, simultaneous process (where the volume being pumped out is roughly the same as the volume of supernatant added). 
2b. The following questions should be resolved by engineering docunents justifying sluicing: a) will the existing liquid in the tank be pumped prior to the introduction of the sluicing liquid? b) will the sluicing liquid be pumped from C-10E during the sluicing operation? c) will there be significant fluctuation in the llavid level? Appropriate operational limits should be specified in the procedures.

Disposition of Compent 2b: As has been mentioned, the 1st full paragraph of Page 2-3 states that the liquid currently in $6-105$ would be pumped out to improve sluicing efficiency prior to the actual slutcing. The revised Section 2.2 describes the process used in this project which mentions that the supernatant wauld be used to sluice the sludge and form a slurry. This slurry would be punped through the transfer lines into Tank AY-102. The heavier particles would settle out under gravity while the relatively clear liquid would remain on top to be used as the supernatant (and thereby forming a continuous operation). The greatest liquid level would be at the start of operations. The siurry pump would remove the slurry at roughily the same rate as the supernatant is added, keeping the liquid level fairly constant (approximately 5,000 gallons). The overall waste volume would steadily decrease throughout the project.

3a1. Questions remain about the current ability to detect leaks. An engineering assessment of the SST waste leak detection capability should be completed and included in the tank leak engineering study, which should, in turn, be referenced in the EA.

Dispostion of coment 3ali The EA was wodified to include a discussion on the ability to detect leaks during sluicing. Both Section 2.2 (3rd paragraph on page 2-4) and Section 5-2 (first paragraph on page 5-11) mention that the presence of flow meters on the transfer lines and mass balance controls on the receiver tank would detect a leak when approximately 8,000 gallons were lost.

3a2. The EA should provide a credible assessment of a leak of 200,000 galions.

Disposition of Conmentraaz: Due to the presence of the above cantrals, a leak of 200,000 gallons from siuicing is unrealistic and overly conservative (see response to Coment 363 ).

3bl. Concerns exist with the integrity of Tank C-106. Additional studies are needed to identify the source for the current soil contamination in and around C-Farm.

Dispesition of Conment 3bl: A paragraph was added on page 2-1 explaining why C-106 has been characterized as sound. In 1992, the ventilation system failed and the tank was nonitored for a period of roughiy six months. During this time, with no additional cooling water added, the level of waste within C-106 remained constant. 
362. Sluicing should not be allowed until information is avallable on if the tank is currentiy sound, if it has leaked in the past, if it is possible to slufce with a minimal amount of free liquid in the tank to mitigate a potential leak.

Disposition of coment 3b2: The tank will be sluiced with a maximum of 5.000 gallons of supernatant added to the siudge at any time. The maximur amount of waste that could be released under these conditions would be the 5,000 gallons and any interstitial liquid in the waste.

3b3. To evaluate a worst case scenario, the EA should examine a leak of over 200,000 galyons. In any case, adequate tank integrity characterization should be performed and operation controls should be put into place to minimize the posstbility of a large leak.

Disposition of Connent 3b3: As has been mentioned, leak detection devices would identify a leak when approximately 8,000 galions of l lquid is unaccounted for in the slulcing process. The EA further mentions that a conservative estimate of a leak is 40,000 gallons (and wauld be determined by the amount of free liquid in the tank, the detection devices, and the abllity of the waste to plug the leak site). It is unrealistic to address a leak of 200,000 gallons from routine sluicing operations, when the total waste volume in $\mathrm{C}-106$ would be less than this amount. The sluicing process, by working from the center outward, is designed to minimize the amount of waste that could leak to the environment. By the the the sluicers are applied to waste near the tank walls, the amount of waste would be greatly reduced.

4. More detail is warranted in the EA on Teak detection of the transfer ilnes and pump pits. A more rigorous assessment is needed to determine the probability of a spill and the instrumentation required to assess the spilt.

Disposition of coment 4: The purp pits would return any leaked waste back into their respective tanks. The transfer lines would collect waste from a break in the primary pipe and carry it to a common point for leak detection. There is a discussion of these points on page 5-2 (3rd and 4 th paragraphs). Please see attached two sheets on desian requirements.

The probability of a spill from the transfer lines has been determined to be $7.0 \times 10^{-4}$, the frequency of a Design Basis Earthquake at the Hanford Site.

5. A more thorough discusssion of the decontamination process is needed, including the nature of the decontamination waste and its environmental impact.

Disposition of Coment 5: Decontamination of equipment and materials used in this project would produce roughly 7,000 gallons of additional liquid waste which would be sent to AY-102 and would still be well within the operating capabilities of that tank. The equipment would be excessed where practical or disposed of as waste. The volume of liquid waste generated from this action is mentioned on Page 5-16. 
6. The transfer line leak scenario should use the pump flow rate of $350 \mathrm{gpm}$ to be cansistent with the description of the proposed action. The probability of this accident should be reexamined.

Disposition of Coment 6: Section 5.2 of the EA was revised to address coment contents.

7. Measures approprtate to mitigate the Impact on workers from organic vapors which might arise from Tank $\mathrm{C}-103$ should be identified.

Disposition of coment 7: Section 5.1 page 5-3, 2nd paragraph of the EA was revised to state that proper respiratory equipment will be used as appropriate.

8. Statements in the EA on potential surface barriers should a leak occur and future recovery and treatment of contaninated soils, do not reflect an assessment of the impact of a release on the groundwater or unsaturated zone and remediation associated with these resources.

Disposition of coment B: Wording was added to the EA to reflect that the accident scenario of a tank rupture from $08 E$ (which has the possibility of the most severe waste release to the soil) is not exciusive to the proposed action. This accident could occur during nomal tank storage activittes and, therefore, should not be a factor in determining the environmental signiffcance of this project. Existing wording in the EA explain that a postulated leak would take a minimum of 60 years to reach the groundwater (and only the most moblle portion of the leak). The EA also explains that contaninated soll from such a spill would likely be remediated as part of the overall site closure of the tank farms under the TPA Mflestone (M-45-06). 
TANK 241-C-106

PAST-PRACTICE SLUICENG WASTE RETRIEVAL

\section{HANFORD SITE, RICHLAND, WASHINGTON U.S. DEPARTMENT OF ENERGY}

FINDING OF NO SIGNIFTCANT IMPACT

FEBRUARY 1995 
HNF-SD-WM-RPT-293 REV 0

This page intentionally left blank 


\section{AGENCY: U.S. Department of Energy}

\section{ACTION: Finding of No Significant Impact}

SUMMARY: The U.S. Department of Energy (DOE) has prepared an Environmental Assessment (EA), DOE/EA 0933, to assess environmental impacts associated with past-practice sluicing as a means of waste retrieval for Tank 241-C-106 (Tank C-106), and activities necessary to support this work at the Hanford Site, Richland, Washington. Tank C-106 is an underground single-shell tank (SST) located in the 241-C Tank Farm in the 200 East Area of the Hanford Site. Alternatives considered in the review process included: the No Action alternative; the preferred alternative to remove heat-producing sludge from Tank C-106 by sluicing using a high-volume, low-pressure stream of liquid to mobilize sludge waste for transfer through two transfer lines to a receiver tank, Tank 241-AY-102 (Tank AY-102), an underground double-shell tank (DST) also located in the 200 East Area; and a batch-transfer alternative that would use an accumulation tank connected to the transfer lines to hold in turn the supernate from Tank AY-102 that would be used to sluice the waste in Tank C-106, then the sluiced solids from Tank C-106 to be sent to Tank AY-102.

Based on the analysis in the EA, and considering preapproval comments from the Yakama Indian Nation, DOE has determined that the proposed action is not a major federal action significantly affecting the quality of the human environment within the meaning of the National Environmental Policy Act of 1969 (NEPA), 42 U.S.C. 4321, et seq. Therefore, the preparation of an Environmental Impact Statement (EIS) is not required.

\section{ADDRESSES AND FURTHER INFORMATION}

Single copies of the EA and further information about the proposed action are available from:

Leif Erickson, Director

Tank Waste Disposal Division

U.S. Department of Energy

Richland Operations Office

P. O. Box 550

Richland, Washington 99352

(509) 376-6406 
For further information regarding the DOE NEPA process, contact:

Carol M. Borgstrom, Director

Office of NEPA Oversight

U.S. Department of Energy

1000 Independence Avenue, S.W.

Washington, D.C. 20585

(202) $586-4600$ or $(800) 472-2756$

PURPOSE AND NEED: DOE needs to take action to eliminate safety concerns with the storage of high-heat waste in Tank C-106, and demonstrate a tank retrieval technology.

BACKGROUND: In November 1990, Public Law 101-510, Section 3137, "Safety Measures for Waste Tanks at Hanford Nuclear Reservation" was enacted, which mandated that the DOE develop plans for response to safety issues associated with the waste storage tanks at the Hanford Site, and to report the progress of implementation of those plans to the U.S. Congress. In the resulting "Status Report on Resolution of Waste Tank Safety Issues at the Hanford Site," Tank C-106 is identified as a high-heat tank and one of the "Priority 1 " safety issues at the Hanford Site.

Tank C-106, which was built during 1943 and 1944, measures 23 meters ( 75 feet) in diameter. It contains 655,000 liters $(173,000$ gallons) of sludge containing a sufficient amount of strontium to be considered high-heat waste. It is estimated that this sludge generates 32.24 plus or minus $5.86 \mathrm{~kW}$ (110,000 plus or minus 20,000 Btu per hour). This decay heat is being currently removed by the addition of approximately 22,700 liters $(6,000$ gallons) of water per month which provides evaporative cooling. It is believed that without active cooling, temperatures in the tank could exceed established limits and eventually affect the structural integrity of the tank resulting in a possible breach of containment. Also, the continued additions of cooling water would increase the amount of material available to be released to the soil column if a loss of containment occurs due to the age of the tank.

In addition, sluicing the waste from Tank C-106 would demonstrate a form of tank waste retrieval as called for in Hanford Federal Facility Agreement and Consent Order (Tri-Party Agreement) Milestone M-45-03-T1 "Complete SST Waste Retrieval Demonstration." While the sluicing operations would need to retrieve approximately 75 
percent of the high-heat sludge to lower the heat output below $11.72 \mathrm{~kW}(40,000 \mathrm{Bu}$ per hour) (the level at which active cooling is no longer required), the proposed action would attempt to retrieve as much waste as possible beyond this 75 percent to demonstrate waste retrieval efficiency.

PROPOSED ACTION: The waste retrieval operation would involve introducing a high-volume, low-pressure stream of liquid to mobilize the siudge waste in Tank C-106 and prepare it for pumping. One or two remotely-aimed "sluicers" would be installed in Tank C-106 at separate locations to ensure full sluicing coverage of the waste. The mobilized waste would be retrieved from Tank C-106 with a submersible pump that would transfer the waste to Tank AY-102 through one of the two newly installed, double-encased pipelines. The waste would be deposited in the receiver tank where the majority of the heavier solid waste particles would settle to the bottom while the liquid portion would remain on top as supernate to be recycled to Tank C-106 as the liquid sluicing agent. A sluice pump would be installed in Tank AY-102 to provide this sluicing agent. The two pipelines, one carrying the sluiced waste to Tank AY-102 and one carrying the supernatant back to Tank C-106, would be partially buried and covered by an earthen berm to reduce radiation dose to tank farm workers.

One of the sluicers in Tank C-106 would operate in the existing sluice pit, while the other would operate in the existing pump pit, if needed. Valves would direct the supernate liquid to one of the sluicers depending upon the area of the tank being sluiced. If it is determined that portions of the waste cannot be mobilized by the one sluicer, the valves would direct the supernatant into the second sluicer. Only one sluicer would operate at any one time.

A new submersible pump would be installed in Tank C-106 to transfer the slumy (i.e., the sluiced waste) to Tank AY-102. To allow for slurry elevation changes, the slurry transfer pump would be manually adjusted to maintain sufficient suction-head pressure. The sluicing operations would start from the center of the tank and work to the outside by remotely adjusting the angle of the sluicers. This is designed to minimize the time that the tank liner is directly exposed to the sluice stream, and minimize the potential for a sluicing-induced tank leak. 
The slurry would be pumped into the transfer line and deposited into Tank AY-102. A slurry distributor would evenly spread the Tank C-106 waste solids in Tank AY-102. This provides a more uniform heat source in Tank AY-102. The distributor also would provide a siphon break to the transfer line back to Tank C-106.

Prior to the sluicing operations, several actions would be required to prepare the tanks for the insertion of the pumps and equipment. Some of the existing equipment in the pump and sluice pits of Tank C-106 must be removed and stored at the Hanford Site for subsequent treatment and disposal. These pits would then require cleaning and the application of paint or fiber coating to the inside surface, which would provide a surface that can be more easily decontaminated. Before the waste from Tank C-106 can be transferred, the supernatant from Tank AY-102 would be pumped out to allow for sufficient space for the waste transfer. After the supernatant from Tank AY-102 is pumped out, supernatant from Tank AY-101 or other appropriate sluicing fluid (which may consist of treated water), would be pumped into Tank AY-102 to be used as the initial sluicing agent.

A new High-Efficiency Particulate Air (HEPA) filtration system would be added to Tank C-106 to minimize releases to the atmosphere. To control the temperature and humidity of the Tank C-106 vapor space during sluicing, the proposed action would install a recirculating air system. Additional methods of cooling the tank may be used, as necessary which may consist of either connecting an air chiller to the recirculation duct or by introducing cooled fluid prior to, or during, the sluicing operation. Additional instrumentation would be required in both tanks and in the transfer lines between the tanks. A double-wide trailer would be installed outside the 241-C Tank Farm, and would serve to house centralized monitoring and control instrumentation. Finally, support services, in the form of raw water, sanitary water, electrical power, telecommunications, and hoisting hardware, would be provided.

ALTERNATIVES CONSIDERED: The EA discussed a variety of sluicing alternatives as well as the No Action Alternative. Of the sluicing alternatives, all but one, the Batch Transfer Alternative, failed to meet the two essential requirements necessary for this project; the ability to remove enough of the waste so that the heat production in Tank C-106 is less 
than $11.72 \mathrm{~kW}(40,000 \mathrm{Btu})$ per hour, and that the sluicing method start retrieval by October 1996. The other alternatives discussed in the EA either resulted in the generation of greater - quantities of liquids requiring tank farm storage or rely upon technologies unproven in a waste tank environment.

Batch-Transfer Altemative. Of the alternatives described in the EA, the only option that could conceivably meet the two requirements was the Batch-Transfer Alternative. This alternative would utilize an accumulation tank which would hold both the supernatant from Tank AY-102 and the slurry from Tank C-106 at various times. The accumulation tank would first be filled with supernate from Tank AY-102, which would be used to sluice the waste in Tank $\mathrm{C}-106$. The solids from Tank $\mathrm{C}-106$ would then be transferred to this accumulation tank and the material batch transferred to the receiver tank. The accumulation tank then would be refilled with supemate from Tank AY-102 and the cycle repeated. While this alternative appears to meet the requirements, it would involve more design, procurement and construction costs, and would be less likely to meet the start date.

No-Action Alternative. This alternative would result in maintaining Tank C-106 in its present condition. No waste transfer operations will be performed, and the high-heat producing waste will continue to generate excessive thermal loads. Water additions to provide evaporative cooling will continue, which increase the amount of liquid available for release to the soil column in the event that the tank starts to leak. This altemative will not resolve the safety issue associated with Tank C-106 and will necessitate missing a Tri-Party Agreement milestone.

ENVTRONMENTAL IMPACTS: Routine conduct of the proposed activity would not result in any significant increase in tank farm emissions. Before beginning the proposed activity, appropriate procedures and administrative controls would be in place to maintain exposure to workers and other onsite personnel to within requirements established by DOE Orders and as low as reasonably achievable principles. The exposure received by onsite personnel is not expected to be greater than doses currently received from routine Hanford Site operations. Potential radiological doses to the public from routine operations would be extremely small and are not expected to result in any health effects. The risks to workers from chemical 
exposures, noxious vapors, burns, and other common industrial hazards are expected to be low; and would be minimized by training and the use of appropriate personal protective - equipment.

. The Tank C-106 ventilation system would keep emissions within applicable regulatory requirements for gaseous and particulate discharges. The tank ventilation system would maintain a slight negative pressure inside Tank C-106 in the event of planned or unforeseen openings of the tank risers.

Most of the liquid necessary for the sluicing operations, after the initial supernatant transfers, would be obtained from and returned to Tank AY-102. Since the amount of slurry is approximately equal to the amount of supernate used to sluice the waste, the overall amount of liquid in Tank C-106 at any one time is not expected to increase substantially. Additional liquid might be required for sluicing line clean-out, but would not be a significant increase in total volume used, and would be within the receiving tank's storage capacity.

The proposed action would result in the generation of solid waste during the life of the project. Such waste would be surveyed and disposed of in the Hanford Site Solid Waste Landfill if uncontaminated, or another applicable, permitted location if found to be contaminated with hazardous or radioactive constituents. At the completion of activities, noncontaminated equipment would be excessed where applicable, while contaminated materials and components would be packaged and stored in a permitted facility as is the current practice at the Hanford Site.

The 200 East Area, and the project location specifically, is a developed, highly disturbed area, and is currently under a vegetation management program which eradicates vegetation. No sensitive or critical plant or animal habitat would be affected. There are no animal species of special concern which are known to use the area exclusively.

The proposed action would not release any particulate matter, thermal releases, or gaseous discharges in significant amounts. Noise levels would rise only slightly for the duration of the project with the majority of the impact during the early construction phase. 
Leaks in the pump and sluice pits would be detected and controlled by special instrumentation during normal sluicing operations. Pit drains would return leaked wastes to - one of the two tanks involved for compatible storage. Leaks in the primary piping system of the transfer lines would be controlled by the secondary containment system (the outer pipe).

- This secondary containment system would be designed to collect released waste at a common point for detection and removal.

\section{Socioeconomic Impacts}

Existing Hanford workers will perform the preparations and sluicing. Therefore no socioeconomic impacts are expected from this action.

\section{Cumulative Impacts}

The proposed action is not expected to contribute substantially to the overall cumulative impacts from operations on the Hanford Site. Standard Operating Procedures will provide sufficient personnel protection such that exposure to radiological and chemical materials will be kept below DOE and contractor guidelines. Routine sluicing operations are not expected to significantly increase the amount of radioactivity released from total Hanford operations. In 1993, the maximally exposed offsite individual was exposed to $3.7 \times 10^{-3}$ millirem EDE from total air emissions, well below allowable limits set by state and federal regulations. The wastes generated from the activities would not add substantially to waste generation rates at the Hanford Site and would be stored or disposed in existing facilities.

\section{Environmental Justice}

Executive Order 12898, Federal Actions to Address Environmental Justice in Minority Populations and Low-Income Populations, requires that Federal agencies identify and address, as appropriate, disproportionately high and adverse human health or environmental effects of their programs and activities on minority and low-income populations. This proposed action would occur within the Hanford Site Boundary. Since no socioeconomic impacts or health effects are expected, it is not expected that there would be any 
disproportionate adverse effects to low-income or minority populations in the surrounding community.

\section{Impacts From Postulated Accidents}

In addition to environmental impacts that were postulated from routine operations, the EA discussed a range of reasonably foreseeable accident scenarios that could lead to environmental impacts.

An unfiltered release through a breach in the recirculation duct of the ventilation system using the supematant from Tank AY-102 as a source term was the accident scenario resulting in the highest dose to both onsite and offsite populations. The resulting 50-year committed dose from this potential accident was found to be $5.0 \times 10^{-1}$ roentgen equivalent man (rem) Effective Dose Equivalent (EDE) for the onsite maximally exposed individual (MEI) and $5.2 \times 10^{-4} \mathrm{rem}$ EDE to the offsite MEI. The likely mechanism for this accident is a vehicular accident, which has a remote probability of occurring if proper administrative controls are in place; however, it is possible that a Design Basis Earthquake (DBE) could lead to similar results. It is not expected that there would be any latent cancer fatalities to either onsite or offsite populations from this accident.

Other accidents analyzed in the EA consisted of a waste transfer line break, a breach in tank confinement as a result of a DBE, a leak developing in the tank as a result of the sluicing operation, and a spray leak from a jumper or connector. It should be noted that a DBE has the potential to initiate three of the accident scenarios; a breach in the recirculation duct, a $s_{\delta}$ lapture of the tank, and a break in the transfer lines. However, the impacts from the three accident scenarios, in terms of human bealth effects, would not be substantially greater than those described for the recirculation line breach except for a potentially greater amount of soil contamination. In addition, the EA examined the possibility of hazardous conditions existing in the receiver tank after sluicing. It was determined that no waste compatibility issues would result from the proposed action. It is not likely that the accidents which were analyzed would produce any cancer fatalities. 
Other accidents that were not analyzed, such as tank dome failure due to exceeded weight limits, tank bottom penetration by dropped equipment, riser damage due to excavation and construction activities, have been analyzed by other tank farm facilities. Finally, the EA addressed the possibility of a sudden release of steam from a submerged waste layer which could overpressurize the tank and lead to a failure of the ventilation system. These accidents were found to have smaller risk, where risk equals the product of probability and consequence, than the accidents described in detail in the EA.

DETERMTNATION: Based on the analysis in the EA, and after considering the preapproval review comments of the Yakama Indian Nation, I conclude that the proposed Past Practice Sluicing of Tank C-106 at the Hanford Site, Richland, Washington does not constitute a major federal action significantly affecting the quality of the human environment within the meaning of NEPA. Therefore, an EIS for the proposed action is not required.

Issued at Richland, Washington, this $17 \frac{\frac{1 / 6}{\text { day }}}{19}$ of Febnuary 1995.

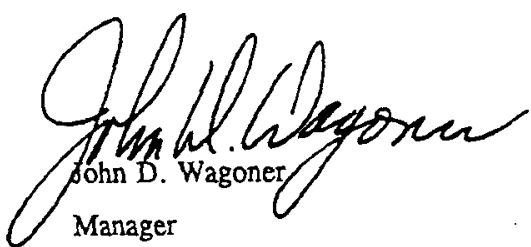

Richland Operations Office 
HNF-SD-WM-RPT-293 REV 0

This page intentionally left blank 
From: Waste Tank Process Control

71320-94-056

Phone: $373-2461$ R2-11

Date: December 6, 1994

Subject: PROJECT W-320 REVISED HEADSPACE CHARACTERIZATION

To: J. W. Bailey S6-12

$\begin{array}{llll}\text { CC: E. G. Allen } & \text { G6-02 } & \text { N. W. Kirch } 20 E \text { R2-11 } \\ \text { B. Apolinario } & \text { R2-70 } & \text { T. H. May } & \text { S6-12 } \\ \text { D. E. Bowers } & \text { S6-01 } & \text { D. A. Reynolds LOE RLen R2-11 } \\ \text { J. C. Conner } & \text { H4-61 } & \text { SDE File/LB }\end{array}$

Reference(s): (1) Internal Memo, S. D. Estey to J. W. Bailey, "Project W-320 Revised Headspace Characterization, " dated December 16, 1993.

(2) WHC-SD-WM-TI-565, "Radionuclide and Chemical Inventories for the Single-Shell Tanks," Rev. 1, dated 1993.

(3) DSTRP-CY94-041, "Aerosol Characteristics in the Offgas from a Pilot-Scale Sluicing Operation," (Draft), dated 1994, Pacific Northwest Laboratory, Richland, Washington.

This memo revises the tank $241-C-106$ (106-C) air stream characterization provided as design criteria for that tank's heating, ventilating and air conditioning (HVAC) unit for the Waste Recovery sluicing System (WRSS). Subsequent to the development of the previous airstream characterization (Reference 1) the project baseline has changed, providing for the use of conditioned water for sluicing in place of dilute complexed supernatant. Current planning calls for sluicing the tank 106-C sludge with $1,900,000$ liters $(500 \mathrm{kgal})$ of water adjusted to $0.05 \mathrm{M}\left[\mathrm{OH}^{-}\right]$and $0.011 \mathrm{M}\left[\mathrm{NO}_{2}^{-}\right]$. This revised characterization accounts for the baseline change as wel1 as incorporating numerous modeling refinements.

The primary non-atmospheric vapor constituent in tank 106-C headspace during sluicing operation is expected to be water. As a conservative assumption, the tank atmosphere is assumed to be saturated with water vapor. In the model described here, temperature effects only the concentrations of air and water in the tank headspace. Due to unknown WRSS operating characteristics and the potentially large energy input from the system pumps, an equilibrium water temperature is difficult to predict at present. The assumption of vapor-liquid equilibrium requires that the tank atmosphere be maintained at the same temperature as the circulating water. Tank atmospheric pressure is stated as $740 \mathrm{~mm} \mathrm{Hg}$ (14.3 psia). Based on estimates of the WRSS operating characteristics which consider the waste heat input to the process from normal pumping operations and radioactive decay, the temperature of the sluicing water may well be capable, depending upon the actual efficiencies 
of the WRSS, of reaching the operational temperature limit of $49^{\circ} \mathrm{C}\left(120^{\circ} \mathrm{F}\right)$. This temperature would require suspension of sluicing operations to allow the waste to cool by forced ventilation. However, the analyses indicate that $35^{\circ} \mathrm{C}\left(95^{\circ} \mathrm{F}\right)$ is a reasonable estimate of the equilibrium temperature for the circulating water and suspended wastes during Project W-320 sluicing operations should the WRSS perform as efficiently as desired. Additionally, $35^{\circ} \mathrm{C}\left(95^{\circ} \mathrm{F}\right)$ should be significantly warmer than the water temperature at the start of WRSS operations, allowing an ample operating margin for commencing the tank-to-tank sluicing activity. Therefore, $35^{\circ} \mathrm{C}\left(95^{\circ} \mathrm{F}\right)$ is chosen as the estimated equilibrium temperature for the circulating WRSS water or slurry solutions.

The presence of any significant quantities of ammonia and other volatile or semi-volatile vapor phase components in the headspace cannot be objectively justified by process knowledge or by available characterization data. Significant amounts of ammonia are not expected because none has been identified in the historical characterization data (Reference 2) and no source mechanism has been identified for its production in tank 106-C. This reasoning also applies to the presence of volatile organic compounds (VOC's). No characterization data on these compounds has been identified for tank 106-C sludge. The position that no VOC's exist in tank 106-C is supported by its thermal history in which its high temperatures indicate that any VOC's wouTd have long since been exhausted from the tank. The analysis of gaseous emissions from studied single shell tanks has revealed an essentially non-existent tritium source term. Additionally, no

characterization data on tritium concentrations has been identified for tank 106-C sludge. This characterization estimates that any concentrations of ammonia, VOC's and tritiated water in the atmosphere of tank 106-C during WRSS operations are below detectable 1 imits, which is further defined here as being non-existent.

During the retrieval operation, it is anticipated that the sluicers, spraying large amounts of pressurized liquids with entrained radioactive sludge, will also contribute to the tank airstream mass loading by way of mists and aerosols. The generation of the mists and aerosols is the only mechanism by which significant quantities of radioactive materials can be introduced into the tank atmosphere. Since the mists and aerosols are mechanically generated, even non-volatiles can be suspended in the headspace. The liquids and solids so suspended are assumed to be composed of process water adjusted to the proper corrosion control chemistry, and tank 106-C sludge, itself a mixture of water and insoluble solids. The characterization data (Reference 2) provides no information on the existence of soluble component concentrations in the sludge. If the limiting water saturation conditions are not reached in the tank atmosphere, the aerosol concentrations may be affected by tank temperature and pressure. Therefore, varying temperature and conditions of water saturation in the tank atmosphere may alter the component mass distributions in the sluice generated aerosols. However, because of the complexities of modeling aerosol behavior in an unsaturated atmosphere, this characterization specifies that the aerosol contribution to the airstream mass loading will not change based on variations in atmospheric temperature, pressure, or degree of saturation. 
The limit for slurry transfer from tank 106-C to tank 102-AY is $30 \mathrm{wt} \%$ solids, and a limit of $10 \mathrm{wt} \%$ solids is assumed for the maximum amount of solids in the sluice flow being returned to tank 106-C. The characterization data, as shown in Attachment 1 , indicates that tank 106-C sludge contains no soluble solids (salts) and is approximately $41 \%$ by weight insoluble solids and $59 \%$ by weight water. This analysis assumes that the maximum activity of the sluice stream will be reached when a 10 wt\% solids slurry is uniformly built-up throughout the WRSS. This corresponds to the situation where no settling of insoluble solids occurs during sluicing operations. With a water volume of $1,900,000$ liters (500,000 gallons), a $10 \mathrm{wt} \%$ solids slurry would be initially reached after about $600,000 \mathrm{~kg}$ sludge in tank $106-\mathrm{C}$ (about $56 \%$ of the total estimated sludge content in tank 106-C removal from tank 106-C would require that an equal amount of sludge settles in the receiving tank, 102-AY, to prevent exceeding the solids loading 1 imit in the sluice stream. These calculations are shown in Attachment 2.

Due to the many concerns regarding the complexities of aerosol generation and characterization as applied to the WRSS operations, Project $W-320$ commissioned PNL testing in hopes of refining some of the estimates made in the previous airstream characterization (Reference 1). The findings of the PNL testing activities are described in Reference 3, which indicate that earlier estimates of aerosol loading were lacking in conservatism. Descriptive information can be found for both wet aerosols (aerosols with insoluble solids and liquids of water and soluble solids (salts) in solution) and dry aerosols (the wet aerosols after evaporation to dryness). Results of the PNL testing indicated that insoluble solids in the aerosols would preferentially settle out of the tank headspace when compared to 1 iquid aerosols, such that the ratio of aerosol insoluble solids mass to liquid mass is only approximately one-half that of the source stream sprayed into tank $106-\mathrm{C}$.

The PNL testing referenced by this analysis was based on a feed slurry characterized by $4.4 \%$ soluble solids, $8.9 \%$ insoluble solids, and a balance of water. this provided a breakdown of the aerosols by total mass concentration, composed of soluble solids (dissolved salts), insoluble solids, and water. These test results were scaled to estimate the behavior of the aerosols which will be generated by the sluicing operations in tank 106-C. These calculations is shown in Attachment 2. This Attachment provides the mass fraction values and subsequent scaling calculation upon which the aerosol composition is based.

With assumed characterizations of tank 106-C siudge and conditioned water, Attachment 3 determines the aerosol composition in the tank $106-C$ headspace. The results show a total aerosol mass of $313 \mathrm{mg} / \mathrm{m}^{3}$. Of this total, $95 \%$ of the aerosol mass is water, $4.8 \%$ of the mass is the insoluble solids from tank 106-C sludge, and $0.2 \%$ of the mass is the soluble solids formed by the $\mathrm{NaOH}$ and $\mathrm{NaNO}_{2}$ added to adjust water chemistry. These component distributions indicate an aerosol activity of $202 \mu \mathrm{Ci} / \mathrm{m}^{3}$, which is contained entirely in the suspended insoluble solids. ${ }^{89 / 90} \mathrm{Sr}$ comprises about $85 \%$ of the total airstream activity. 
The size distribution ranges for the aerosols are reproduced from Reference 3 as follows:

Bulk Aerosol (Water, Soluble Solids, Insoluble Solids)
Aerodynamic Particle Diameter Range $\%$ of Total Wet Aerosol Mass $\therefore$

$\begin{array}{ll}>10 \mu \mathrm{m} & 60-70 \\ 1-10 \mu \mathrm{m} & 10-20 \\ <1 \mu \mathrm{m} & 10\end{array}$

Dry Aerosol (Soluble Solids, Insoluble Solids) Aerodynamic Particle Diameter Range q of Total Wet Aerosol Mass

$\begin{array}{ll}>10 \mu \mathrm{m} & 30 \\ 1-10 \mu \mathrm{m} & 50 \\ <1 \mu \mathrm{m} & 20\end{array}$

In conclusion, the estimated characterization of the airstream from the tank 106-C atmosphere entering the HVAC system during slutcing operations is summarized as follows:

- water saturated air at $35^{\circ} \mathrm{C}\left(95^{\circ} \mathrm{F}\right), 740 \mathrm{~mm} \mathrm{Hg}(14.3 \mathrm{psia})$

- an aerosol mass loading of $313 \mathrm{mg} / \mathrm{m}^{3}$

- an aerosol composition of $4.8 \mathrm{wt} \%$ insoluble solids, $0.2 \mathrm{wt} \%$ $\mathrm{NaOH}$ and $\mathrm{NaNO}_{2}$ as soluble solids from tank 106-C sludge, and $95.0 \mathrm{wt} \%$ water

- an activity of $202 \mu \mathrm{Ci} / \mathrm{m}^{3}$

- an ${ }^{129} \mathrm{I}$ concentration of $7.1 \times 10^{-6} \mu \mathrm{Ci} / \mathrm{m}^{3}$

- no detectable concentrations of ammonia, VOC's, and ${ }^{3} \mathrm{H}$ in the tank atmosphere.

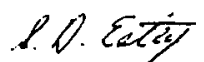

S. D. Estery, Engineer

Waste Tanks Process Englneering

mjg

Attachments 
Characterization Date is from R. J. Ven Vleat, 1993, "Radionuclide and Chemical tnventories for the Singte-Shall Taniks" WHC-SD-WM-TI-585, Rev. 1, Westinghouse Hantord Company, Riehland, Washington

Assumptions:

This analysis use the eharacterization date reported in the source document for the tank studge.

The charecterization date is sasumad to ba raported on a bulk sumple besis (i.e., per $\mathrm{kg}$ or per liter of the sludge sample).

This enalvase considers the non-equeout cenponents of the sludge to be ineoluble selids, and the non-equeous component:

in the interttitial laquids to be soluble solide (however, the reference liats no chemical characterization dets an interstital liquids).

The reference doucmant lists'the density of tank $106-C$ sludge at both 1.75 and 1.43 .

The spd. of 1.43 is chosin for this air streem characterizntion calculations.

This cheracterization atsumes that draineble liquid llated in the reterence socumem is not the same as the intersoitlal liquid in the sludge.

Because the drainable liquid ectivites ore so much lower then the studge ectivities,

any errors that would be introduced if this aesumption is wong are alight.

The reported activities of the eludge are adjusted to what should be expected from a $32 \mathrm{MW}$ (1 $10 \mathrm{kBtu} / \mathrm{hr}$ ) decay heat foad.

reported sludge spg.

Components

Components
Aluminum
Antimony
Arsenic
Barium
Boron
Calcium
Carium
Chromium
Copper
Iron
Load
Magnasium
Manganese
Neodymium
Phoaphorout
Selarium
Siticon
Silver
Sodium
Strontium
Thalium
Titanium
Zirconium

Sum of non-aqueous components

Water

Total

Calculated interstitial liquid spg.

Calculated Insoluble solids spg. =

Radionuctidos

activity of 106 -

insoluble solids
Calculatod

(uCi/kg studge

mass of $106-$

insoluble solids

( $m$ g/kg sludge)

1.15E + 05

$2.90 E+03$

$3.90 E+02$

$3.50 E+02$

$3.50 E+02$

$1.90 E+03$

$4.90 \mathrm{E}+02$

$1.75 E+03$

$+02$

$2.50 E+03$

$4.20 E+02$

$4.50 \mathrm{E}+03$

5. $\mathrm{BOE}+\mathrm{O} 2$

$7.30 \mathrm{E}+03$

$1.40 E+03$

$2.60 E+04$

2.10E + 03

$1.56 \mathrm{E}+0.5$

$1.10 E+02$

$1.20 E+03$

$3.30 E+02$

.09E + 02

$4.09 E+05$

-

N/A

$2.05 E+00$

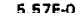

2.13E +03

4.75E + 06

$5.26 E+02$

$1.94 \mathrm{E}-01$

$7.92 \mathrm{E}+05$

$6.46 \mathrm{E}+03$

2.52E + 03

$5.56 E+06$
Aeported
meas of $106-C$ (mgliter sludga) (mg/kg sludgal

$0.00 E+00$

$0.00 E+00$

$0.00 E+\infty$

$0.00 E+\infty 0$

$0.00 E+\infty 0$

$0.00 E+00$

$0.00 E+00$

$0.00 E+00$

$0.00 E+00$

$0.00 E+00$

$0.00 E+00$

$0.00 E+00$

$0.00 E+00$

$0.00 E+00$

$0.00 E+00$

$0.00 E+00$

$0.00 E+\infty 0$

$0.00 E+00$

$0.00 E+00$

$0.00 E+00$

$0.00 E+00$

$0.00 E+00$

$0.00 E+00$

$0.00 E+00$

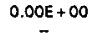

$0.00 E+00$

$0.00 E+00$

$0.00 E+00$
Calculated

mass of $106-C$

soiuble solids

(mg/kg sludge)

$0.00 E+00$

$0.00 E+00$

$0.00 E+00$

$0.00 E+00$

$0.00 \mathrm{E}+00$

$0.00 E+00$

$0.00 E+00$

$0.00 E+00$

$0.00 E+00$

$0.00 E+00$

$0.00 E+00$

$0.00 E+00$

$0.00 E+00$

$0.00 E+00$

$0.00 E+00$

$0.00 E+00$

$0.00 E+00$

$0.00 E+00$

$0.00 E+00$

$0.00 E+00$

$0.00 E+00$

$0.00 E+00$

$0.00 E+00$

$0.00 E+00$

$\begin{array}{cc}0.00 E+00 & 4.09 E+05 \\ - & 5.91 E+05 \\ - & 1.00 E+06\end{array}$

Calculated

mases of $108-C$

bulk sludge

(mg/kg tiudge)

$1.16 E+05$

$2.90 E+03$

$3.90 E+02$

$3.50 E+02$

$3.50 E+02$

$1.90 E+03$

$4.90 E+02$

1. $76 \mathrm{EE}+03$

$3.00 E+02$

$8.24 E+04$

$2.50 E+03$

$4.20 E+02$

$4.50 E+03$

$5.60 E+02$

$7.30 \mathrm{E}+03$

$1.405+03$

$2.60 E+04$

$2.10 E+03$

1.56E + 05

1. $10 E+02$

1. $20 E+03$

$3.30 \mathrm{E}+02$

$4.09 E+02$

$6.00 E+02$

$5.91 E+05$
$1.00 E+06$
239/240 Pu

Total
Calculated

Calculated

activity of $108-C$

interstital fiquids interstital liquids

(uCi/liter sludgel (uCi/kg sludge)

$0.00 E+00$

$0,00 E+00$

$0.00 E+O O$

$0.00 \mathrm{E}+00$

$0.00 E+00$

$0.00 E+O 0$

$0.00 E+00$

$0.00 E+O O$

$0.00 E+00$
$0.00 E+00$

$0.00 E+00$

$0.00 E+00$

$0.00 E+00$

$0.00 E+00$

$0.00 E+\infty 0$

$0.00 E+00$

$0,00 E+00$

$0.00 E+00$
Calculated*

Calculated Cativity of 106-C soluble solids bulk sludge (uCi/kg sludget (uCi/kg sludge)

$\begin{array}{lr}0.00 E+00 & 5.57 E-01 \\ 0.00 E+00 & 2.13 E+03 \\ 0.00 E+00 & 4.75 E+06 \\ 0.00 E+00 & 5.26 E+02 \\ 0.00 E+00 & 1.94 E-01 \\ 0.00 E+00 & 7.92 E+05 \\ 0.00 E+00 & 6.46 E+03 \\ 0.00 E+00 & 2.52 E+03 \\ 0.00 E+00 & 5.56 E+06\end{array}$

- calculated velues are adjusted to equats to the $32 \mathrm{~kW}(110 \mathrm{kBtu} / \mathrm{hr})$ tank decay heat load by multiplying raported values by 2.4 
Determination of sluice stream composition at the limiting activity concentration.

The first issue is to determine the composition of the conditioned water to be used in the WRSS. What amount of $\mathrm{NaOH}$ and $\mathrm{NaNO} 2$ must be mixed with what amount of process water so that the resulting solution meets DST corrosion control chemistry requirements (chosen as an $\mathrm{OH}$ concentration of $0.05 \mathrm{M}(0.85 \mathrm{~g} /)$ and an NO2- concentration of $0.011 \mathrm{M}(0.51 \mathrm{~g} / \mathrm{l}))$ ?

The following information is known or assumed:

Water in the conditioned water solution has a spg. of 1.000 .

$1 \mathrm{~g} \mathrm{NaOH}$ contains $0.425 \mathrm{~g} \mathrm{OH}$ - and occupies a volume of $0.334 \mathrm{ml}$ in solution. This gives dissolved $\mathrm{NaOH}$ an apparent spg. of $2994 \mathrm{~g} /$.

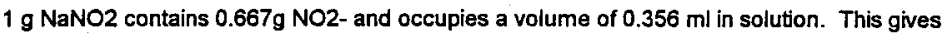
dissolved NaNO2 an apparent spg. of $2809 \mathrm{~g} /$.

It is assumed that any volume changes upon mixing the caustic and salt with water is Indlcated by the value of the apparent spg. of that species in the solution.

The following relationships can be developed:

$V w$ is the volume fraction of water in the conditioned water solution.

Voh is the volume fraction $\mathrm{NaOH}$ in the conditioned water solution.

$\mathrm{VnO} 2$ is the volume fraction of $\mathrm{NaNO} 2$ in the conditioned water solution.

The system of equations to be solved is:

$V w+V o h+V_{n o 2}=1.0$ (liters)

Voh(liters) $\left.{ }^{*} 2994 \mathrm{~g} / /^{*} 0.425 \mathrm{~g} / \mathrm{g}\right) /\left(\mathrm{Vw}+\mathrm{Voh}+\mathrm{Vno}_{\mathrm{n}}\right) \mathrm{l}=0.85 \mathrm{~g} / \mathrm{l}$

Nno2(liters) $\left.{ }^{*} 2809 \mathrm{~g} / /^{*} 0.667 \mathrm{~g} / \mathrm{g}\right) /\left(V_{w}+V_{0 h}+V_{n o 2}\right) \mid=0.51 \mathrm{~g} / l$

The equation solution uses the Mathcad 4.0 program (1), starting from initial guesses for $V w$, Voh and Vno2. Specific gravity of the resulting solution is stated as spgw:

$V w:=0.999$

Voh $:=0.0005$

Vno2 : $=0.0005$

(1) copyright 1991-1993 by MathSoft, Inc., 201 Broadway, Cambridge, MA 02139 
given

$\mathrm{Vw}+\mathrm{Voh}+\mathrm{Vno2}_{\mathrm{no}}=1$

$\frac{V o h \cdot 2994 \cdot 0.425}{V w+V o h+V n o 2}=0.85$

$\frac{V_{n o 2} \cdot 2809 \cdot 0.667}{V w+V o h+V n o 2}=0.51$

find $(V w, V o h, V n o 2)=\left(\begin{array}{l}0.99906 \\ 0.000668 \\ 0.000272\end{array}\right)$

water $:=0.99906 \cdot 1.000$

water $=0.99906$

$\mathrm{kg}$ of water per liter of conditioned water

$\mathrm{NaOH}:=0.000668 \cdot 2.994$

$\mathrm{NaOH}=0.00200$

$\mathrm{kg}$ of $\mathrm{NaOH}$ per liter of conditioned water

NaNO2 $:=0.000272 \cdot 2.809$

$\mathrm{NaNO} 2=0.00076$

$\mathrm{kg}$ of NaNO2 per liter of conditioned water

spgw := water $+\mathrm{NaOH}+\mathrm{NaNO} 2$

$\operatorname{spgw}=1.00182$

spg. of conditioned water $(\mathrm{kg} / \mathrm{l})$

chem : $=\mathrm{NaOH}+\mathrm{NaNO} 2$

chem $=0.00276$

$\mathrm{kg}$ of $\mathrm{NaOH}$ and $\mathrm{NaNO} 2$ per liter of conditioned water

masswater := $\frac{\text { water }}{\text { spgw }}$

masswater $=0.99724$

$\mathrm{kg}$ of water per $\mathrm{kg}$ conditioned water

$\operatorname{massNaOH}:=\frac{\mathrm{NaOH}}{\text { spgw }}$

mass $\mathrm{NaOH}=0.00200 \quad \mathrm{~kg}$ of $\mathrm{NaOH}$ per $\mathrm{kg}$ conditioned water

massNaNO2 : $=\frac{\text { NaNO2 }}{\text { spgw }}$

massNaNO2 $=0.00076 \mathrm{~kg}$ of NaNO2 per $\mathrm{kg}$ conditioned water

The result is that the volume fraction of process water $=0.99906$, the volume fraction of the added $\mathrm{NaOH}$ is 0.000668 , and the volume fraction of the added $\mathrm{NaNO} 2$ is 0.000272 . One liter of chemically conditioned water will contain 999.06 grams of water with 2.00 grams $\mathrm{NaOH}$ and 0.76 grams $\mathrm{NaNO} 2$ in solution. The spg. of the conditioned water is 1.00182 . 
The water volume chosen for the WRSS upon which the airstream characterization is based is $1,900,000$ liters $(500,000)$ gallons of water adjusted to a [OH-] of $0.05 \mathrm{M}$ and an [NO2-] concentration of $0.011 \mathrm{M}$. The model assumes that early in the sluicing operation the slurry solids concentration builds up uniformly to $10 \mathrm{wt} \%$, and until this point is reached the ratio of the concentration of insoluble solids to soluble solids is equal to the ratio of those solids in the bulk 106-C sludge adjusted for $\mathrm{NaOH}$ and $\mathrm{NaNO} 2$ added to the water for corrosion control. At this point, a given amount of sludige from tank 106-C will have been siuiced out and converted into the uniform 10 wt\% solids loading of the slurry in the WRSS. Thereafter, the 10 wt\% solids limit must not be exceeded in the sluice header. Therefore, any further transfer of sludge out of tank 106-C must be accompanied by a continuous settling out of insoluble solids in tank 102-AY.

Knowing the volume and composition of water in the WRSS, a simple mass balance allows a determination of the amount of sludge which must be sluiced from tank 106-C to achieve a uniform $10 w$ t\% solids siurry throughout the system.

mass fraction $(\mathrm{mf})=$ mass of all solids $/$ (mass of all solids + mass of all water)

$\mathrm{mf}=$ mass of (sludge solids $+\mathrm{NaOH}+\mathrm{NaNO} 2)$

mass of (sludge solids $+\mathrm{NaOH}+\mathrm{NaNO2}+$ interstitial water + process water)

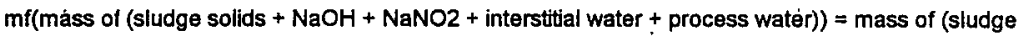
solids $+\mathrm{NaOH}+\mathrm{NaNO} 2)$ mass of (sludge solids) $-\mathrm{mf}$ (mass of sludge (solids + interstitial water) $=\mathrm{mf}$ (mass of $(\mathrm{NaOH}+$ $\mathrm{NaNO} 2+$ process water)) - (mass of $(\mathrm{NaOH}+\mathrm{NaNO} 2)$ )

However, the mass of sludge solids + interstitial water is equal to the mass of sludge, and the ratio of the mass of sludge solids to the mass of sludge is known ( 0.409 from Attachment 1$)$

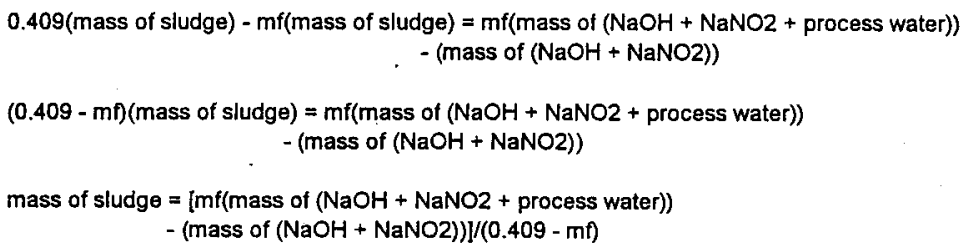

solids : $=0.1$ mass fraction $(\mathrm{mf})$ of solids in slurry

$w:=1900000$ volume of water in WRSS (l)

insf : $=0.409$ mass fraction of insoluble solids in 106-C sludge (from Attachment 1 )

solf : $=0.000$ mass fraction of soluble solids in 106-C sludge (from Attachment 1)

sludgef : $=$ insf + solf mass fraction of total solids in 106-C sludige

intf : $=1$ - sludgef $\quad$ mass fraction of interstitial water in 106-C sludge 
HNF-SD-WM-RPT-293 REV 0

Attachment 2

Page 4 of 6

mass : $=\frac{\text { solids }(\text { spgw } \cdot \mathbf{w})-w \cdot \text { chem }}{\text { sludgef }- \text { solids }}$

mass of 106-C sludge which must be sluiced out of the tank to first achieve a 10 wt\% solids slurry $(\mathrm{kg})$

mass $=5.99013 \cdot 10^{5}$

insf mass $=2.44996 \cdot 10^{5}$,

solf mass $=0.00000$

corresponding insoluble and soluble masses in the above sludge mass:

$\frac{\text { insf.mass }+ \text { solf } \text { mass }+w \cdot \text { chem }}{w \cdot s p g w+\text { mass }}=0.10000$ check of the mass fraction of solids in this slurry

$\overline{\text { insf } \text { mass }+ \text { solf } \cdot \text { mass }+w \text {-chem }}=0.97901$ fraction of solids that are from $106-\mathrm{C}$ insoluble solids

$\overline{\text { insf }} \frac{\text { mass }+ \text { solf } \text { mass }}{\text { mass }+w \cdot c h e m}=0.00000$ fraction of solids that are from 106-C soluble solids

$\frac{\text { w.chem }}{\text { insf-mass }+ \text { solf } \text { mass }+ \text { w.chem }}=0.02099$ fraction of solids that are from added $\mathrm{NaOH} \&$ NaNO2

thoslurryC106 is the density of the sluice stream returned to tank 241-C-106 (kg/)). It is assumed that the clear solution density (soluble solids in water) is given by the relationship:

Solution Density $=0.0085935$ (wt\% salt) +0.99345 . The mass and volume of the suspended

insolubile solids is then factored into the density equation:

(mass of insouble solids + mass of solution)/(volume of insoluble solids + volume of solution)

pslurryCl06 : $=\frac{\text { mass }+w \cdot \text { spgw }}{\left(\frac{\text { insf } \cdot \text { mass }}{2.05}\right)+\left[\frac{w-\text { spgw }+ \text { solf } \cdot \text { mass }+ \text { intf } \cdot \text { mass }}{0.0085935 \cdot\left(100 \cdot \frac{\text { solf } \cdot \text { mass }+w \cdot c h e m}{\text { solf } \cdot \text { mass }+ \text { intf } \cdot \text { mass }+w \cdot \text { spgw }}\right)+0.99345}\right]}$

psiurryC106 $=1.04824$

C106solwt\% : $=\frac{\text { (solf.mass }+ \text { w.chem) } \cdot 100}{w \cdot s p g w+\text { mass }} \quad \begin{aligned} & \text { wt } \% \text { soluble solids in the sluice stream returned to tank } \\ & 241-C-106\end{aligned}$

C106solwt $\%=0.20986$

C106insolw1\%: $:=\frac{\text { (insf-mass) } \cdot 100}{w \cdot s p g w+\text { mass }} \quad \begin{aligned} & w \% \text { insoluble solids in the siuice stream returned to tank } \\ & 241-C-106\end{aligned}$

C106insolwt $\%=9.79014$

$\mathrm{Cl} 06 \mathrm{H} 2 \mathrm{Owt} \%:=\frac{(\text { water } \cdot \mathrm{w}+\text { intf } \cdot \text { mass }) \cdot 100}{\mathrm{w} \cdot \mathrm{spgw}+\text { mass }}$

$w t \%$ water in sluice stream returned to tank 241-C-106

$\mathrm{C} 106 \mathrm{H} 2 \mathrm{Owt} \%=90.00000$ 
Reference 3 presents scaling equations to be used to estimate the aerosol densities present in the headspace of tank 241-C-106 during sluicing. The expected sluicing slurry composition is ratioed to the test slurry composition and the experimental results which were determined. From the process mass balance information, this $10 \mathrm{wt} \%$ solids slurry has a spg. of 1.04545 and is composed of 90 wt\% water, 6.43 wt\% insoluble solids, and 3.57 wt\% soluble solids. The information below is taken from Reference 3 describing the test condition with both soluble and insoluble solids:

$$
\begin{array}{ll}
\text { testmgsol : }=15.1 & \mathrm{mg} / \mathrm{m} 3 \text { of soluble aerosols in test air (dry basis) } \\
\text { testsolwt\% }:=4.4 & \text { wt\% soluble solids in pilot scale test sluice stream } \\
\text { testrmginsol }:=14.1 & \mathrm{mg} / \mathrm{m} 3 \text { of insoluble aerosols in test air (dry basis) } \\
\text { testinsolwt } \%:=8.9 & \text { w\% insoluble solids in test sluice stream } \\
\text { pslurrytest : }=1.09 & \text { slurry density of test fluid }(\mathrm{kg} / \mathrm{l})
\end{array}
$$

The above parameters are used in the following equations to determine the masses of the various areosol compenents in the tank 241-C-106 airstream:

$$
\begin{aligned}
& \mathrm{xsol}:=\left(\text { testmgsol } \cdot \frac{\mathrm{Cl06 \text {solwt\% }}}{\text { testsolwt\% }}\right) \cdot\left(\frac{\text { sslurryC106 }}{\text { pslurrytest }}\right) \begin{array}{l}
\mathrm{mg} / \mathrm{m} 3 \text { (dry aerosol basis) of soluble aerosol } \\
\text { expected in tank } 241-\mathrm{C}-106
\end{array} \\
& \text { xinsol := (testmginsol } \left.\cdot \frac{\mathrm{Cl} \text { (06insolwt\% }}{\text { testinsolwt\% }}\right) \cdot\left(\frac{\text { pslurryCl06 }}{\text { pslurrytest }}\right) \quad \begin{array}{l}
\mathrm{mg} / \mathrm{m} 3 \text { (dry aerosol basis) of insoluble aerosol } \\
\text { expected in tank } 241-\mathrm{C}-106
\end{array} \\
& \mathrm{xtd}:=\mathrm{xsol}+\mathrm{xinsol} \quad \text { total } \mathrm{mg} / \mathrm{m} 3 \text { (dry aerosol basis) expected in tank 241-C-106 }
\end{aligned}
$$

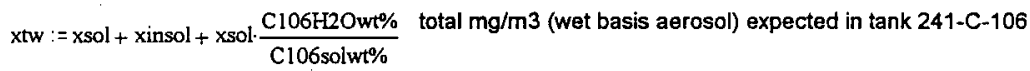

Solving the four equations yields:

$$
\begin{aligned}
& x \text { sol }=0.69261 \\
& x i n s o l=14.91601 \\
& x t d=15.60861 \\
& x t w=312.63925
\end{aligned}
$$

and, calculating the mass percentages of soluble solids, insoluble solids, and both combined:

$$
100 \cdot \frac{x \text { sol }}{x t w}=0.22154 \quad 100 \cdot \frac{x i n s o l}{x t w}=4.77100 \quad 100 \cdot \frac{x t d}{x t w}=4.99253
$$




\section{Code Quantity}

slurry solids fraction $=$

conditioned water volume $=$ conditioned water density conditioned water salt concentration $=$

-106-C Sludga Mass Fractions "

\section{fraction insoluble $=$}

traction soluble $=$

fraction all solids $=$

fraction interstitial water $=$

mass $=$

-10wt \% Solids Slurry Mass Fractions"

solids $=$

106-C insoluble solids =

106-C soluble solids =

$\mathrm{NaOH} \& \mathrm{NaNO} 2$ solids

slurry density $=$

"10wt \% Solids Slurry Mass Parcentages"

$\begin{array}{lr}\text { C.106 solwt } \%= & 2.10 E-01 w t \% \\ \text { C.106 insolwt } \%= & 9.79 E+00 w t \% \\ \text { C-106H2Owt } \%= & 9.00 E+01 w t \%\end{array}$

-Data from Reference 3"

testmgsol $=$

testsolwt $\%=$

testmginsol $=$

testinsolwt \% =

test șlurry density $=$

-Calculated Aerosot Qusntities"

xsol $=$

xinsol

$x \operatorname{td}=$

$\mathbf{x t} \mathbf{w} \cdot \mathbf{=}$

$100^{\circ} \times$ sol/ $\times$ tw $=$

$100^{\circ}$ xinsollytw

$100^{\circ} \times \mathrm{xtd} / \mathrm{xtw}=$
Value Units

1.00E-01 (dimensionless)

$1.90 E+06$ liter

$1.00 \mathrm{E}+00 \mathrm{~kg} / \mathrm{iter}$

$2.76 \mathrm{E}-03 \mathrm{~kg}$ hite

4.09E-01 (dimensionless) $0.00 E+00$ (dimensionless)
$4.09 E-01$ (dimensionless) 5.91E-01 (dimensionlass)

$5.99 E+05 \times 9$

1.00E-01 (dimensionless) 9.79E-02 (dimansionless)

$0.00 E+00$ (dimensionless)
$2.10 \mathrm{E}-03$ (dimensionless)

$1.05 \mathrm{E}+00 \mathrm{~kg} / \mathrm{iter}$

$1.51 \mathrm{E}+01 \mathrm{mg} / \mathrm{m}^{3}$

$4.40 E+00 w t \%$

$1.41 \mathrm{E}+01 \mathrm{mg} / \mathrm{m} 3$

a. $90 \mathrm{OE}+00 \mathrm{wt} \%$

$1.09 \mathrm{E}+00 \mathrm{~kg} / \mathrm{liter}$

$6.92 E-01 \mathrm{mg} / \mathrm{m} 3$

$1.49 \mathrm{E}+01 \mathrm{mg} / \mathrm{m}^{3}$

$1.56 \mathrm{E}+01 \mathrm{mg} / \mathrm{m} 3$

3.13E + $02 \mathrm{mg} / \mathrm{m} 3$

2.21E-01 w: $\%$

4.77E+00 wt \%

$4.99 E+00 w+\%$
Equations (using Coded identifiers for the applicable Quanthtos) \& Notes

..... given sluice flow solids limit

.... value from conditioned water mass balonce - page 2

.... value from conditioned water mass balonce - page 2

..... value from conditioned water mass balance - paga 2

\section{i... value from Attachment 1 \\ .... value from Attachment 1 \\ .... value from Attechment \\ .... value from Attechment}

$\left(a^{*} b^{*} c-b^{*} d / /(a-a) \quad \ldots .\right.$. mass of sludge required to form the limiting slurry concentration

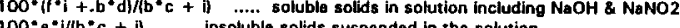

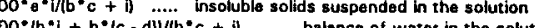

$\cdot 1 /(a=b+i) \ldots . .$. the corresponding fraction of soluble slurry solids from $C \cdot 106$ sludge

$(* i /(a) b+i) \ldots .$. the corresponding fraction of insoluble slurry solids from $C-106$ sludge

$b^{*} d /\left(a^{*} b+i\right) \quad . . .$. the corresponding fraction of $\mathrm{NaOH} \& \mathrm{NaNO} 2$ from conditioned water in the slurry

$\left(i+b^{*} c\right) /\left(e^{*} i / 2.05\right)+\left(\left(b^{*} c+\left(f^{*} i+h^{*} n /\left(1 / 0.0085935^{*} 100^{*}\left(f^{*} i+b^{*} d\right)+0.99345\right) /\left(t^{*} i+h^{*}\right)+b^{*} c\right) \|\right)\right.$

... specific graviry of the $10 \mathrm{wr} \%$ solids slurry with maximum radionuclide content

( $h{ }^{*} i+b *(c-d) /(b * c+i) \quad \ldots .$. balance of water in the solution

. obteined from test run in Roference 3

.... obtained from test iun in Roloron

.... obtained trom test run in Raference 3

..... obtained from test run in Reference 3

.... obtained from test run in Relerence 3

.... obtained from scaling equations given in Reference 3

$\left(r^{*} \mathrm{o} / \mathrm{s}\right)^{\bullet}(\mathrm{n} / \mathrm{M}) \quad \ldots . .$. soluble solids concentration in aerosol including $\mathrm{NsOH}$ and $\mathrm{NaNO}$

$\left(t^{*} \mathrm{p} / \mathrm{u}\right\}^{*}(\mathrm{n} / \mathrm{v}) \quad \ldots .$. insoluble solids concentration in aerosol

$w+x \quad \ldots .$. total solids concentration in aerosol

$w+x+w^{*}$ a/o ..... total aerosol concentration

$100^{\circ} \mathrm{w} / 2$..... mass \% soluble solids in aerosol

$100^{\circ} x / 2 \quad \ldots .$. mass $\%$ insoluble solids in arrosol

$100^{\circ} y / z \quad \ldots .$. mass \% total solids in aerosol 


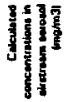
18

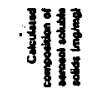

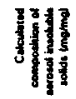

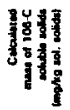

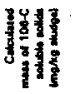

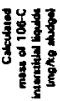<smiles>[Si]#[W]#[W]</smiles>

8 娄这

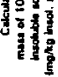

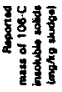

88888888888888888888888888888 8.8.80

998888888888888888888888888

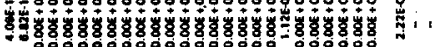

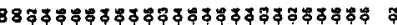

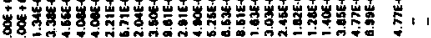

8888888888888888888888888888

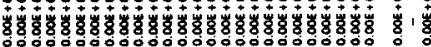

88888888888888888888888888888

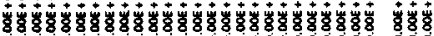

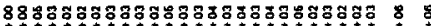

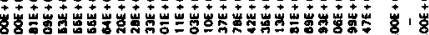
8
8
4
8
8
0
0

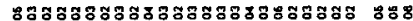

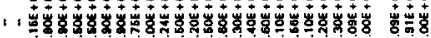

童等

ชิ fla

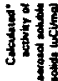

888888888

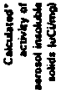

话起

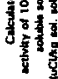
影产事

88888888

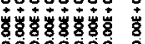

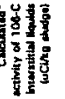

$88888888 \quad 8$

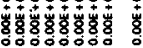<smiles>N#CC#N</smiles>

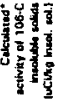

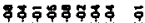

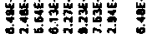

888888888

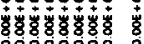
000000:

ชี

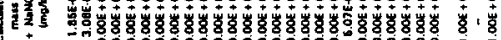

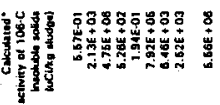

8두요 888888888

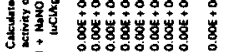

888888888

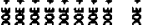
0

88 ำำรว

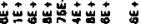

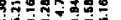

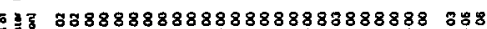

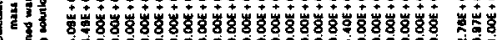
害

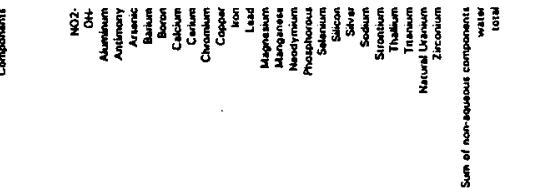

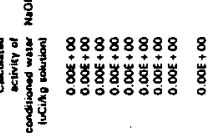
$\frac{8}{8}$ 
From: Waste Tanks Process Engineering

Phone: $\quad 373-2461$ R2-11

Date: May 9, 1995

- Subject: TANK 241-C-106 HEADSPACE ORGANIC CONCENTRATION DURING PROJECT $W-320$ SLUICING OPERATIONS

To:

$\begin{array}{ll}\text { CC: J. W. Bailey } & S 6-12 \\ \text { W. B. Barton } & R 2-11 \\ \text { N. A. Homan } & H 6-25 \\ \text { T. H. May } & S 6-12 \\ \text { SDE File/LB } & \end{array}$

References: (1.) Internal Memo, 5. D. Estey to J. W. Bailey,
"PROJECT W-320 REVISED HEADSPACE CHARACTERIZATION," dated December $\sigma$, 1994.

(2) WHC-SD-WM-TI-578, "IOI-AY, 102-AY, \& 106-C Data Compendium;" Rev. 1, dated 1994.

(3) Internal Memo, 5. O. Estey to J. W. Bailey, "PROJECT W-320 REVISED HEADSPACE CHARACTERIZATION, " dated December 16, 1993.

Reference (1) provides the latest direction for the coricentration and speciation of waste materials present in the atmosphere of tank 241-C-106 during sluicing operations. However, the waste characterization upon which the atmospheric model was based contained no provisions for the presence of organics, and therefore the model predicted that no organics would be present in the tank headspace. Project $y-320$ has since identified the need to specify the concentration of TOC present in the tank headspace during sluicing operations, as weil as speciation of the constituents whose carbon atoms contribute to the value of TOC.

Reference (2) surveys the availabie characterization data for waste in tank 241-C-106 and provides a basis for the mass concentration of TOC contained within the tank waste. This memo will project an expected concentration of TOC in the headspace and will offer an estimated characterization of the TOC. Reference (3) provided a basis for the speciation of TOC in the headspace, and that basis wi11 be expounded upon in this memo.

The mass of TOC in the sludge in tank 241-C-106 is taken from Reference (2) as $6.06 \mathrm{grams} / \mathrm{kg}$, or a mass fraction of 0.00606 . It is assumed that the concentration of solids (both soiuble and insoluble) suspended in the headspace as aerosols has the same mass fraction of TOC. The suspended mass of aerosol sol ids is taken from Reference (1) as $15.6 \mathrm{mg} / \mathrm{m}^{3}$. Therefore, the mass of TOC suspended in aerosol form is assumed here as:

$$
\left(15.6 \mathrm{mg} / \mathrm{m}^{3}\right) \star(0.00606)=0.0945 \mathrm{mg} / \mathrm{m}^{3} \mathrm{TOC}
$$


J. P. Harris

Page 2

May 9, 1995

From Reference (3), percentages of carbon in the TOC value are present as the carbon contained in salts of organic acids. These include the sodium salts of ethylenediaminetetraacetic acid (EDTA), N-hydroxyethyl-

" ethylenediamine triaacatic acid (HEDTA), citric acid, and various degradation products of these materiais in the following amounts:

$\begin{array}{lr}\text { sodium salt of EDTA } & 5.3 \% \\ \text { sodium salt of HEDTA } & 5.2 \% \\ \text { sadium citrate } & 29.5 \% \\ \text { sodium oxalate } & 29.5 \% \\ \text { sodium formate } & 29.5 \%\end{array}$

The molecular weights (NW) of the organic species and grams of carbon per gram mole are:

\section{Component}

sodium salt of EDTA

[ $\left.\left(\mathrm{NaOOCCH}_{2}\right)_{2} \mathrm{NCH}_{2} \mathrm{CH}_{2} \mathrm{~N}\left(\mathrm{CH}_{2} \mathrm{COONa}\right)_{2}\right]$

sodium salt of HEOTA

[ $\left.\left(\mathrm{NaOOCCH}_{2}\right)_{2} \mathrm{NCH}_{2} \mathrm{CH}_{2} \mathrm{~N}\left(\mathrm{C}_{2} \mathrm{H}+\mathrm{OH}\right)\left(\mathrm{CH}_{2} \mathrm{COONa}\right)\right]$

sodium citrate

$\left[\mathrm{C}_{3} \mathrm{H}_{6} \mathrm{OH}(\mathrm{COONa})_{3}\right]$

sodium oxalate

[ $\mathrm{NaO}_{2} \mathrm{CCO}_{2} \mathrm{Na}$ ]

sodium formate

[ $\mathrm{HCOONa}$ ]
MW

g carbon/amol

380

72

343

72

258

72

102

24

68

12

The masses of these organics in the headspace atmosphere are obtained by multiplying the fraction of the TOC contained in the individual organic species by the ratio of the (MW of the organic compound)/(grams carbon per mole of the organic compound):

EDTA: $\quad\left(0.0945 \mathrm{mg} / \mathrm{m}^{3}\right) *(0.063) *(380 / 72)=0.031 \mathrm{mg} / \mathrm{m}^{3}$ HEDTA: $\quad\left(0.0945 \mathrm{mg} / \mathrm{m}^{3}\right) *(0.052) *(343 / 72)=0.023 \mathrm{mg} / \mathrm{m}^{3}$ citrate: $\left(0.0945 \mathrm{mg} / \mathrm{m}^{3}\right) *(0.195) *(258 / 72)=0.066 \mathrm{mg} / \mathrm{m}^{3}$ oxalate: $\left(0.0945 \mathrm{mg} / \mathrm{m}^{3}\right) *(0.195) *(102 / 24)=0.078 \mathrm{mg} / \mathrm{m}^{3}$ formate: $\left(0.0945 \mathrm{mg} / \mathrm{m}^{3}\right) *(0.195) *(68 / 12)=0.104 \mathrm{mg} / \mathrm{m}^{3}$ concentration of organics in headspace $=0.302 \mathrm{mg} / \mathrm{m}^{3}$ If you have any questions please call me at 373-2461.

2.0. Estay

S. D. Estey, Engineer

Waste Tanks Process Engineering.

mig 
From: Waste Tanks Process Engineering

Phone: $\quad 373-2461$ R2-11

Date: June 23, 1995

Subject: TANK 241-C-106 HEADSPACE ORGANIC CONCENTRATION DURING PROJECT $W-320$ SLUICING OPERATIONS

To:

J. P. Harris $52-48$
ce:
J. W. Bailey
S6-12
N. A. Homan
R2-11
T. H. May
H6-25
SOE File/LB

Reference: Internal Memo, S. D. Estey to J. P. Harris, "Tank 241-C-106 Headspace Organic Concentration during Project $W-320$ Sluicing Operations," dated May 9, 1995.

This Memo supersedes the direction of the Reference by providing additional conservatism in the logic and correcting various calculational errors.

The mass of TOC in the sludge in tank $241-C-106$ is stated in the Reference as $6.06 \mathrm{grams} / \mathrm{kg}$, or a mass fraction of 0.00606 . This is further qualified by using as a basis the mass of sludge solids instead of the total sludge mass. This increases the mass fraction by a factor of 100/65 yielding a mass fraction value of 0.009323 . The aerosol mass loading of TOC is then determined as 0.009323 times the mass of the suspended aerosol solids (15.6 $\mathrm{mg} / \mathrm{m}^{3}$ ) or $0.1454 \mathrm{mg} / \mathrm{m}^{3}$. The distribution of organics remains at $6.3 \%$ sodium salt of EDTA, 5.2\% sodium salt of HEDTA, $29.5 \%$ sodium citrate, $29.5 \%$ sodium oxalate, and $29.5 \%$ sodium formate.

The following corrections are made to the remaining calculations:

Component

sodium sait of EDTA

[ $\left.(\mathrm{NaOOCCH})_{2} \mathrm{NCH}_{2} \mathrm{CH}_{2} \mathrm{~N}\left(\mathrm{CH}_{2} \mathrm{COONa}\right)_{2}\right]$

sodium salt of HEDTA

[ $\left.\left(\mathrm{NaOOCCH}_{2}\right)_{2} \mathrm{NCH}_{2} \mathrm{CH}_{2} \mathrm{~N}\left(\mathrm{C}_{2} \mathrm{H}_{6} \mathrm{OH}\right)\left(\mathrm{CH}_{2} \mathrm{COONa}\right)\right]$

sodium citrate

[ $\left.\mathrm{C}_{3} \mathrm{H}_{4} \mathrm{OH}(\mathrm{COONa})_{3}\right]$

;

sodium oxalate

[ $\mathrm{NaO}_{2} \mathrm{CCO}_{2} \mathrm{Na}$ ]

sodium formate

[ HCOONa]
MW

q carbon/amol

380

120

343

120

258

72

134

24

68

12 
J. P. Harris

Page 2

June 23,1995

The masses of these organics in the headspace atmosphere are obtained by multiplying the fraction of the TOC contained in the individual organic species by the ratio of the (MW of the organic compound)/(grams carbon per mole of the organic compound):

EDTA: $\quad\left(0.1454 \mathrm{mg} / \mathrm{m}^{3}\right) *(0.063) *(380 / 120)=0.3290 \mathrm{mg} / \mathrm{m}^{3}$

HEDTA: $\quad\left(0.1454 \mathrm{mg} / \mathrm{m}^{3}\right) *(0.052) *(343 / 120)=0.0216 \mathrm{mg} / \mathrm{m}^{3}$

citrate: $\left(0.1454 \mathrm{mg} / \mathrm{m}^{3}\right) *(0.295) *(258 / 72)=0.1537 \mathrm{mg} / \mathrm{m}^{3}$

oxalate: $\left(0.1454 \mathrm{mg} / \mathrm{m}^{3}\right) *(0.295) *(134 / 24)=0.2395 \mathrm{mg} / \mathrm{m}^{3}$

formate: $\left(0.1454 \mathrm{mg} / \mathrm{m}^{3}\right) *(0.295) *(68 / 12)=0.2431 \mathrm{mg} / \mathrm{m}^{3}$

concentration of organics in headspace $\quad=0.6869 \mathrm{mg} / \mathrm{m}^{3}$

In light of the uncertainties in this analysis, it is recommended that an organic concentration of $0.7 \mathrm{mg} / \mathrm{m}^{3}$ be used.

\subsection{Elaty}

S. D. Estey, Engineer

Waste Tanks Process Engineering

mjg 
HNF-SD-WM-RPT-293 REV 0

Westinghouse

Internal

Hanford Company

Memo

From: $\quad$ Waste Tanks Process Engineering

Phone: $\quad 373-2461$ R2-11

Date: May 25, 1995

Subject: WASTE COMPATIBILITY EVALUATION FOR INHIBITED PROPYLENE GLYCOL

To:

D. J. Minteer

S2-24

$\begin{array}{ll}\text { CC: E. G. Allen } & \text { G6-02 } \\ \text { W. B. Barton } & \text { R2-11 } \\ \text { W. W. Jenkins } & 52-24 \\ \text { J. R. Kriskovich } & 52-24 \\ \text { R. A. Pina } & 52-47 \\ \text { D. A. Reynolds } & \text { R2-11 } \\ \text { SDE FiTe/LB } & \end{array}$

Reference(s): (1) Internal Memo, S. D. Estey to E. G. Allen, "WASTE COMPATIBILITY EVALUATION FOR INHIBITED PROPYLENE GLYCOL, " dated March 23, 1994.

(2) R. Reid; J. Prausnitz, T. Sherwood, THE PROPERTIES OF LIQUIDS AND GASES, 3rd ed., McGraw-Hill, New York, 1977.

Interpretation of Reference (1) lead to additional questions about the conditions under which propylene glycol could vaporize to form flammable mixtures in air. In the context of Project $W-320$, Tank 241-C-106 Sluicing, Reference ( 1 ) avoided these questions by stating that the necessary conditions for such an event could not occur. However, if this is not the case, postulated accident scenarios of an extreme nature could be thought to produce conditions whereby, provided a sufficient amount of fuel (propylene glycol) is present, a flammable mixture could form in the tank atmosphere. This memo analyzes these conditions, and makes the case that such conditions are incredible.

In every case, the minimal requirements would be that the liquid and vapor phases of the propylene glycol were at or above its flashpoint and that propylene glycol be present in sufficient quantities to form flammable mixtures in air. Reference (1) analyzed a formulated propylene glycol mixture containing about $5 \%$ detergent by mass with a stated flashpoint of $214^{\circ} \mathrm{F}$. This memo considers only pure propylene glycol, which is conservative from a flammability standpoint (i.e., has a lower flashpoint). The flashpoint, $210^{\circ} \mathrm{F}$ for pure propylene glycol, can be interpreted as the temperature at which the vapor pressure of the combustible liquid is high enough to form a flammable concentration in air. The conditions required are that a sufficient mass of fuel is present to produce the requisite amount of vapor, and that the vapor be allowed to concentrate in the volume of the tarik atmosphere. Such 


$$
\text { HNF-SD-WM-RPT-293 REV } 0
$$

D. J. Minteer

75510-95-031

Page 2 of 4

May 25, 1995

conditions could occur as a result of an extended loss of forced ventilation.

The most simple condition to analyze is the presence of a volume of pure propylene giycol in contact with the atmosphere of the tank. If a sufficient mass of liquid propylene glycol pools on top of the sludge, the vapor pressure of propylene glycol will eventually reach its equilibrium value in a stagnant tank headspace. If the tank were dry the sludge would be more likely to reach or exceed $210^{\circ} \mathrm{F}$. There must still be a heat transfer mechanism which could keep the tank atmosphere at or above $210^{\circ} \mathrm{F}$, and if water is absent from the tank, sludge temperatures would have to increase drastically above $210^{\circ} \mathrm{F}$ in order to maintain the atmosphere at $210^{\circ} \mathrm{F}$. It is highly unlikely that such a poot, or some other separated phase, of pure propylene glycol could form in the tank as the glycol would most likely enter the tank as a 50/50

water/glycol antifreeze mixture. In this case, the partial pressure of the glycol in the tank atmosphere would be reduced compared to the vapor pressure of the pure component.

In more realistic cases, the volume of water in the tank should be large compared to the volume of propylene glycol which could leak into the tank. If significant amounts of water are in the tank (eg. 30,000 gallons), the propylene glycol would be diluted to a very low concentration in the water, and the equilibrium concentration of its vapor above the glycol-water solution would have be determined through analysis of vapor-liquid equilibrium data for a water-propylene glycol mixture. The simplest example would be a Henry's Law $(y=k x)$ type of relationship, where $y$ is the vapor phase mole fraction and $x$ is the liquid phase mole fraction. In such cases, the effect of the dilution water will be to reduce the partial pressure of propylene glycol in the atmosphere when compared to the partial pressure of the pure component in contact with the atmosphere.

A calculation of the amount of propylene glycol which must evaporate to form an LEL condition in the headspace of tank 241-C-106 follows:

Given:

Propylene Glycol

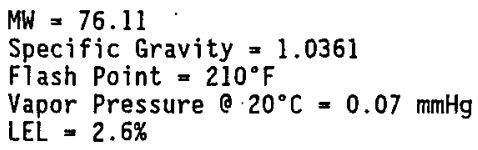

A quick check of the properties of concern to vapor phase flammability is through verification that the vapor pressure of the material at its flash point is equivalent to the LEL. A method for estimating the vapor pressure of a pure substance as a function of temperature is provided by Antoine's 
D. J. Minteer

$75510-95-031$

Page 3 of 4

May 25, 1995

Equation. Reference (2) gives the following form of Antoine's equation for propylene glycol:

vapor pressure $(\mathrm{mmHg})=\exp [20.534-(6091.95 /(T-22.46)]$

where $T$ is in $K:\left(T(K)=273.15+(5 / 9) *\left(T\left({ }^{\circ} F\right)-32\right)\right)$

This equation yields a vapor pressure of $0.14 \mathrm{mmHg}$ at $20^{\circ} \mathrm{C}\left(68^{\circ} \mathrm{F}\right)$ compared to the commonly stated value of $0.07 \mathrm{mmHg}$. At $210^{\circ} \mathrm{F}$, the vapor pressure is calculated as $22.4 \mathrm{mmHg}$ or $2.9 \%$, which is close to the LEL of $2.6 \%$. In this case, Antoine's equation produces a reasonable correlation between the vapor pressure at the stated flash point $\left(210^{\circ} \mathrm{F}\right)$, and the LEL.

Determine volume of tank headspace:

$$
\begin{aligned}
& \text { dome volume }=33,000 \mathrm{ft}^{3} \\
& \text { cylindrical volume }=(500,000 \mathrm{gal}-197,000 \mathrm{gal}) /\left(7.48 \mathrm{gal} / \mathrm{ft}^{3}\right) \\
& \text { total volume }=33,000+40,500=73,500 \mathrm{ft}^{3}
\end{aligned}
$$

Determine to mols $\left(n_{\text {air }}\right)$ of gas in tank headspace at $210^{\circ} \mathrm{F}$ :

$$
\begin{aligned}
& n=(P \star V) /(R * T) \\
& P=1 \text { atm } \\
& V=73,500 \mathrm{ft}^{3} \\
& R=0.7302\left(\mathrm{ft}^{3} \star_{\mathrm{atm}}\right) /\left(1 \mathrm{~b} \mathrm{~mol} *^{\circ} \mathrm{R}\right) \\
& T=\left(210^{\circ} \mathrm{F}+460^{\circ} \mathrm{F}\right)\left({ }^{\circ} \mathrm{R} /{ }^{\circ} \mathrm{F}\right)=670^{\circ} \mathrm{R} \\
& n_{\text {air }}=\left(1 \mathrm{~atm} * 73,500 \mathrm{ft}^{3}\right) /\left(0.7302\left(\mathrm{ft}^{3} * \mathrm{~atm}\right) /(1 \mathrm{~b} \mathrm{mol* \circ}) * 670^{\circ} \mathrm{R}\right) \\
& n_{\text {air }}=1501 \mathrm{~b} \mathrm{mols}
\end{aligned}
$$

Determine $1 \mathrm{~b}$ mols of propylene glycol $\left(\mathrm{n}_{\mathrm{glycol}}\right)$ required to reach the LEL in tank headspace:

$$
\begin{aligned}
& n_{\text {glycol }}=n_{\text {air }} * L E L / 100 \% \\
& n_{\text {glycol }}=150 \mathrm{lb} \mathrm{mols} * 2.6 \% / 100 \%=3.91 \mathrm{~b} \mathrm{mols}
\end{aligned}
$$

Converting to gallons of propylene glycol evaporated:

$$
\begin{aligned}
\text { volume } & =3.9 \mathrm{lb} \mathrm{mols} *(76.11 \mathrm{lb} / 1 \mathrm{~b} \mathrm{~mol}) /(8.34 * 1.0361 \mathrm{lb} / \mathrm{gal}) \\
& =34 \text { gallons propylene glycol }
\end{aligned}
$$

Therefore, under the conditions mentioned previously, if 34 gallons of propylene glycol were to evaporate into a $210^{\circ} \mathrm{F}$ headspace, a flammable mixture 
D. J. Minteer

$75510-95-031$

Page 4 of 4

May 25, 1995

could be formed. This is the limiting condition which could only occur if the volume of liquid propylene glycol were present as a separable phase in the tank. If any propylene glycol leaking into the tank mixes with the water already in the tank, the partial pressure of the propylene glycol will be less then the vapor pressure of the pure substance. In this case, as a minimum requirement, temperatures higher than the flashpoint would be needed to form a flammable vapor concentration. Even then, the partial pressure of water may lower concentrations of fuel and oxidizer in the headspace to a level which would not support combustion. Therefore, the limiting condition, and thus the probability of formation of a flammable atmospheric mixture, is considered incredible because:

1) The propylene glycol would be added to the tank as a $50 / 50$ mix with water.

2)

Propylene glycol entering the tank would most likely be further diluted by a large volume of water already present in the tank.

3)

The partial pressure of any water in the tank will dilute concentrations of both fuel (propylene glycol) and oxidizer (oxygen) in the headspace, possibly to the point where combustion could not occur.

4)

The temperatures required to produce the necessary vapor pressure of propylene glycol could only result from an extended loss of forced ventilation (i.e., on the order of about one year at a minimum).

The history of tank farms always indicates that for steady gas/vapor release scenarios, the combination of natural or other inadvertent means of tank ventilation prevents the formation of flammable concentrations in the tank headspace.

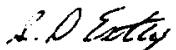

S. D. Estey, Engineer

Waste Tanks Process Engineering

mjg

Concurrence:
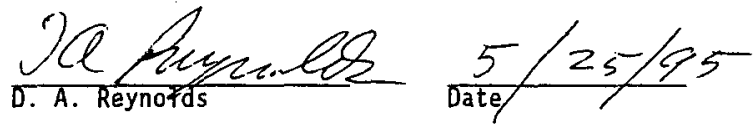

(signature indicates agreement with this memo and the supporting memo Reference (1)) 


\section{ILF KAISER \\ ENGINEERS}

A-94-001

icF Kaisea Enaineeas, Ine.

6400 UPTOWH BLVD.. SUITE $397 \mathrm{~W}$

Alguouefoue, New Mexico 97110

505/881-1593 FAX 505/8B1-0814

January 10, 1994

Kaiser Engineers Hanford Company

1200 Jadwin Avenue

Richland, WA

Attention: Mr. D. J. Shrimpton

Reference: Project W-320, Tank 24l-C-106 Sluicing

An analysis of the energy balance surrounding the referenced project has been completed. The report of results is enclosed. The purpose of the analysis and report is to illustrated the effect of various operating scenarios upon the temperature which may be attained in Tank $\mathrm{AY}-102$.

As shown in the report, temperatures under certain scenarios may reach above 150 degrees Fahrenheit. The scenarios themselves include some cases where the assumptions are inconsistent with operating reality. For instance, operations are assumed to be continuous for up to one year with high stream factor and high solids loading of the transfer slurry. Under these conditions the transfer operation will either only take a very short time or the entire solids content of $\mathrm{C}-106$ will be suspended and recycled without settling in AY-102. Thus these scenarios should be considered bounding rather than necessarily expected.

This analysis assumed as given the design performance of the $\mathrm{C}-106$ vent recycle energy removal system. It is noted that the design point of this system for exhaust vapor is based on 95 degree temperature with 100 percent relative humidity. Should the temperatures reach well above 95 degrees, several impacts on the vent system should be considered. Included are:

- overloading of the exhaust cooler with condensate flooding the heat exchanger.

- overloading the compressor of the refrigeration unit.

- increasing the temperature requirements of the vent gas superheater.

- possible need for thermal protection insulation on some piping systems. 
The report has been written in wordperfect* 5.1 with tables generated by Microsoft Excel. Included in the transmittal are two bound coples, one unbound copy, and a disk file.

Reports from other subtasks will follow this week.<smiles>[AsH2]</smiles>

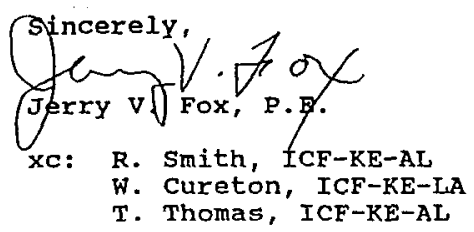

*Wordperfect is a trademark of the Hordperfect Corporation. $K \mathrm{~N}$ 
然

United Stales Government memorandum

12.09893

EH-36.

Delegatton of Approval Authority to Streami ine Tank Waste Renadiation System (Turs) Doctuencation

Habagur, DOE Richland pperations office

Hey alements for sucesss of the tank safaty progran iaciude developing High-guality documentation of Safety and Enviroxinntal Assassments (5is/EAs) and streanlining the process used for approving these doevwents. Conststent with the division of roles and responstbilities addressed in Tow Grubiy's memprandua to you, dated August 23 , 1993, the DOE Richland Operatetons office (RL) has the prieary responstbility to onsure that lestinghouse Hanford boepany (Wif) documents are adnquately raviesed and checked for quality. To accomplish this obfective, RL wst be tgchnically and managerially capabie of ensuring the deyelopment of high-quality sAs and Eks.

Secretarial safety Intitiatives issued on september 13, 1993, requitro DOE Hoadquarters (HQ) to take four actions in Kovenbar 1993;

- Accopt Intario Safety Basis;

- Defegate authority to RL for approval of Safaty Analysis Reports;

- Delegato approval authority for Hational Environmental Policy ACt (KEPA) documentation and Safety Assessments for the 106-ᄃ siufeing Project on a prlot basis; and

- belegate Progran Secretarial Officer (PSO) approval authority, to the ll Manager, for proeurenent actions and key Deetsions 3 and 4, al so on a pl)ot basts.

I. plan to accapt the Iateria Safety Basis (ISB) and its implementing pracudures besed on your raviex and approva?. As discusaed in $3 i 71$ Lytle's Way 5, 1993, guidance: woworadu to you concerning safoty analysts for the Hantord htgh-lovel wasta tank faras, tho Headquarter focus will be to astablish a couphehisive safuty envelope consfdering all hazards fram ivclear and chenical aspects that are inportant to worker protection and facility oparattons. : Even thaugh the 158 is based in part on existing Safaty Analysis Reports (SARS), recognize the need to support on-goting operattons and to procead vith eertain letiyities related to the resolution of safaty issues. Accaptance of the ISB is contingent on your aggressive developmeat of a coagrahensive safety basts by July 199, as laid out in the Secretary's safaty Intiatives.

Regarding the delegat,ton of approyal authority for SAs and SARS, it appears there is an inconsistancy in the Safety Initiatives. It is prudent for us to take a phased approach in delegaling this critical authority. Therefore, we ara delegating to the Rl Hanager the authority to approve safety documentation for the 106-C Juieing Project on a pliot basis. Please subnit a pian to us by January 10, I994, describing how RL and the WHC would assume the authority and accountability for approving sars for 
271 TWBS activitfes. Plase ensure that this plan reflects the ampomeromt principlas as discussed by the Secretary in hor Hoy 10, 1993, Town keeting

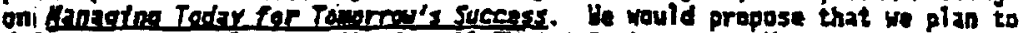
delegate approval author:ty for all TiRS SIRs to the RL Hanagar, by Apr11 1984, to alfow. RL and WHC the apportunity to demonstrate your

planning/approval proets wth the Tank 105-C Sluicing Project safety and environiented docrentation.

With respect to the uEp documatation for the Tank 106-C s7ucting Project, by her signature on this acandve you have been dolegated the authority to approve the Tank $106-C$ Ea and issue the finding of no stgniffeant inpact, if appropriate, by the Assistent Seretary for Environuent, Safety and Health. HQ staffy Pron the Offless of Environental Restoration and Waste Hunagement and Envirowont, Safety and fealth vill be doyeloping performance measures to,gauge the sucenss of this delegatfon of authority.

We are now also delegating the PSO approval authority to the RL Manger for procurement actions and: Kay Dacisions 3 and 4 an 2 pjlat basis for the Tank I0s-C Siticing Project. RL will be responsibie far fully documenting the Hapford decision-making:processes and will continue to raport progress to HQ: Current and updated planning and eanagennt contral doeyments will bo provided to $\mathrm{HQ}$. for information.

We; along with the socretary. are coumittad to enpowering the field; 1. e. glving greater responstolfiky and acconntability to the operations offices and Kanagenent and Oparatiag contractors for progran and project exzeution. Ye +are interested in dejegating appropriate responsibility to RL and WHC for all Hanford waste mangenant pragrans and projoct eanagenent processes.

Plaasa proride us your concepts and plans, in conpliance with DOE Order 4700.1 , for accepting thesa responsibilities and denanstrating actountabtitty, with ansurable'performance geasures. Identify the leval of progranyproject anagoent authority you deas approprtate, how you will implenent the nes responsibility, wat ippediments exist to suceassful progray/oroject inplentation, and hat rexponsfbilities need to be dolagated from B4. Plesse provtde as your plan by January 10, 1994.

In all of these actions, it is eritical that laforastion flow upwards, uniapeded, fros the subcontractors ta WK, to RL, and to HQ. PTease cail us or Jill Lytle if you have any questions. Staff contact for this program is John Tseng, 301-903-7170.

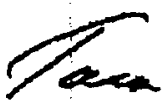

Tara D'Toole, K.D., A.P.H. Asaistant Secratary : Environment, Safoty and Health

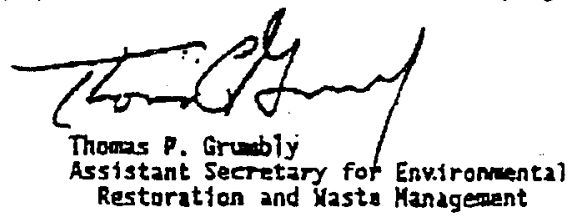


From: Consequence Analysis

8M400-BEH-95015

Phone: $\quad 376-2921$ H4-64

Date: $\quad$ October 19, 1995

Subject: ESTIMATED DOSE TO ONSITE INDIVIDUAL FROM TANK C-106 TRANSFER POOL SPILL

To:

J. C. Conner

$$
\begin{aligned}
& \text { CC: L. E. Johnson } \\
& \text { D. S. Leach } \\
& \text { J. C. Van Keuren } \\
& \text { BEH LB }
\end{aligned}
$$

As requested, doses were calculated for the subject scenario using assumptions consistent with Section 3.4.2.3 of WHC-SD-WM-SAR-065, Rev. 0, "Interim Chapter 3.0 Hazard and Accident Analysis." Specifically these assumptions are:

1. The radioactive liquid spills onto flat ground and soaks down to a depth of $31 \mathrm{~cm}$.

2. All radioactivity is captured in the top $5 \mathrm{~cm}$ of the soil layer.

3. Soil density is $1.6 \mathrm{~g} / \mathrm{cc}$ and porosity is $30 \%$. Source shielding effectiveness is treated as low density concrete mixed with water.

4. The onsite individual is represented by a dose point $100 \mathrm{~m}$ from the nearest edge of the pool and $1.5 \mathrm{~m}$ above the ground.

5. The exposure duration is 8 hrs.

Results for two spill sizes of 320,000 and $5,200 \mathrm{~L}$ are $9.8 \mathrm{R}$ and $170 \mathrm{mR}$ respectively for an 8 hour exposure. Doses are approximately linear with pool spill volume. Therefore, alternate doses can be estimated by linear interpolation. Doses are also proportional to exposure time and approximately proportional to Cs-137 concentration. The bremsstrahlung dose due to $\mathrm{Sr}-90 / \mathrm{Y}-90$ contributes 1 ess than $5 \%$ of the total dose.

Attached are the code output produced during the analysis. Also attached is the $\mathrm{C}-106$ radionuclide inventory assumed in the analysis.

If you havg any questions concerning this information, please do not

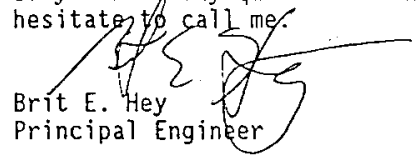

gjr

Attachment

Concurrence:

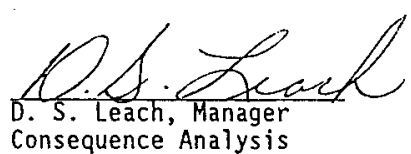

155

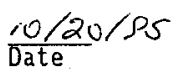


HNF-SD-WM-RPT-293 REV $0 \quad$ 8M400-BEH-95-015

\section{ATTACHMENT}

CODE OUTPUT FOR ANALYSIS TO ESTIMATE DOSE TO ONSITE INDIVIDUAL FROM TANK C-106 TRANSFER POOL SPILL 


\section{Microshield 4.00- Serial \#4.00-00128 \\ Westinghouse Hanford Company}
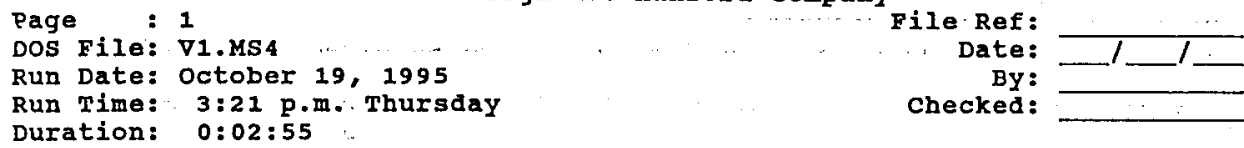

Case Title: Pool spill of 320,000 L - Co, Cs and Eu Direct Contribution

\begin{tabular}{rrrr}
\multicolumn{2}{c}{ GEOMETRY 8 - Cylinder Volume } & - End Shields \\
Dose point coordinate X: & 13340.0 & feet and inches \\
Dose point coordinate Y: & 150.0 & 437.0 & 8.0 \\
Dose point coordinate Z: & 0.0 & 4.0 & 11.1 \\
Cylinder height: & 5.0 & 0.0 & .0 \\
Cylinder radius: & 3340.0 & 0.0 & 2.0 \\
Air Gap: & 145.0 & 109.0 & 7.0 \\
Side clad: & 10000.0 & 4.0 & 9.1 \\
& & 328.0 & 1.0
\end{tabular}

Source Volume: $1.75232 \mathrm{e}+8 \mathrm{~cm}^{\wedge} 36188.25 \mathrm{cu}$ ft. $1.06933 \mathrm{e}+7 \mathrm{cu}$ in.

$\begin{array}{llcc}\text { Material } & \begin{array}{c}\text { Source } \\ \text { Shield }\end{array} & \text { Air Gap } & \begin{array}{c}\text { Side clad } \\ \text { Shield }\end{array} \\ \text { Air } & & 0.00122 & \\ \text { Concrete } & 1.6 & & 1.6 \\ \text { Water } & 0.3 & & \end{array}$

BUILDUP

Method: Buildup Factor Tables

The material reference is source

\section{INTEGRATION PARAMETERS}

Radial

Circumferential

Axial (along $z$ )
Quadrature order

$$
\begin{aligned}
& 22 \\
& 22 \\
& 22
\end{aligned}
$$

$\begin{array}{lccccc}\text { Nuclide } & \text { curies } & \mu \mathrm{Ci} / \mathrm{Cm}^{\wedge} 3 & \text { Nuclide } & \text { curies } & \mu \mathrm{Ci}^{2} \mathrm{~cm}^{\wedge} 3 \\ \mathrm{Ba}-137 \mathrm{~m} & 2.1987 \mathrm{e}+005 & 1.2547 \mathrm{e}+003 & \mathrm{Co}-60 & 2.5937 \mathrm{e}+002 & 1.4801 \mathrm{e}+000 \\ \mathrm{Cs}-137 & 2.3242 \mathrm{e}+005 & 1.3263 \mathrm{e}+003 & \text { Eu-154 } & 9.4574 \mathrm{e}+003 & 5.3971 \mathrm{e}+001\end{array}$


Page : 2

Dos File: V1.MS4

Run Date: October 19, 1995

Run Time: $3: 21$ p.m. Thursday

Title : Pool spill of $320,000 \mathrm{I}$ - Co, Cs and Eu Direct Contribution

\begin{tabular}{|c|c|c|c|c|c|}
\hline $\begin{array}{l}\text { Energy } \\
\text { (MeV) }\end{array}$ & $\begin{array}{c}\text { Activity } \\
\text { (photons/sec) }\end{array}$ & $\begin{array}{r}\text { Energy Fl } \\
(\mathrm{MeV} / \mathrm{sq}\end{array}$ & $\begin{array}{l}\text { zence Rate } \\
\mathrm{cm} / \mathrm{sec} \text { ) }\end{array}$ & $\begin{array}{r}\text { Exposure } R a \\
(\mathrm{mR} / \mathrm{h}\end{array}$ & $\begin{array}{l}\text { te } \operatorname{In~} \mathrm{Air} \\
\text { r) }\end{array}$ \\
\hline & & No Builaup & Fith Buildup & No Buildup & Fith Build \\
\hline 0.6625 & $7.417 \mathrm{e}+015$ & $1.046 e+004$ & $5.263 e+004$ & $2.027 \mathrm{e}+001$ & $1.020 e+002$ \\
\hline 0.8723 & $4.910 e+013$ & $1.192 \mathrm{e}+002$ & $4.879 e+002$ & $2.242 e-001$ & $9.180 e-001$ \\
\hline 1.0024 & $9.948 e+013$ & $3.174 \mathrm{e}+002$ & $1.181 \mathrm{e}+003$ & $5.848 e-001$ & $2.176 e+000$ \\
\hline 1.2651 & $1.391 e+014$ & $7.008 e+002$ & $2.249 e+003$ & $1.231 \mathrm{e}+000$ & $3.951 e+000$ \\
\hline 1.3325 & $9.597 e+012$ & $5.351 \mathrm{e}+001$ & $1.665 e+002$ & $9.283 e-002$ & $2.889 e-001$ \\
\hline 1.5767 & $1.233 e+013$ & $9.526 e+001$ & $2.706 e+002$ & $1.581 e-001$ & $4.491 e-001$ \\
\hline TOTAL: & $\overline{7.726 e+015}$ & $174 \mathrm{e}+004$ & $\overline{698 e+004}$ & $.256 e+001$ & 1.09 \\
\hline
\end{tabular}


Microshield*4.00 - Serial \#4.00-00128

Westinghouse Hanford Company

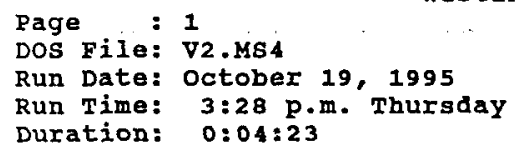

\section{File Ref:}

Date:

BY:

Checked:

Case Title: Pool spill of 5,200 I - Co, Cs and Eu Direct contribution

\begin{tabular}{rrrr}
\multicolumn{2}{c}{ GEOMETRY 8 - Cylinder Volume } & End shields \\
centimeters & feet and inches \\
Dose point coordinate X: & 10430.0 & 342.0 & 2.3 \\
Dose point coordinate Y: & 150.0 & 4.0 & 11.1 \\
Dose point coordinate Z: & 0.0 & 0.0 & .0 \\
CYlinder height: & 5.0 & 0.0 & 2.0 \\
CYlinder radius: & 430.0 & 14.0 & 1.3 \\
Air Gap: & 145.0 & 4.0 & 9.1 \\
Side clad: & 10000.0 & 328.0 & 1.0
\end{tabular}

Source Volume: $2.9044 \mathrm{e}+6 \mathrm{~cm}^{-3} \quad 102.568 \mathrm{cu}$ ft. 177238 . cu in.

$\begin{array}{llcc}\text { Material } & \text { Source } & \text { MATERIAC DENSITIES }\left(\mathrm{g} / \mathrm{cm}^{2} 3\right) \\ \text { Air Gap } & \begin{array}{c}\text { Side Clad } \\ \text { Shield }\end{array} \\ \begin{array}{l}\text { Air } \\ \text { Concrete }\end{array} & 1.6 & 0.00122 & \\ \text { Hater } & 0.3 & & 1.6\end{array}$

BUILDUP

Method: Buildup Factor Tables

The material reference is source

INTEGRATION PARAMETERS

Radial

Quadrature order

22

Axial (along $Z$ ) 22

\begin{tabular}{|c|c|c|c|c|c|}
\hline & curies & $\mu \mathrm{Ci} / \mathrm{cm}^{\text {SOURCE }}$ & $\begin{array}{r}\text { NUCLIDES } \\
\text { Nuelide }\end{array}$ & curies & $\mu \mathrm{Ci} / \mathrm{cm}^{3} 3$ \\
\hline 37 m & $3.5792 \mathrm{e}+003^{\prime}$ & $1.2323 \mathrm{e}+003$ & $\mathrm{Co}-60$ & $4.3228 \mathrm{e}+000^{\prime}$ & $1.4884 \mathrm{e}+000$ \\
\hline$s-137$ & $3.7835 \mathrm{e}+003$ & $1.3027 \mathrm{e}+003$ & Eu-154 & $1.5402 \mathrm{e}+002^{\prime}$ & $5.3030 e+001$ \\
\hline
\end{tabular}

FMicroshield is a registered trademark of Grove Engineering, Inc., Rockville, MD. KN 
Page : 2

DOS File: V2.MS4

Run Date: October 19, 1995

Run Time: $3: 28$ p.m. Thursday

Title .... Pool spill of 5,200 L - Co, Cs and Eu Direct Contribution

\begin{tabular}{|c|c|c|c|c|c|}
\hline $\begin{array}{l}\text { Energy } \\
\text { (MeV) }\end{array}$ & $\begin{array}{c}\text { Activity } \\
\text { (photons/sec) }\end{array}$ & $\begin{array}{r}\text { Energy Fl } \\
(\mathrm{MeV} / \mathrm{sq}\end{array}$ & $\begin{array}{l}\text { dence Rate } \\
\mathrm{cm} / \mathrm{sec} \text { ) }\end{array}$ & $\begin{array}{r}\text { Exposure } R \\
(\mathrm{mR} / \mathrm{l}\end{array}$ & te In Air \\
\hline & & Buildup & Fith Buildup & No Buildup & With Builaup \\
\hline $\begin{array}{l}0.1231 \\
0.246\end{array}$ & $\begin{array}{l}2.306 e+012 \\
3.892 e+011\end{array}$ & $\begin{array}{l}3.270 e-001 \\
2.050 e-001\end{array}$ & $\begin{array}{l}6.832 e+000 \\
2.208 e+000\end{array}$ & $\begin{array}{l}5.135 e-004 \\
3.771 e-004\end{array}$ & $\begin{array}{l}1.073 e-002 \\
4.061 e-003\end{array}$ \\
\hline 0.4426 & $5.300 e+010$ & $8.450 e-002$ & $5.309 e-001$ & $1.655 e-004$ & $1.040 e-003$ \\
\hline 0.5907 & $3.552 \mathrm{e}+011$ & $9.754 e-001$ & $4.841 e+000$ & $1.905 e-003$ & $9.457 e-003$ \\
\hline 0.6625 & $1.207 e+014$ & $4.116 e+002$ & $1.874 \mathrm{e}+003$ & $7.978 e-001$ & $3.632 \mathrm{e}+000$ \\
\hline 0.8723 & $7.996 e+011$ & $4.580 e+000$ & $1.722 \mathrm{e}+001$ & $8.619 \mathrm{e}-003$ & $3.240 e-002$ \\
\hline 1.0024 & $1.620 e+012$ & $1.206 e+001$ & $4.151 e+001$ & $2.222 e-002$ & $7.649 \mathrm{e}-002$ \\
\hline 1.2649 & $2.269 e+012$ & $2.618 e+001$ & $7.864 e+001$ & $4.599 e-002$ & $1.382 e-001$ \\
\hline 1.3325 & $1.599 \mathrm{e}+011$ & $2.035 e+000$ & $5.943 e+000$ & $3.530 e-003$ & $1.031 e-002$ \\
\hline 1.5767 & $2.009 e+011$ & $3.496 e+000$ & $9.388 e+000$ & $5.803 e-003$ & $1.558 \mathrm{e}-002$ \\
\hline TOTAL: & $\overline{1.289 e+014}$ & $\overline{4.615 e+002}$ & $041 e+003$ & $.869 e-001$ & $3.930 \mathrm{e}$ \\
\hline
\end{tabular}




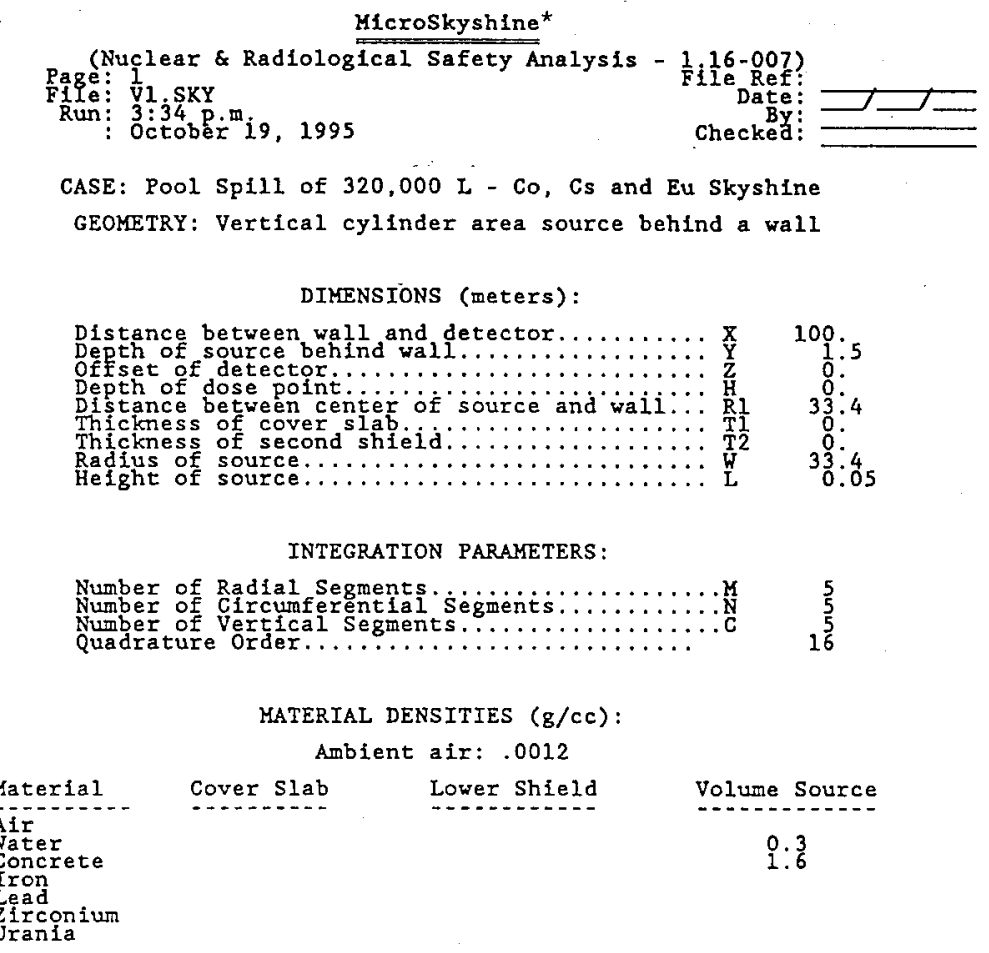

Buildup factor based on: WATER.

*Microskyshine is a registered trademark of Grove Engineering, Inc., Rockville, MD. ${ }^{N}$ 
Page 2

HNF-SD-WM-RPT-293 REV 0

CASE: Pool Sp11l of 320,000 L - Co, Gs and Eu Skyshine SOURCE NUCLIDES :

Nuc11de

Ba-137m

Curies

2. $3242 \mathrm{e}+05$

Nuclide

Co-60

Eu-154

Curies

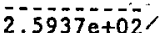

$9.4574 \mathrm{e}+03$

RESULTS :

\begin{tabular}{c} 
Group \\
\#⿰ \\
\hdashline $1--$ \\
1 \\
2 \\
3 \\
4 \\
5 \\
6 \\
7 \\
8 \\
99 \\
10 \\
11 \\
12 \\
13 \\
14 \\
15 \\
16 \\
17 \\
18 \\
19 \\
20
\end{tabular}

\begin{tabular}{ccc}
$\begin{array}{c}\text { Energy } \\
\text { (mev) }\end{array}$ & $\begin{array}{c}\text { Activity } \\
\text { (photons/sec) }\end{array}$ & $\begin{array}{c}\text { Dose polnt } \\
\text { rads/photon }\end{array}$ \\
\hline 1.30 & $1.497 \mathrm{e}+14$ & $3.332 \mathrm{e}-20$ \\
1.02 & $7.108 \mathrm{e}+14$ & $3.449-20$ \\
.84 & $6.425 \mathrm{e}+13$ & $3.364 \mathrm{e}-20$ \\
.66 & $7.422 \mathrm{e}+15$ & $3.456 \mathrm{e}-20$ \\
.48 & $3.416 \mathrm{e}+12$ & $3.543 \mathrm{e}-20$ \\
.40 & $7.328 \mathrm{e}+11$ & $3.439 \mathrm{e}-20$ \\
.24 & $2.310 \mathrm{e}+13$ & $3.165 \mathrm{e}-20$ \\
.20 & $7.949 \mathrm{e}+11$ & $2.988 \mathrm{e}-20$ \\
.12 & $1.416 \mathrm{e}+14$ & $2.35 \mathrm{e}-20$
\end{tabular}

Dose rate

-

$.575 \mathrm{e}+01$

8.912 e+oo

$1.058 \mathrm{e}+03$

4.991 e- 01

1. $015 e+00$

$9.795 \mathrm{e}-02$

1. $372 \mathrm{e}+01$

TOTALS: $\quad \overline{7} . \overline{17} \overline{\mathrm{e}}+\overline{15}$

$1.120 \mathrm{e}+0 \overline{3}$ 
Hicroskyshine

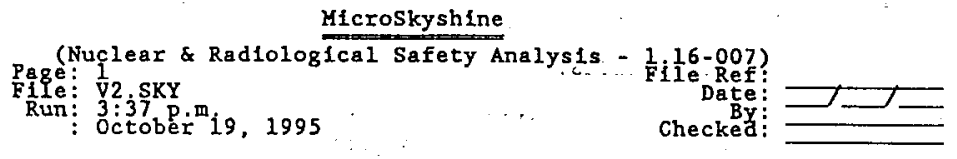

CASE : Pool Spill of 5,200 L - Co, Cs and Eu skyshine

GEOMETRY: Vertical cylinder area source behind a wall

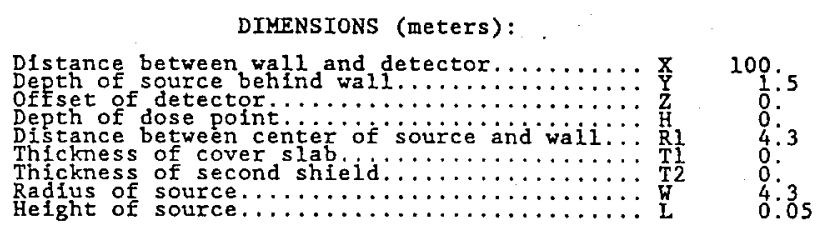

INTEGRATION PARAMETERS :

Number of Radial Segments . . . . . . . . . . . .

Number of Gircumferential segments.............

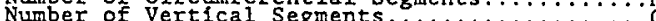

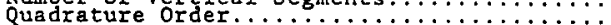

$$
\begin{array}{r}
5 \\
5 \\
5 \\
16
\end{array}
$$

MATERIAL DENSITIES $(g / c c)$ :

Ambient alr: .0012

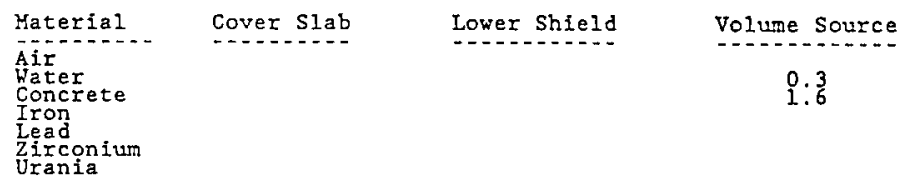

Buildup factor based on: WATER. 
Page 2

I HNF-SD-WM-RPT-293 REV 0

CASE: Pool splll of $5,200 \mathrm{~L}$ - Co, Cs and Eu skyshine SOURCE NUCLIDES: ${ }^{x} \ldots \ldots$.

Nucilde Curies.

Ba-137m $3.5792 \mathrm{e}+03$;
Nuclide Co-60

Eu-154
Curies $4 . \overline{2} 28 \mathrm{e}+00^{\prime}$ $1.5402 \mathrm{e}+02$.

RESULTS :

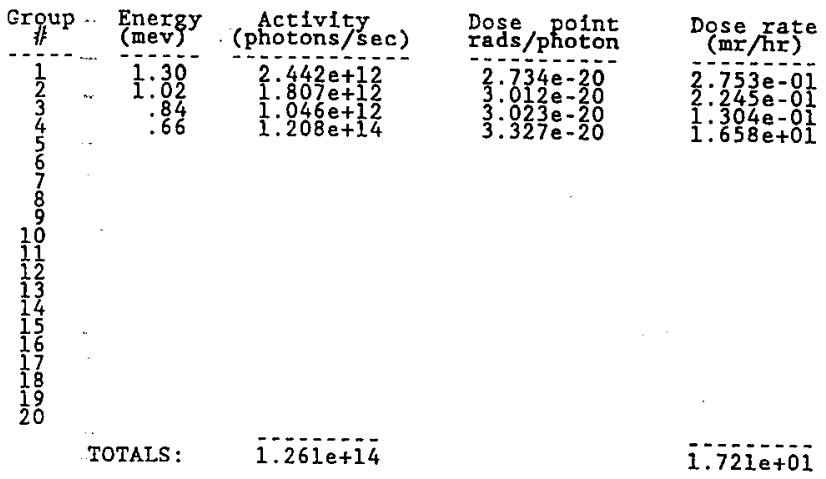


HNF-SD-WM-RPT-293 REV 0

Table A-1. C-106 Radionuclide Inventory Data. (Savino 1994 and Conner 1995a)

\begin{tabular}{|c|c|c|c|c|c|c|c|c|c|}
\hline \multicolumn{2}{|c|}{ sample type } & \multicolumn{3}{|c|}{ Drainoble interstitial licuid } & \multicolumn{4}{|c|}{ sludge/slurry solids } & Tank inv. \\
\hline \multicolumn{2}{|c|}{ SAMPLE DATE } & \multicolumn{4}{|c|}{$05 / 19 / 88$} & \multicolumn{3}{|c|}{$05 / 19 / 86$} & $05 / 19 / 86$ \\
\hline \multicolumn{2}{|c|}{ Dersity $g / m$} & & & & \multicolumn{4}{|c|}{1.43} & \\
\hline \multicolumn{2}{|c|}{ Vol. (KGAl) } & \multicolumn{3}{|c|}{16} & \multicolumn{4}{|c|}{197} & 213 \\
\hline \multicolumn{2}{|l|}{ vol. (L) } & \multicolumn{3}{|c|}{$6.06 E+04$} & \multicolumn{4}{|c|}{$7.46 E+05$} & $8.06 \mathrm{E}+05$ \\
\hline \multicolumn{10}{|c|}{$\begin{array}{l}\text { Composite } 100 \text { Percentile - solids } \\
\text { (Maximum Sample Activity Concentration) }\end{array}$} \\
\hline Nuclide & $\begin{array}{l}\text { Yolume } \\
\text { Aetivity } \\
\text { (Bo/L) }\end{array}$ & $\begin{array}{l}\text { CEDE DOSe } \\
(5 \mathrm{~V} / \mathrm{L})\end{array}$ & $\begin{array}{c}\text { Contri- } \\
\text { bution } \\
(x)\end{array}$ & $\begin{array}{l}\text { Mest Lood } \\
(W / L)\end{array}$ & $\begin{array}{l}\text { Contri- } \\
\text { bution } \\
(y)\end{array}$ & $\begin{array}{l}\text { Lung Dose } \\
(S V / L)\end{array}$ & $\begin{array}{c}\text { Contir- } \\
\text { bution } \\
(x)\end{array}$ & $\begin{array}{l}\text { Bone Sur } \\
\text { Dose } \\
\text { (5V/L) }\end{array}$ & $\begin{array}{l}\text { Contri- } \\
\text { bution } \\
\text { (x) }\end{array}$ \\
\hline${ }^{21} \mathrm{c}$ & $1.2 E+04$ & 6.9 E-OS & 0.0 & $0.0 E+00$ & 0.0 & $6.9 \varepsilon-06$ & 0.0 & $6.9 \mathrm{E}-0.6$ & 0.0 \\
\hline${ }^{m} \mathrm{Co}_{0}$ & $3.0 \mathrm{E}+07$ & $1.8 \mathrm{E}+00$ & 0.0 & $1.2 E-05$ & 0.1 & $1.0 E+01$ & 0.1 & $4.1 \mathrm{E}-0 \mathrm{t}$ & 0.0 \\
\hline$n_{\mathrm{se}}$ & $0.0 E+00$ & $0.0 E+00$ & 0.0 & $0.0 \mathrm{E}+00$ & 0.0 & $0.0 E+\infty$ & 0.0 & $0.0 E+00$ & 0.0 \\
\hline${ }^{n} \mathrm{sr}$ & $9.7 \mathrm{E}+10$ & $6.3 \mathrm{E}+03$ & $8.8 \div$ & 3.0 E-03 & 14.0 & $3.6 \mathrm{E}+02$ & 3.3 & $7.1 \mathrm{E}+04$ & 5.7 \\
\hline 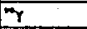 & $9.7 \mathrm{E}+10$ & $2.2 E+02$ & 0.3 & $1.5 E-02$ & 67.0 & $9.1 E+02$ & 8.4 & $1.5 \mathrm{E}+00$ & 0.0 \\
\hline$n r$ & $0.0 \mathrm{E}+00$ & $0.0 \mathrm{E}+00$ & 0.0 & $0.0 E+00$ & 0.0 & $0.0 E+00$ & 0.0 & $0.0 E+00$ & 0.0 \\
\hline The & $1.2 \varepsilon+07$ & $3.2 \mathrm{E}-03$ & 0.0 & $1.6 \varepsilon-07$ & 0.0 & $4.1 E-03$ & 0.0 & $5.2 \mathrm{E}-04$ & 0.0 \\
\hline Int & $0.0 E+00$ & $0.0 E+00$ & 0.0 & $0.0 \mathrm{E}+00$ & 0.0 & $0.0 \mathrm{E}+\infty$ & 0.0 & $0.0 E+00$ & 0.0 \\
\hline${ }^{10 x} \mathrm{sb}$ & $0.0 \mathrm{E}+00$ & $0.0 \mathrm{E}+00$ & 0.0 & $0.0 \mathrm{E}+00$ & 0.0 & $0.0 E+00$ & 0.0 & $0.0 E+00$ & 0.0 \\
\hline $1+\infty$ & $6.3 E+03$ & $2.0 \mathrm{E}-4$ & 0.0 & $5.4 \mathrm{E}-11$ & 0.0 & $1.3 E-06$ & 0.0 & $5.9 \mathrm{E}-07$ & 0.0 \\
\hline wes & $0.0 E+00$ & $0.0 E+00$ & 0.0 & $0.0 \mathrm{E}+00$ & 0.0 & 0.0 E 00 & 0.0 & $0.0 \mathrm{E}+00$ & 0.0 \\
\hline${ }^{\prime \prime}$ es & $2.7 \mathrm{E}+10$ & $2.3 \varepsilon+02$ & 0.3 & $3.4 \mathrm{E}-03$ & 15.7 & $2.4 E-02$ & 2.2 & $2.1 E+02$ & 0.0 \\
\hline $3{ }^{34} c_{e}$ & $0.0 E+00$ & $0.0 E+00$ & 0.0 & $0.0 \mathrm{E}+00$ & 0.0 & 0.0 E.00 & 0.0 & $0.0 \mathrm{E}+00$ & 0.0 \\
\hline${ }^{241} \mathrm{Pm}_{\mathrm{m}}$ & $0.0 \mathrm{E}+00$ & $0.0 \mathrm{E}+00$ & 0.0 & $0.0 E+00$ & 0.0 & $0.0 \mathrm{E}+\infty$ & 0.0 & $0.0 \mathrm{E}+00$ & 0.0 \\
\hline "ES & $1.1 E+09$ & $8.8 \mathrm{E}+09$ & 0.1 & $2.8 \varepsilon-0<$ & 1.3 & $9.0 \mathrm{E}+0 t$ & 0.8 & $6.0 E+02$ & 0.0 \\
\hline$D_{\mathrm{ND}}$ & $0.0 E+00$ & $0.0 E+00$ & 0.0 & $0.0 E+00$ & 0.0 & $0.0 E+\infty$ & 0.0 & $0.0 E+00$ & 0.0 \\
\hline TPu & $1,4 E+08$ & $1.5 E+06$ & 20.5 & $1.2 E-04$ & 0.6 & $2.5 E+03$ & 23.5 & $2.6 \mathrm{E}+05$ & 21.0 \\
\hline$m_{P u}$ & $3.35+08$ & $3.8 \mathrm{E}+04$ & 52.9 & $2.7 E-04$ & 1.2 & $5.7 \mathrm{E}+03$ & 52.2 & $6.9 E+05$ & 55.2 \\
\hline mp & $0.0 E+00$ & $0.0 \mathrm{E}+00$ & 0.0 & $0.0 \mathrm{E}+00$ & 0.0 & $0.0 \mathrm{E}+\infty 0$ & 0.0 & $0.0 \mathrm{E}+00$ & 0.0 \\
\hline $201 P U$ & $2.6 E+09$ & $5.7 \varepsilon+03$ & 7.9 & $2.1 \mathrm{E}-06$ & 0.0 & $1.9 E+01$ & 0.2 & $1.1 E+05$ & 8.6 \\
\hline "1. An & $5.5 E+07$ & $6.6 E+03$ & 9.2 & $6.9 E-05$ & 0.2 & $1.0 \mathrm{E}+03$ & 9.3 & $1.2 E+05$ & 9.5 \\
\hline$\Rightarrow \operatorname{Ax}$ & $0.0 E+00$ & $0.0 E+00$ & 0.0 & $0.0 \mathrm{E}+00$ & 0.0 & $0.0 \mathrm{E}+\infty$ & 0.0 & $0.0 E+00$ & 0.0 \\
\hline$" A_{n}$ & $0.0 E+00$ & 0.0 E +00 & 0.0 & $0.0 \mathrm{E}+00$ & 0.0 & $0.0 \mathrm{E}+0 \mathrm{~g}$ & 0.0 & $0.0 E+00$ & 0.0 \\
\hline${ }^{2 \mu 1} \mathrm{~cm}$ & $0.0 E+00$ & $0.0 \varepsilon+00$ & 0.0 & $0.0 \mathrm{E}+00$ & 0.0 & $0.0 \mathrm{E}+00$ & 0.0 & $0.0 E+00$ & 0.0 \\
\hline${ }^{2 m} \mathrm{~cm}$ & $0.0 E+00$ & $0.0 E+\infty 0$ & 0.0 & $0.0 E+00$ & 0.0 & $0.0 E+\infty$ & 0.0 & $0.0 E+00$ & 0.0 \\
\hline EU & $0.0 \mathrm{E}+00$ & $0.0 \leqslant+00$ & 0.0 & $0.0 E+00$ & 0.0 & $0.0 E+00$ & 0.0 & $0.0 E+00$ & 0.0 \\
\hline Total & $2.3 E+19$ & $7.2 \mathrm{E}+0.4$ & & $2.2 \mathrm{E}-02$ & & $1.1 E+06$ & & $9.3 E+0$. & \\
\hline
\end{tabular}




\section{PEER REVIEN CHECKLIST}

Document Reviewed: 8M400-BEH-95-015, Internal Memorandum to J. C. Conner entitled "ESTIMATED DOSE TO ONSITE INDIVIDUAL FROM TANK C-106 TRANSFER POOL SPILL".

Author: Brit E. Hey

Date: October 19, 1995

Scope of Review: Entire Document

Yes No NA

[ ] [ ] [u

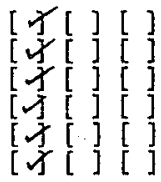

$[4[][]$

[ง [ ] [ ]

$[x[][]$

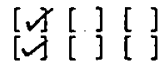

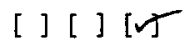

$[\mathcal{X}[][]$

[n] [ ] [ ]

[ ] [ ] [

[ ] [ ] [ [

$[X[][]$
Previous reviews complete and cover analysis, up to scope of this review, with no gaps.

Problem completely defined.

Accident scenarios developed in a clear and logical manner. Necessary assumptions explicitly stated and supported.

Computer codes and data files documented.

Data used in calculations explicitly stated in document.

Data checked for consistency with original source information as applicable.

Mathematical derivations checked including dimensional consistency of results:

Models appropriate and used within range of validity or use outside range of established validity justified.

Hand calculations checked for errors. Spreadsheet results should be treated exactly the same as hand calculations.

Software input correct and consistent with document reviewed.

Software output consistent with input and with results reported in document reviewed.

Limits/criteria/guidelines applied to analysis results are appropriate and referenced. Limits/criteria/guidelines checked against references.

Safety margins consistent with good engineering practices. Conclusions consistent with analytical results and applicable limits.

Results and conclusions address all points required in the problem statement.

Format consistent with appropriate NRC Regulatory Guide or other standards

Review calculations, comments, and/or notes are attached.

Document approved. 
OATE: FEg 17 lQ95

ATTM OS: $95-$ PRI-086

SUBAES: PRELIMINARY SAFETY SIALUATION REPORT (PSCR)

:o: J. O. Wagoner

Attached is a Preliminary Saiety Evaluation Report (PSER) for Project W-j20, 241-C-i06 wasta Ratrjeval Siuicing Systam. Completion of Project: W-320 is included in the iri-Party Agregment Milestones. This PSER documents the THRS independent review of 'WHC's Proliminary Satety Assassinent.

DOE Order $\$ 480.23$ requires that DOE periorm an independent review of the contractor's safety analysis and dociment that review in a safaty Evaluation Report (SER). The attacied represents the first such conpliance with that requirement at Haniord. It is our intant that future TiRS projects will also comply with this requirement as we imorove our saitity oversignt responsibilities and integrate safety more fully into the program management procass.

Your approval of the attached PSeR is recsmmended.

PRI:OHA

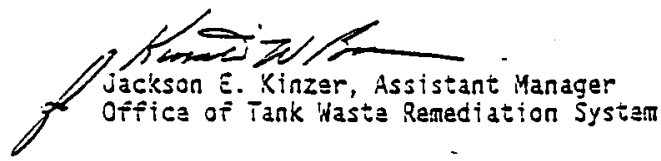




\section{i HNF-SD-WM-RPT-293 REV O,}

Q5-PRI -

Bes:

PRI OFE FILE

PRI ROG FILE

CCC FILE

D. ALEKANDER, PRI

K. 8RACKEN, TWR

W. EDWAROS, PRI

W. WRZESINSKI, THP

SANDERS, TWP .

KRUGER, OSA

RECORO NOTE: NONE

File: PRI:OHA/Prlim.Safety

RECEบบ

FE3 22 i495

\begin{tabular}{|c|c|c|c|c|c|c|}
\hline OFFiCE > & PRI I IDA & Jogr & & & & DOE-ALCCS \\
\hline & 1062 & Frat & TWP & ITHP & OSA & THR \\
\hline S. . IAME> & ALEXANDER & EOHAROS & HRZESINSKI & SANDERS & KRUGER & KINZER \\
\hline OATE $>$ & $1 c$ & $P_{R}=V_{.}$. & PaEvi. Can & PRer. 1 & pleev. & 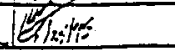 \\
\hline
\end{tabular}




\section{SAFETY EVALUATION}

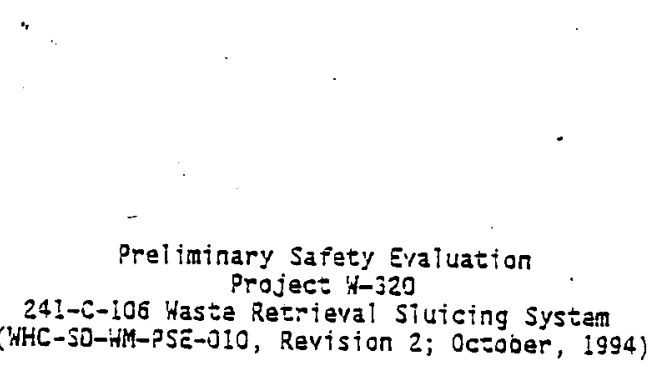

December 1994

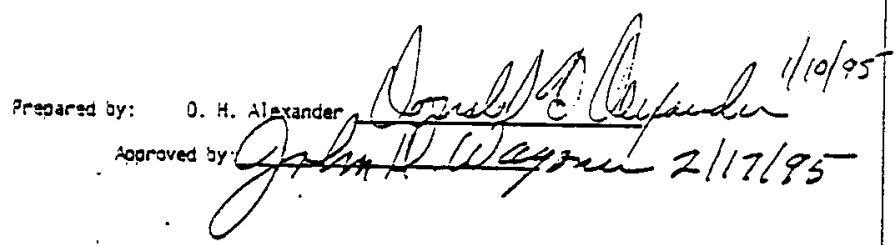

U. S. Deparzene of Energy Rteriand Coerations Otfics 


\section{CONCURREXCE PAGE}

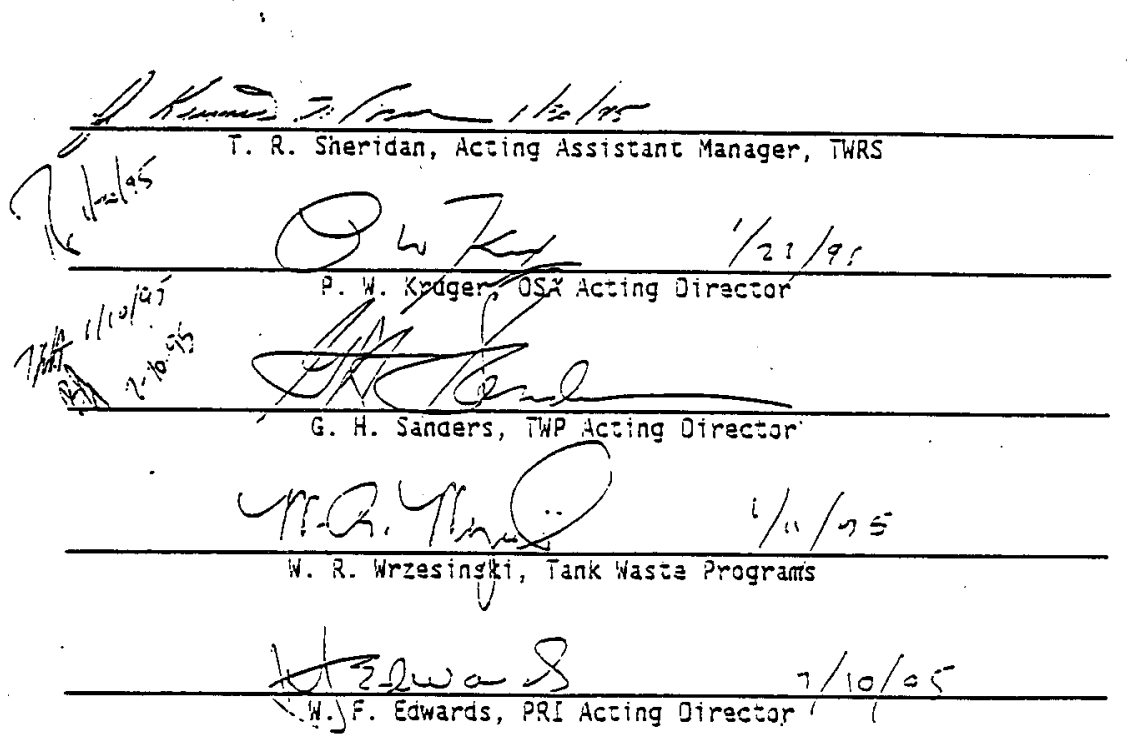




\section{INTROOUCTION}

This raport provides the U. S. Department of Energy (DOE) Richiand Operations Offica (RL) praliminary satety avaluation of the proposad sluicine of the nuclear wasts in singie-shelled, high heat, "watcili ist" Tank 241-6-106 (C-106) and transiar of this wasta to double-sinelled Tank 24]-AY-102 (AY-102). This avaluation is based in part on the Preliminary Safaty Evaluation (PSE), WHC-SOWM-PSE-010, Revision 2, datad Octoder 1994, and in part upon inceoendent raview mestings and comments. The purpose of this review is to supoort the satetyrelatad information provided in the Environmental Assassment and to determine whether project planning and system design, construction and sesting sinould be continued as proposed, be modified, or be terminatad beczuse of sarety considerations. This safety evaluation does not addross non-safety ralated issues which could imoact on project success unless those issues also could impact the health and safety of on-site or ofi-sita personnel or the anvironment.

Because this is a limitad-scope avaluation it does not comoletaly conform to the requi rements of Attachment 1, Section 4.f oi ook order 5480.23, nor does the PSE on which it is orimarily basad. Guidanca from OOE Headquartars (HQ; iettar, isang to Anttonen, July 13, 1993) does not require a new or ravisad Safaty Analys is Report (SAR) for this action. RL, using their Deiegation of Authority (lettar, 0'Toole and Grumbly to Manager, RL; Decmioer 9 , 1993), has adootsd th is same guidance as their own. Therotors, a Praliminary SAR witl not be requirsd prior to the start of the Wasta Retrieval Siuicing System procurement and construetion, and a Final SAR will not be required prior to operations. RL will, however, raview and approve a Safaty Assassment (SA) prior to authorizing wasta retrieval operations.

Pudic Law 101-310, Section 3137 (Wyden Amendment), "Safaty Measures for Wasta Tanks at Hanford Nuciear Reseryation", mandates that the Unitad States Department of Energy develoo pians for rosoonsa to safety issues associatad with the wasta storige tanks at the hanford Sits, and to report the progress of implementing these pians to Congress. The "Yanford Faderal Facil ity Agraement and Consant Order 89-10", aiso known as the Tri-Party Agrsement, includes milestones to demonstrata singla-sinell tank (55i) wasta ratriaval. Milestone M-45-03A, "Initiata Sluicing Retrieval of $C-106$, "by 0ctober 1997 , requires the retrieval of wasta from Tank 24l-C-106 to resolve the high-heat safety issue and to demonstrata wasta retrieval. Tank 241-6-106 has been identified during the 1994 re-negotiation of the Tri-Party Agraement as the M-45-03 retrieval demonstration tank by the COE and the Washington Stata Department of Eicology. 


\section{gACKGROUND}

Tank C-106 is a 2-inillion $L$ (530,000-gal) capacity sst. It contains approximataly $746,000 \mathrm{~L}(197,000 \mathrm{gal})$ of sludge waste. This voiume consists of a $91,000 \mathrm{~L}(24,000 \mathrm{ga}$ ) hard-pan layer, 534,000 L (141,000 gai) of high-heat sludge, 12$\}, 000 \mathrm{~L}(32,000 \mathrm{gai})$ of supernata, and a minera) crust (at the location of a 1986 core sample). The sludge is jelieved to contain a hign concantration of ${ }^{90} \mathrm{Sr}$, making it the najor soures of heat. Current heat-generation rats is estimatad at II6-MU/h $(110,0003 T U / h)$, enough to evaporats approximately 23,000 $L(6,000 \mathrm{gal})$ of makaup watar per month. The oojective of this project is to refuce the heat generation rate to below $42 \mathrm{MJ} / \mathrm{h}(40,000 \mathrm{STU} / \mathrm{h})$. Reducing the heat load to this level will aliow closura of the tank sataty issue.

The postuiatad safaty hazard for the tank without the mitigating sfiacts of the proposed project is higin-level nuclear waste ralease caused by the loss of tank intsgrity. There are two potential scanarios leading to loss of tank integrity. The first scanario is the inevitable degradation of the tank due to its usa iveli beyond its design lite, resulting in a significant tank leak. The sacond scanario (which may result from the first scanario or other causas) postuiatas loss of evaporative cooling followed by siudge dryout, resulting in the reiniorsed concrete overheating and faling. Reflooding of the sludge after dryout could presant stean sputtaring that would further stress the tank iner and concrata.

It is estimated by hestinginousa Hanrors Company (WHC) that without remediation this single shell tank could raquire cooling watar addition untit the year 2045 . Tank-to-tank sluicing will provide the earliest rassonable closura ot this sataty concarn. Removal of the heat-generating sludge is axpected to allow tarmination of the cooling watar addition and permit ink $C-i 06$ to be placed into a sata, intarim-stabilized stata.

Tinis project is to design, iabricata, develop, tast, and operate a new retrievai system, the Wasta Retrieval sluicing systam. The design oojective or the retrieval system is to remove a minimum of $i 5 \%$ of the heat-generating waste in Tank C-106. The proposad design usas doubia-0ipe transfer lines to move sludge from Tank $C-106$ to $A Y-102$ and to return sluicing filuid from $A Y-102$ to $C-106$. Two sluicing nozzlas wiit be designed and faoricated for the project. The nozzles will be remotaly operated from a control room using visual information from intank closed-circuit $T \%$.

This project has identified that radioactive and ehemical hazards are availabie during the construction period. Oesign and installation will have to account for the existance of these hazards. 


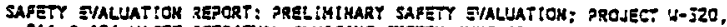

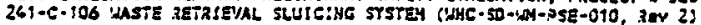

\section{EVALUATION}

\section{Design and operation}

For the purposes of this evaluation, possibly the most important factor is that the proposad siuicing operation has been completed sucsessiuliy more than fitty times in the past. This is particularly imoortant beciusa it aliminates the question of whether the siuicing ean. be conducted safely. Past siuicing operations, particulariy those concucted prior to 1960, experiencad operational probiems, primarily with pump iallures. Sluicing operations aftar that time, using improved pumps, have not experienced similar proolems. Line plugging, although it hasn't ocsurrad in the past, is a valid concern. Proposad improved instrumentation sinould provide sarly information and reduea this concarn.

As proposad, the wasta transier line will be a doubie-walled oioe and will be designed to conform to OOE Order 5430 . LA. Instrumentation will be provided to detact leaks of the inside pipe. While this design would appear to provide improved saitety, it is not clear that this aporact is the most cost-afiective method of eniancing iacility safety. Because the most likaly pioe rupturo mecianism apoears to be a seismically initiated failure or other mechanicai danage, satrety may be ennancad at lower cost by using single-walled piping, designed to the most stringent ASide eades with large saisaic design margins. Double-walled piping is particularly usaful when corrosion or erosion type failuras are a concern; neither should be an issue for this short sarvica lite systim. However, Washington doministrative Code ('NAC) Part 173, Section 303.640, Paragraph 3 requires double containment at all points for this type of operation. The cost and schedule impacts of ootaining a variancs from this gart of the WAC for this project are not ofisat by any jecrease in risk, but at some later time may be warrantad generically for iuture Hanford Site tank wasta retrieval operations.

HHC has statad (Tettar 94072828 RI, C.A. Augustine to R.L. Long, Novemicer 29, 1994) that the Project $H-320$ pipel ine system is designed in accordance with ANSi code 83!.3, Chemical plant and Rerinery Piping. This choica was identified as an aporopriate code for the project in complianca with the allowancs of DoE Order $6430.1 \mathrm{~A}$, Section 1300, for the usa of comparable safaty-rolated codes. RL agraes that for the low pressure, short life sarvice of this piping, ANSI 831.3 is an aporooriate code to satisiy the requiraments of Dog order 3430 . IA for the inner piping. $K L$ also agrees that the outar piping, which is primarily a leak collector and spray inhibitor, can be designed to less stringent standards; however, those standards aust be clearly identified, justified and carefully followed. We note, however, that the design of the outer oiping must be such that it does not allow its existance, operzition or fallure to degrade the inner piping or limit the inner piping's ability to mest its code requirements. Seismic requiraments for both piges shall be such that it can be shown by analysis that the inner giping will not fail when the entirs systam is subjectad to a Catagory I $(0.29$ Z?A) earthquaka.

At present, all involyed tariks (C-106, AY-102 and AY-10!) ara substantially 


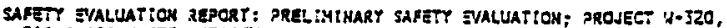

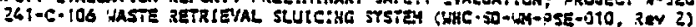

subcritical by both fissile coneantration and nuciear poison concantration. The sluicing of C-106, slurry transiar, and dispersai in Tank AY-102 are all mixing type operations which should maintain potential criticality produces in dispersad form.

Similariy, this agitating and mixing operation shouid sarve to liberata, rather than capture, formed or releasad nydrogen during the siuicing and transiar operation. Aceordingly, hydrogen build-ip during the sluicing and transier operations should not be a concern. Although hydrogen acsumulation during sluicing and transiar should not be an issue, at least four altarnative siuicing media other than the one described in the PSE have been proposad. Attar the transizer operation is completed, the contants of Tank AY-iOZ may be of a composttion that will trao ilammade gases, eventualiy releasing then suddenly into the tank headspaca at above the lower flanmability limit. The PSE does not discuss this mechanism for tite various siuicing fiuid options. The SA must, therefore, orovide an eppropriate analysis and justificition for the sluicino fiuid chosen, particularly as it difeces receiver tank chemistry. and the potential for hycrogen rotantion and subsequent ralease.

A possibie concarn is erosion of Tank C-106 during the sluicing ooeration. To address this issue, WHC proposas to work from the centar of the tank outward, impinging siuicing Fuid on the tank walls only when the minimun amount of siurry is lett in the tank. This apoears to be a reasonable aporoach in the avent that sluicing action causes failurs of an already weakened tank wail or raopens a tank leak currentiy piugged by corrosion products or viscous slucge. A related concarn is the shock wave or direct shock efiect of the sluicing fluid, transmittad to the tank wall and causing mechanical failure. WHC has statad that the design of the sluicing system pumos and nozzles aro such that sluicing medium velocity is linited to a degres that this is not a serious concern, but this information is not discussad in the PSE. Limits on siuicing energy must be covered in the SA and assoctatad Technicai Safaty Requiraments.

'HHC's proliminary satety evaluation has identified a seismically initiated transfer line braak as one of the "event hazardous conditions estimated to be worst case". Their analysis assumes that for the worst case, unmitigated scenario) pumoing continues and a suostantial fraction of the tank contants are raleased to the graund suriaca. To mitigate the consequences of this acsident, they propose a seismic switch, inttiated at sone nominal ground acesieration, which would shut ofi the pump and minimize the amount of radioactive mataria] released to the environment. This seismic switch is a fairly simole device which reduces risk during a seisaic event; however, it cannot be creditad with absoluta reliability. The design evaluated in the $5 A$ should consider the known rel iability of the Saity Class I seismic switches to bettar demonstrata that the resultant risk is well within the acesptable range.

Conciusion - the proposed design aporoach appears reasonable, except that systems for transiarring tank wasta should be analyzed to show the ir ability to withstand at least a 0.29 ZPA without containment failure. 
HNF-SD-WM-RPT-293 REV 0

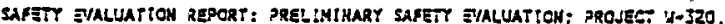

241-E-106 WASTE RETRIEVAL SLUICING STSTEY (UHC-50-SAH-PSE-010, RaY 2)

Accident Analysis

The PSE provides detarministic analysas of a spectrum ot postulatad aceidents. Rough estimates of aceident probabilities are presented but not used to calculata quantitative risks. The spectrum of accidents considered appears rassonabie, and consaquenca calculations are adequately, possibly excessively, consarvative. Calculations are limitad to standard hearest sita boundary and loo-netar points. This aporoach is adequate at this pSe stage because it bounds oossibie consequences. At the SA stage, accident calculations should usa more ralistic, although conservative, numioers and should make rasonabie estimates of risk in order to bettar identify necassary safety enhancaments. Facility workar safety must also be explicitly addressad.

This PSE assumes that for accidents with unaccaptable consaquences, use of safaty-class equipment or barriers will result in accaptabie rasults, a.g. the seismic switcies and the cover blocks on the pump and jumper pits. This is a defacto probadilistic anaiysis that assumes that the probability of thesa eninancements faiting is sufficiently small to make the overall probability of the event accsptable. Ihis is an acsaptable approach at this pSe siage; however, the SA must provide sufificient quantitative information to confirm thesa assumptions, or additional design (or operational) staps must be takan.

Revision 2 of the PSE provides calculatad Efiactive Dosa Equivalents (EDE) for unbounded acsidents (beyond OBAs) which ars substantially in excess of those allowable by WHC and OOE guideitines, particuiarly on-sita. These EDE's are clearly conseryative and not inconsistant with thosa used for other Hanford projects. As such, they raprosent an adequate basis for estabi ising that this project rapresents no greater bounding hazard than others at the Haniord sita. The SA shouid provide more ralistic calculations, including beyond DBAs, to place a bettar perspective on the overall project risk.

The PSe does not calculate hazard consequences from chemical releases. It does indicate that such consaquencas are expectad to be small when compared with radiological consaquences. This is a reasonable position at this pSe stage; however, the SA must provide a comolete assessment of potantidl chemical hazards.

Conciusion. - The PSE has identitied and analyzed a spectrum of aceidents which appear to encompass the proposed project. Calculated consaquencas from these accidents, without mitigation, range from ninimal to unaccsotade. Mitigative measures apoear to be avaliable to bring ail postulated acsidents within dosa guidelines. More realistic, but still conservative, assumptions should bring these postulatad accidents further within guidel ines. The usa of risk nethodology at the SA stage should assure that aceidents with lessar consaquences don't represent disproportionata risks. As such, the accident calculations provided at this stage in the project appear adequate and the calculatad consacuences do not preciude continuation with more detailed design and rigorous safaty analysis. 


\section{REITEH APPROACH}

The review sumarized in this evaluation coverad a considerabie period of time and included numerous experts from national laboratories, RL, $R L$ and $H Q$ supoort contractors, private industry and consultants. A substantial numoer of questions, many unrelated to the scope of this evaiuation, wera raisad and resolved. All of the associatad questions and resolutions aro contained in the review fite and are available as requirad. All of the raview intormation was considered in developing this raport.

As this review was being compieted, RL racognized the need to develop a mora disciplined and compleze review procass. That process is being implemented on subsequent projects and will be used for the SA on this one; however, it did not saem appropriata or necassary to "start over" on this reviaw. This report does evoke a number of the principles being imolemented in this more disciolined and complete review procass and provides reiated guidance so that the SA will be consistant with the new raquirements.

Reviewers' comments not covered in this evaluation included: assurance that the necassary heat-iearing materials wouid be removed by the siuicing, possible foaming of supernate, and potantial alternate approaches for retrieval. Although these are all. valid issues and responses were provided, they do not directly relate to this avaluation. The more disciplined review procadures to be used for future RL safety reviews will assure that satety reviewers' comments ars more properly iocused.

It is important to note, that from a safety perspective; failurs of this project to accompiisi all or its goals is not necessarily negative. At some point, watchlist tanks such as C-106 must be processed, either to reduce the ir hazard potential or to pravent their leaking. Sluicing and transfar is considerad a viabie means of performing much of this processing. Lessons learned from this demonstration project will aid in meeting this requirement. Should unexpected - results occur, this information can be iactored into future designs and operations. 
SAFET F/ALUATION REPGRT: PRELLAIKARY SAFTTY g/ALUATION; PROJET W-j20,

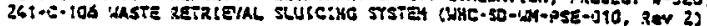

\section{RECENT EVENTS}

During the period of this raview, Tank $C-i 06$ has experienced anomalous temperaturs readings. Cooling water in the tank was deliberataly allowed to droo to the level of the sludge (as part of a procsss test) followed by the addition of about $98,000 \mathrm{~L}(26,000 \mathrm{gal})$ of water. Following the watar addition, indicatad tamperature on one of two installed themocouples slowiy rosa to some $217^{\circ} \mathrm{F}$, dropped to more nomal values, and has experienced some oscillations. Although this appears, at worst, to be a local eriect, it emphasizes the concarns with leaving Tank $C-106$ in its current high-heat situation. At. this point it does not apoear that this recent anomaiy should affect the proposad siuicing and transter operation or the results of this evaluation. Revision 2 of the PSe acknowiedges this situation and commits to reporting further details and results of an investigation of $i t$ in the upcoming $S A$ for the project.

\section{CONCLUSIONS}

Based on the reviews conducted as summarized in this Evaluation. TWRS believes that there is reasonabie assurance that Tank 241-6-106 Wasta Retrieval siuicing Systan project can be designed, orocured, constructed, and tastad with no undue risk to facility workers, co-located workers, the public, or the snvironment. In large measure, that conclusion is basad on similar past succassiul operations. From a safety and heal th standpoint, project $H-320$ procurement, construction, and testing are approved. This approval is basad on WHC's full compliance with ANSI 331.3 for the inner waste transfer piping for Project $1-320$, except that quality assurance and record kesping shall be in aceordance with DOE Order 5700.5C. Any proposed deviations or variances from the raquirements of ANS I 831.3 must be identified, justified and requestad in writing to DoE. They shall not be implemented untit writtan approval is racsived. In no casa will deviations or variances be approved if they decrease satety margins or otherwisa increasa the risk to facility workars, co-iocated workers, the pubilic, or the snvironment. - The SA must include verification of comolianca with 831.3 for the inner piping, identification of the standards usad for the outar piping and verification of complianca, and yerification that the inner piping ean withstand a 0.29 zoA earthquake including consideration of the behavior of the outer piping and associated supports during this event.

Befors a definitive conclusion can be rached on commencament of the grogosad wasta sluicing and transfer operations, an SA must be completad. This evaluation identifies several issues that must be considered in that SA and which will be assessad in RL's roview of the SA:

6. Documentation that all piping carrying radioactive or hazardous materials has been designed, procured, and installed to ANSI 831.3 (or ASME B\&PY code, Section (ii). Any deviations or variances must be justified and pre-approved in writing by RL.

$v$ - Documentation that all guard piping (outer piping of dual piping) 


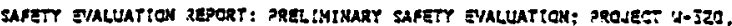

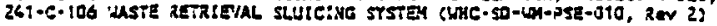

has been designed, procured and installed to clearly identified, written procedures and that the installation, operation, or faiture of this piping or its connections shall not compromise the integrity of the inner piping.

- An arialysis (including the infiuenca of the existance and fatiurs of the outer piping) showing that the inner piping can withstand a Category I ( 0.29 Z?A) sarthquake without faiture.

4 - An appropriatz. analysis and justification for the sluicing fiuid chosen, particulariy as it afiects recaiver tank chemistry and the potential for hydrogen gas trapping.

5 - Provision of limits on sluicing energy as related to potential for mechanical damage to C-106 containment.

6 - Design evaiuation using the known reliabilities of the Safety Class 1 seismic sititeh and other emponents to bettar demonstrata quantitatively that the rasultant risk is well within the acsaptadie range.

7 - More ralistic yet consaryative, caiculations, inciuding beyond DBAs, to place a better perspective on oyerall project risk.

8 - Explicit evaluation of facility worker safaty.

$q$ - Complete assassment of potential chemical hazards.

10 - Investigation, analysis and conclusions ragarding the anomalous temperatura readings event. 
Fauske \& Associates, Inc.

DATE:

TO:

FROM:

SUBJECT:

REFERENCE:
January 12, 1996

John Harris, WHC

Marty Plys

C-106 Power Distribution

T. Bander, Revised Thermal History of Tank 241-C-106, WHC-SD-WMER-200, Nov. 9, 1993.

D. Ogden, WHC, personal communication, Dec. 28, 1995.

Independent of the properties of the waste in C-106, it is easily demonstrated that the heat source is not grossly skewed toward the lower hardpan layer of the tank, and that it is probably fairly evenly distributed. The references show that computer modeling is effective for a detailed understanding of the waste temperature distribution, and that the models are in basic accord with observations. The approach taken here is to show what would happen if power were assumed to be skewed toward the hardpan, and to demonstrate that this would conflict with the current understanding of the tank as described by the references.

For C-106, about $90 \%$ of the power is lost through the headspace, so the temperature distribution can be fairly represented as one-dimensional for this analysis. For reference, an average temperature drop between 33 to $40 \mathrm{C}$ is observed over a distance of about 6 feet in the soft layer at the riser 8 location. The temperature difference across the softer upper layer(s) due to internal heat generation is given by:

$$
\Delta T=\frac{(Q / A) L}{2 k}
$$

where $\mathrm{Q}$ is the power generated in the layer, $\mathrm{L}$ is its thickness, and $\mathrm{k}$ is its thermal conductivity. In addition, power produced in the lower layer induces a temperature difference in the upper layer of exactly twice the value given by the equation above.

Clearly if all the power were generated in the hardpan, the temperature difference observed and calculated woud be much higher than actually observed, so this hypothesis can be quickly discarded. If a fraction $F$ of the power were produced in the hardpan, the ratio of the resulting temperature difference to the nominal temperature difference would be: 


$$
\frac{\Delta T^{\prime}}{\Delta T}=\frac{F+0.5(1-F)}{0.5}
$$

Note that this ratio is independent of the waste properties and depth. If $25 \%$ percent of the power were produced in the hardpan, then the value of the ratio is 1.25 , i.e., the observed temperature difference would disagree by about $10 \mathrm{C}$ with models assuming little power in the hardpan. While a $10 \mathrm{C}$ discrepency between observations and calculations could potentially be attributed to factors such as the thermal conductivity or two-dimensional effects (Riser 8 is near the periphery), it would be unrealistic to hypothesize that much more than $25 \%$ of the power could be produced in the hardpan.

Therefore, independent of the waste properties in C-106, it can be concluded that most of the power is produced in the soft, upper layer, and that it is unlikely that a substantial fraction of the power is produced in the bottom hardpan layer.

16W070 West 83rd Street • Burr Ridge, Illinois 60521 • (708) 323-8750

Telefax (708) 986-5481 
President

Westinghouse Hanford Company

Richland, Washington

Dear Sir:

PROJECT 93L-EWW-320, TANK 241-C-106 SLUICING - SLUICING FLUID BASELINE CHANGE TO CORROSION INHIBITED WATER

Reference: Letter from C. A. Augustine, Westinghouse Hanford Company (WHC) to R. L. Long, Department of Energy Richl and Operation Office (RL) dated November 2, 1994, Project 93L-EWW-320, Tank 241-C-106 sluicing - Fluid Baseline Change to Corrosion Inhtbited Water

WHC has recommended to RL a change in the baseline slutcing fluid for Project $W-320$, Tank 24l-C-106 sluicing, to corrosion inhtbited water. This change alleviates safety issues identified in the Preliminary Safety Evaluation (PSE) and avoids charactization issues which would be difficult, time consuming; and expensive to resolve.

RL concurs with the WHC recommendation to proceed with use of corrosion inhibited water to sluice tank $\mathrm{C}-105$.

WHC should continue to pursue waste minimization concepts (e.g. use of - supernatants, effluents) for waste retrieval operations.

Please contact Wendell Wrzesinski at 376-6751 wth any questions on this subject.

RTI :NLW

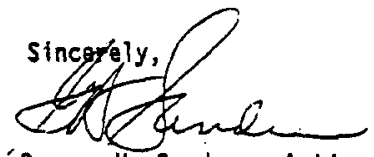

'George H. Sanders, Acting Director

Tank Waste Retrieval, Treatment and Immobilization Diviston 
HNF-SD-WM-RPT-293 REV 0

This page intentionally left blank. 
From: Plant Systems Safety Basis

Phone: $\quad 376-2527 \quad$ HO-34

Date: September 20, 1995

Subject: CURRENT STATUS OF THERMAL HYDRAULIC ANALYSIS AND RESULTS IN SUPPORT OF THE SAFETY DOCUMENTATION FOR PROJECT $W-320$

To:

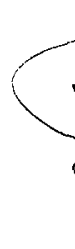

J. C. Conner

CC: R. J. Cash

B. C. Fryer

J. P. Harris, III

G. T. Maclean

D. E. Place<smiles>[AsH4]</smiles>

$-41-84$

$\$ 7-15$

HO-34

S2-48

H5-49

H5-27

74010-95-PSSB-KS-036

References:

(1) Internal Memo, J. C. Conner to D. M. Ogden, "Assistance to be provided by Safety Fluid Mechanics to Project SAR Engineering in Support of the Safety Documentation for Project $W-320, "$ dated June. 15, 1995.

(2) HanTon B. M., 1995, "Waste Tank Summary Report for Month Ending January 31, 1995," WHC-EP-0182-82, Westinghouse Hanford Company, Richland, Washington.

(3) CcMail, Gary R. Tardiff to K. Sathyanarayana dated August 30, 1995.

(4) Bander T. J. and M. J. Thurgood, 1995, "Tank 241-C-106 Thermal Hydraulic Analysis to Establish a Minimum Liquid Leve 1," WHC-SD-WM-ER-495, Rev.0, Westinghouse Hanford Company, Richland, Washington.

\section{Purpose:}

The purpose of the thermal hydraulic analysis is to provide support (Ref. 1) for the Project $W-320$, Tank 241-C-106 S7uicing, safety documentation. The analysis has been performed to address two areas of concern. The first item of concern is the safe storage of C-106 sludge in tank AY-102 without considering the operation of air-lift circulators (ALCS). The second item deals with the Criteria for the sluicing activity.

\section{Problem Description:}

The proposed sludge transfer from tank C-106 to tank AY-102 will increase both sludge and thermal loading in tank $A Y-102$. The increased sludge and thermal loading will lead to higher sludge temperatures. Tank AY-102, a double-shell tank, which has a design capacity of one million gallons, presently contains 812,000 gallons of waste in the form of supernate and 
sludge. Based on latest information (Ref.2), the tank contains 32,000 gallons of sludge and 780,000 gallons of supernate. Currently, tank AY-102 is operated with about 600 cfm primary ventilation flow and no secondary (annulus) ventilation flow. Based on the data about ventilation flows, sludge temperature distribution and waste level data, it is estimated that the tank has a heat. Joad of $33,000 \mathrm{Btu} / \mathrm{hr}$. The relevant parameters of the waste in tank $A Y-102$, tank $C-106$, and the combined waste in tank $A Y-102$ are given in Table 1. Based on the information of Gary Tardiff (Ref.3), it may be possible to provide secondary ventilation flow up to $3,000 \mathrm{cfm}$ for tank AY-102.

Tank C-106, a single-shell tank, which has a design capacity of 530,000 gallons, contains 197,000 gallons of sludge and 22,000 gallons of supernate. Thermal hydraulic analysis (Ref. 4) of tank C-106 1994 - Process Test resulted in an upper bound heat load estimate of $132,400 \mathrm{Btu} / \mathrm{hr}$. The heat distribution in the sludge (Ref. 4) is shown in Table 1. The sludge is represented as three layers with increasing heat loads from top to bottom. The bottom layer of $-2 \mathrm{ft}$ contains a heat source of $64,500 \mathrm{Btu} / \mathrm{hr}$. Currently, the tank is cooled with a primary ventilation flow of about 2,300 cfin.

\section{Results:}

Combined sludge temperature distribution calculations are performed using HUB, an engineering calculational software, assuming that a heat load of $92,400 \mathrm{Btu} / \mathrm{hr}$ (4.8 ft of C-106 sludge) is transferred to tank $A Y-102$ and the remaining $-40,000 \mathrm{Btu} / \mathrm{hr}(-1.2 \mathrm{ft}$ of bottom sludge) will stay in tank C-106. It is also assumed that the sludge from tank $C-106$ will resettle in tank $A Y-$ 102 to twice its original thickness (Fluffiness Factor $=2$ ). Without the operation of secondary ventilation to cool the tank floor (i.e., an adiabatic boundary condition), the sludge temperatures (See Table 2 for zero cooling effectiveness) will reach local saturation temperature and produce steam if the sludge is a nonconvective medium. With the secondary ventilation cooling availabie, the peak siudge temperatures can be reduced below saturation if high air flow rates can be obtained. Sludge thermal performance corresponding to two values of secondary ventilation flows of 2,000 and $3,000 \mathrm{cfm}$ have been estimated and the results are shown in Table 2. Calcutations were performed to estimate the combined waste temperature distribution versus the effectiveness of secondary ventilation flow. The effectiveness of the ventilation flow is defined as the ratio of actual air temperature rise to maximum possible afr temperature rise. The maximum air temperature is that which would occur if the air reached bottom sludge temperature. Figure 1 shows the temperature distribution in sludge for different values of secondary ventilation effectiveness with 2,000 $\mathrm{cfm}$ flow: Similar results for $3,000 \mathrm{cfm}$ secondary ventilation flow are shown in Figure 2 .

The results show that the peak sludge temperatures will be about 203 and $190^{\circ} \mathrm{F}$ with an effectiveness of $35 \%$ and flow rates 2,000 and $3,000 \mathrm{cfm}$, respectively, for the secondary ventilation cooling system. Table 2 also presents the local saturation temperature at the peak temperature location. The lower saturation temperature assumes the liquid in the tank sludge is 
Page 3

September 20, 1995

water and the higher value corresponds to an aqueous solution whose vapor pressure is about $85 \%$ of water.

A separate detailed analysis of floor cooling channel effectiveness using the GOTH Computer code was performed to evaluate two-dimensional thermal effects in the sludge near the floor and floor cooling channel. The analysis shows that the effectiveness will be about $37 \%$ for $2,000 \mathrm{cfm}$ flow and $32.5 \%$ for $3,000 \mathrm{cfm}$ flow. The peak sludge temperature and the secondary ventilation flow floor exit temperature for 2,000 cfm flow are shown in Figures 3 and 4 . For $3,000 \mathrm{cfm}$ secondary ventilation flow, these parameters are shown in Figures 5 and 6 . For 2,000 cfm secondary flow case, the peak siudge temperature of $204{ }^{\circ} \mathrm{F}$ is predicted at $3.75 \mathrm{ft}$ from the tank bottom. The secondary flow with an inlet temperature of $70^{\circ} \mathrm{F}$ will enter the cooling channel at the center of the tank bottom and is predicted to exit to the annulus at $107^{\circ} \mathrm{F}$. Using $3,000 \mathrm{cfm}$ secondary flow, the estimated peak siudge temperature is $192^{\circ} \mathrm{F}$ at $4.25 \mathrm{ft}$ from the bottom. The secondary ventilation flow is estimated to heat up to $96^{\circ} \mathrm{F}$ (See Fig. 7). Therefore, as the results in the Table 2 show, the peak sludge temperature will be about 192 ' $\mathrm{F}$ with secondary ventilation floor flow of 3,000 cfm and for an assumed inlet air temperature of $70^{\circ} \mathrm{F}$. To assure the peak temperature during hot summer conditions will not exceed this value, additional GOTH simulations are being performed using Hanford annual meteorological conditions for the air inflow. This may result in lower peak temperature values than those shown in Table 2 due to thermal inertia effects combined with colder conditions during the winter.

Conclusions:

1. Thermat Effects of Combined Sludge:

The calculations performed using HUB show that the peak sludge temperature of $191^{\circ} \mathrm{F}$ at a sludge height of $4.25 \mathrm{ft}$ and $201^{\circ} \mathrm{F}$ at a sludge height of $3.75 \mathrm{ft}$ using 3,000 and 2,000 $\mathrm{cfm}$ secondary ventilation flow, respectively to cool the tank floor. The GOTH model to evaluate the cooling effectiveness of the secondary flow in the tank floor channels predicts $192^{\circ} \mathrm{F}$ and $204^{\circ} \mathrm{F}$ peak sludge temperatures with 3,000 and $2,000 \mathrm{cfm}$ secondary flow, respectively. The cooling effectiveness of these cooling air channels at the tank bottom has been estimated to be $32.5 \%$ and $37 \%$ for 3,000 and $2,000 \mathrm{cfm}$ flow, respectively. The local saturation temperatures range from $236^{\circ} \mathrm{F}$ to $246^{\circ} \mathrm{F}$ depending on the supernate vapor pressure characteristics and total waste height of $24.5 \mathrm{ft}$. Therefore, in summary, the transfer of $92,400 \mathrm{Btu} / \mathrm{hr}$ waste from tank C-106 to tank AY-102 is acceptable provided the annulus floor ventilation flow can be maintained between 2,000 and 3,000 cfm preferably at the higher level.

2. Criteria for the sluicing activity in $\mathrm{C}-106$ :

Sluicing may be initiated in tank 241-C-106 when the following conditions are met after operation of the air chiller system to mitigate any postulated "saturated zone" within the tank. 
September 20, 1995

1. The chiller on the tank inlet vent has run long enough to cool the sludge such that the temperature at thermocouple \#1 on tree 8 is at or below its normal winter time temperature (148 ${ }^{\circ} \mathrm{F}$ ).

2. The behavior of the thermocouples on tree 14 do not contain large random variations in temperature, such as occurred during the process test.

3. Prior to initiating of siuicing, a GOTH simulation will be run with the then current conditions to confirm the nonexistence of the saturation zone.

sluicing may be continued so long as the following criteria are met:

1. The temperatures on all thermocouples remain below the local saturation temperature.

2. The temperature of thermocouple \#l on tree \#8 remains at or below $170^{\circ} \mathrm{F}$.

NOTE: It is very likely, though not certain, that the temperature readings from the thermocouples on tree \#14 will start to read high temperatures similar to the readings that occurred following the process test since the sluicing process may wash debris into the annular gap around the tree, disrupting the convective cooling of the tree. This should not cause any concern as long as the temperature readings are below the saturation temperature. If readings at or above saturation temperature are read, continuation of the sluicing process should be reviewed. It is also possible that the temperature readings on tree \#8 will increase as there are some indication that some convective cooling of this tree is also occurring and it may be disrupted by the sluicing process. This is acceptable as long at the temperature of $170{ }^{\circ} \mathrm{F}$ (the maximum winter temperature predicted by GOTH assuming no gap exists) is not exceeded.

K. Sallef Cunanay 7 9/20195

Plant Systems Safety Basis

bab

Attachments 2

CONCURRENCE:

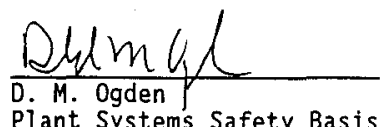

Date: 9121195

Plant Systems Safety Basis 
HNF-SD-WM-RPT-293 REV 0

Table 1. Parameters Used in AY-102 and C-106 Siudge Consolidation.

1. Tank AY-102

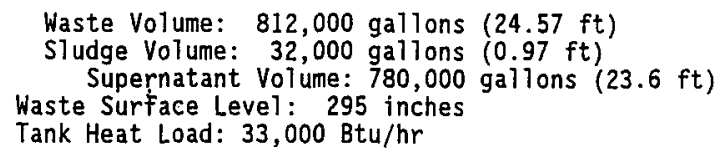

2. Tank $\mathrm{C}-106$

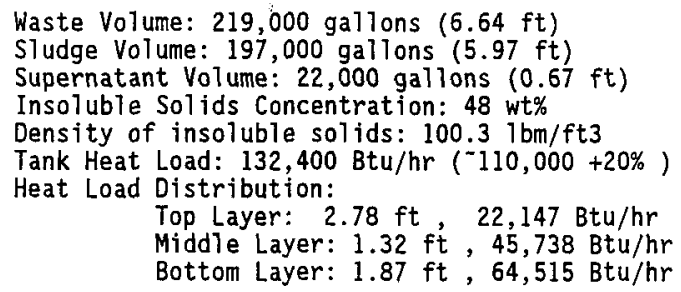

3. Tank AY-102 with Combined Sludge

1. Sludge:

Bottom Layer: AY-102 \$1udge, $0.97 \mathrm{ft} ., 33,000 \mathrm{Btu} / \mathrm{hr}$

Top Layer: Transferred C-106 Sludge, Sludge Height: $9.62 \mathrm{ft}$ Fluffiness Factor: 2

Heat Load: 92,400 Btu/hr (Heat load remained

Total Waste Volume: $812,000 \mathrm{gallons}(24.57 \mathrm{ft})$

2. Primary Ventilation

Flow: $630 \mathrm{cfm}$

Inlet air Temperature: $70^{\circ} \mathrm{F}$

Relative Humidity: $50 \%$

3. Secondary Ventilation

Flow: 2000 and $3000 \mathrm{cfm}$

Inlet air temperature: $70^{\circ} \mathrm{F}$ 
Table 2. Tank AY-102 Combined Sludge Peak Temperatures versus Secondary Ventilation Effectiveness.

\begin{tabular}{|c|c|c|c|c|}
\hline \multicolumn{2}{|c|}{ Secondary ventilation } & \multicolumn{2}{|c|}{$\begin{array}{c}\text { Peak sludge } \\
\text { temperature } \\
\left({ }^{\circ} \mathrm{F}\right)\end{array}$} & \multirow[t]{2}{*}{$\begin{array}{c}\text { Local } \\
\text { saturation } \\
\text { temperature } \\
\left({ }^{\circ} \mathrm{F}\right) \\
\end{array}$} \\
\hline $\begin{array}{c}\text { Effectiveness } \\
\downarrow\end{array}$ & $\begin{array}{l}\mathrm{Flow} \\
(\mathrm{cfm})\end{array}$ & $\begin{array}{l}2,000 \\
(\mathrm{cfm})\end{array}$ & $\begin{array}{l}3,000 \\
\text { (cfm) }\end{array}$ & \\
\hline \multicolumn{2}{|l|}{0.0} & 518 & 518 & $243-252$ \\
\hline \multicolumn{2}{|l|}{0.1} & 286 & 253 & $238-248$ \\
\hline \multicolumn{2}{|l|}{0.25} & 220 & 200 & $237-246$ \\
\hline \multicolumn{2}{|l|}{0.35} & 203 & 189 & $236-245$ \\
\hline \multicolumn{2}{|l|}{1.0} & 174 & 168 & $236-245$ \\
\hline
\end{tabular}


Figure I Temperature Distribution in Siudge Layer of Tank AY-102 with Annulus Ventilation Flow Effetiveness as a parameter for secondary Vent. Flow of $2000 \mathrm{cfm}$.

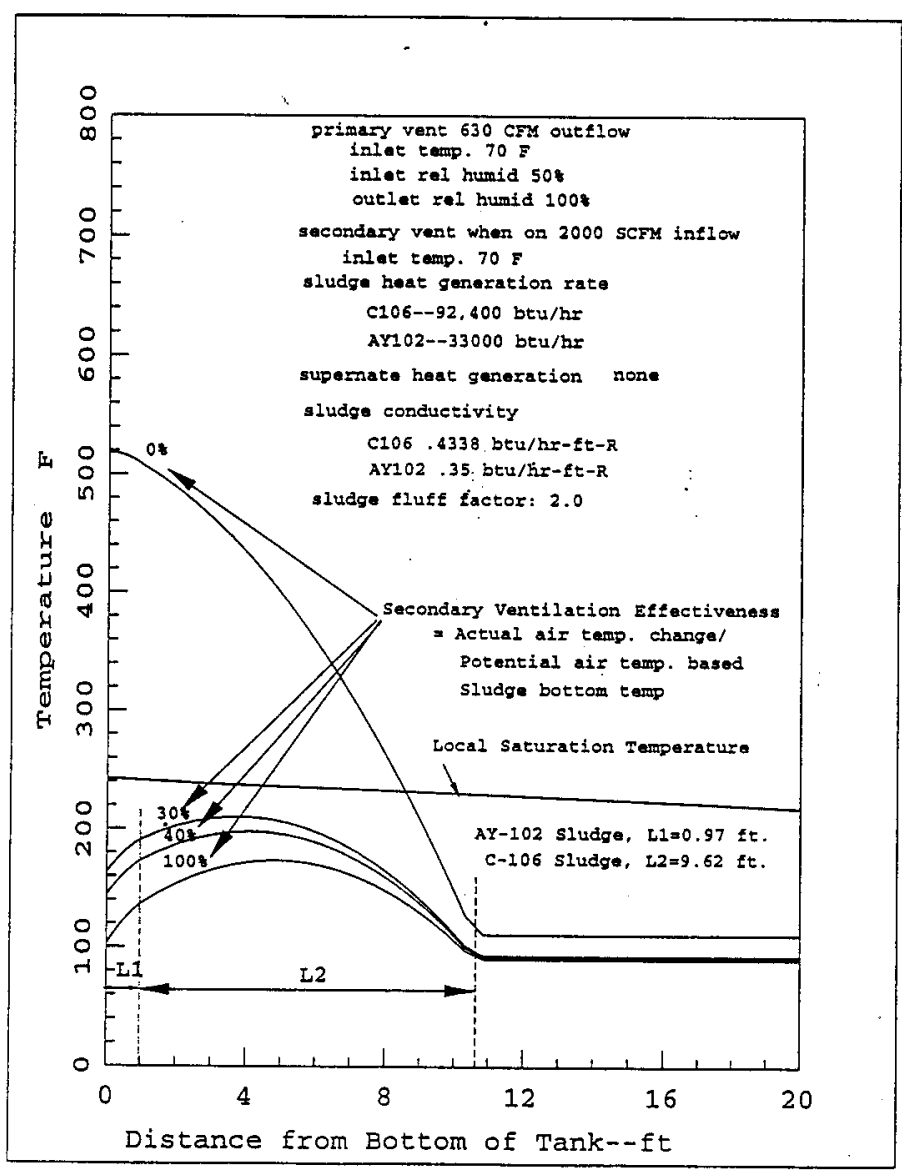


Figure 2 Temperature Distribution in Sludge Layer of Tank AY-102 with Annulus Vent. Flow Effetiveness as a parameter for secondary vent. Flow $=3000 \mathrm{cfm}$.

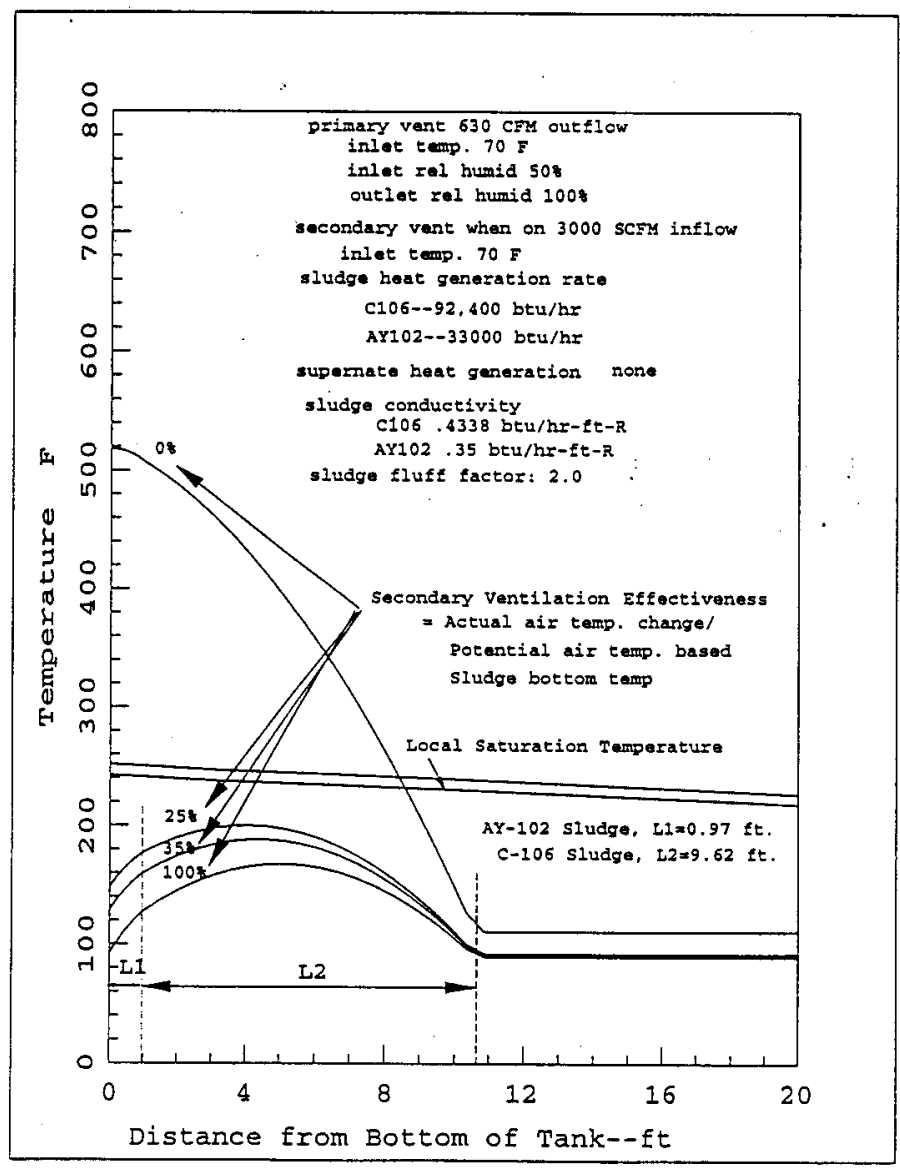


$\therefore$.

Figure 3. Combined Sludge Peak Temperature for Secondary Ventilation Flow of $2000 \mathrm{cfm}$.

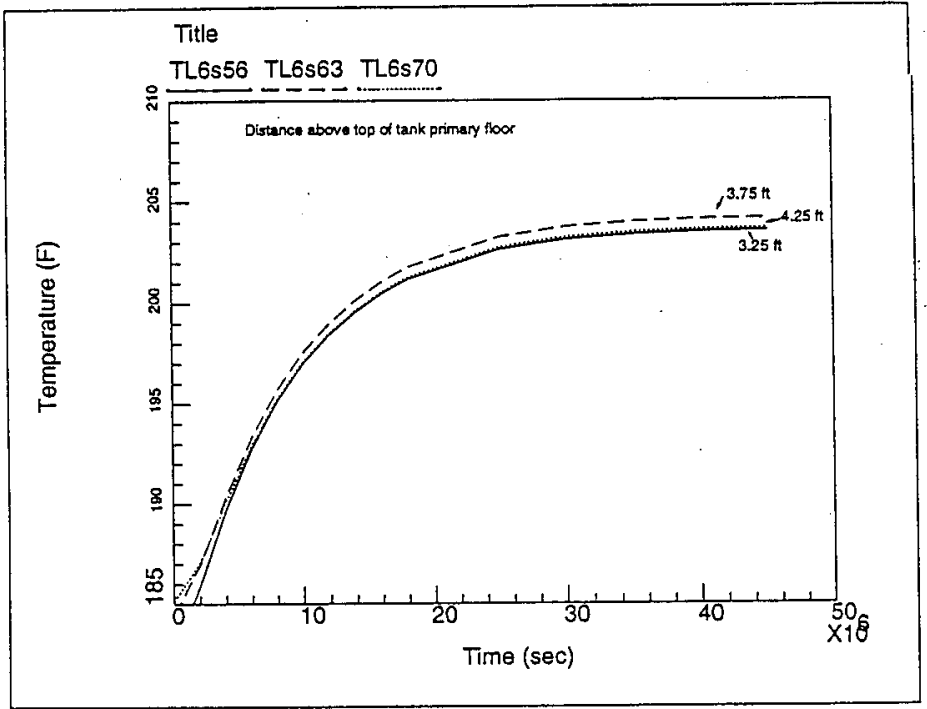

*GOTH is a trademark of MII, which is derived from GOTHIC - a registered trademark of the EPRI Corp. of California. 
Figure 4. Seconcary Ventilation Flow Air Temperature in the Tank Floor Cooling Channel for $2000 \mathrm{cfm}$ Flow.

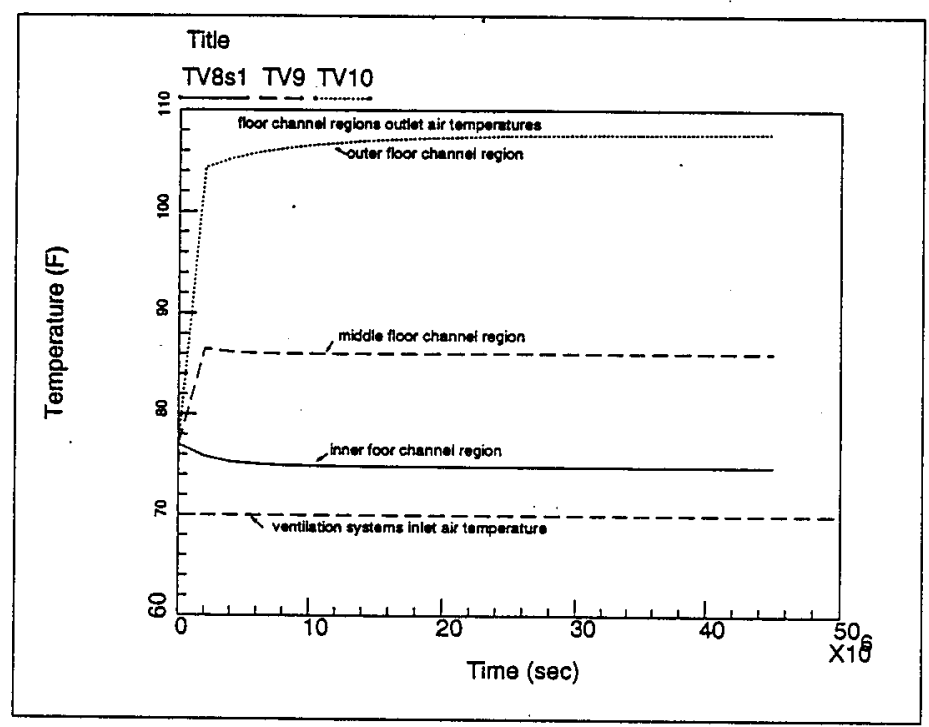


Figure 5. Combined Sludge Peak Temperature for Secondary Ventilation Flow of $3000 \mathrm{cfm}$.

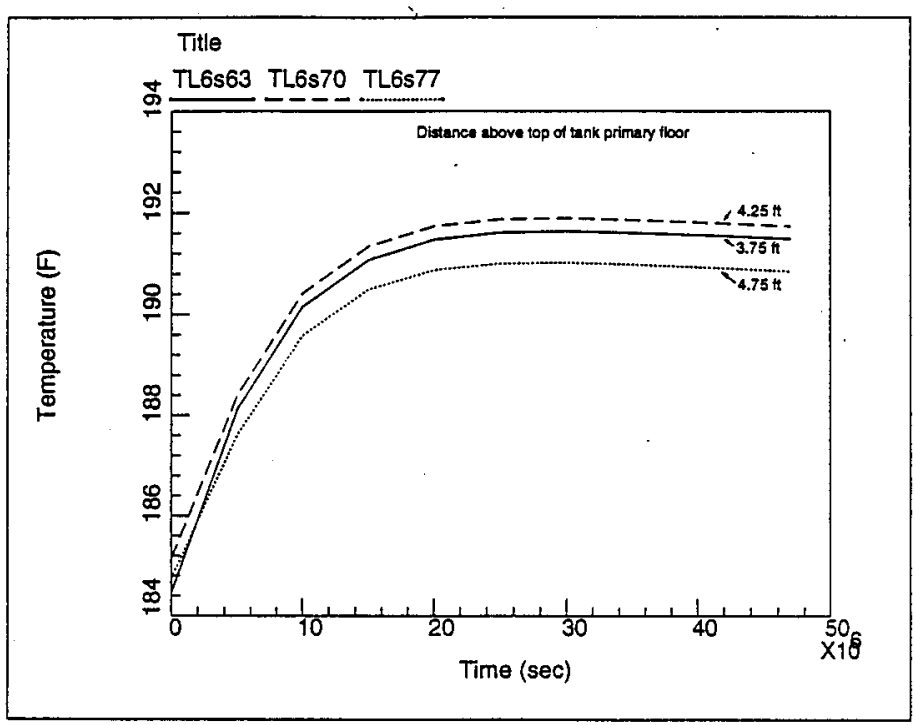


Figure 6. Secondary Ventilation Flow Air Temperature in the Tank Floor Cooling Channel for $3000 \mathrm{cfm}$ Flow.

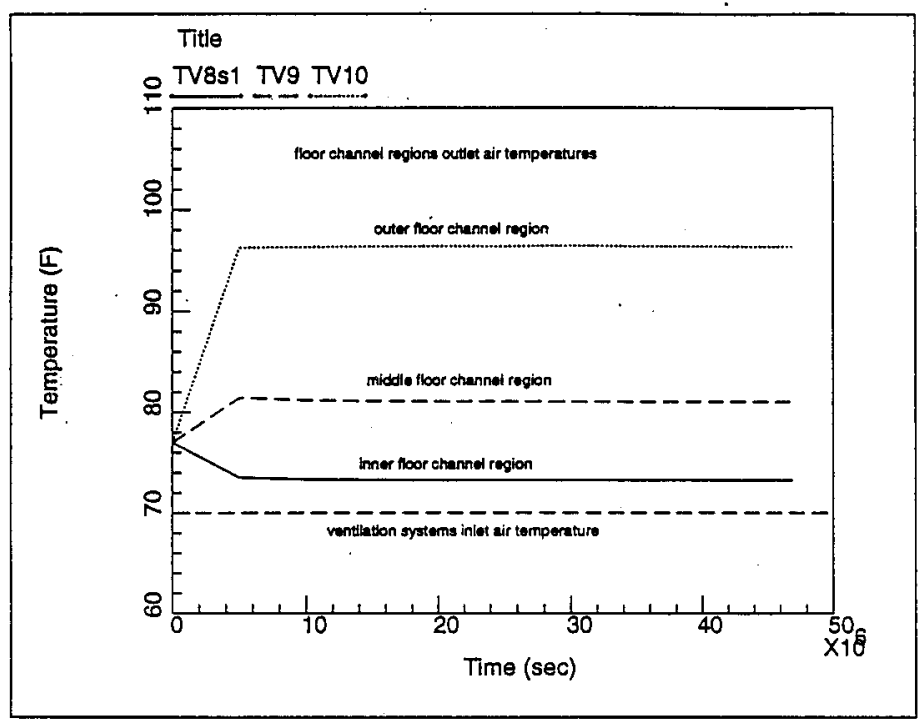


Figure 7. AY-102 Floor Ventilation Channel Regions and Air outlet Temperatures For 3000 CFM Floor Ventilation Flow at $70 \mathrm{~F}$ after a 93400 Btu/hr C-106 sludge Transfer

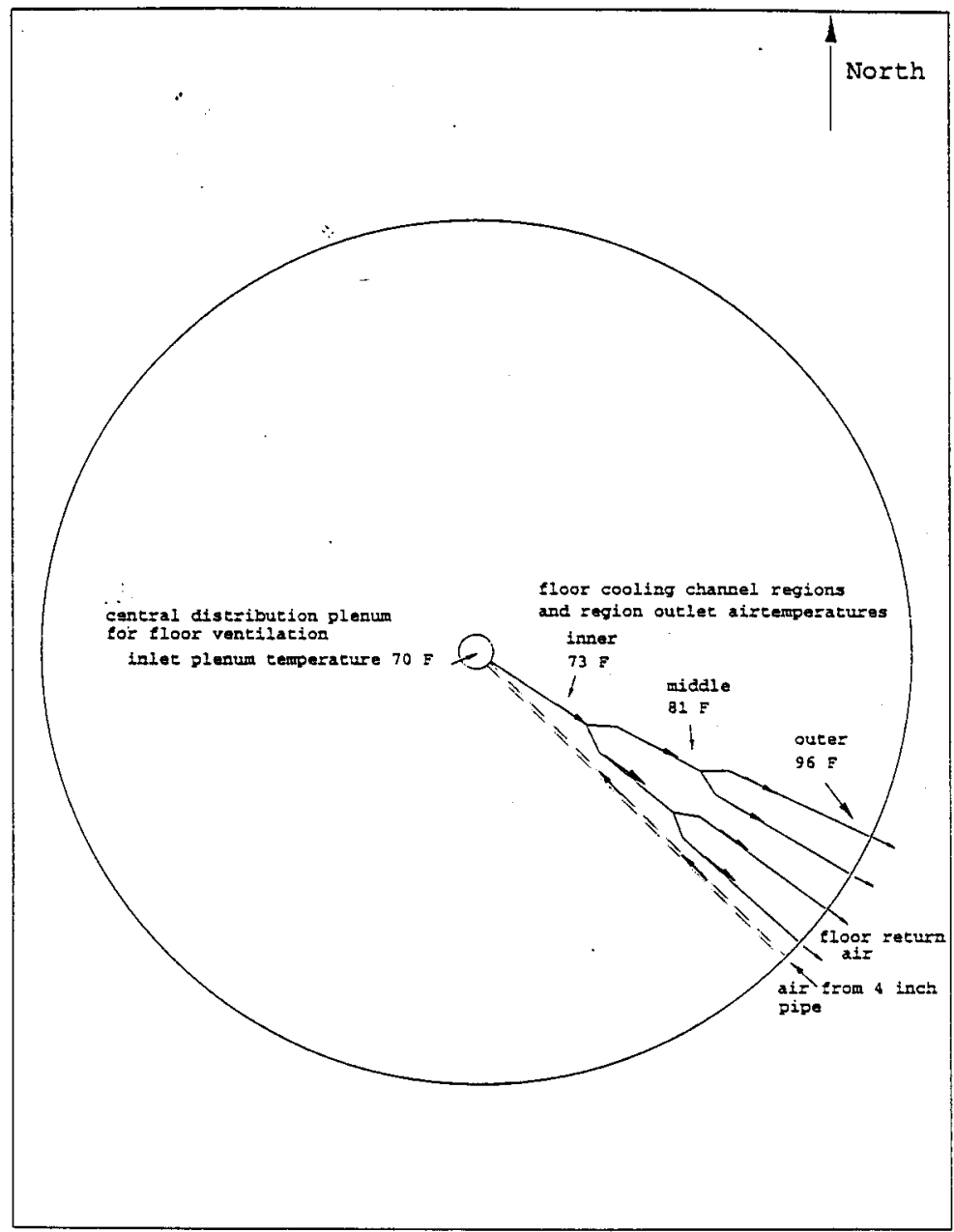


HNF-SD-WM-RPT-293 REV 0

This page intentionally left blank. 
If you have any questions, please contact Mr. Greg Morgan of my staff on (509) $373-2346$.

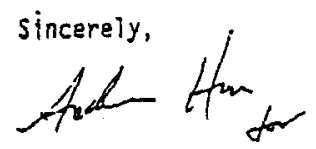

Ami 8. Sidpara, Director

Tank Operations Division

\section{Enclosure}

C. W`encl:

R. Raymond, WHC

J. Lee, WHC

R. Sehlosser, WHC

G. Franz, WHC

J. Badden, WHC

D. Busche, WHC

G. Jones, MACTEC 


\title{
Enclosure
}

\section{Tank Farm Risk Acceptance Criteria}

\author{
Radiological Criteria
}

\begin{tabular}{|c|c|}
\hline Range of Annual Frequency & Effective Dose Equivalent (REM) \\
\hline \multicolumn{2}{|c|}{ On-Site Guidelines } \\
\hline 1.0 E-0I to 1.0 E-02 * & $1-5$ \\
\hline $1.0 \mathrm{E}-02$ to $1.0 \mathrm{E}-04^{\circ}$ & 5- 25 \\
\hline $1.0 \mathrm{E}-04$ to $1.0 \mathrm{E}-06^{\circ}$ & $25-100$ \\
\hline \multicolumn{2}{|c|}{ Off-Site Guidelines } \\
\hline $1.0 E+00$ to $1.0 \quad E-02^{\circ}$ & $.01-.5$ \\
\hline $1.0 E-02$ to 1.0 E-0. & $.5-4$ \\
\hline $1.0 E-04$ to 1.0 E-06 & $4-25$ \\
\hline
\end{tabular}

* Note: If a specific single point frequency is used, the guidelines are to be applied as curves. However, if a qualitative frequency ranking is used, the corresponding consequence limit (in REM) shall be used equal to the lowest REM limit for that frequency range. 
HNF-SD-WM-RPT-293 REV 0

\section{Toxicological Criteria s}

\begin{tabular}{|c|c|c|}
\hline Range of Annual Frequency & $\begin{array}{c}\text { On-Site } \\
\text { Guidelines }\end{array}$ & $\begin{array}{c}\text { Offi-Site } \\
\text { Guidelines }\end{array}$ \\
\hline 1.0 E-02 to 1.0 E+00 & $\leq$ ERPG-1 & $\leq$ PEL-TWA \\
\hline 1.0 E-04 to 1.0 E-02 & $\leq$ ERPG-2 & $\leq$ ERPG-1 \\
\hline 1.0 E-06 to 1.0 E-04 & $\leq$ ERPG-3 & $\leq E R P G-2$ \\
\hline
\end{tabular}




\section{memorandum}

oATE:

ACAMY TO ATtiv Co:

SURECT:

Te:

JUL 13

EM-36

Safoty Doeumentation for Tank 241-6-106 Ratrieval Operations $\therefore$

John Antotonen, Acting Progran Manager Offica uf Tank Wasta Remeditation Systen DOE Richland Operations Ofitce

This menorandum is being sant to provide guidanca in the prsparation of safaty docimentation for Tank $2 \$ 1-C-106$ retriayal operations.

For specific operations, such as retrieval of Tank 24?-106-C, the safety documentation should: systematically identify the hazards; describe and analyze measures taken to alimtnate, control, or mitigate identiffed hazards; and analyze potential aceidents and their associated risks. This documentation (safety assessment) should be prapared tn accorfanca with the atached "Interia Guidance for Proparing safety assassments," datad March 6, 1992. Given our eurrent strategy not to develog supolements to the existing outdated Safety Analysis Reports (SARS), we believe that the safety assassment can serve as an essantial stap fo ostaolishing the safaty anvelope for Tank 241-6-106. The safety assessment can later be used as a referenca document for providing incut to the new SAR for itanfor' Tank Farms.

The implementation of this guidance would require that Hestinghouse Hanford Company (WHC) not grapare supolements to the axisting SARS or any new Preliminary or Final Safaty Analysis Raports on this issue at this time. in add:tion, WHC should discantinue unnecessary work an deyelooing SAR chaptars at this time and stoo development of Limitad Scope Safety Analysis Report: when much of the information is incorporatad by reierancing existing documents.

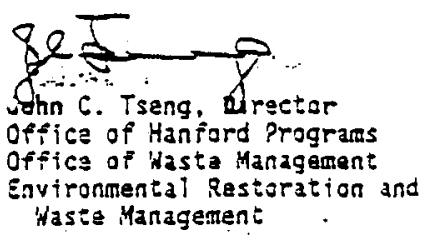

Attachment

CG:

8. Nicolt, DOE-RL

H. WrzesinsXi, DOE-RL 
HNF-SD-WM-RPT-293 REV 0

Oistrtbution:

bce:

EM-351, X. Chacey

SM-361, J. Mockrick -

EM-36i, J. Daly

E:4-362, H. Esker.

Ex-362, 0. Gup C3

WHC, N. Croskrey

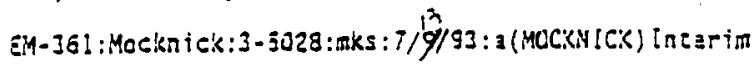
EM-36 Fila 2.3 .1 .3

- xprevious concurrances ara vaijo

EM-36 Corraspondance Reviewer_/4
EM-36!

MOCRNICK

$C \log / 93$

EM-362

ECKERT

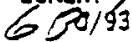

E:4-56!

WYNNE

$3 / 6 / 93$

ह4-36!

GHACE! IL

$7 / 6 / 93$ 
Westinghouse

Internal Hanford Company

From: Radiation Physics and Shielding

Phone: 0 -3765 HO-35

Date: January 6,1994

SUDjec: TANKS IOG-C AND 102-AY SOUTFMENT PAC:KAGING DOSE CONSEDUENCE ANALYSIS FOR SAFETY CLASS ASIIGIMENT

To:

D. B. Calmus $62-02$

es:

3. G. Field

$62-02$

J. Greeniorg

HO-35

R. L. Simons

HO- 35

S. R. Gedeon

HO- 35

HUG File/LB

REFFREYCES: Internal Memo 22570-HJG-94-001, H.J.Goldberg to 0.3.Cainus, "Tanks 106-C and 102-AY Equipment Packaqing Oose Consequenca Analysis", 7 Oczoier 1993

The following anaiysis is a modification of the analysis roterenced ibove that was deveioped to suoport evaluations in the Safazy Evaluation for Packacing (SEP) for the 106-C project. The prosent analysis is to facilitate the assignment of a safety classification to the packages. The reiesse is assumed to be an unmittgated release, and thus $100 \%$ of the inventories have been assumed to have been released in the accident scenario. In addition, the onsite worker has been assumed to be $100 \mathrm{n}$ irom

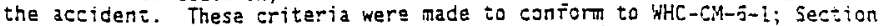
E?-?.1 Rev. 1. Standard Enginesring Practicas: Saraty Classification.

In the previous analysis, the waste was in a solid crystalline form. As per WHC-CI-to-1. 100\% of this material was assumed to be released from the shipoing container. In orcer to ascercain the fraction in the resoiratle range that becomes airborne, the matarial was assumed to be in a powder fora when released. Since the time of the original anaiysis, severai questions have arisen which will be discussed beiow.

It can be argued that 100\% of reiease irom the shipping container does not imply 100\% reiease of the material from the pump surface. This material was wasted with a 3,000 psi watar soray. While it was decided that no credit would be taxen for the cleaning efiect of this spray procass, it can easity be argued that any material that remains on the pumo aftar this treatment is reiatively fixed. It boggles the nind to imagine that material that is so fixed could be completely dislodged by a fall of a meter or so from the shipping container on the back of a truck. 
In addition, oniy a fraction of these crystals wauld be crushed to a powder that is respirabie ( $S I \mu$ ). An analysis of an FFif assembly came to the canclusion that, at most, only about $10 \%$ of the fual would be powdered by being crushed between a transport venicle and a cancrete floor. I can dig this number out of the literature, but in the time available for this epistle necessitates that I must rely on my memory.

I would think that, if an accident were to oceur, the pump slides out of the damaged container, and a portion of it is crusined by the overcurned truex, a conservative estimate of that portion of the attached erystalline material that is removed from the pump might be $50 \%$.

of this material, it is also quite consarvative it we assume that half of that released material is crushed into a powder of a respirabie sized particles. The rest will be in the form of larger crystals. While I do not have very much experience with this materiai and its form on removed equipment, I do recall reading reports about the removal of the air lanca from the $101-5 \%$ tank.

In that operation. large chunks of material, some solid and some in a more iicuid form, fell to the ground. From what I read of the solids in that case it is extremely unlikely that crystals of that size would have become airjorne in iess than a tornado. In addition $1 t$ takes an active imagination to imagine a nostril capable of inhaling suct chunks.

Thus, I would not find it difficult to estimate that $25 \%-30 \%$ of the material were to be released to the ground in the form of particles that are respirable. To this inventory, the previously apolied airborne fraction would be avaliable for inhalation by persons standing 100 a from the accident sita. With these changes in the parameters of the problem, the doses to a worker and to the maximally exposed farmer are as follows; 
0. B. Cajmus

Page 3

22570-HJG-94-005

6 January 1994

\begin{tabular}{|c|c|c|}
\hline & Dose to Worker (ram) & Dose to Farmer (ram) \\
\hline 106-G Heal Pumo & 3.3 & 0.03 \\
\hline 106-C Transier Pumo & 0.45 & 0.0030 \\
\hline 102-AY Agitator Pumo & 2.0 & 0.036 \\
\hline
\end{tabular}

Thus, it would seem that all of the packages analyzed are in safety class three. This conclusion is based on saitety class criteria presanted in $g$ ? 1.4 indicating that estimated releasas less than 0.5 rem for ofisite workers and grazter than 5 ram for onsite workers are safety class two and roieases less than 5 rem to onsite workers are safety class threa.

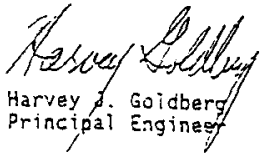

CONCIJRRENCE:

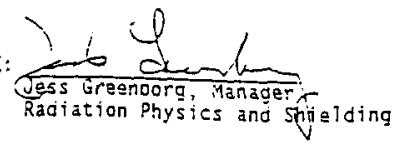


This page intentionally left blank. 
Westinghouse

Internal

Hanford Company

Memo

From: Process Engineering Analysis

Phone: $\quad 376-0205$ H0-34

Date: $\quad$ February 27, 1996

Subject: TANK C-106 HEAT DISTRIBUTION AND POST SLUICING TEMPERATURES

To:
R. J. Cash
S7-14
cc:
H. Babad
T. J. Bander
$57 \cdot 14$
$\mathrm{HO}-34$
J. C. Conner
A2-25
J. P. Harris, III
D. M. Ogden
J. P. Sloughter
BAC File/LB

74A50-96-BAC-006

References:

(1) WHC, Boyless, V. C., 1996, Operating Specifications for Single-Shell Waste Storage Tanks, OSD-T-151-00013, Rev. D-10, Westinghouse Hanford Company, Richland, Washington.

(2) Fryer, B. C., and M. J. Thurgood, 1995, Revised Tank Heat Load Estimate for Tank C-206 Based on GOTH Analysis of the Process Test, JMI-WTO02, John Marvin, Inc., Richland, Washington.

(3) Ogden, D. M., and K. Sathyanarayana, 1995, GOTH Tank C-106 Thermal Hydraulic Analysis Related to the 1994 Process Tests, NAI-940708-3, Numerical Applications, Inc., Richland, Washington.

(4) Webb, A. B., et al., 1995, Preliminary Safety Criteria for Organic Watch List Tanks at the Hanford Site, WHC-SD-WM-SARR-033, Rev, O, Westinghouse Hanford Company, Richland, Washington.

(5) Gaddis, L. A., 1995, Supporting Document for the Historical Tank Content Estimate for C Tank Farm, WHC-SD-WM-ER-313, Rev. 0 , Westinghouse Hanford Company, Richland, Washington.

(6) Willingham, C. E., 1994, Thermophysical Properties of Hanford HighLevel Tank Wastes - A Preliminary Survey of Recent Data, PNL-9419, Pacific Northwest Laboratory, Richland, Washington.

(7) Bander, T. J. 1993, Revised Thermal History of Tank 241-C-106, WHC-SD-WM-ER-200, Westinghouse Hanford Company, Richland, Washington.

\section{INTRODUCTION}

Retrieval of tank C-106 waste will be accomplished through Project W-320 in late 1996 . The goal of the project is to sluice the tank soft sludge and thereby eliminate the need for water additions or active ventilation cooling. The success of the project depends in part on the heat distribution in the waste. A concern was expressed during the Tier 2 review of Project W-320 that much of the tank heat may be in a non-sluiceable hard pan which could jeopardize the success of the project. 
R. J. Cash

74A50-96-BAC-006

Page 2

February 27, 1996

A study was performed to address this concern. Analyses have shown that for very conservative assumptions for soft waste volume, heat load distribution and dry waste thermal conductivity, sufficient heat can be removed to eliminate the need for further water additions. In addition, using best estimate heat load distributions, which are consistent with the measured tank data, the project will achieve the full project goals.

\section{HEAT LOAD DISTRIBUTION}

Heat load estimates for tank C-106 were derived through thermal analyses of the lank and comparison with tank temperature data. Reference 7 gives an estimated heat load of $110,000 \mathrm{Btu} / \mathrm{h}$. This heat is distributed over two regions ( 0 to 4 feet, 4 to 6 feet). The tank data suggest that the tank heat is skewed toward the bottom with $89 \%$ of the heat in roughly $66 \%$ of the sludge. A comparison of the results of this model with the Riser 8 thermocouple data is shown in Figure 1 . There is exceilent agreement for the first three thermal couples. Thermocouple 4 is believed to be near the pool/dome space interface and therefore does not represent a waste temperature.

The heat load estimate for tank C-106 was re-evaluated using a two-fluid computer code, which mechanistically accounted for water evaporation (Reference 2). The revised heat load estimate was 132,400 Btu/h. This heat load estimate was used for all the analyses reported in the following sections. Table 1 summarizes the heat load distributions used for this study. These include the best estimate heat load distribution of Reference 7 and conservative distributions that will be discussed later.

Table 1. Heat Load Distributions.

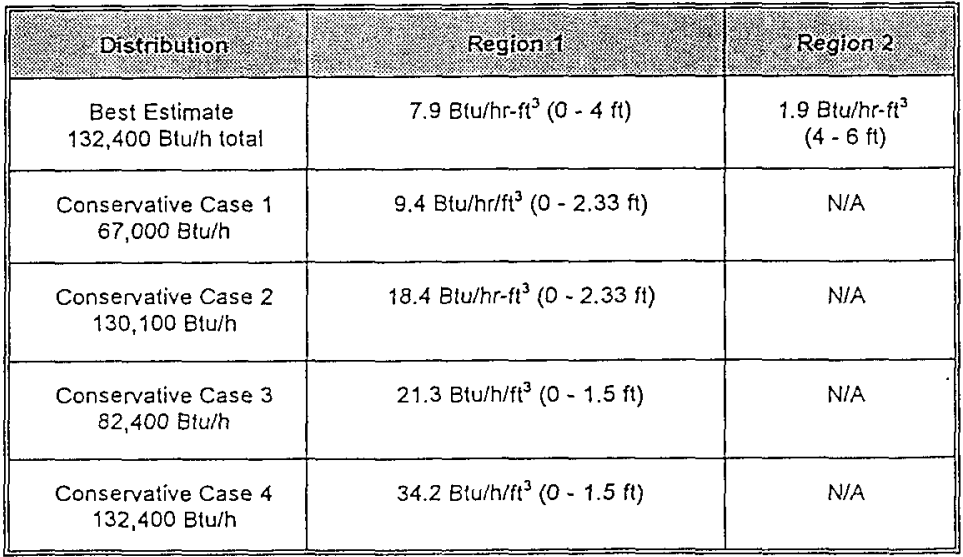

Differences in temperature in the waste are an indication of the local heat load distribution within the lank. Figure 2 shows a comparison of the temperature gradients for the Riser 8 
thermocouples with the calculated gradients based upon the heat load distribution of Reference 7. The temperature gradients for heat generation at the surface, heat generation at the bottom, and uniform heat generation are also shown for information. The best estimate heat load is in reasonable agreement with the data from Riser 8.

\section{NON-SLUICEABLE HARD PAN}

Concerns for the success of Project W-320 are based on the heat load distribution and the volume of the non-sluiceable hard pan that may exist in the bottom of the tank. Figure 3 shows the tank $\mathrm{C}-106$ sludge level history. The metal bearing waste was added to the tank during the early waste additions (prior to 1965). It is this material that may have formed a hard pan. As shown in Figure 3, the maximum thickness of the hard pan region could be no more than 1.5 feet. This is about $15 \%$ of the total waste volume. The historical document suggests that most of the tank heat was added after 1965 (Reference 5). Thus, the hard pan should contain very little heat. Migration of radionuclides into the hard pan may have occurred but could not exceed the best estimate uniform heat distribution.

\section{MODEL DESCRIPTIONS}

\section{Scoping Mode!}

Scoping analyses were performed with a one-dimensional model. A solution to Poisson's equation for one-dimensional, steady-state heat conduction was used. The model assumed axial heat conduction with no heat loss from the tank bottom. Heat removal from the dome included heat conduction to the soil and convective heat transfer through the ventilation system.

\section{Detailed Thermal Model}

Detailed two-dimensional models were used to confirm the results of the scoping analyses. The primary model employs P/THERMAL, a standard thermal analyses computer code. Models were developed for previous analyses of tank C-106 and are documented in Reference 7. The P/THERMAL model is a two-dimensional finite element model. Two configurations of the model were used. Both were derived from the model documented in Reference 7 . One of the models is configured to account for about $75 \%$ waste removal (the remaining waste varies from a thickness of 2.33 feet in the center to 1.33 feet at the outside of the tank). This is considered a conservative estimate of the sluiceable sludge. The second model is conigured to match the best estimate of the sluice able sludge (the remaining waste varies from a thickness of 1.5 feet in the center to 0.5 feet at the edge of the tank). The waste conductivities were modified to simulate the conductivity of dry sludge. The model is shown in Figure 4. 
R. J. Cash

74A50-96-BAC-006

Page 4

February 27, 1996

\section{Dry Waste Thermal Conductivity}

For a dry waste tank, a major determinant of peak waste temperature is the dry waste thermal conductivity. There are no reported values for thermal conductivity of the waste in tank $\mathrm{C}-106$ that are based on an actual sample of the waste. The values used in the models of References 2 and 7 are based on values that give the best fit to the observed temperature data. These values are consistent with parallel conduction models for conduction in a water sludge mixture. These values are for wet waste and will decrease significantly for dry waste.

Measured thermal conductivities for actual tank waste are documented in Reference 6 . These data are shown in Figure 5. The average value of $0.27 \mathrm{Btu} / \mathrm{h}-\mathrm{ft}_{-}^{\circ} \mathrm{F}$ at $300^{\circ} \mathrm{F}$ was selected as the best estimate dry conductivity. The lowest measured value $\left(0.089 \mathrm{Btu} / \mathrm{h}-\mathrm{ft}-{ }^{\circ} \mathrm{F}\right)$ was selected as a conservative estimate of the conductivity. The conductivity of tank C-106 hard pan material is expected to be higher than these values since it is compacted with a much smaller porosity than the powders of Reference 6.

\section{TEMPERATURE LIMITS}

The temperature limits for tank C-106 are based on the operating specifications for single-shell tanks (Reference 1). The Operational Safety Document (OSD) structural temperature limit is $300^{\circ} \mathrm{F}$ in the waste and $350^{\circ} \mathrm{F}$ in the concrete.

Organic reactions may be possible if organics are present. However, these reactions normally occur near $390^{\circ} \mathrm{F}$ (Reference 4 ) which is well above the OSD temperature limit.

The 1994 process test and subsequent analyses (Reference 3) demonstrated that tank C-106 operates near safuration temperatures, creating the potential for steam release events. This will not be a concern after sluicing since the remaining material will be hard (non-sluiceable) and therefore not subject to steam bumps. Steam generated during drying will be released nearly continuously.

Based upon the above considerations, the OSD limit of $300^{\circ} \mathrm{F}$ in the sludge was selected as the temperature limit for this siudy.

\section{RESULTS OF SCOPING ANALYSES}

Results from the one-dimensional scoping calculations are shown in Figure 6 . The analyses assume waste dryout occurs with ventilation cooling $(2300 \mathrm{cfm})$ only. The analyses were done for the best estimate (BE) and conservative thermal conductivities. The straight lines represent the remaining heat load as a function of remaining waste depth. This is shown for both the best estimate heat load (Table 1) and 2 times the BE heat load. The curved lines are the result of the scoping model for the two thermal conductivities considered. They represent the heat load as a function of remaining waste depth that will result in a maximum waste temperature of $300^{\circ} \mathrm{F}$ (OSD limit). The point of intersection of the curves is the maximum waste depth allowed for the assumed thermal conductivity. As an example, for the best estimate heat load and best estimate thermal conductivity, the OSD limit will not be exceeded for waste depths up 
R. J. Cash

74A50-96-BAC-006

Page 5

February 27, 1996

to about 3.25 feet. For the conservative heat load the OSD limit will not be exceeded for waste depths up to about 2.25 feet. For the conservative thermal conductivity, the values are 2 feet and just under 1.5 feet. The non sluicable hard pan is not expected to exceed 1.5 feet in the center of the tank. Thus, these scoping analyses suggest that, both on a best estimate and conservative basis (for both heat load and thermal conductivity), no water additions will be required after sluicing to keep sludge temperatures below OSD limits.

\section{RESULTS OF PITHERMAL ANALYSES}

Analyses were performed for two waste retrieval scenarios. The first assumes that $75 \%$ of the waste will be removed by sluicing. This is clearly a conservative assumption since the hard pan material as discussed above should be no more than $15 \%$ of the waste volume. The best estimate second scenarios assumes that all soft waste is removed by sluicing leaving only a hard pan material of about $15 \%$. The analyses results are presented below.

\section{CONSERVATIVE WASTE REMOVAL}

Removal of $75 \%$ of the waste by sluicing leaves a depth of $2.33 \mathrm{ft}$ in the center and $1.33 \mathrm{ft}$ at the edge (see Figure 4). Analyses were performed to determine how much heat load could remain without exceeding the OSD temperature limit. The waste was assumed to be dry and heat removal occurred by soil heat concuction and dome ventilation flow of $2300 \mathrm{cfm}$ (no evaporation).

The results are summarized in Table 2 . Three heat load distributions were considered as summarized in Table 1. The conservative heat loads were selected so the maximum waste temperatures did not exceed the OSD limits for the two thermal conductivities considered.

Table 2. Results for $75 \%$ Waste Removal.

\begin{tabular}{|c|c|c|c|}
\hline 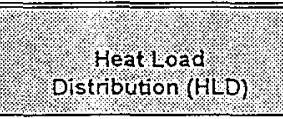 & $\begin{array}{l}\text { Heat load } \\
\text { (Bturh) }\end{array}$ & $\begin{array}{l}\text { conservative } \\
\text { conductivity. } \\
(0.089 \text { Btulht f-F })\end{array}$ & $\begin{array}{l}\text { Bestestimate } \\
\text { Condoctinty } \\
0.27 \text { Btuhr the }\end{array}$ \\
\hline $\begin{array}{l}\text { Best estimate HLD with } \\
2300 \mathrm{cfm} \text { ventilation }\end{array}$ & 56,000 & $264^{\circ} \mathrm{F}$ & $175^{\circ} \mathrm{F}$ \\
\hline $\begin{array}{l}\text { Conservative HLD with } \\
\text { conservative conductivity } \\
\text { Conservative Case } 1\end{array}$ & 66,600 & $300^{\circ} \mathrm{F}$ & N/A \\
\hline $\begin{array}{l}\text { Conservative HLD with } \\
\text { best estimate conductivity } \\
\text { Conservative Case } 2\end{array}$ & 130,000 & N/A & $300^{\circ} \mathrm{F}$ \\
\hline
\end{tabular}


R. J. Cash

74A50-96-BAC-006

Page 6

February 27, 1996

For the best estimate Heat Load Distribution with fult ventilation flow, the maximum waste temperature would be $264^{\circ} \mathrm{F}$ for the most conservative conductivity and $175^{\circ} \mathrm{F}$ for the best estimate thermal conductivity (Note that the scoping model results discussed in the previous section predict that the OSD limit would be exceeded for a waste depth of 2.33 feet. Because the scoping model is one-dimensional, it does not account for the tank bottom dish nor thermal conduction to the soil through the tank bottom and sides. Thus, as expected the model gives conservative results).

The second analysis establishes the maximum allowable heat load with the conservative conductivity. With $75 \%$ waste removal, 67,000 Btu/h could remain in the sludge without exceeding the OSD temperature limit. This is $51 \%$ of the total tank heat load.

The third analyses shows the maximum allowable heat load for the best estimate thermal conductivity. A heat load of 130,000 Btu/h or $98 \%$ of the total tank heat load could remain after sluicing without exceeding the OSD limit.

A representative temperature contour plot is shown in Figure 7. This temperature distribution is representative of $75 \%$ waste removal with a Conservative Case 1 heat load distribution and best estimate thermal conductivity.

The results of both the scoping and P/THERMAL analyses show that for the conservative case of $75 \%$ waste removal, the dry waste temperatures can be maintained below OSD temperature limits without evaporative cooling with a significant amount of the fotal heat load remaining in the waste. These heat load distributions however are clearly not consistent with the measured tank temperature data. The steady-state temperature gradient (prior to sluicing) for the two conservative heat load distributions are compared with actual tank data in Figure 8 . The measured temperature difference between TC1 and TC2 for the riser 8 thermocouple tree is less than the temperature difference that would exist for either of the conservative heaf laad distributions.

The P/THERMAL analyses show that water additions following sluicing will not be required even for very conservative assumptions for waste removal, heat load distribution, and dry waste thermal conductivity.

\section{BEST ESTIMATE WASTE REMOVAL}

The analyses of the previous section assumed only $75 \%$ waste removal. This is a very conservative estimate. The best estimate for the non-sluiceable hard pan is $15 \%$ of the waste volume with a thickness at lank center of 1.5 feet. Analyses were performed with the twodimensional P/THERMAL model to again demonstrate that a large amount of the tank heat could exist in the hard pan without jeopardizing the success of the project even though such heat load distribution are inconsistent with the tank data. The analyses assumed total waste dryout and were performed for full ventilation $(2300 \mathrm{~cm})$ and ventilation flows representative of passive ventilation flow rates with high lank heat loads $(50 \mathrm{cfm})$. The results are summarized in Table 3. The conservative heat loads were selected so the maximum waste temperatures did not exceed the OSD limits for the two thermal conductivities considered. 
Table 3. Results for Best Estimate Waste Removal.

\begin{tabular}{|c|c|c|c|}
\hline Heat coaddistribution & $\begin{array}{l}\text { Heat Load } \\
\text { (Bturh)! }\end{array}$ & $\begin{array}{l}\text { conservative } \\
\text { conductivity } \\
(0.089 \text { Bturt } \mathrm{ft}-\mathrm{r})\end{array}$ & $\begin{array}{l}\text { Best Estimate } \\
\text { conductivity } \\
(0.27 \text { Btultig } \mathrm{ft})\end{array}$ \\
\hline $\begin{array}{l}\text { Best Estimate HLD } \\
\text { with } 2300 \text { cfm ventilation }\end{array}$ & 32,200 & $151^{\circ} \mathrm{F}$ & $106^{\circ} \mathrm{F}$ \\
\hline $\begin{array}{l}\text { Best estimate HLD } \\
\text { with } 50 \mathrm{cfm} \text { ventilation }\end{array}$ & 32,200 & $230^{\circ} \mathrm{F}$ & $188^{\circ} \mathrm{F}$ \\
\hline $\begin{array}{l}\text { Conservative HLD with } \\
\text { conservative conductivity } \\
\text { Conservative Case } 3\end{array}$ & 82,400 & $300^{\circ} \mathrm{F}$ & $185^{\circ} \mathrm{F}$ \\
\hline $\begin{array}{l}\text { Conservative HLD with } \\
\text { best estimate conductivity } \\
\text { Conservative Case } 4\end{array}$ & 132,400 & $N / A$ & $262^{\circ} \mathrm{F}$ \\
\hline
\end{tabular}

For the best estimate Heat Load Distribution with full ventilation flow, the maximum waste temperature would be $151^{\circ} \mathrm{F}$ for the most conservative conductivity and $106^{\circ} \mathrm{F}$ for the best estimate thermal conductivity. These temperatures are well below the OSD limits. The heat load of $32,000 \mathrm{Btu} / \mathrm{h}$ is also below the $40,000 \mathrm{Btu} / \mathrm{h}$ limit for high heat tanks. Thus, the project should be successful in eliminating the tank from the high heat tank list and eliminating water additions.

It should be noted that the best estimate heat load assumes a uniform heat load in the bottom 4 feet of the tank. While the data are sufficient to show that large amounts of heat are not present in the hard pan, the data cannot show that the hard pan is not heat bearing. However, the historical record of tank waste additions suggests that the hard pan should contain little heat. Thus, the actual remaining heat load would probably be less than 32,000 Etu/h.

The second analyses were performed with the best estimate heat load and 50 cim ventilation flow. This value is comparable to natural convection flows or passive breathing. The analyses indicate the removal of the soft sludge will allow for the elimination of active ventilation with no water additions even assuming conservative values for dry waste thermal conductivity.

The third analyses establishes the maximum allowable heat load with the conservative conductivity. This is Conservative Case 3 in Table 1 . With removal of all the soft sludge, $82,000 \mathrm{Btu} / \mathrm{h}$ or $62 \%$ of the total tank heat load could remain in the sludge without exceeding the OSD limit. 
R. J. Cash

74A50-96-BAC-006

Page 8

February 27, 1996

The fourth analyses shows the maximum allowable heat load for the best estimate thermal conductivity. This is Conservative Case 4 in Table 1 . The entire heat load of the tank could remain without exceeding the OSD temperature limit.

The results of both the scoping and P/THERMAL analyses show that for the best estimate waste removal, dry waste temperatures can be maintained below OSD temperature limits without evaporative cooling with a significant amount of the total heat load remaining in the waste. These heat load distributions however are clearly not consistent with the measured tank temperature data. The steady-state temperature gradient (prior to sluicing) for the two conservative heat load distributions are compared with actual tank data in Figure 9 . The measured temperature difference between TC1 and TC2 for the Riser 8 thermocouple tree is significantly less than the temperature difference that would exist for either of the conservative heat load distributions.

The PITHERMAL analyses show that water additions and active ventilation following sluicing will not be required even for very conservative assumptions for heat load distribution and dry waste thermal conductivity.

\section{PROJECT GOALS REVISITED}

The Project W-320 goals are based in part upon safety and environmental concerns. Because of the heat load of tank C-106, frequent water additions and active ventilation are required to control the waste temperatures below OSD limits. In the event of a tank leak, the drainable liquid would be leaked to the environment and water additions (either bulk or spray) would still be required, which could allow continued leakage. In addition, the 1994 process test demonstrated that steam can accumulate in the waste, thus providing a potential for steam bump events. It needs to be understood that Project W-320 does not need to retrieve all the soft sludge in tank C-106 to reduce the environmental and safety risk associated with a potential tank leak.

Figure 10 shows the calculated peak waste temperature as a function of waste depth using the best estimate thermal conductivity $\left(0.27 \mathrm{Btu} / \mathrm{h}-\mathrm{ft}^{\circ} \mathrm{F}\right)$ of $\mathrm{dry}$ waste. The analyses were performed with the PITHERMAL model using the best estimate heat load distribution and full ventilation flow. The analyses show that if the tank leaked and was allowed to dry out with the current water inventory, the temperatures would well exceed the OSD limits. This would create a serious concern for the structural integrity of the tank. Thus, continued bulk water additions or a water spray system would be required to maintain tank cooling. However, if three feet of sludge is removed, the tank temperatures could be maintained below OSD temperature limits 
R. J. Cash

Page 9

February 27, 1996

with ventilation flow only. Removal of any sludge will allow the remaining waste to be cooled more easily. This is due both to heat removal and a shorter conduction path.

Achieving the full goals of Project $W-320$ is very desirable, but any waste removal will improve both the environmental and safety risk associated with tank C-106 operations.

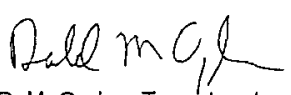

D. M. Ogden, Team Leader Process Engineering Analysis

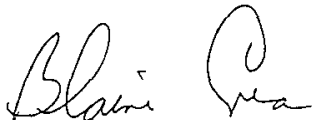

B. A. Crea, Principal Engineer Process Engineering Analysis

bab

Attachment

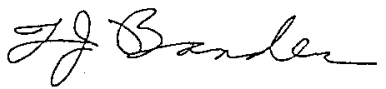

T. J. Bander, Principal Engineer Process Engineering Analysis 
74A50-96-BAC-006

ATTACHMENT

FIGURES 1 - 10

Consisting of 6 pages, including cover page 
Figure 1. Riser 8 Temperature Profile for Normal Conditions

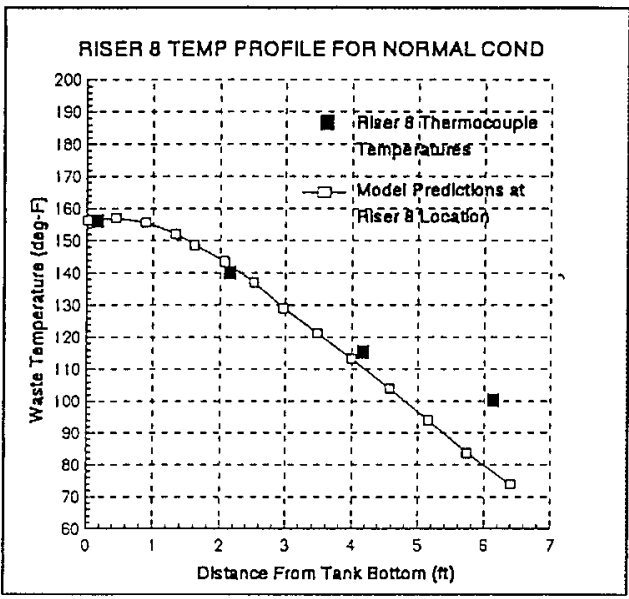

Figure 2. Tank C-106 Temperature Gradients

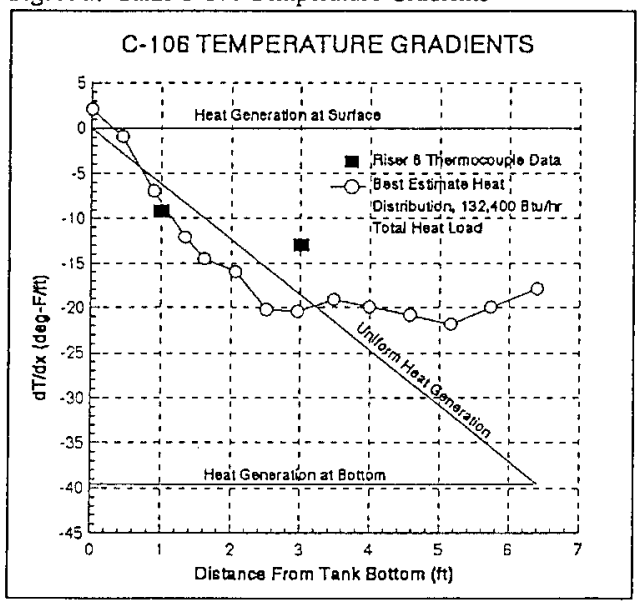


Figure 3. Tank C-106 Fill History

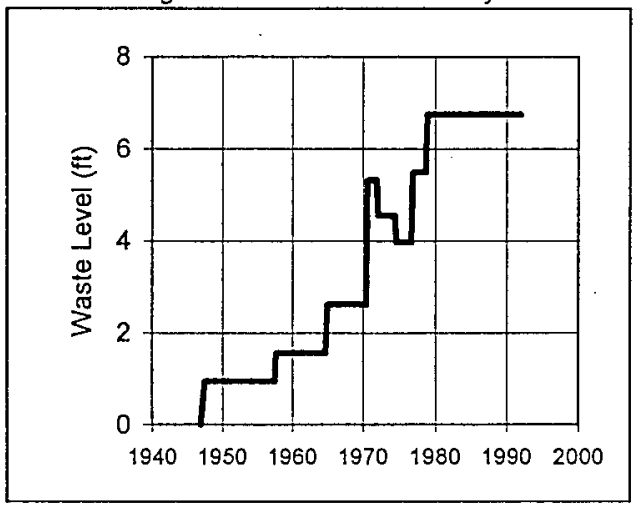

Figure 4. P/THERMAL Finite Element Model.

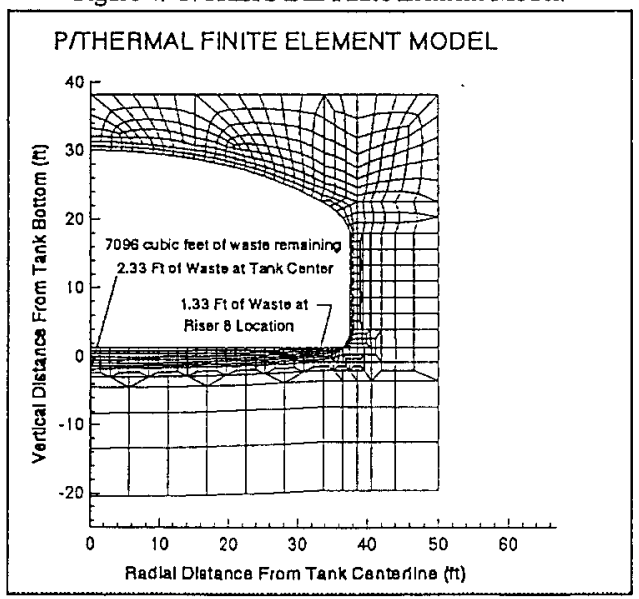


Figure 5. Elevated Temperature Conductivity.

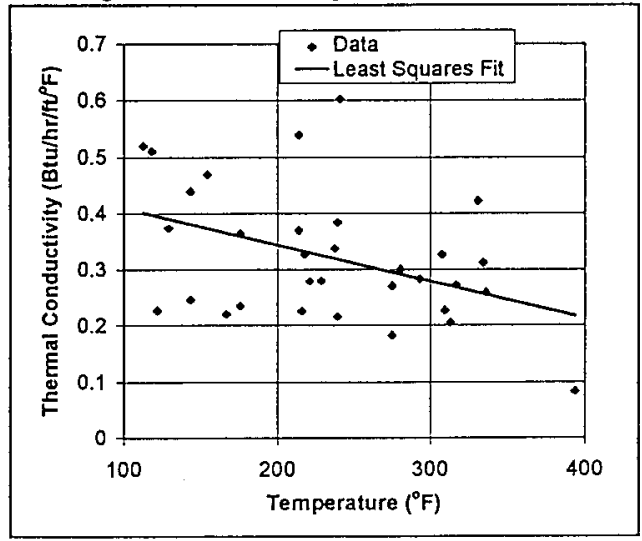

Figure 6. Scoping Model Results.

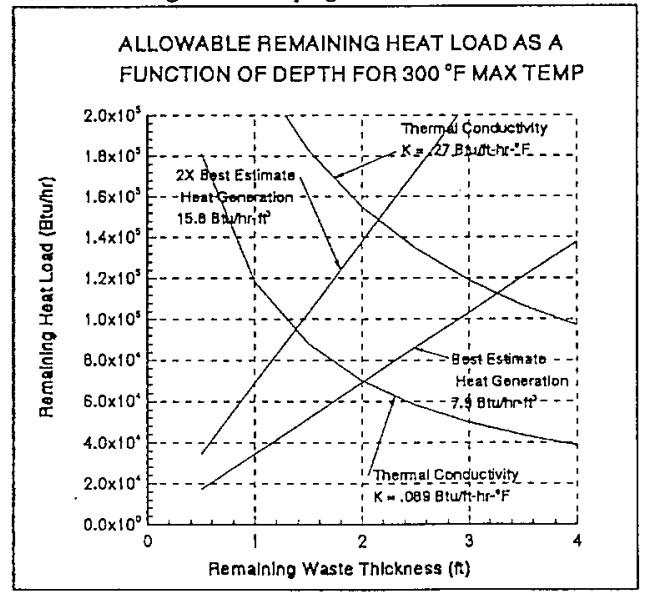


Figure 7. Temperature Distributions After Sluicing.

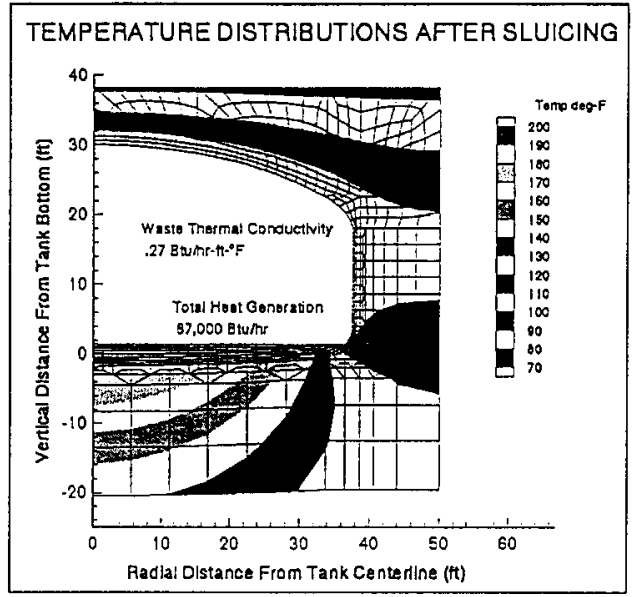

Figure 8. Conservative Waste Removal Compared to Data.

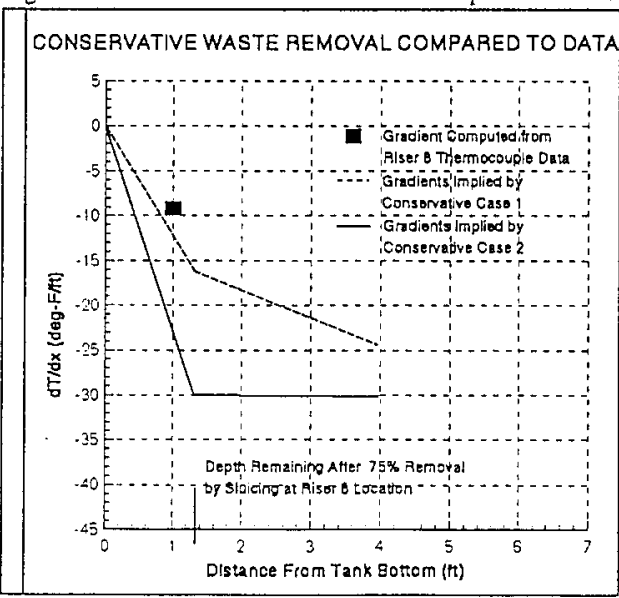


Figure 9. Conservative Heat distribution Compared to Data

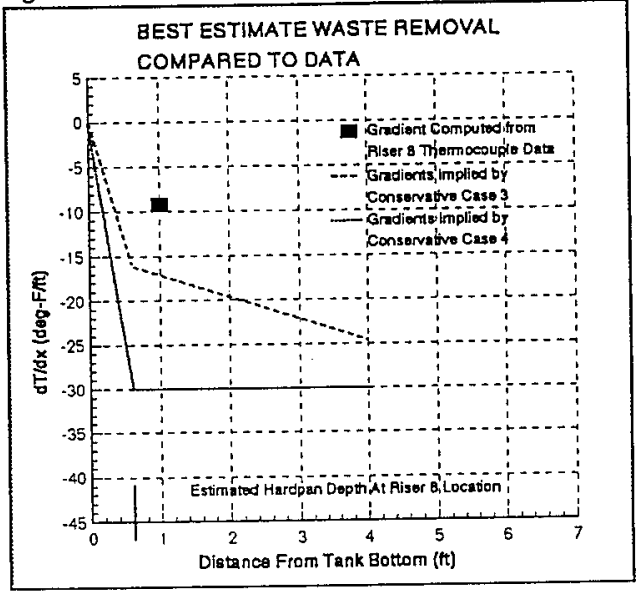

Figue 10. Maximum Temperature for Dry Waste.

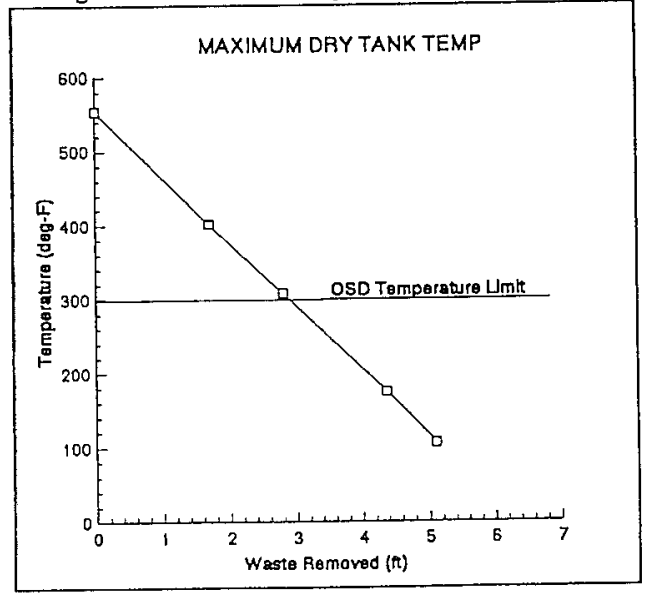


This page intentionally left blank. 


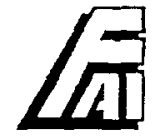

FAX Transminal

DATE: $\quad$ February 6, 1996

TO: Mr. John Harris - WHC

FAX NO.: $\quad 509-376-0546$

FROM: Martin G. Plys $M G P$

SURJECT: C-106 "Lending Edge Question" Response

This FAX transmittal equals a lotal of 4 page(s).

\subsection{INTRODUCTION}

Dana Powers of the chemical reactions sub-TAP asked whether the leading edge of pumped slurry could freeze or gel as it passes through a cold transfer line. Freezing may be a prior ruled out because the lop of pipe of the encasement has an earth cover of $36^{\prime \prime}$ and the maximum frost line depth is $30^{\circ}$ [1]. Cooling of the leading edge of fluid may occur if the transfer begins when the pipe is cold (out still above $0^{\circ} \mathrm{C}$ ), so salt may precipitate. A straightforward heat transfer analysis is presented here to estimate the cooldown of slurry fluid and estimate the solid fraction change.

\subsection{SUMMARY OF ASSUMED VALUES}

The following approximate values are used based on references [1] and [2]:
$\mathrm{D}=0.1 \mathrm{~m}$
4" Line, slight roundod overestimate.
$A=0.0078 \mathrm{~m}^{2}$
Corresponding area.
$\mathrm{U}=2 \mathrm{~m} / \mathrm{s}$
$6 \mathrm{ft} / \mathrm{s}$ approximately.
$\mathrm{L}=550 \mathrm{~m}$
$1800 \mathrm{ft}=549 \mathrm{~km}$ slurry line.
$\mu=0.1 \mathrm{~kg} / \mathrm{ms}$
Case of about $30 \%$ solids,
$=0.01 \mathrm{~kg} / \mathrm{ms}$
Case of about $10 \%$ solids.

16w070 West 83rd Streel - Burr Ridge, Mllinois 60521 - (708) 323-8750

Telefox (708) 986-5481 
Case of about $10 \%$ solids.

Water value.

Water value.

Derived by $W=\rho \mathrm{UA}$.

Derived by $\alpha=k / \rho c_{p}$.

Case of $30 \%$ solids by $\nu=\mu / \rho$,

Case of 30\% solids.

Case of $30 \%$ solids $\mathrm{Pr}=\nu / \alpha$,

Case of $10 \%$ solids.

Case of $30 \%$ solids $\mathrm{Re}=\mathrm{UD} / \nu$,

Case of $10 \%$ solids.

$\mathrm{P}=\boldsymbol{\pi} \mathrm{D}$.

$80^{\circ} \mathrm{F}$ approximately.

Above freezing, conservatively low.

\subsection{TEMPERATURE DROP ANALXSIS}

Using the data listed in the "Summary of Assumed Values" and following symbols listed in "Nomenclature" the slurry line Keynolds number may take on values between 2200 and 22000 for $30 \%$ and $10 \%$ solids, respectively, so that turbulent flow should be expected for the leading edge. The heat transfer coefficient is given approximately by:

$$
N_{u}=\frac{h D}{k}=0.023 \operatorname{Re}^{01} \mathrm{Pr}^{0.8}
$$

from which $\mathrm{h}=300 \mathrm{~W} / \mathrm{m}^{2} \mathrm{~K}$ for $30 \%$ solids and $\mathrm{h}=120 \mathrm{~W} / \mathrm{m}^{2} \mathrm{~K}$ for $10 \%$ solids.

The temperature change of the fluid along the transfer line is given by:

$$
\frac{T \cdot T_{w}}{T_{0}-T_{w}}=\exp \left[-\left(\frac{h P}{W c_{p}}\right) L\right]=\exp (\cdot \lambda L)
$$

So for $30 \%$ solids $\lambda L=1.5$, and for $10 \%$ solids $\lambda L=0.60$. Thus, the frnal fluid temperatures are $7^{\circ} \mathrm{C}$ and $15^{\circ} \mathrm{C}$ for the two cases, respectively. 


\begin{tabular}{|c|c|c|c|}
\hline SENT BY: & 2- 6-96:4:24PM: & FAI - NO. SHORE- & $5093760546: \# 3 / 4$ \\
\hline $\begin{array}{l}\text { PAX: C-106 "Leading } \\
\text { Edge Question" Response }\end{array}$ & Page 3 & & February 6, 1996 \\
\hline
\end{tabular}

\subsection{ERECIPITATION POTENTLAL}

From [3] the concentrations of important salts in C-106 solution are:

$\begin{array}{lll}\mathrm{NO}_{3} & 67 \mathrm{~g} / \mathrm{L} & \mathrm{NaNO}_{3} \text { equivalent } 92 \mathrm{~g} / \mathrm{L} . \\ \mathrm{OH} & 2 \mathrm{~g} / \mathrm{L} & \mathrm{NaOH}_{\text {equivalent }} 3.5 \mathrm{~g} / \mathrm{L} \\ \mathrm{PO}_{4} & 4.4 \mathrm{~g} / \mathrm{L} & \mathrm{Na}_{3} \mathrm{PO}_{4} \text { equivalent } 7.6 \mathrm{~g} / \mathrm{L} . \\ \mathrm{SO}_{4} & 5.0 \mathrm{~g} / \mathrm{L} & \mathrm{Na}_{2} \mathrm{SO}_{4} \text { equivalent } 7.4 \mathrm{~g} / \mathrm{L} .\end{array}$

Lacking solubility data for such a mixture, a heuristic approach is to assume an equivalent of $120 \mathrm{~g} / \mathrm{L} \mathrm{NaNO}_{3}$, which exceeds the sum of salt concentrations. The ratio of interest for solubility is:

$$
\frac{\text { g Nitrate }}{\text { g Water }}-\frac{g / L \text { Nitrate }}{g / L \text { Solution }- \text { g/L Nitrate }}=\frac{120}{1180-120}=0.11
$$

where it is assumed that other compounds have negligible concentration by comparison.

The solubility limit of $\mathrm{NaNO}_{3}$ is about $0.037 \mathrm{~g} \mathrm{NaNO}, 1 \mathrm{~g} \mathrm{H} \mathrm{H}_{2} \mathrm{O}$ at $0^{\circ} \mathrm{C}$ and 0.178 at $25^{\circ} \mathrm{C}$ [4]. By linear interpolation, the solubility limits at $7^{\circ} \mathrm{C}$ and $15^{\circ} \mathrm{C}$ are 0.077 and $0.12 \mathrm{~g}$ NaNO, $1 \mathrm{~g} \mathrm{H}_{2} \mathrm{O}$, respectively.

Since the C-106 sludge and interstitial solution will be diluted by sluicing water, it is clear that a figure below $0.05 \mathrm{~g} \mathrm{NaNO}, 1 \mathrm{~g} \mathrm{H}_{2} \mathrm{O}$ is better representative of the pumped siumy than the actual $\mathrm{C}-106$ value. Hence, no precipitation of slurry salts would be expected.

\subsection{NOMENCLATURE}

A Pipe area, $\mathrm{m}^{2}$,

c Specific heat of fluid, $J / \mathrm{kg} \cdot \mathrm{K}$,

D Pipe diameter, $m$

h Heat transfer coefficient, $w / m^{2} K$,

L Pipe length, $m$

Nu Nussell number,

$P \quad$ Pipe wall perimeter, $m$,

Pr Prandu number, 
FAX: C-106 "Leading

Re Reynolds number,

$T$ Fluid temperature, $\mathrm{K}$,

$T_{0} \quad$ Initial fluid temperature, $K$,

$T_{w} \quad$ Wall (pipe) temperature, $K$.

U Fluid speed, $\mathrm{m} / \mathrm{s}$,

W Fluid mass flowrate, $\mathrm{kg} / \mathrm{s}$,

a Thermai diffusivity, $\mathrm{m}^{2} / \mathrm{s}$,

$\rho$ Density, $\mathrm{kg} / \mathrm{m}^{3}$,

H Viscosity, $\mathrm{kg} / \mathrm{ms}$,

v Kinematic viscosity, $\mathrm{m}^{2} / \mathrm{s}$, and

$\lambda$ Inverse length for temperature profile, $\mathrm{m}^{-1}$.

\subsection{REFERENCES}

[1] D.L. Evans, WHC internal memorandum to T.H. May, W-320s Process Transfer Lines, Physical Data, January 26, 1996.

[2] Tom May, WHC, personal communication:

[3] Bruce Castaing, 101-AY, 102-AY, and 106-C Data Compendium, WHC-SD-WM-TI578, Rev. 1.

[4] International Critical Tables, p. 372.

MGP:vdl 
$02 / 12 / 96 \quad 17: 35 \quad 8509376 \quad 0546$

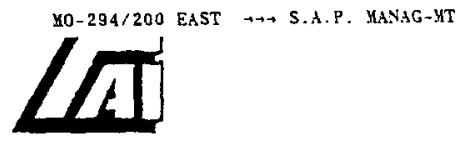

Furske \& A.ssociares, Ine:

DATE: February 8, 1996

TO: John Harris and Bob Cash, WHC 509-376-0546
FROM: Marty Plys M. Mly

SUBJECI: Response to C-106 "Trailing E.dge" Question

Dana Powers of the Chemical Reaction sub-TAP asked whether slurry solids in the transfer line would settlc out when pumping is stopped and flow reverses. By examining the fallout velocity for large slurry particles, we may show that little settling would be expected during the flow reversal and spillback time. According 10 [1], abour $25 \%$ of the particle mass is found between 40 and $5 S$ microns, with 45 mieron being roughly the average diameter of this size bin. Also from [1], the mixture viscosity increases from $4 \mathrm{cP}(0.004 \mathrm{~kg} / \mathrm{m}, \mathrm{s})$ for clear liquid (water) to $13 \mathrm{cP}$ at $10 \%$ solids loading and $105 \mathrm{CP}$ at $30 \%$ solids loading. Clearly the large increase in viscosity is due to the abundance of strall particles, comohonated by $35 \%$ of the mass belonging to particles below 10 micron sire. The small particles simply cannot fall out during operations, and act to impede the fallow of the large particles.

Thus, fallour of the large particles can be treated as if the mixture viscosity acts upon them. The case of $10 \%$ solids loading will be considered here because fallout times for the $30 \%$ lnading case would be ten times longer. The Stokes law terminal velocity for a 45 micron particle of density 1720 $\mathrm{kg} / \mathrm{m}^{\wedge} 3$ in fluid with a density of $1000 \mathrm{~kg} / \mathrm{m}^{\wedge} 3$ and viscosity $0.013 \mathrm{~kg} / \mathrm{m.s}$ is $0.06 \mathrm{~mm} / \mathrm{s}$. This means that during the fluid velocity reversal time on the order of 10 seconds or less, the largest perlicles wnuld fall less than $1 \mathrm{~mm}$, or less than $1 \%$ of a pipe diameter. Therefore, during the time period when bulk fuid velocities in the pipe may be low, very little settling ean oceur.

Indeed, during the neverse flow drainage time which is less than 10 minutes, thesc particles would only lall about $30 \%$ of the pipe diancter. Note that particles that could fall out during transfer line reverse flow drainage could also be reentrained. While methods exist to predict the batch sertling of particles more precisely, as a heuristic rule for this example we can state that less than $50 \%$ of the lerge particles, representing about $12 \%$ of the wal suspended mass, could potentially fall out in this case, which meins that the total solids fraction would change from 10\% $109 \%$. Simply put, there will not be crough solid tallout to block a pipe.

[1] Tom May, Westinghouse Hanford Company, personal communication, 1/24/96.

I6W070 West 83rd Street - Burr Ridge, Illinois 60521 • (708) .323.8750

Telefax (7U8) $986-5781$ 
This page intentionally left blank. 
HNF-SD-WM-RPT-293 REV 0

$03 / 01 / 96 \quad 10: 52$

$8509 \quad 376 \quad 0546$

YO-294/200 EAST $\rightarrow \rightarrow$ S.A.P. MANAG-MT

002

SENT BY:

2-28-96:3:24PM: FAI - NO. SHORE-

$509376 \quad 0546: \neq 1 / 1$

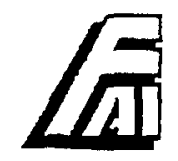

Fauske \& Associates, inc.

16W070 West 83rd St., Burr Ridge, it 60521.

FAX: (708) 986-5481 - Phone: (708) 323-8750 - cmail: fai@xnet.com

DATE: $\quad$ February 28, 1996.

TO: John Harris, WHC

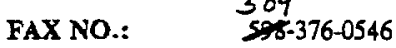

FROM: $\quad$ M. G. Plys $M G$

SUBJECT: $\quad$ C-106 3-Phase Flow

REFERENCES: 1) Hopkins, J. D., Flammable Gas Evaluation of Tank 241-C-106, WHC Internal Memo, Febriary 26, 1996.

2) Collier, J. G., Convective Boiling and Condensation, McGraw-Hill, 1981 .

3) Tom May, Westinghouse Hanford Company, personal communication, $1 / 24 / 96$

\section{This FAX transmittal equals a tatal of 1 page(s).}

According to Hopkins, Reference 1, the stored gas volume fraction in C-106 waste is about $2 \%$. If this gas is retained as large bubbles, it may be released in the tank during sluicing, while if it is retained as small bubbles, it may be pumped with sluicing liquid. At such a low volume fraction, the gas will be transported as a bubbly or intermittent piug flow if the bubbles can coalesce (see any two-phase flow reference such as Ref. 2). There is no reason to suppose that the presence of this small quantity of gas would cause settling of suspended solids, most of whose mass is represented by particles below 40 micron size (indeed $35 \%$ of the mass is below 10 micron size, Ref. 3).

MGP:jgk 
This page intentionaliy left blank. 
Westinghouse

Internal Hanford Company

Memo

From: Process Engineering Analysis

Phone: $\quad 376-0205 \cdot \mathrm{HO}-34$

Date: February 1, 1996

Subject: RESOLUTION OF PROJECT W-320 TIER 2 REVIEW COMMENTS

To:
R. J. Cash
S7-14
cc: H. Babad
$57-14$
J. C. Conner
A2- 25
J. P. Harris, III $\$ 2-48$
D. M. Ogden HO-34
J. P. Sioughter R2-54
BAC File/LB

74A50-96-BAC-003

\section{INTRODUCTION}

Engineering analyses has been performed to address specific comments resulting from the Tier 2 review of Project $W-320$ (Tank $C-106$ retrieval). The following questions have been identified by the Technical Advisory Panel, Chemical SubTap (J. L. Kovach letter, dated November 10, 1995):

- Would the remnants of the waste in tank $c-106$ still require water addition to prevent waste dry-out, or would the waste be permitted to dry out?

- If tank $\mathrm{C}-106$ remnants are left to dry out, would there be an aggravation of the potential organic condensed phase reaction problem?

- Is it considered that tank C-106 may require humidification or other means of water addition after the $-75 \%$ waste removal?

The peak waste temperatures following the Project $W-320$ sluicing operation is dependent upon the quantity of tank waste removed, the spatial distribution of the tank heat and the thermal conductivity of the "dry hardpan" remaining.

The purpose of this letter is to summarize the results of an engineering study which evaluated the above issues. Parametric analyses were performed for the tank heat load distribution and waste conductivity. The study determined the minimum fraction of heat that must be removed as a function of remaining waste thickness to maintain the tank waste below applicable temperature limits without the continued addition of cooling water.

\section{MODEL DESCRIPIIONS}

Scoping analyses was performed with a one dimensional model. A solution to Poisson's equation for one dimension, steady state heat conduction was used with the following assumptions:

- Energy removal by convection only from the waste surface 
R. J. Cash

Page 2

February 1, 1996

- No heat loss from the tank bottom

- Dome ventilation at current levels $(2300 \mathrm{cfm})$.

Detailed two-dimensional models were used to confirm the results of the scoping analyses. The primary model empioys P/THERMAL, a standard thermal analyses computer code. Models were developed for previous analyses of tank $C-106$ and are documented in Reference 1 . The P/THERMAL model, shown in Figure 1 , is a two dimensional finite element model. The model was modified from the model documented in Reference 1 to account for about $75 \%$ waste removal (the remaining waste varies from a thickness of 2.33 feet in the center to 1.33 feet at the outside of the tank) and waste conductivities were modified to simulate the conductivity of dry sludge.

Both the one- and two-dimensional models used a total tank heat load of $132,400 \mathrm{Btu} / \mathrm{hr}$ as recommended by Reference 3 . The basic heat load distribution was however derived based on a model with a tank heat load of $110,000 \mathrm{Btu} / \mathrm{hr}$ (Reference 1). A comparison of the results of this model with the Riser 8 thermocouple results is shown as Figure 2 . The heat load distributions used for the study are summarized in Table 1 . The best estimate distribution with $110,000 \mathrm{Btu} / \mathrm{hr}$ total best fits the Riser 8 thermocouple date. The conservative heat load distributions will be discussed in the results section.

Table 1. Heat Load Distributions.

\begin{tabular}{|l|l|l|}
\hline \multicolumn{1}{|c|}{ Distribution } & \multicolumn{1}{|c|}{ Region 1 } & \multicolumn{1}{c|}{ Region 2 } \\
\hline $\begin{array}{l}\text { Best Estimate } \\
110,000 \text { Btu/hr } \\
\text { Total }\end{array}$ & $6.3 \mathrm{Btu} / \mathrm{hr}-\mathrm{ft}^{3}(0-4 \mathrm{ft})$ & $\begin{array}{l}1.5 \mathrm{Btu} / \mathrm{hr}-\mathrm{ft}^{3} \\
(4-6 \mathrm{ft})\end{array}$ \\
\hline $\begin{array}{l}\text { Best Estimate } \\
132,400 \text { Btu/hr } \\
\text { Total }\end{array}$ & $7.9 \mathrm{Btu} / \mathrm{hr}-\mathrm{ft}^{3}(0-4 \mathrm{ft})$ & $\begin{array}{l}1.9 \mathrm{Btu} / \mathrm{hr}-\mathrm{ft}^{3} \\
(4-6 \mathrm{ft})\end{array}$ \\
\hline $\begin{array}{l}\text { Conservative Case 1 } \\
67,000 \text { Btu/hr }\end{array}$ & $9.4 \mathrm{Btu} / \mathrm{hr} / \mathrm{ft}^{3}(0-2.33 \mathrm{ft})$ & $\mathrm{N} / \mathrm{A}$ \\
\hline $\begin{array}{l}\text { Conservative Case 2 } \\
130,100 \text { Btu/hr }\end{array}$ & $18.4 \mathrm{Btu} / \mathrm{hr}-\mathrm{ft}^{3}(0-2.33 \mathrm{ft})$ & $\mathrm{N} / \mathrm{A}$ \\
\hline
\end{tabular}

Differences in temperature gradients in the waste are an indication of the local heat load distribution. Figure 3 shows temperature gradients. The temperature gradients for heat generation at the surface, heat generation at the bottom and uniform heat generation are shown for reference. The best estimate is based upon the Reference I distribution using the Reference 3 total heat load. It is in good agreement with the data from Riser 8 for the lower portion of the tank. 
Page 3

February 1, 1996

\section{DRY WASTE THERMAL CONDUCTIYITY}

For a dry waste tank, a major determinant of peak waste temperature is the dry waste thermal conductivity. There are no reported values for therma? conductivity of the waste in tank $\mathrm{C}-106$ that are based on an actual sample of the waste. The values that are used in the models documented in References 1 and 3 are based on values that give the best fit to the observed temperature data. These values are consistent with paralle? conduction models for conduction in a water sludge mixture. These values are for wet waste and will decrease significantly for dry waste.

Measured thermal conductivities for actual tank waste are documented in Reference 2. This data is shown in Figure 4 . The average value of $0.27 \mathrm{Btu} / \mathrm{hr}-\mathrm{ft}-{ }^{\circ} \mathrm{F}$ at $300^{\circ} \mathrm{F}$ was selected as the best estimate dry conductivity. The lowest measured value $\left(0.089 \mathrm{Btu} / \mathrm{hr}-\mathrm{ft}-{ }^{\circ} \mathrm{F}\right)$ was selected as a conservative estimate of the conductivity. The conductivity of tank C-106 "hardpan" material is expected to be higher than these values since it is completed with a smaller porosity.

\section{TEMPERATURE LIMITS}

The temperature limits for tank $C-106$ are based on the operating specifications for single-shell tanks (Reference 4). The Operational Safety Document (OSO) structural temperature limit is $300^{\circ} \mathrm{F}$ in the waste and $350^{\circ} \mathrm{F}$ in the concrete. Organic reactions may be possible if organics are present. However, these reactions normally occur near $390^{\circ} \mathrm{F}$ (Reference 5 ) which is well above the OSD temperature limit. Therefore, the OSD limit of $300^{\circ} \mathrm{F}$ in the siudge was selected for this study (analyses have shown that the concrete temperatures are lower than the sludge temperatures).

\section{ANALYSIS RESULTS}

Results from the one-dimensional scoping calculations are shown in Figure 5 . The results show the heat load that can remain after sluicing and not exceed the OSD limit of $300^{\circ} \mathrm{F}$. The analyses was done for the best estimate (B.E.) and conservative thermal conductivities. The straight lines represent the heat load distribution for the best estimate heat load (Table 1) and 2 times the best estimate heat load. With the B.E. conductivity and heat load, $3.25 \mathrm{ft}$ of siudge could remain, it would have a 115,000 Btu/hr heat load. With the conservative conductivity and heat load distribution, less than $1.5 \mathrm{ft}$ of sludge could remain, it would have a $100,000 \mathrm{Btu} / \mathrm{hr}$ heat load. The hard pan region is thought to be on the order of l foot thick, and based on the historical tank data should not contain much of the tank heat load. These analyses therefore suggest that both on a best estimate and conservative basis, no water additions will be required after sluicing to keep sludge temperatures below OSD limits. 
R. J. Cash

$74 A 50-96-B A C-003$

Page 4

February 1, 1996

Analyses were also performed with the two-dimensional P/THERMAL model. Seventy five percent of the waste was assumed to be removed by the sluicing operation. This gave a depth of $2.33 \mathrm{ft}$ in the center and $1.33 \mathrm{ft}$ at the edge (see Figure 1). Analyses were performed to determine how much the tank : heat load could remain without exceeding the OSD temperature limit. The waste was assumed to be dry and heat removal occurred by dome ventilation flow of $2300 \mathrm{cfm}$ (without evaporation) and soil heat conduction.

The results are sumnarized in Table 2. Three heat load distribution were considered as sumarized in Table 1. The conservative heat loads were selected so the maximum temperatures did not exceed the OSD 1 imits for the two thermal conductivities considered.

Table 2. Results of P/THERMAL. Anatyses.

\begin{tabular}{|c|c|c|c|}
\hline $\begin{array}{c}\text { Heat Load } \\
\text { Distribution }\end{array}$ & $\begin{array}{c}\text { Heat Load } \\
\text { (Btu/hr) }\end{array}$ & $\begin{array}{c}\text { Conservative } \\
\text { Conductivity }\end{array}$ & $\begin{array}{c}\text { Best Estimate } \\
\text { Conductivity }\end{array}$ \\
\hline Best Estimate & 56,000 & $264^{\circ} \mathrm{F}$ & $175^{\circ} \mathrm{F}$ \\
\hline Conservative Case 1 & 67,000 & $300^{\circ} \mathrm{F}$ & $193^{\circ} \mathrm{F}$ \\
\hline Conservative Case 2 & 130,000 & & $300^{\circ} \mathrm{F}$ \\
\hline
\end{tabular}

For the best estimate case, the maximum temperature would be $264^{\circ} \mathrm{F}$ for the most conservative conductivity. Assuming the best estimate thermal conductivity, 130,000 Btu/hr could remain in the sludge. This is $98 \%$ of the + total tank heat load. A heat load of $67,000 \mathrm{Btu} / \mathrm{hr}$ or $51 \%$ of the total tank heat load could remain for the most conservative thermal conductivity (The one-dimensional model (Figure 5) for a $2.33 \mathrm{ft}$ waste depth gives a values lower than the P/THERMAL model. This is expected because of the nonuniform waste depth and conduction losses from the tank bottom).

A representative temperature contour plot is shown in Figure 6 . This temperature distribution is representative of a Conservative Case 1 heat load distribution combined with the best estimate thermal conductivity.

The results of both the scoping and P/THERMAL analyses show that for $75 \%$ waste removal, the dry waste temperatures can be maintained below OSD temperature limits without evaporative cooling with a significant amount of the total heat load remaining.

The steady-state temperature gradient (prior to sluicing) for the two conservative heat load distributions are compared with actual tank data in Figure 7 . While the OSD temperature limits will not be exceeded with these conservative heat load distributions, they are clearly inconsistent with the Riser 8 data. 
R. J. Cash

Page 5

February 1, 1996

\section{CONCLUSIONS}

Tank C-106 waste temperatures will not exceed the 0SD temperature 13 mits following Project $W-320$ waste retrieval and evaporative cooling, ano continued water additions will not be required.

\section{REFERENCES}

1. Bander, T. J., 1993, Revised Thermal History of Tank 241-C-106, WHC-SD-WM-ER-200, Westinghouse Hanford Company, Richland, Washington.

2. Hillingham. C. E., 1994, Thermophysical Properties of Hanford High-Level Tank Wastes - A Preliminary Survey of Recent Data, PNL-9419, Pacific Northwest Laboratory. Richland, Washington.

3. Fryer, B. C., and M. J. Thurgood, 1995, Revised Tank Heat Load Estimate for Tank C-106 Based on Goth Analysis of the Process Test, JMI-WTO02, John Marvin, Inc., Richland Washington.

4. WHC, Boyless, V. C. 1995, Operating Specifications for Single-Shell Waste Storage Tanks, OSD-T-151-00013, Westinghouse Hanford Company, Richland, Washington.

5. Webb, A. B., et al., 1995, Preliminary Safety Criteria for Organic Watch List Tanks at the Hanford Site, WHC-SD-WM-SARR-033, Rev. 0, West inghouse Hanford Company, Richland, Washington.

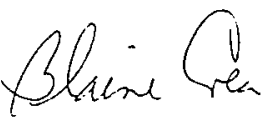

B. A. Crea, Principal Engineer Process Engineering Analysis

bab

Attachments 2

CONCURRENCE:
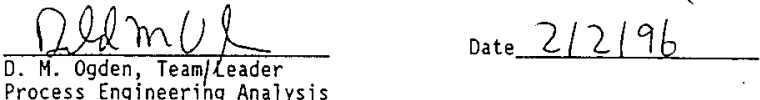
HNF-SD-WM-RPT-293 REV 0

74A50-96-BAC-003

ATTACHMENT

FIGURES 1 - 7

Consisting of 5 pages,

including cover page 
Figure 1. P/Thermal Finite Element Model.

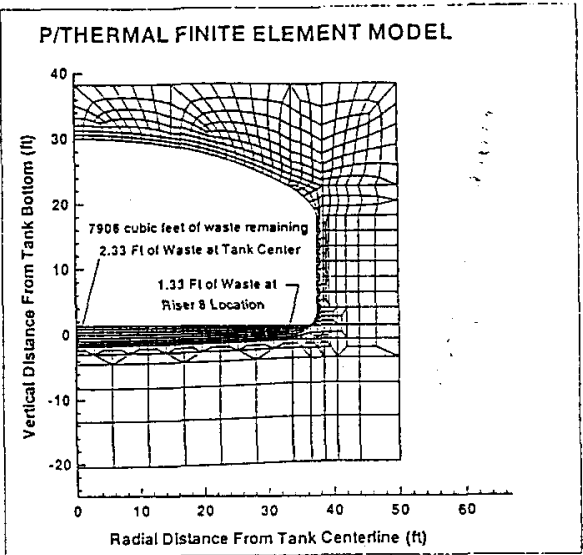

Figure 2. Riser 8 Temperature Profile for Normal Conditions (110,000 Btu/Hr)

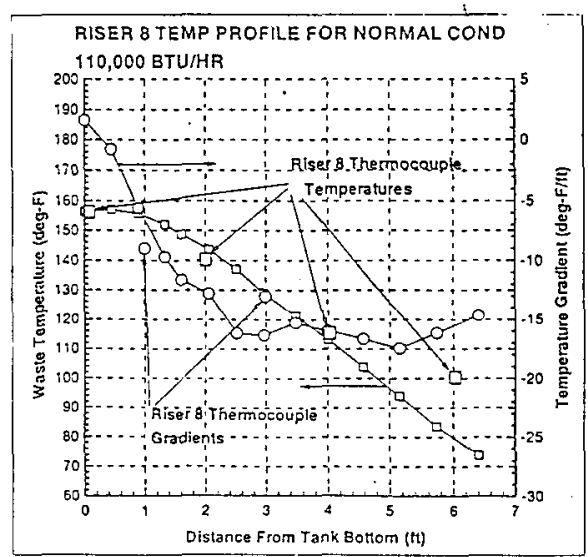


Figure 3. C-106 Temperature Gradients.

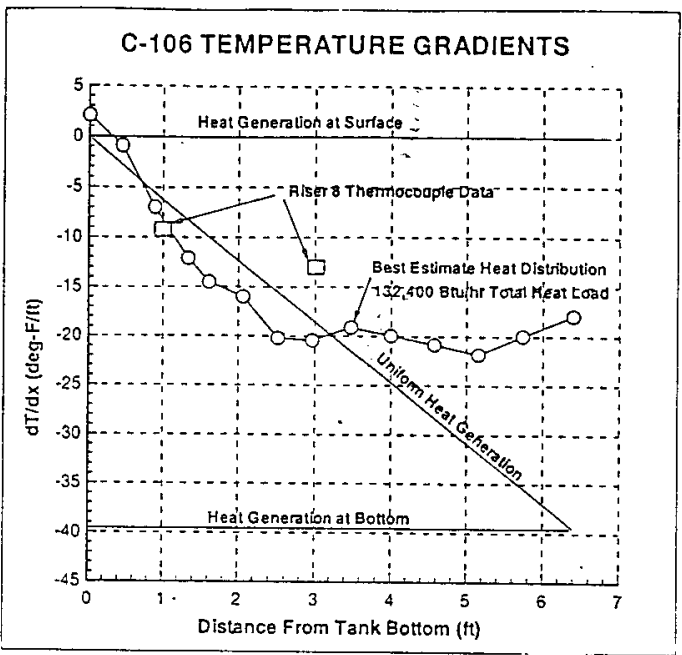

Figure 4. Elevated Temperature Thermal Conductivity.

(Reference 2)

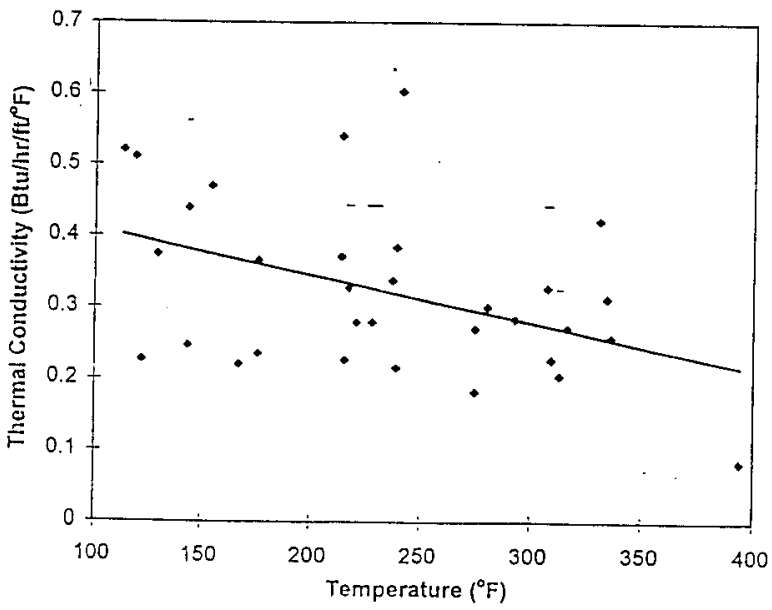


Figure 5. Allowable Remaining Heat Load as a Function of Depth for $300 \%$ Maximum Temperature.

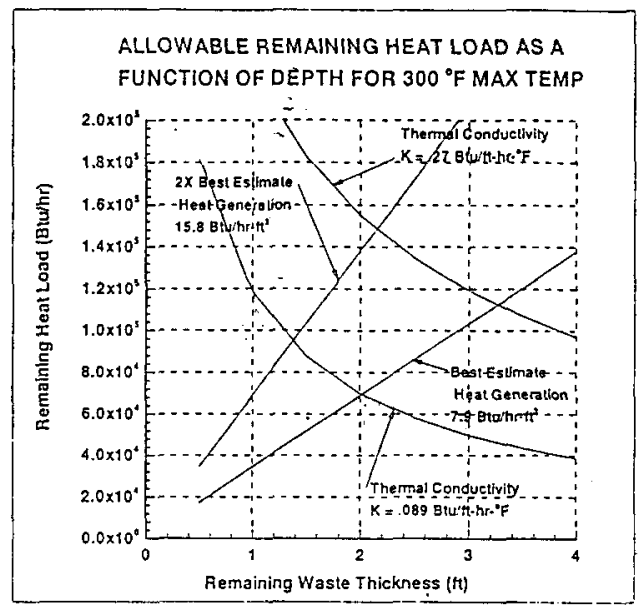

Figure 6. Temperature Distributions After Sluicing.

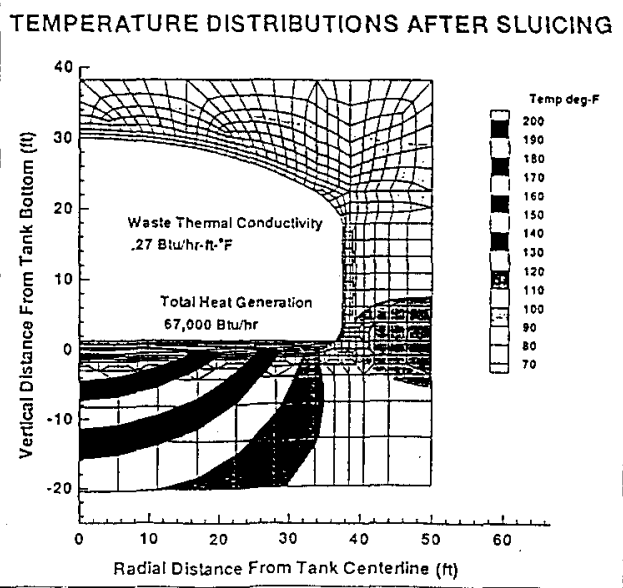


Figure 7. Conservative Cases Compared to Data.

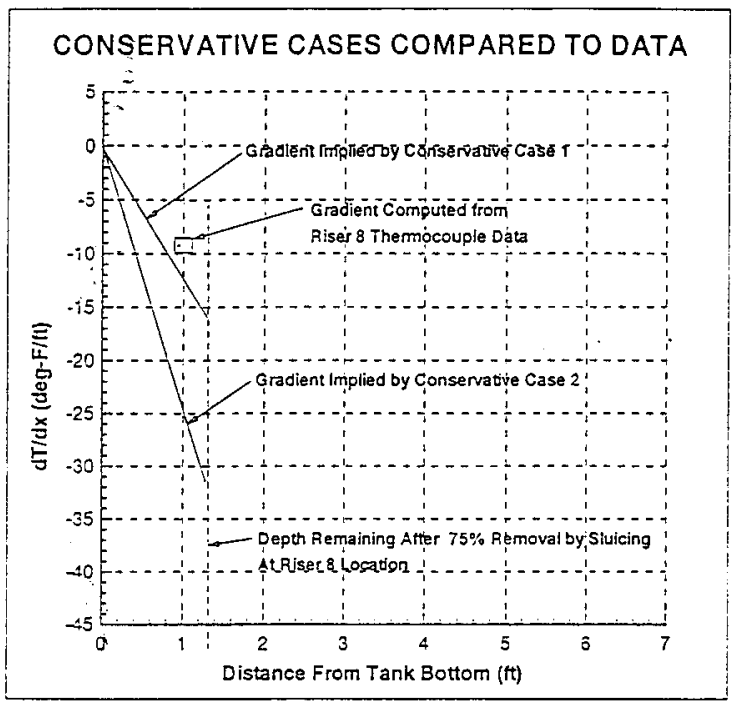


From: Thermal Hydraulic Analys is

Phone: 6-7143 H0-33

$23210-T J B-93-048$

Date: January 22, 1993

Subject: TOTAL HEAT SOURCE IN TANK C-106

To:

J. P. Harris

$54-55$

cc:
S. H. Claybrook
HO-34
C. Defigh-Price
W. L. Knecht
T. B. McCall
R2-31
HO-34
0 . S. Wang
$\mathrm{H} 0-33$
TJB File/LB
R2-32

A comparison of transient calculated temperatures with thermocouple measurements during the ventilation outage in 1992 indicate that the total heat source in tank $C=106$ is $110,000+/-20,000 \mathrm{Btu} / \mathrm{h}$. The attached figures show the calculated temperatures curves versus the measured thermocouple data $\left(x^{\prime} s\right)$ for total heat sources of 130,000 , 110,000 , and $90,000 \mathrm{Btu} / \mathrm{hr}$. The top figure is for level 1 of the thermocouple tree ( $4 \mathrm{in}$. from the bottom of the tank), the middle figure for level 2 ( $2 \mathrm{ft} 4 \mathrm{in}$. from the bottom of the tank), and the bottom figure for leve? 3 (4 ft 4 in. from the bottom of the tank). Differences between measured and calculated temperatures at the other three ievels of the thermocouple tree ( $6 \mathrm{ft} 4 \mathrm{in.;} 8 \mathrm{ft} 4 \mathrm{in.}$; $10 \mathrm{ft} 4 \mathrm{in.}$ ) are small.

A two-layer model was used for the calculated temperatures, since the temperature profiles for this model fit the measured profiles best. This model combines the bottom two siudge layers of the three-layer model previously developed. Some of the heat from the top layer has been inciuded in the bottom layer due to settiing of the radionuclide particles from the top layer to the bottom layer. The analyses for the complete history of the tank can incorporate this movement between layers by adjusting the heat source in each iayer.

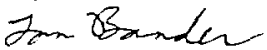

T. J. Bander

Software Engineer

dsa

Attachment

CONCURRENCE:

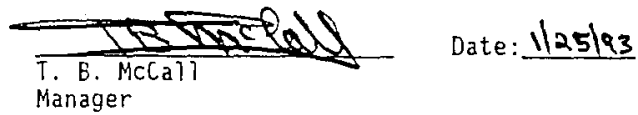


HNF-SD-WM-RPT-293 REV 0

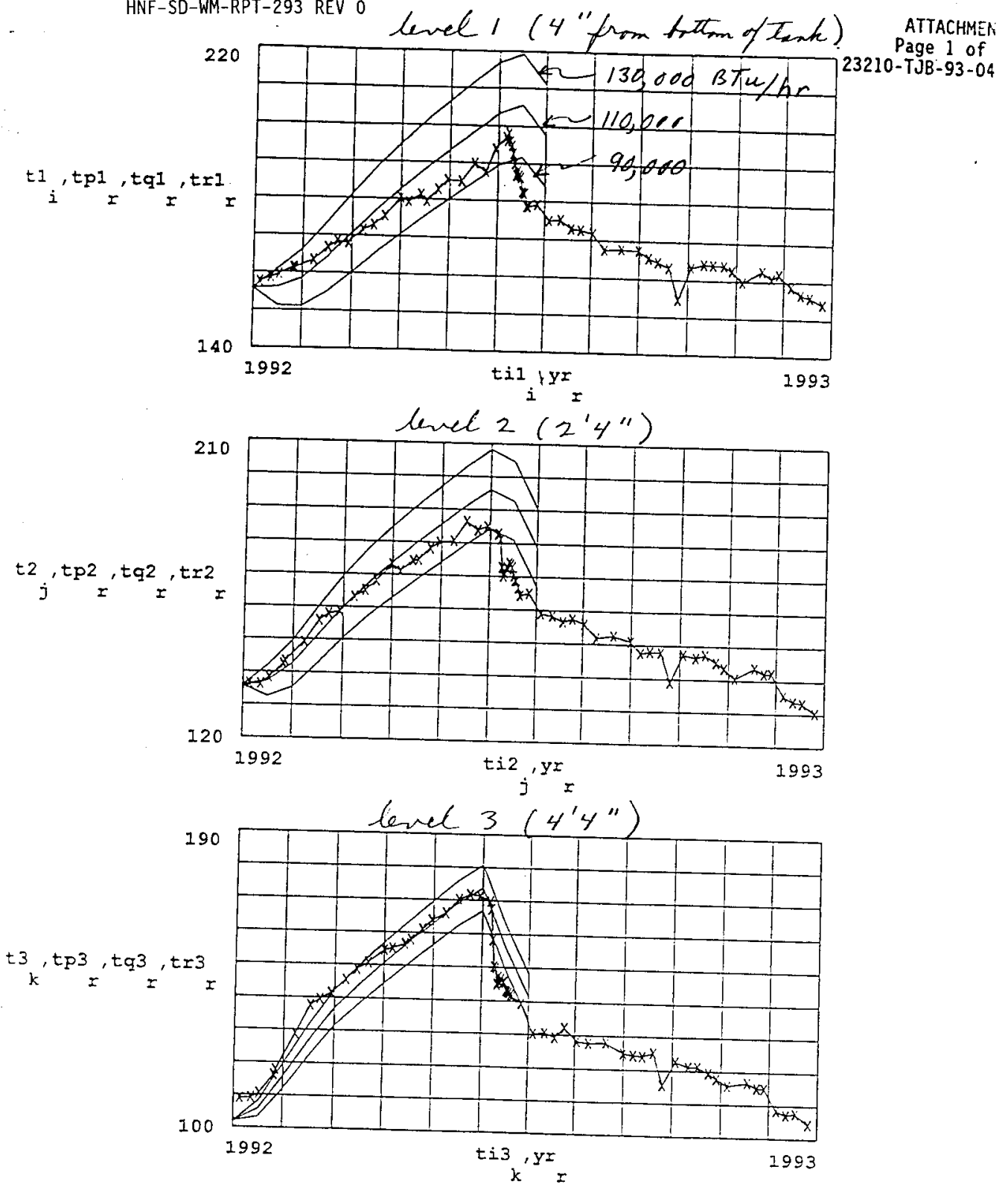


From: Process Engineering Analysis

Phone: $\quad 376-0438$ HO-34

Date: July 12, 1996

Subject: RECOMMENDATION FOR C-106 SLUICING

To:

$\begin{array}{lll}\text { J. P. Harris, III } & \mathrm{S} 2-48 \\ \text { cc: } & \text { T. J. Bander } & \mathrm{H} 0-34 \\ & \text { J. P. Bailey } & \mathrm{S}-40 \\ \text { B. A. Crea } & \mathrm{HO}-34 \\ \text { J. C. Conner } & \mathrm{A} 2-25 \\ \text { G. T. Dukelow } & \mathrm{S7}-14 \\ \text { J. P. Sloughter } & \mathrm{R} 2-54 \\ \text { DMO File/LB } & \end{array}$

References: (1) Bander, T. J., B. A. Crea, and D. M. Ogden, 1996, Tank 241-C-106 Sluicing Evaluation, WHC-SD-WM-ER-588, Rev. 1, Westinghouse Hanford Company, Richland, Washington

(2) Conner, J. C., 1996, Safety Assessment for Tank 241-C-106 Waste Retrieval, Project W-320, WHC-SD-WM-SAD-024, DRAFT, Westinghouse Hanford Company, Richland, Washington.

(3) Bander, T. J., 1995, Tank 241-C-106 Process Test Report, WHC-SDWM-427, Rev. 0, Westinghouse Hanford Company, Richland, Washington.

(4) Ogden, D. M., and M. J. Thurgood, 1996, Tank C-106 Contingency Chiller System Analysis, WHC-SD-WM-ER-457, Rev. 0, Westinghouse Hanford Company, Richland, Washington.

\section{Introduction}

A thermal evaluation of the Project $W-320$ retrieval process was performed and documented in Reference 1. This study recommended incremental sluicing of tank 241-C-106. Incremental sluicing and hold periods of tank cooling will maintain the maximum waste temperatures below the local saturation (boiling) temperature during the sluicing operation as required by the project safety evaluation (Reference 2). The purpose of this letter is to provide a recommendation for the size of the incremental steps, the duration of the cooling periods, and necessary tank monitoring. 
J. P. Harris, III

74A50-96-DMO-006

Page 2

July 12, 1996

\section{Proposed Sluicing Strategy}

The proposed incremental sluicing eliminates the potential for steam bumps by maintaining a safe margin of subcooling (waste temperatures below the local saturation temperature) in the waste at all times. The sluicing is performed in incremental steps which are small so that the loss of pressure due to the waste removal will not reduce the saturation temperature to the local waste temperature, which is possible with the designed capacitiy of the sluicing system. The size of the incremental steps must account for uncertainties in parameters such as the maximum waste and saturation temperatures and level control during sluicing (uniform sluicing is desirable).

A meeting was conducted with Project W-320 personnel (John Harris, Construction Projects; John Bailey, Retrieval Engineering; John Conner, Projects SAR Engineering) to review the sluicing operation and level control issues. Historically, the liquid pool is removed prior to sluicing. This makes level control difficult and level monitoring possible by visual inspection only. In light of these difficulties, John Bailey recommended that the 241C-106 sluicing be performed with a liquid pool covering the waste. Level would be maintained by controlling the slurry and sluicing jet pump rates. Sluicing (at a constant level) will continue until the particle loading of the transfer line reaches a minimum value, indicating that the waste some distance below the surface has been removed. Past sluicing has shown that sludge can be removed up to 1 foot below the liquid surface. The constant level sluicing will control the maximum sluicing depth and promote uniformity of the sluicing.

The proposed incremental sluicing (based upon the thermal evaluation of Reference 1 and discussions with Retrieval Engineering) is shown in Figure 1 and discussed in the following. The proposed liquid level for the first constant level sluicing is 72 Figure 1. Proposed Incremental Sluicing for 241-C-106. inches (ENRAF measurement).

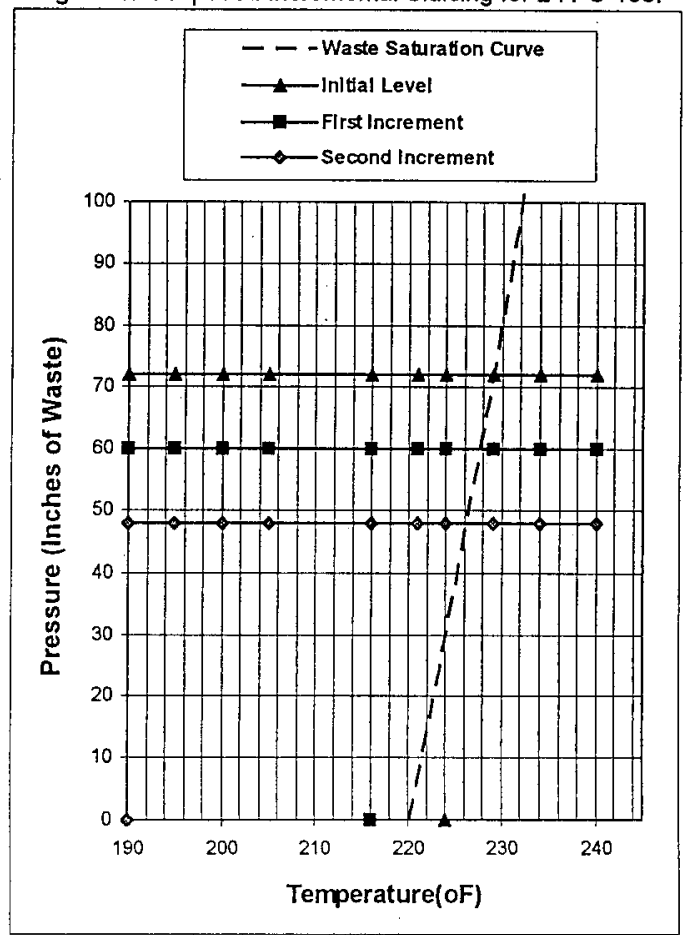

The C-106 1994 process test (Reference 3), which evaporated the liquid pool, showed that the 
sludge level was near 69 inches. This would leave 2 to 3 inches covering the sludge. Figure 1 shows the saturation curve for $\mathrm{C}-106$ waste, which includes vapor suppression. The saturation temperature for a waste level of 72 inches is about $229^{\circ} \mathrm{F}$. The maximum waste temperature Figure 2. Slab Model (5 ft) Transient Temperatures. following the operation of the tank chiller system (Reference 4 ) is predicted by analyses to be $224^{\circ} \mathrm{F}$ (shown on the abscissa of the graph). This is approximately $5^{\circ} \mathrm{F}$ subcooling, which should provide a margin of safety for uncertainties in temperatures and level.

The first incremental sluicing (prior to the draw down to the second incremental step) will remove sludge down to the 60 -inch level while reducing the tank bottom pressure by only $5 \%$. The liquid pool supports only a very small temperature gradient (due to convective flows). Thus, the conduction length for the sludge will be reduced by 1 foot with nearly the same pool boundary temperature and bottom pressure. A simple one-dimensional slab conduction model can be used to estimate the effect of the reduced conduction length (Reference 1).

Figure 2 shows the transient temperature response of a 5 foot slab of waste with a step change in the boundary temperature equivalent to the removal of 1 foot of sludge. After two weeks, the temperature at

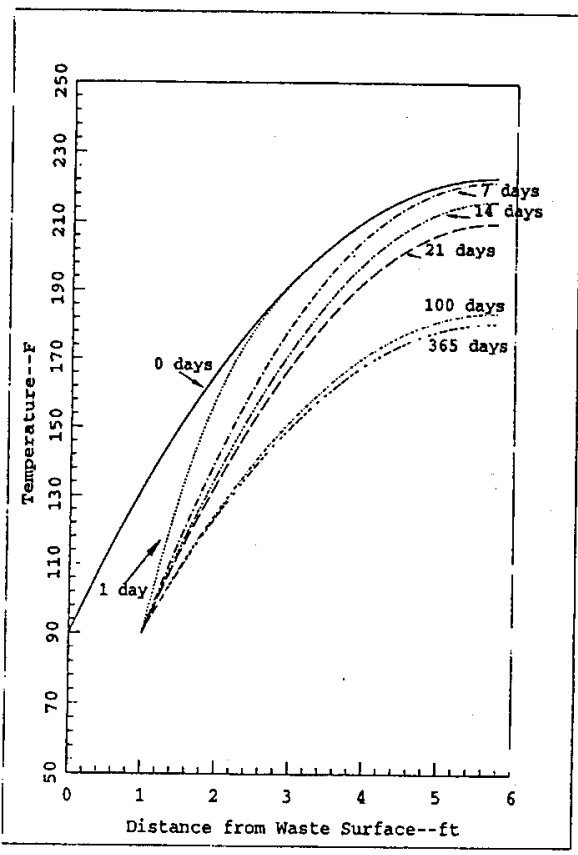
the 6 foot elevation has decreased from $224^{\circ} \mathrm{F}$ to near $216^{\circ} \mathrm{F}$ (shown on the abscissa of Figure 1). Thus, sluicing with a tank level at 72 inches followed by a cooling period of 14 days will reduce the maximum waste temperature to about $216^{\circ} \mathrm{F}$. if the liquid level is then drawn down to the 60-inch level to complete the first incremental sluicing, as seen in Figure 1 , the saturation temperature will decrease to about $228^{\circ} \mathrm{F}$, but the waste temperature will have decreased to approximately $216^{\circ} \mathrm{F}$. This is over $10^{\circ} \mathrm{F}$ of subcooling, which again will provide a margin of safety for uncertainties.

The second incremental sluicing should be performed at a constant liquid level of 60 inches, following the same procedure described above. The effect of the removal of an additional foot of sludge is shown in Figure 3, which shows the transient temperature history for a 4 foot slab of waste with a step boundary temperature change equivalent to the removal of 2 feet of sludge. After 14 days, the maximum waste temperature has decreased over $30^{\circ} \mathrm{F}$. The new 
J. P. Harris, III

74A50-96-DMO-006

Page 4

July 12, 1996

waste temperature would be approximately $185^{\circ} \mathrm{F}$ to $190^{\circ} \mathrm{F}$ (shown on the abscissa of Figure 1). The second incremental retrieval is completed by drawing the liquid level down to 48 inches. The new saturation temperature will be about $226^{\circ} \mathrm{F}$, while the maximum waste temperature will have decreased to $190^{\circ} \mathrm{F}$ or less. This is over $30^{\circ} \mathrm{F}$ subcooling. Furthermore, the maximum waste temperature is below the saturation temperature at atmospheric pressure, which completely eliminates any potential steam generation. Incremental retrieval to prevent steam bumps is not required after the second incremental step. However, flammable gas issues in the receiver tank (241-AY-102) may require the continuation of incremental retrieval.

\section{Tank Monitoring}

The proposed sluicing strategy requires the monitoring of tank liquid level during the retrieval process. The slurry submersible pump, which will be sluiced into the sludge, will include conductivity probes. The purpose of the probes is to measure the level in the well surrounding the pump. For the proposed constant liquid level sluicing, this instrument will measure the pool liquid level. This will provide a continuous level measurement. The ENRAF gauge will be withdrawn during the actual sluicing operation. However, it is recommended that the ENRAF gauge be periodically inserted to provide a second level measurement. It is recommended that the level be maintained as near constant as possible during sluicing. However, because of the subcooling margin discussed in the previous section, the level can deviate from the intended level by 6 inches and still provide adequate subcooling.

Other tank data, including temperature, should be continuously recorded, but will be most useful for a post sluicing evaluation. During the cooling period after each incremental sluicing, the temperature and ENRAF level data can be used to provide an assessment of the remaining tank heat load.
Figure 3. Slab Model (4 ft) Transient Temperatures.

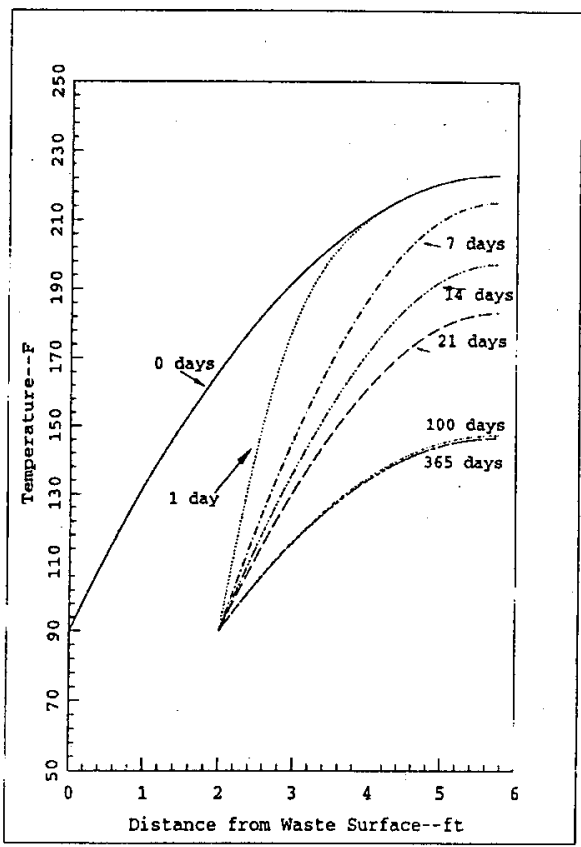


HNF-SD-WM-RPT-293 REV 0

J. P. Harris, III

74A50-96-DMO-006

Page 5

July 12, 1996

Summary of Recommendations

The following is a summary of the recommendations:

1. Tank 241-C-106 sluicing should be performed in 1 foot incremental steps with a 14 day cooling period. Two incremental steps are required to eliminate the steam bump potential.

2. The sluicing should be performed with a constant liquid pool, 72 inches for the first step, and 60 inches for the second.

3. Level should be continuously monitored by the submersible slurry pump conductivity probes with periodic verification by ENRAF measurements.

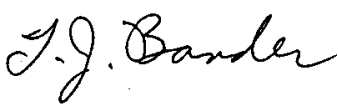

T. J. Bander, Principal Engineer Process Engineering Analysis

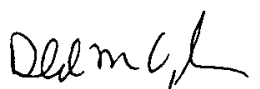

D. M. Ogden, team Leader Process Engineering Analysis

bah

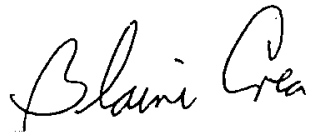

B. A. Crea, Principal Engineer Process Engineering Analysis

247 
HNF-SD-WM-RPT-293 REV O

This page intentionally left blank. 
From: Waste Tanks Process Engineering

$74 A 10-96-082$

Phone: 373-2461

Date: June 10, 1996

Subject: TANK 241-C-106 RETRIEVAL INDUCED FLAMMABLE GAS PLUME ANALYSIS

To:
J. P. Harris
$52-48$

$$
\begin{array}{ll}
\text { cc: D. G. Baide } & S 2-48 \\
\text { J. W. Bailey } & S 2-48 \\
\text { W. B. Barton YWK R R R } & \text { R2-11 } \\
\text { J. C. Conner } & \text { A2-25 }
\end{array}
$$

P. A. Gauglitz

F. J. Heard

C. W. Stewart

SDE File/LB

This memo discusses the issue of a potential gas plume resulting from disturbance and subsequent release of gas trapped in tank 241-C-106 waste by the mechanical agitation imparted by the sluice spray. At focus is the possibility of a localized gas release from the waste which could produce a gas plume in the tank headspace with a fuel concentration sufficient to support combustion. This memo documents the technical viewpoints of a number of experts on the behavior of gases in tank waste. The viewpoints regarding a sluicing induced gas plume at tank $241-6-106$ are detajled in the supporting Attachments. The general findings are summarized below:

- There is not a significant amount of gas trapped in the tank.

- It is highly unlikely the gas is concentrated in any one location prone to immediate agitation and subsequent release by way of the sluice spray.

- Any waste, regardless of how rapidly or vigorously it is agitated, would release gas relatively slowly permitting significant dilution of the emitted gases by forced ventilation and other means of convection within the tank headspace.

- The gas would be diffused through a relatively large area of the waste surface, a fact which naturally tends to limit the resulting fuel concentration in any generated plume.

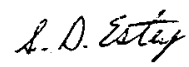

S. D. Estey

Senior Engineer

mjg

Attachments 
HNF-SD-WM-RPT-293 REV 0

This page intentionally left blank. 


\title{
ATTACHMENT A
}

74A10-96-082

TANK 241-C-106 RETRIEVAL INDUCED FLAMMABLE GAS PLUME ANALYSIS

\author{
consisting of 6 pages
}


HNF-SD-WM-RPT-293 REV 0

This page intentionally left blank. 


\section{Introduction}

This analysis provides estimates of the magnitude of a plume formation in tank 241-C-106 which would be caused by the mechanical agitation of the tank waste due to the sluicing spray. The unique subjects to be addressed in this anatysis are:

\section{1) Distribution of Trapped Gas: What is the distribution of the} flammable gas trapped within the tank waste?

2) Maximum Waste Volume Immediately Disturbed: What is the maximum amount of tank waste which could be immediately disturbed by the sluice spray?

3) Maximum Immediate Gas Release: Combining (1) and (2), what would be the maximum amount of gas which could be immediately released into the tank headspace?

The referenced memo analyzed the global situation where a maximum amount of trapped gas is immediately released and uniformly distributed within the tank headspace. With the assumptions and analyzed conditions, the limiting results were a total release of $100 \%$ of $531 \mathrm{ft}^{3}$ of trapped gas, which is $97 \%$ hydrogen (Reference 1) equating to 546 SCF of hydrogen when corrected for estimated gas temperature and pressure (Attachment $B$ ). This would result in a fuel concentration of $17 \%$ LFL in the tank headspace. Thus, in this case the entire volume of gas trapped in tank 241-C-106 waste is insufficient to form a uniform flammable concentration throughout the tank headspace.

\section{Distribution of Trapped Gas}

The distribution of gas within the tank waste represents a range of possibilities. The gas could be trapped homogeneousiy throughout the waste or concentrated in discrete locations. The extreme situations would be that the waste volume which is being immediately sluiced contains either the entire volume of trapped gas, or none at al1. A more reasonable scenario obviously is the one where the trapped gas is distributed uniformly throughout the waste volume. Varying degrees of these possibilities could be imagined, but uniform gas distribution would be viewed as more credible than the two extreme cases.

For the gas to be released from the waste, it must be located where the mechanical energy input of the sluice stream can dislodge it from the solids matrix. This leads to a conservative assumption that all the gas must be located in the soft sludge of the tank - the upper $3 / 4$ of the waste volume as it is believed that the bottom $1 / 4$ of the waste volume - the hardpan - has mechanical strength higher than that which can be overcome by the sluice stream. This assumption leads to a waste volume of $150 \mathrm{kgal}$ in which the gas can be distributed. 
Two methods are used to estimate the volume of trapped gas for this analysis:

Case 1 - The values from Reference 1 and Attachment $B$ are used, yielding $531 \mathrm{ft}^{3}$ of compressed gas with $97 \%$ hydrogen which equates to in 546 SCF of hydrogen.

Case 2 - A conservative assumption that the tank waste has a $5 \%$ void volume containing gas. Level rise/evaporation methods for estimating tank waste gas content, which were used in Reference I, may be considered unreliable. Therefore, a conservative approach, when no gas volume estimate is available, is to assume the waste has a $5 \%$ void volume. The latest estimates of waste gas generation show that the hydrogen content in the waste gases produced can be conservatively stated as $50 \%$ by volume (Reference 2 ). With such an estimate, the maximum yolume of gas that can be released is $150,000 \times 0.05 / 7.48 \times 0.5$ $=500 \mathrm{ft}^{3}$ hydrogen, which can be equated to $500 \times 1.22 \times 0.87$ or 530 SCF hydrogen in accordance with the assumptions of Attachment $B$.

Maximum Waste Volume Immediately Disturbed

Two estimates have been provided by Project $W-320$ to indicate the maximum volume of waste which could be disturbed by the sluicer spray at any one time. The calculation of these estimates are shown in Attachment $C$. One estimate is that approximately 3,500 gallons, or about $2.3 \%$ of the total volume of waste capable of trapping gas within the tank, can be immediately disturbed. The second estimate yielded a volumetric disturbance rate of 1,800 gallons per second, which could be maintained for a maximum of 15 seconds at the maximum sluicer sweep rate of 6 degrees arc per second. These estimates yield a number of possibilities for the gas "source term". These include 3,500 gallons of waste disturbed instantaneous $7 y, 1,800$ gallons of waste disturbed in one second, and 27,000 gallons of waste disturbed in 15 seconds. This analysis will choose two of these possibilities:

Case $A-3,500$ gallons of waste disturbed instantaneously

Case B - 27,000 gallons disturbed in 15 seconds

Any larger waste disturbances would require longer agitation periods, and thus the gas released would more likely be dissipated by headspace convection to a lower fuel concentration.

Resulting Gas Release

From the preceding, the smallest volume of gas that could be immediately released is, obvious7y, O SCF. The largest would be the entire volume of hydrogen, 546 SCF for Case 1 and 530 SCF for Case 2. A more reasonable estimate of the volume of gas released would be that originating from the volume of waste which is disturbed. This would be $(3,500 / 150,000)$ or $2.3 \%$ of the total hydrogen volume for Case $A$ or $(27,000 / 150,000)$ or $18 \%$ for Case B. 
Waste Disturbance Estimate

Limiting (all gas released)

Case $A(3,500$ gal disturbed)

Case B (27,000 gal disturbed)
Gas Inventory Estimate

Case 1 Case 2

546

530

$13 \quad 12$

$98 \quad 95$

\section{Additional Considerations}

The problem with the limiting scenario, the instantaneous release of the total volume of trapped hydrogen, is that there is no known mechanism which explains how it could occur. For example, it is estimated that if tank waste has enough mechanical strength to retain a $1 \mathrm{~m}^{3}\left(55 \mathrm{ft}^{3}\right)$ gas bubble, it will have a yield strength of $6700 \mathrm{~Pa}$. If the yield strength is reduced to $67 \mathrm{~Pa}$, the maximum bubble size becomes $1 \mathrm{~cm}^{3}\left(5.5 \times 10^{-5} \mathrm{ft}^{3}\right)$ (References $\left.3 \& 4\right)$. The fact that the high heat sludge in the tank is easily sampled via the bottle on a string method indicates that the yield strength of this sludge can be no more than a few hundred $\mathrm{Pa}$. Correspondingly, the liargest bubble size to be expected is no more than a few to a few tens of $\mathrm{cm}^{3}$, an indication that any trapped gas must be well distributed throughout the waste. Therefore, it appears the probability that the gas is distributed in such a way as to be immediately released upon agitation by sluicing is extremely unlikely, thus preventing the limiting release from becoming the best estimated release.

A temporal mitigating factor is thought to apply to this situation. This is the actual rate of gas release from the agitated waste. As has been demonstrated in testing with the mixer pump in tank 241-SY-101, the gas released from agitated waste is not instantaneous (References $5 \& 6$ ). Although the situations are different in that gas released from agitated waste in tank 241-C-106 does not have to diffuse and/or buoy itself through as great a distance as in tank 241-SY-101, some delay between waste disturbance and the majority of gas release is expected. This provides the expectation that a gas release on the order of minutes would be much more likely than a release on the order of seconds following an immediate disturbance of the waste.

The apparent lag time between waste agitation and complete gas release from the waste seems to suggest that over short time periods (e.g., 15 seconds or less), it is the total volume of waste disturbed, and not the rate at which it is disturbed, that is important in determining the volume of a gas release. However, regardless of the volume of hydrogen released, any delay between waste agitation and complete gas emission allows for dilution of the released 
74A10-96-082

Attachment A

hydrogen through convective action in the tank headspace, making it less

likely that a flammable plume could develop. This argument is assumed here to indicate that the hydrogen release determined from Case B forms a better "best estimated worst release" than that determined from Case $A$.

In addition, spatial factors should constrain the maximum achievable plume fuel concentration. The gas produced from the disturbance of tank waste will be emitted over a significant area of the waste surface. This is particularly true for Case $B$, where the waste disturbance is over a path six feet wide and through an arc length of about 70 feet with radius 45 feet, yielding a surface area of about 420 square feet. Even a waste disturbance over the smallest surface area, indicated by Case $A$ as a circle six feet in diameter, represents an area of about 30 square feet. Compared to a point release, the geometry of sluicer operation suggests a small hydrogen flux passing through the waste surface, further limiting the achievable fuel concentration at any point in the tank headspace.

\section{Other Gas Release Concerns}

Concerns over the release of gasses dissolved in the tank waste can be postulated. The only gas of significance in this category is ammonia. Agitation of the tank waste will alter the pressure on and temperature of the wastes containing the ammonia and will result in a new partitioning of the ammonia between its gaseous and condensed phases - possibly increasing the ammonia concentration of the headspace. However, even this concern has several mitigating features associated with it. First, the amount of ammonia will not be sufficient to create, or significantly contribute to, a flammable condition in the tank headspace. Second, the act of agitating the sludge with the sluice spray will most likely cool the waste, increasing the solubility of any dissolved gases, thus lowering the partial pressure of the ammonia. Finally, the rate of release of the soluble gas depends on the surface area for mass transfer, which itself is a function of the amount of waste agitation. This indicates that the rate of release of dissolved ammonia can be controlled by the rate of sluicing in the tank, and will decay to its steady state equilibrium value when sluicing is stopped. 
74A10-96-082

Attachment $A$

\section{Conclusions}

The hydrogen volumes which could be released due to sluicing agitation appear to be insignificant for tank 241-C-106, and the physical behavior of the released gases further diminishes the probability of forming a flammable plume in the tank headspace. The best estimates from this analysis are that:

1. If the total volume of gas trapped in the tank waste is released, the maximum amount of hydrogen gas emitted should not exceed 550 SCF. However, because homogeneous distribution of trapped gas is suspected, the total amount of hydrogen released over a short time period due to sluicing agitation is unlikely to exceed 100 SCF.

2. Even if the hydrogen is released over a short time period, the actual rate of gas release from the waste would tend to lower the plume fuel concentration when compared to an instantaneous gas release.

3. Regardless of the amount of hydrogen released, the large waste surface area through which the hydrogen will be diffused would produce a plume with significantly lower fuel concentration compared to that produced via emission from a point source. 
74A10-96-082

Attachment A

References:

(1) Internal Memo 74A10-96-027, J. D. Hopkins to J. C. Conner, FLAMMABLE GAS EVALUATION OF TANK 241-C-106, February 26, 1996.

(2) Antoniak, Z. I., and K. P. Recknagle, May 31, 1996, Modeling Hydrogen Plume Concentrations in Single and Double Shell Tank Domes, TWSFG96.12, Pacific Northwest National Laboratory.

(3) Alleman, R. T., October 1995, A Discussion of Some Mechanisms for Sudden Gas Release from Single Shell Waste Tanks at Hanford, PNL-WTS-101095, Pacific Northwest Laboratory.

(4) Proceedings of 29th European Study Group with Industry, March 18-22, 1996, Mathematical Institute, Oxford University, U.K.

(5) Alleman, R. T., Z. I. Antoniak, W. D. Chvala, L. E. Efferding, J. G. Fadeff, J. R. Friley, W. B. Gregory, J. D. Hudson, J. J. Irwin, N. W. Kirch, T. E. Michener, F. E. Panisko, C. W. Stewart, B. M. Wise, 1994, Mitigation of Tank 241-SY-101 by Pump Mixing: Results of Testing Phases $A$ and $B$, PNL-9423, Pacific Northwest Laboratory

(6) Stewart, C. W., J. D. Hudson, J. R. Friley, F. E. Panisko, Z. I. Antoniak, J. J. Irwin, J. G. Fadeff, L. E. Efferding, T. E. Michener, N. W. Kirch, D. A. Reynolds, 1994, Mitigation of Tank 241-SY-101 by Pump Mixing: Results of Full Scale Testing, PNL-9959, Pacific Northwest Laboratory 
HNF-SD-WM-RPT-293 REV O

\section{ATTACHMENT B}

74A10-96-082

TANK 241-C-106 RETRIEVAL INDUCED FLAMMABLE GAS PLUME ANALYSIS

consisting of 2 pages 


\section{Barometric Analysis - Tank 241-C-106}

Tank No.
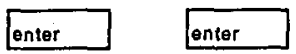

C-106

\section{Calculation date:}

Total Waste, gal. - from Hanion's Summary Rpt

Total Wasie, tis. - converted from above

Total solids (sludge + salicake), ind. gas - from Hanion's Summary Repart

Total Solids, th3. - converted from above

Current surface level ht. in inches.

Supernate vol., gal - from Hanlon's Summary Report

Supernate density, $g / \mathrm{mL}$

If unknown, enter 1.40 .

Supernate depth = supernate vol (gal)/2754 galín

Solids density, $g / \mathrm{mL}$

If unknown, enter 1.80 .

WET Solids (below water table) \& solios thickness - est. im photo \& total solids

Average gas location above tank bottom

Solids thickness over center of trapped gas (from lop of solids)

Average temp, "F:

Average tank temp, ${ }^{\circ} \mathrm{C}$ :

Average tank temp, K:

Tank TOTAL VOL, $\mathrm{t3}$ - info in following lines

SST, Dish, $530 \mathrm{kgal}$ - B, BX,C, T, U

SST, Dish, $758 \mathrm{kgal}-\mathrm{BY}, \mathrm{S}, \mathrm{TX}, \mathrm{Tr}$

SST, Dish, $1000 \mathrm{kgal}$ - SX

SST, FLAT, $1000 \mathrm{kgal}$ - A A AX

DST, FLAT: AN, AP, AW, AY, AZ, SY

Waste Volume (cu it) with teapped gas, calculated from eurrent suriace level

TK Hd Space (b4 release) mDome vol+waste volume (w trappd gas)

\subsection{7}

\section{CALCULATION USING PAUL WHITNEY'S SLOPE}

Patm, in. $\mathrm{Hg}$

Patm

Pliq

liq density

liq hoight

Pliq

Psolids

solids density

solids height over center of trapped gas

Psl

Psurface tension

PTOTAL

Percentile level

Paul Whitney's SLOPE $=\Delta$ surface level $/ \Delta$ in. $H g$

Porosity: 1.0 for normal eval, actual porosity for ILL data

$V(i t 3$, compressed $)=$ Porosity at liq sic $-A(s q \mathrm{ft}) \times$ Total $P(\mathrm{in} . \mathrm{Hg}) \times$ slope $($ in. $f$ in $H g)$

$V($ scf $)=$ Porosity $\times V($ compressed $) * T$ Correctn $* P$ correctn

\begin{tabular}{l} 
enter \\
\hline enter \\
\hline enter \\
\hline enter \\
\hline enter \\
\hline
\end{tabular}

in.

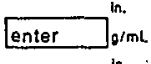

In.

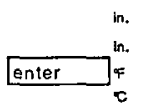

enter ${ }_{113}^{K}$

113

113

113

$\$ 13$

113

113

113

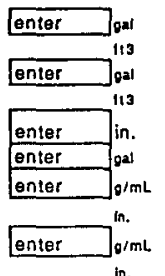

r

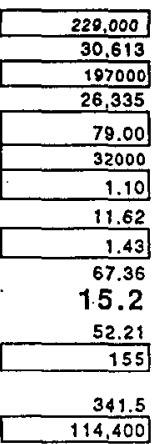

30.750

83,641

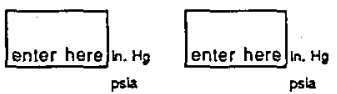

29.5

14,489
g/mL

in

psi

o/ml

in

psl

psia

17.698

\begin{tabular}{llll}
\hline enter here & $75 \%$ enter here & $75 \%$ & $75 \%$ \\
\hline
\end{tabular}

11.62

0.462

1.43

52.21

2.697

0.050

Infin $\mathrm{H}_{\mathrm{g}}$

$-0.040$

Inin $\mathrm{Ho}$

113

531 


\section{Barometric Analysis - Tank 241-C-106}

enter

C.106
Tank No.

\section{CALCULATION OF \%LFL}

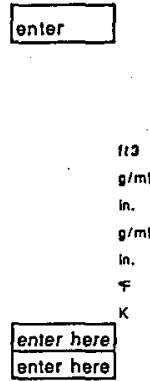

Volume of Entrappod Gas Released to Dome Space

sct

$\operatorname{sel}$

set

sct
Fraction of entrapped gas released (\%)

Calculations

Supernate head = supemate density $x$ supemt depth (psi)

Solids head $=$ solids density $\times$ solids depth (psi)

Pressure in dome, in psia (If cal'g H2 in sct, use 14.69)

Total head (psi) $=$ Press in dome + sup. head + solids head

Pressure adjustment to sef $=$ total headTANK PRESSURE in psia

Temperature adjustment to scf $=298.15 \mathrm{KW}$ Waste temp at gas depth (K)

Comprsd vol $\times P$ adjstm! $\times T$ adjstmt $\times$ tractn of gas releasd=

Vol of entrapped gas released to dome space (sch)

Volume of H2 Released to Dome Space

Comprsd vol $\times$ P adjstmt $\times$ T adjstmt $\times \% H_{2} \times$ fractn of gas releasd $=$

H2 Released to Dome Space (scf)

Supernate density

Solids density

Waste temp at gas depth (F)

Vol. of Head Space

Vol of head space before burp

Compressed vol $X$ fraction of entrapped gas released = sic level drop

'ahead space vol. increase caused by sfe tevel drop'

Vol of head space atier burp

H2 \% in Head Space

Vol. of $\mathrm{H} 2$ in Head SpaceNol of head space after burp
531

1.10

11.62

1.43

52.21

155.0

341.48

enter here

0.25 enter here

$97 \%$

$100 \%$

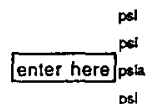

$\underbrace{\text { pol }}_{\text {psi }}$

0.462

2.70

14.69

17.85

1.22

0.87

563

sct

563

set

546

546

it3

113

83,641

113

113

531

ft 3

113

84,172

NH3 \% In head space =

Assume $\mathrm{NH3}$ vol $=$ this fraction of entrapped gas released (max $=0.259$ )

enter here

enter here

$\mathrm{NH} 3 \%$ in head space $=$
0.220

124

$0.147 \%$

$0.649 \%$

$17.20 \%$

$1.73 \%$

$2.01 \%$

OK

Tank No.

Slope at $95 \%$ confidence

Slope at $75 \%$ confidence

\begin{tabular}{|l|l}
\hline enter & in/in $\mathrm{Hg}$ \\
\hline enter & in/in $\mathrm{Hg}$
\end{tabular}

\begin{tabular}{|l|l|}
\hline enter & in/in $\mathrm{Ho}$ \\
\hline enter & infin $\mathrm{Hg}$ \\
\hline
\end{tabular}

C. 106

REALTY CHECK: void space of solids (except for pockets, voids > $20 \%$ unlikely)

RESULTS:

enter in/in

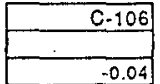


HNF-SD-WM-RPT-293 REV 0

ATTACHMENT $C$

74A10-96-082

TANK 241-C-106 RETRIEVAL INDUCED FLAMMABLE GAS PLUME ANALYSIS

consisting of 4 pages 
Westinghouse Hanford Company
HNF-SD-WM-RPT-293 REV 0

DESIGN ANALYSIS
Calc. No, $\omega-320-5 \omega B-1$

Revision $\varnothing$

Pago No. $\frac{1}{4}$ of

\begin{tabular}{|c|c|c|}
\hline Subject Tank 241-C-106 Sluic ing- & Date $5 / 30 / 26$ & By John $W$ \\
\hline Disturbed Solids Volume Estimate & Checked & By \\
\hline Location & Revised & By \\
\hline
\end{tabular}

Purpose- This calculation estimates the volume of solids in tank $241-c-106$ which could be disturbed by the sluicing stream on an instantaneous basis.

Background - The preparing engineer conducted sluice nazzlo testing in 1926 to refine the sluicer aiming diagram usse - in operating procedures at that time. The effectivenes of the sluice stream to remove sand from a $4^{\prime} \times \overline{8}^{\prime \prime}$ fest.pan was also evaluated. The results of this -undocum ented testing is used as the basis for this estimete. NOTE: The sluice stream at a range from the sJuice noz le of approximately $45^{\prime}$ remove the majority of a "6". layer of sand from the test pan - in less than 5 secouds.

Sluicer siuice Stream Configuration -

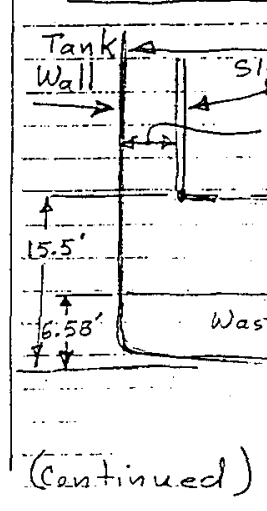

a.8.0. $689-996^{-1} 12 / 9$ 
Westinghouse ${ }^{\cdots}$ HNF-SD-WM-RPT-293 REV 0 Hanford Company

DESIGN.ANALYSIS

Call. No. $\frac{\omega-320-5 \omega B-1}{\phi}$

Revision $\frac{\phi}{2 \quad \text { of } 4}$

Subject Tank 241-C-106 Sluicing__ Date 5/30/96 By J.W. Bailey $\begin{array}{ll}\text { Disturbed Solids Volume Estimate Checked } & \text { By } \\ \text { Location } & \text { Revised }\end{array}$

Assumption - The sluice stream is most effective at disturbing sludge solids in the center of the stream and becomes marked less effective as you move away. - from the center of the stream. For purposes of this estimate the below model is used to estimate the volume of disturbed solids.

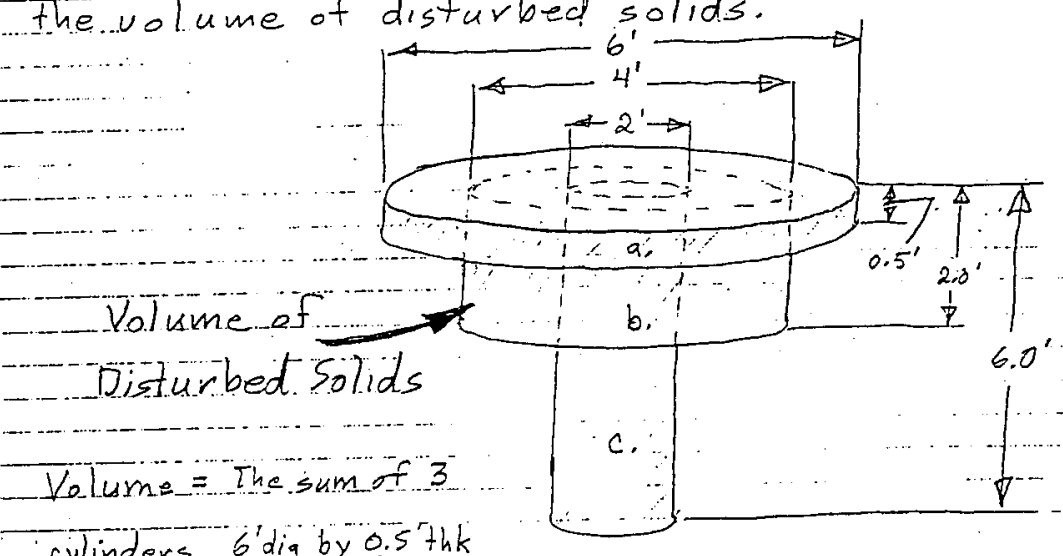

cylinders 6 dig by $0.5^{5}$ th k

$$
\begin{aligned}
\text { Formula } \sum_{c}^{2} \pi r^{2} h & =\pi 3^{2}(0.5)+\pi 2^{2}(1.5)+\pi 1^{2}(4) \\
& =\pi(4.5+6+4) \\
& =14.5 \pi=45.6 \mathrm{ft}^{3}
\end{aligned}
$$

Converting to gallons $45.6 \mathrm{ft}^{3} \times \frac{7.5 \mathrm{gal}}{\mathrm{ft}^{3}} \cong 342 \mathrm{gal}$.

Rounding up to 350 gal.

To assure conservatism and to address both the potential! for (continued)

म aPO.

$-12194$

$264^{\circ}$ 
Westinghouse
Hanford Company

HNF-SD-WM-RPT-293 REV 0

\section{DESIGN ANALYSIS}

Calc. No. $\underline{\omega \cdot 320 \cdot J \omega 8-1}$

Revision

Page No.

\begin{tabular}{|c|c|c|c|}
\hline Subject Tauk 241-C-10G Sluicino - & $5 / 30 / 96$ & By & Joln. W. Bailey \\
\hline Disturbed Solids Volume Estivenate & Checked & By & \\
\hline Location & Revised & By & \\
\hline
\end{tabular}

the disturbed solids to effect the immediafely adjacen undisturbed solids causing them to release gas ono -potential effects of the moving sluice stream to - enlarge the disturbed zone, the above estinat - is increesed by an ordser of magnitude to 3,500 go - or roughly $2 \%$ of the current sludge volume in tank $241-c-106$.

\section{ALTERNATE CALCULATION APPROACH:}

A solids disfurbed per unit time celculation was performed.

It assumed the same disturbet solids volume was swept across the widest port of the tonk with the sluicer drive set to maxium trave) rate ( $6^{\circ} / \mathrm{sec}$ ). The figure to the right -.shows this path. At $6 \%$ ser this path would be swept -in 15 seconds. The volume

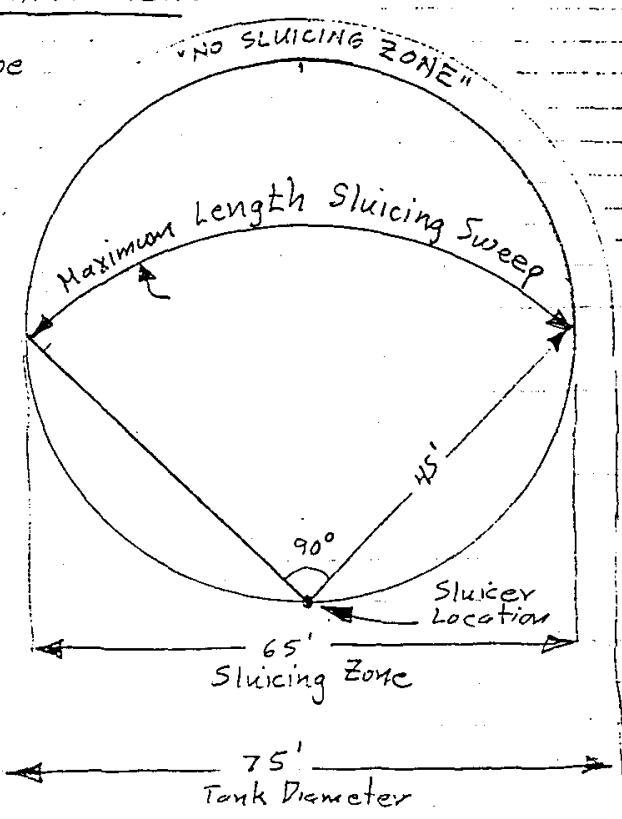


\begin{tabular}{l|l} 
Westinghouse & HNF-SD-WM-RPT-293 REV 0
\end{tabular}

Hanford Company

DESIGN ANALYSIS

Talc. No. $\omega-320-0 \omega B-l$

Revision No. $\frac{9}{4}$ of 4

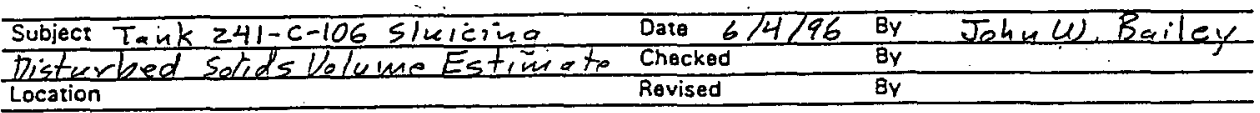

- of solids disturbed in this is seconds would be approximate each to the length of the path times the cross sectional area of the Disturbed Solids Volume figure (Ref Pg Hz).

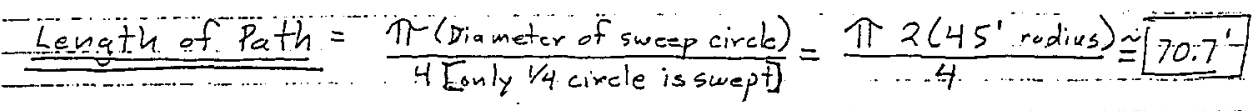

Cress Sectional Area

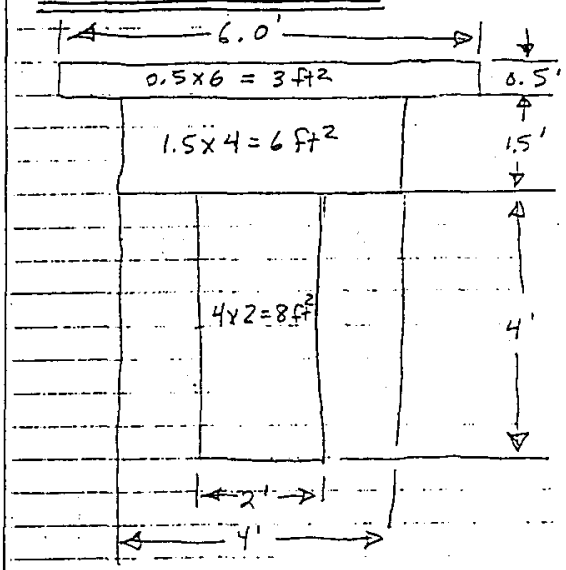

Summing the 3 areas

$$
3 \mathrm{ft}^{2}+6 f \mathrm{t}^{2}+8 f \mathrm{t}^{2}=17 \mathrm{ft}^{2}
$$

Disturbed Volume

$70.7^{\prime} \times 17 \mathrm{ft}^{2} \cong 1202 \mathrm{ft}^{3}$

Converting to gallons

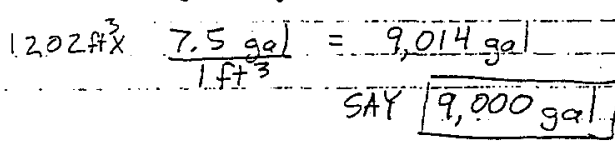

Unit Time Disturbed Volume

$$
-\frac{9000 \mathrm{gal}}{15 \mathrm{sec} e \mathrm{nds}}=600 \mathrm{gal} / \mathrm{sec}
$$

To ensure conservatism and address the potential for the disturbed solids to effect the immediately adjacent solids causing them to release trapped gases

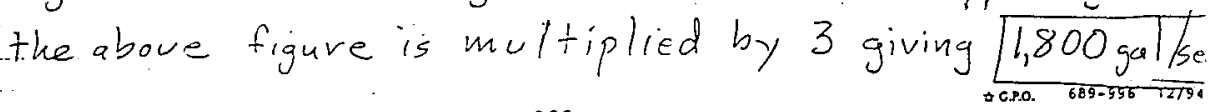

266 


\section{Meeting Hinutes \\ Discussion of Interim Status Requirements \\ Pump and Siuice Pits at Tank Farm 241-C \\ Sluicing of Tank 241-C-106}

\section{VIDEOCONFERENCE MINUTES}

June 27, 1995

The undersigned indicate by their signatures that these meeting minutes reflect the actual occurrences of the above dated Meeting.

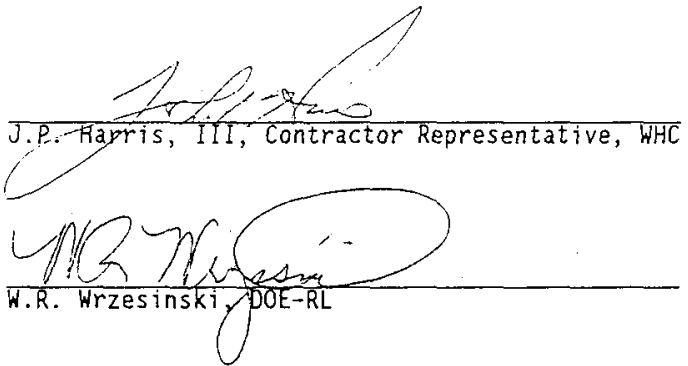

Date: $2-2.95$

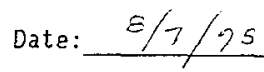

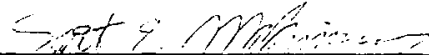

Date:

S. McKinney, Washington, State Department of EcoTogy

Purpose: Discuss coating of the pump and sluice pits at Tank Farm 241-C and the associated ventilation duct secondary containment. 
MEETING MINUTES

Subject: Project W-320, Tank 241-C-106 Sluicing/Pit Compliance and Ventilation Duct Containment Issues

TO: Scott McKinney BUILDING Ecology/Lacey

FROM: John P. Harris III WHC, SST Retrieval Projects

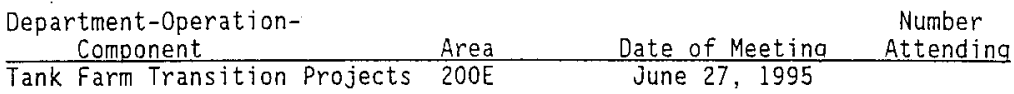

This meeting was called by WHC to discuss two issues, the first of which involved the coating of the pump and sluice pits at Tank Farm 24l-C. The second issue involved the ventilation duct containment.

\section{$\underline{\text { Issue } \# 1}$}

The preparation for the siujcing retrieval does not include plans to apply an impervious coating to the internal concrete surfaces of the pits due to the radiological activity levels within the pits. These activity levels require all upgrade work to be done remotely with the associated increased costs and time required before the sluicing operation may begin.

The pump and sluice pits are to be used during the sluicing of Tank 24l-C-106 (C-106) to resolve the high-heat safety issue within the tank in accordance with Tri-Party Agreement Milestone M-45-03A (the third pit on the tank, the heel pit, is not currently within the project scope to be used during the sluicing retrieval). The sluicing of Tank $C-106$ is the first phase of, and supports the eventual closure of this single shell tank. Therefore, it was felt that any upgrades to this ancillary equipment on the tank, as required by 40 CFR 265.193(f), would not provide a benefit commensurate with the environmental and health risks, based on the radioactive dose investment requirements by the involved workers; nor would it be cost effective, based on the cost and schedule impacts to the successful completion of the safety issue resolution. The waste retrieval sluicing system (WRSS) is being designed and constructed for a useful lifetime of 2 years, of which the sluicing retrieval is expected to take a period of approximately 3-o months of actual pumping operation. Current requirements call for a scheduled commencement of retrieval in October, 1996 (DOE Secretarial Safety Initiative); one year ahead of the Tri-Party Agreement Milestone requirement of October, 1997.

During the sluicing activity; two at-grade, bermed, double-encased transfer lines are to be installed between C-106 and Tank 241-AY-102 (AY-102). These lines are to be used simultaneously to set up a flow loop between the tanks. The sluice line will transfer $350 \mathrm{gpm}$ of clarified supernate from AY-102 to a sluice nozzle in $\mathrm{C}-106$. The mobilized slurry will then be pumped back to AY102 via the slurry line, again at roughly $350 \mathrm{gpm}$, where the solids wiil 
settle, and the flow loop will continue. The slurry line will enter the $c-106$ pump pit, where it will be jumpered to the slurry pump discharge riser. The sluice line will be routed to the sluice pit directly, bypassing the pump pit. Because of this piping arrangement, a possible accident scenario for the pump and siuice pits would involve a maximum leakage rate of $350 \mathrm{gpm}$, which has been provided for in the design via slotted extensions to the pump riser and the sluicer riser to be able to drain the worst case leakage flow to the tank without accumulating liquid in the pits. In addition, the pump pit also has a floor drain with leak detection to accommodate small volume leaks (the sluice pit floor drain is currently plugged and will probably not be able to be cleared). Should there be a recurrence of past difficulties with pluggage of the floor drain in the pump pit (the floor drain design involves the use of an annular space on the order of $1 / 8^{4}$ around a 12 " riser in the pit, so that debris and sand have plugged these in the past), sump pumps will be installed in the pits to remove the approximately one inch depth between the bottom of the high-volume drain slots and the pit floor.

Visual inspections during preparatory work in 1994 to clean the pits of debris and lower the radiation fields revealed some standing water in the pits from precipitation intrusion (the floor drains in both pits were then plugged). Videotapes of this standing water in A-pit (Pump pit) were obtained on October 12, 13, and 14, 1994 and again on November 15, 16, and 17, 1994. The C-pit (sluice pit) was videotaped on January 16, 17, and 18, 1995.

Examination of these tapes, combined with field observations around these dates indicated no visible drop in the liquid levels in the pits. Based on this evidence, it was determined by WHC that the pits could contain any potential leakage experienced (until the sump pumps could remove any residual liquid below the bottom of the high-volume drain slots) with minimal risk of additional environmental insult to the soil column in the vicinity of the tank.

The pits are of concrete construction with a sloping bottom. The pump pit has dimensions of 11 feet by 14.5 feet by 6.4 feet depth for a volume of 1021 cubic feet. The sluice pit has dimensions of 8.5 feet by 9 feet by 7.67 feet depth for a volume of 587 cubic feet. The maximum drainback possible from the transfer 1 ines to $\mathrm{C}-106$ pits with the pumps stopped is approximately 1000 gations per line. Given these considerations, any threat to the environment from a pipe failure would be minimal.

Originaity, the scope of the project included a coating of the pits. These pits are extremely contaminated, and will be in use only during the tank sluicing. The ALARA concerns involved in coating these pits far exceed any potential benefits. Workers are exposed to general radiation fields around the pit of approximately $70 \mathrm{mrem} / \mathrm{hr}$, though current decontamination efforts are continuing to attempt to lower this by an order of magnitude. In order for the pit coating to be done (assuming no great success in reducing the radiation field), workers would be exposed to fields as high as several rem (directly in the "shine" of the radiation fields coming out of the pits). These factors greatly increase the costs and time that would be involved in coating the pit, since this work would involve several employee-months of time to complete. Currently, there is also a move to bring the project costs within the available budget (recent events such as the temperature anomalies experienced in the tank in 1994 have caused delays in the project's schedule with resultant schedule compressions and cost increases). This cost reduction 
effort has driven some project scope reductions (as outlined in the Unit Manager Meeting of June, 1995). Coating of the $\mathrm{C}-106$ pits was dropped based on the aforementioned cost/risk/benefit evaluation.

Given that the design of the pits, combined with operational commitments on the operation of the pit sump pumps, will prevent the accumulation of 7 iquids within the pit, as well as the ALARA and cost concerns discussed above, it was agreed by the signatories of these minutes that this project will proceed without requiring coating of the $C-106$ pits.

\section{Issue $\# 2$}

The second issue that needed to be discussed was the acceptability of the proposed method of providing secondary containment for a valve in the proposed tank ventilation system recirculation duct. This issue arose as a result of analyses relating to tank headspace radioactive and non-radioactive source terms. The design, as originally provided to Ecology, included the use of a heater in the recirculation line (downstream of a condenser and a de-mister) which would ensure that the air flow would have a moisture content well below the saturation point. The aforementioned analyses indicated that a possibility existed that the use of the heater could accumulate dry particulate in the headspace of the tank beyond that reported as a source term for the Air Permit Notice of Construction. So, WHC proposed to leave the heater off during operation, at which point it was realized that this would result in cold, saturated air going through the vent duct back to the tank. Though this was not a process problem, it would require a double containment for the non-sealless valve in the duct, since some condensation could occur in the duct (though the duct would remain at several inches negative pressure during operation so that any leakage occurring should be inward).

40 CFR 265.193(f) requires that ancillary equipment for a tank system must have double-containment unless it contains sealless valves, that are inspected on a daily basis. The secondary containment planned for the applicable sections of the vent line is a flexibie membrane, which has been standard practice for similar systems at the Hanford Site. The vent line will be visually inspected for leaks on a daily basis. Any accumulated liquid in the secondary containment of the vent line will be removed in as timely a manner as is possible to prevent harm to human health or the environment, though Ecology stressed at the meeting that it was not the intent that operators should immediately remove any iiquid discovered in the container, since condensation from the air in the secondary container bag was a likely occurrence, especially during warm weather. Rather, it was expected by Ecology that operators would exercise sound judgement in observing the condition of the container to determine whether ambient conditions and trends supported an apparent leak, or a sweating of the duct. To try to minimize the occurrence of sweating of the duct, the signatories agreed to the insuiating of the ventilation recirculation duct from the process building to the tank, combined with the "bagging" of the valve. It was agreed by the signatories of these minutes that this method of providing secondary containment for the associated vent 7 ines meets the intent of the interim status standards contained in the WAC $173-303-400$ and 40 CFR Part 265.193.

As an additional discussion area, WHC brought up the point that, during the investigation of the physical configuration of the recirculation line valve in 
the design drawings in preparation for the meeting, it was realized that there were several other singly contained ventilation lines coming out of the process building with non-sealless valves. All of these lines ended with a blank flange ( $i$.e., a bolted cover which would be removed immediately before use). These lines included maintenance lines for flushing of the condenser, monitoring 7 ines for determining decontamination factors for control equipment such as the High Efficiency Mist Eliminator and the High Efficiency Metal Filter, and a line for connection of a portable exhauster (should a failure of the ventilation system occur). The signatories of these minutes agreed that, because these lines were sloped inward toward the process building such that no condensation could pool in the lines, they did not require secondary containment. 
This page intentionally left blank. 
From: Liquịd Effluents Services

Phone: $\quad 373-0087$ H6-06

Date: August 1, 1996

Subject: CONSISTENCY REVIEW OF WHC-SD-WM-SAD-024, REV 0 "SAFETY ASSESSMENT FOR TANK 241-C-106 WASTE RETRIEVAL PROJECT W-320"

To:
3. P. Harris, III
$52-48$
cc: W. Abdu1, RL
S7-53
D. G. Baide
$\mathrm{S} 2-48$
J. C. Conner
A2 -25
B. L. Nicol1, RL $57-53$

Per your request, I have completed a consistency review of the subject safety assessment (SAD) with respect to the conclusions presented in the following documents:

(1) WHC-SD-WM-ER-588, Rev 0, "Tank 21-C-106 Sluicing Evaluation" and the associated Westinghouse Hanford Company Internal Memo 74A5096-DM0-006, "Recommendation for C-106 Sluicing."

(2) WHC-SD-W320-T.I-007, Rev 0, "Flammable Gas and Steam Controls for WRSS Operation, Project W-320."

(3) WHC-SD-WM-ER-594, Rev 0, "Evaluation of Recommendation for Addition of Tanks to the Flammable Gas Watch List."

The consistency of the SAD to the above document conclusions was assessed by first reviewing each document separately and listing the important conclusions presented in each document. The product of this initial review is provided in Attachments 1 through 3, where the important conclusions are listed for each document. Next a page-by-page review of the SAD was undertaken during which the SAD content was compared to the combined conclusions contained in Attachments 1 through 3 . Where it was felt that an inconsistency may exist between the May 1996 version of the SAD and the above document conclusions, this was noted along with the exact location in the $S A D$ and suggested modifications to eliminate the inconsistency. The product of the page-by-page $S A D$ review is as follows:

1. Section 2.1.6.2, p. 2-12, first paragraph: Suggest qualifying the May 1996 version discussion on "...continuous, closed-loop sluicing process" to include the incremental waste retrieval approach followed with monitoring or hold periods. An appropriate SAD section reference where this approach is discussed in detail should be provided. 
J. P. Harris, III

August 1, 1996

Page 2

2. P. 2-46, 1ast paragraph: Suggest that the May 1996 version discussion of "...series of sluice channels...to channel the slurry flow directly to the slurry pump" be revised since this may not be compatible with the concept of incremental retrieval of waste by controlled level sluicing (i.e., constant liquid level covering the sludge layer).

3. P. 2-47, fourth full paragraph and subsection "Sluicing Temporary Shutdown Operations": Suggest that the May 1996 version discussion of alternative approaches for precluding local superheated waste locations "...by maintaining a wet waste surface by either submersion or through frequent...hosing down of the waste surface..." and two bullets in subsequent subsection be revised to indicate that sluicing will be performed with a constant Tiquid pool level in tank C-106 with no waste exposed (except possibly at the tank wall).

4. P. 4-34, first paragraph: Suggest that the May 1966 version discussion of sluicing-induced steam flash in tank C-106 be modified to include the concept that the waste sludge will always remain covered with supernatant and that a constant pool liquid level will be maintained. Also, the "...1 to 2 week hold period..." should be changed to a minimum hold period of 2 weeks.

5. Table 5-9, P. 5-18, Mitigation" column under "Temperature anomaly and steam release" and Section 5.6.1.4, P. 5-30: Suggest that the May 1996 version be modified to include a discussion of the mitigation that will be provided by the process controls and procedures associated with the incremental waste retrieval operation followed by cooling hold periods.

6. Table 5-9, P. 5-18, "Mitigation" column under "Tank bump" event:

Suggest adding "monitoring/hold periods" to the controls that will mitigate this event.

During the page-by-page $S A D$ review, a number of typographical/editorial errors were noted. These will be forwarded for your review and consideration under separate cover.

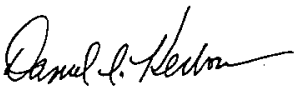

D.I. Herborn, Fellow Engineer

$a j b$

Attachments (3) 
Attachment 1

IMPORTANT CONCLUSIONS

WHC-SD-WM-ER-588, Rev 0, "Tank 241-C-106 Sluicing Evaluation" and

WHC Internal Memo, "Recommendation for C-106 Sluicing"

1. Purpose of evaluation to characterize thermal response of tank waste during the sluicing operation to define operating limits in terms of maintaining waste subcooling and thus eliminating possibility of steam bumping.

2. Sluicing ventilation system can be operated in three modes:

a) Normal day-to-day configuration.

b) Pre-sluicing tank chiller system configuration that can subcool bottom waste to near-winter conditions (takes 3 to 4 months and achieves a minimum temperature of $224^{\circ} \mathrm{F}$ [ 4 to $6{ }^{\circ} \mathrm{F}$ subcooling]).

c) Sluicing configuration for visibility defogging and not heat removal.

3. Waste must remain subcooled at all times during waste retrieval (below local saturation temperature).

4. Rapid sluicing can eliminate the waste subcooling and result in local steam generation in the waste.

5. Incremental retrieval of waste (sluicing 0.3 to $0.9 \mathrm{~m}[1$ to $3 \mathrm{ft}]$ ) followed by cooling hold periods of 1 to 2 weeks which allows waste to become significantly subcooled can eliminate the possibility of steam bump.

a) First sluice step will remove sludge down to $60-i n$. Tevel (3/4 to 1 ft) followed by 14 day cooling period.

b) Second sluice step will remove an additional $\mathrm{l} f \mathrm{ft}$ of sludge followed by 14 day cooling period.

6. Sluicing should be performed with a constant liquid pool level with no waste exposed (except at tank wall) in order to maintain a constant tank waste bottom pressure an ensure accurate level measurements.

a) For first sluice, perform at 72 in. ( 2 to 3 in. covering sludge) which maintains about $6{ }^{\circ} \mathrm{F}$ subcooling.

b) For second sluice, perform at $60 \mathrm{in}$, which maintains over $10^{\circ} \mathrm{F}$ subcooling. 
c) After second sluice, draw liquid level down to $48 \mathrm{in.}$, which will result in $30^{\circ} \mathrm{F}$ subcooling with maximum waste temperature below saturation temperature at atmospheric pressure (eliminates potential steam generation).

d) Pool liquid level should be continuously monitored by the submersible slurry pump conductivity probes with periodic verification by ENRAF measurements.

7. Post-sluicing dry waste steady-state analyses indicate sufficient heat can be removed to el iminate the need for further water additions:

a) Non-sluiceable hard pan should contain very little heat; most tank heat in waste above this region.

b) If $2 \mathrm{ft}(33 \%)$ of waste retrieved and active ventilation is maintained, water additions can be eliminated.

c) If $4 \mathrm{ft}(66 \%)$ of waste retrieved with passive ventilation, water additions can be eliminated.

d) Waste dry out will proceed slowly; time to reach peak waste temperatures may exceed 10 years. 


\author{
Attachment 2
}

\title{
IMPORTANT CONCLUSIONS
}

\section{WHC-SD-W320-TI-007, Rev 0, "Flammable Gas and Steam Controls for WRSS Operation, Project W-320"}

1. Operational control philosophy is that following a significant amount of waste retrieval, sluicing operations will be halted and waste analysis will be performed during the shutdown.
a) Approach calls for a sequenced incremental retrieval of waste from tank $\mathrm{C}-106$ (by volume) followed by a monitoring period during which waste behavior will be observed.
b) 1-ft depth waste retrieval increment represents a volume of about 25,000 gallons.
c) Minimum hold or monitoring period of 2 weeks.

2. Ability to detect a developing flammable gas retention condition in tank $A Y-102$ is also of concern.
a) Limiting waste retrieval from $\mathrm{C}-106$ to $50 \%$ of total will el iminate flammable gas retention in $A Y-102$ and subsequent gas release event (GRE) concern.
b) After $50 \%$ waste retrieval has been achieved, WRSS system wi1l be shutdown and tank AY-102 will be monitored for slurry growth.

3. General control actions will place 1-2 in. supernate above waste in $\mathrm{C}-106$ ( 6 in. nominally) and AY-102 supernate level will be held constant during sluicing period (controlled level sluicing).
a) Increments of $1-\mathrm{ft}$ depth of waste will be removed by sluicing.
b) Then 6 in. supernate pumped to $\mathrm{C}-106$ from $\mathrm{AY}-102$ and temperatures of thermocouple trees 8 and 14 monitored for one week.
c) Then $C-105$ supernate volume pumped down until 1-2 in. remains over solid waste; temperatures monitored for one week to verify adequate waste subcooling.
d) Sluicing sequence repeated.

4. To mitigate against tank $\mathrm{C}-106 \mathrm{flammable}$ gas plume generation:

a) Suggested that HVAC system be operational during and following termination of sluicing operations.

b) Standard hydrogen monitoring system (SHMS) will monitor C-106 for indication of hydrogen being released into head space. 
5. To mitigate against tank $A Y-102 \mathrm{flammable} \mathrm{gas} \mathrm{retention/release:}$

a) Gas retention monitoring will be performed during each sluicing incremental hold period (for slurry growth by observation during the hold period).

b) 1-ft waste removal increment and 2-week hold period will be maintained beyond 50,000 gal waste retrieval specification.

6. Upon satisfactory removal of $50 \%(100,000$ gal) waste from $\mathrm{C}-106$, a heat balance measurement will be made to see if sufficient source term has been removed. 
HNF-SD-WM-RPT-293 REV 0

Attachment 3

IMPORTANT CONCLUSIONS

WHC-SD-WM-ER-594, Rev 0, "Evaluation of Recommendation for Addition of Tanks to the Flammable Gas Watch List"

1. Additional tanks should not be recommended for the Flammable Gas Watch List. (FGWL).

a) Results of analyses are not sufficiently definitive because models are too primitive and current data lacks precision.

b) FGWL tanks do not include $\mathrm{C}-106$ or $\mathrm{AY}-102$.

c) 32 candidate tanks for FGWL do not include C-106 or AY-102.

2. Tanks with a significant potential for radioactive release are controlled under the USQ process for flammable gas.

3. Level perturbations induced by atmospheric pressure changes [Barometric Pressure Effect (BPE)] considered possible basis for establishing flammable gas retention by waste.

4. Leve1 perturbations by continuing surface leve] increase [Surface Leve] Rise (SLR)] considered possible basis for establishing flammable gas retention by waste.

5. Tank liquid or solid waste surface level can be measured by:
a) FIC gauge.
b) ENRAF gauge.
c) Manual tape.
d) Neutron logging instrumentation.

6. Calculational model relates waste surface linear displacement measurement with volume of retained gas:

a) Concentration of flammable gas in tank headspace following postulated gas release event (GRE) depends on fraction of gas trapped in waste that is released (assumed $25 \%$ ) and fraction of gas released that is flammable (assumed $97 \%$ hydrogen).

b) Criterion for candidates to FGWL is general flammable gas concentration in headspace assumed to be a hazard when greater than $25 \%$ of the Lower Flammability Limit (LFL).

c) Reexamination suggests $100 \%$ of the LFL more appropriate requirement for determining serious release consequences.

d) Non-flammable gases (e.g., nitrogen) normally constitute at last $50 \%$ of released tank gas; assumption of $97 \%$ hydrogen concentration is far 
too conservative (nominal $25 \%$ hydrogen with bounding value of $50 \%$ expected).

e) Current methods yield "ballpark" estimates of the volume of trapped gas.

7. General view is that buoyancy-induced rollover is the only mechanism likely to produce rapid release of large fraction of waste-retained flammable gas:

a) Rollovers occur in tanks with a supernatant liquid depth approximating the depth of settled waste solids.

b) Effects of massive release of plumes of waste-retained flammable gas stimulated by intrusive activities (e.g., sluicing) have not been considered.

8. Consideration of released flammable gas plume burn is very important, versus consideration of average dome space flammable gas concentration. 
HNF-SD-WM-RPT-293 REV 0

Department of Energy

Richland Operations Office

P.O. Box 550

Richland, Washington 99352
9601358

LiHC CC Reed: 06/04/95 an

MAY 31 S6

$96-W 50-062$

Dr. A. L. Trego, President

Westinghouse Hanford Company

Richland, Washington

Dear Dr. Trego:

DIRECTION FOR RISK EVALUATION GUIDELINES AND OFFSITE MAXIMUM EXPOSED INDIVIDUAL (MEI) LOCATION

References: 1. Memorandum from $R$. Guimond, HQ, to Manager, RL, "Interim Radiological Dose Acceptance Crjteria for the Hanford Tank Farms Safety Analysis," dated April 4, 1996.

2. Letter from A. Sidpara, RL, to A. L. Trego, WHC, "Risk Acceptance Criteria for Tank Farm Operation, "dated June 14, 1995.

3. Letter from W. B. Scott, RL, to President, WHC, "Clarification of Hanford Site Boundaries for Current and Future Use in Safety Analysis," \#9504327, dated September 26, 1995.

4. Letter, from P. H. Kruger, RL, to President, WHC, "Further Discussion on Previous Site Boundary Memorandum," \#9600588, dated Warch 5, 1996.

This letter provides direction for use of risk evaluation guidelines and defines the location of the offsite MEI for consideration during preparation of Tank Waste Remediation Systern (TWRS) safety analyses. Specifically, this direction applies to the safety documentation associated with TWRS projects and the TWRS Basis for Interim Operation (8I0)/Final Safety Analysis Report (FSAR).

The risk evaluation guidelines presented in Reference 1 are effectively the same as those presented in Reference 2 for the offsite receptor. The guidelines presented in Reference I are more conservative in application (step function) than those presented in Reference 2 by about a factor of two for the onsite receptor when considering events with an extremely unlikely estimated frequency of occurrence. Very ittle difference in controls and other mitigative measures required for risk management is expected through application of either set of risk evaluation guidelines. 
Therefore, TWRS safety analyses that were initiated for projects prior to issuance of Reference 1 (April 4, 1996) shall continue utilizing the risk evaluation guidelines previously established in Reference 2. Examples of these include those safety assessments in progress for Rotary Mode Core Sampling of Flammable Gas Tanks and Saltwell Pumping of Flammable Gas Tanks. These safety analyses will be revised as required to reflect the risk evaluation guidelines presented in Reference 1 during the first annual update or when incorporated into the TWRS BIO/FSAR unless Reference 1 is superseded.

The TWRS BIO/FSAR will use the risk evaluation guidelines presented in Reference 1. Other safety analyses within ThRS that start after April 4, 1996, shall also use the risk evaluation guidelines presented in Reference 1.

References 3 and 4 identify that, as a public waterway, access to the Columbia River is not controlled by U.S. Department of Energy, Richland Operations Office (RL). During the performance of safety analyses, the Columbia River must be considered as potentially being the nearest point of uncontrolled public access. This will depend upon the location of the facility or activity being analyzed and associated meteorological parameters.

For TWRS facilities, the near shore of the Columbia River becomes the location of the offsite MEI. Examination of dispersion parameters indicates that the radiological dose consequences for a receptor at this new offsite MEI location compared to the previously defined offsite MEI location would increase approximately 30 percent for events initiated at TWRS facilities in 200W, and approximately 50 percent for events initiated at TWRS facilities in 200E. No additional controls or other mitigative measures required for risk management are expected through application of either offsite MEI location in TWRS safety anatyses.

Therefore, TWRS safety analyses that were initiated for projects prior to issuance of Reference 4 (March 5, 1996) shall continue utilizing the previously defined offsite MEI location (Hanford Reservation Boundary). These safety analyses will be revised during the first annual update or when incorporated into the TWRS BIO/FSAR as required to address the new offsite MEI location resulting from consideration of the Columbia River as the nearest point of uncontrolied public access.

The TWRS BI0/FSAR will use the new offsite MEI location resulting from consideration of the Columbia River as the nearest point of uncontrolled public access. Other safety analyses within THRS that start after March 5, 1996, shall also use the new offsite MEI location. 
The above direction will result in a smooth and consistent transition to these new requirements while maintaining adequate risk management. This direction does not impact current project safety documentation preparation activities. Westinghouse Hanford Company shall expeditious Ty submit a change request for RL approval addressing the impact of the above direction on the TWRS BIO/FSAR preparation activity.

If you have any questions, please contact Carol Sohn on 376-8523.

WSD:MJR

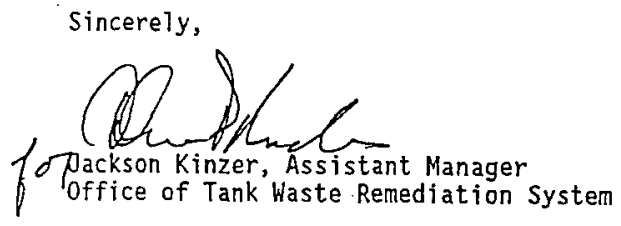

cc: R. F. Bacon, WHC

M. L. Cowan, WHC

G. L. Dunford, HHC

G. R. Franz, WHC

R. S. Popielarczyk, HHC 

HNF-SD-WM-RPT-293 REV 0

This page intentionally left blank. 
HNF-SD-WM-RPT-293 REV 0

CORRESPONDENCE DISTRIBUTION COVERSHEET

Author

Addressee

Correspondence No.

J. P. Harris

B. L. Nicol1, RL

9652542

372-1237

subject: PROJECT 93E-EWW-320, "TANK 241-C-106 SLUICING," MODIFICATION OF SLUICING FLUID SELECTION

INTERNAL DISTRIBUTION

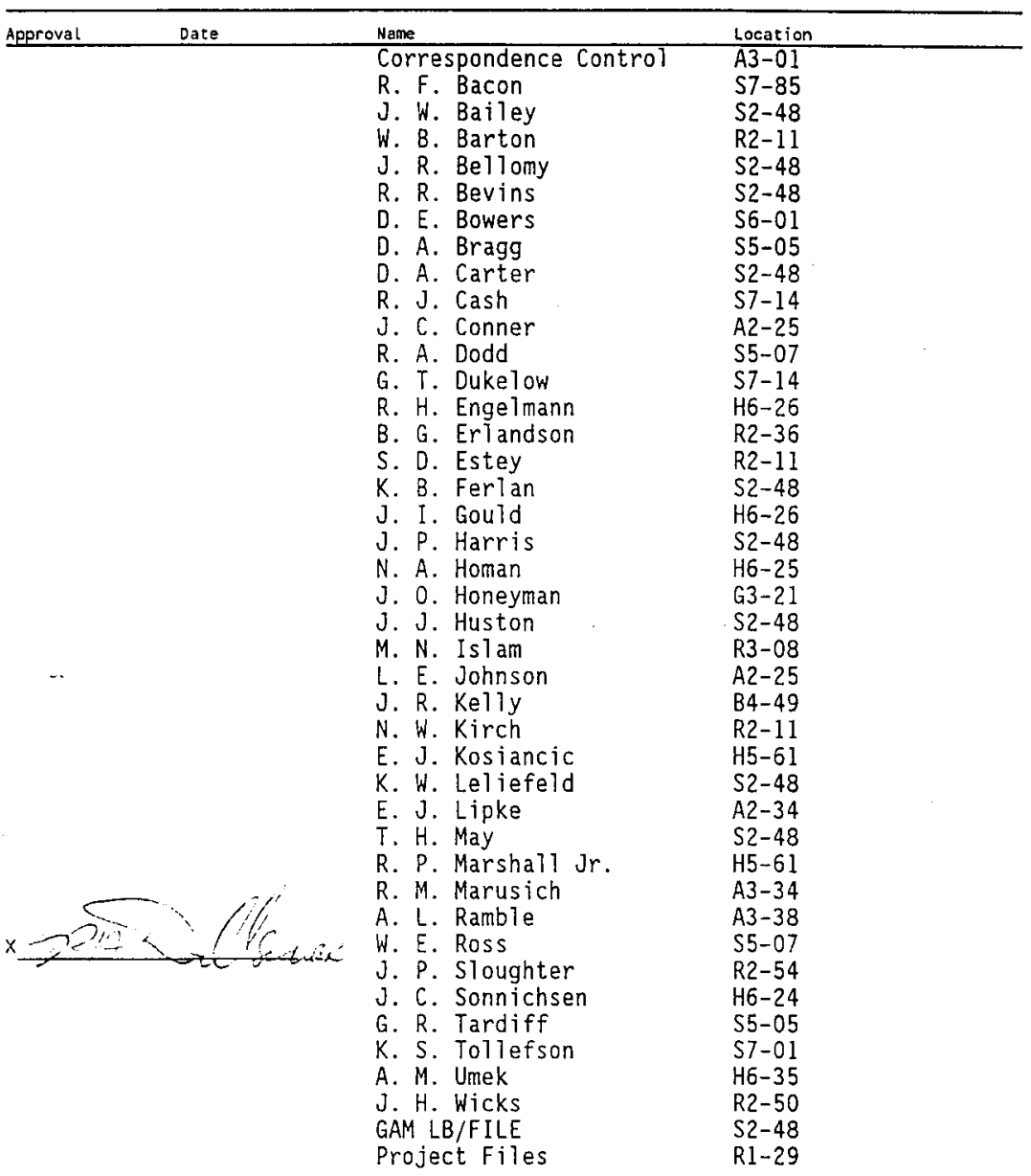


HNF-SD-WM-RPT-293 REV 0

This page intentionally left blank. 
P.O. Box 1970 Richland. WA 99352

June 10,1996

9652542

Mr. B. L. Nicol1, Project Director

TWRS Waste Retrieval

U.S. Department of Energy

Richland Operations Office

Richland, Washington 99352

Dear Mr. Nicoll:

PROJECT 93E-EWW-320, "TANK 241-C-106 SLUICING," MOOIFICATION OF SLUICING FLUID SELECTION

References: 1. Letter, C. A. Augustine, WHC, to R. L. Long, RL, "Project 93L-EWW-320, Tank 24l-C-106 sluicing - Sluicing Fluid Baseline Change to Corrosion Inhibited Water, "9457345, dated November 17, 1994.

2. J. P. Sederburg, WHC-SD-WM-ES-290, Rev. 2, "Chemical Compatibility of Tank Wastes in 241-C-106, 241-AY-101, and 241-AY-102," dated August 24, 1994.

3. Letter, S. W. Bork and R. A. Harrington, ICF KH, to J. W. Bailey, WHC, "Project W-320 Tank 106-C Waste Retrieval Study Analysis Session Report, "W-320-04, dated August $17,1993$.

This letter documents the technical baseline change to Project $W-320$, "Tank $241=-106$ Sluicing", changing the sluicing fluid from corrosion inhibited water to Tank 241-AY-102 (AY-102) supernatant. The technical basis and justification are discussed below, as well as background and insight into the selection changes experienced during the project's formulation, design, and construction phases.

Originally, Tank 241-AY-101 (AY-101) supernatant was selected as the sluicing fluid of choice, based on the outcome of a Study Analysis Session (SAS) facilitated by Inner City Fund - ICF Kaiser Hanford Company (ICF KH) in 1993 (Reference 3). This SAS utilized Value Engineering principles to consider compatibility issues in connection with other issues to make a decision about the designation of a receiver tank and the sluicing media to be used by the project. These issues included schedule, likelihood of success, program interfaces, initial cost, minimization of liquid transuranic (TRU) waste, support of overall waste minimization, life cycle costs, and tank configuration. The major criterion for selection of the AY101 fluid as the optimal sluicing media was the desire to minimize complexed 
waste volume, since both wastes had been classified as containing organic complexants.

In November, 1994, Reference 1 was sent to the U.S. Department of Energy, Richland Operations Office (RL) Tank Waste Projects Division, out ining a change in the baseline sluicing fluid from AY-10l supernatant to corrosion inhibited water. This change was predicated on ammonia concentration uncertainties in the new ventilation system stack exhaust as a result of potential ammonia concentrations in the AY-101 supernatant. Certain AY-101 characterization data suggested supernatant ammonia concentrations which could have been high enough to be a significant concern. Using that data, analyses of ammonia transfer into the atmosphere of Tank 241-C-106 (C-106) had been unable to preclude the possibility of ammonia releases from the new ventilation system which would be dangerous to on-site personnel.

As a result of this discovery, other sluicing fluid options were evaluated. The project's Chemical Compatibility Analysis Reference 2, had been revised prior to this (in August 1994) to evaluate a total of four potentia? sluicing fluids as a result of questions/comments related to alumina precipitates in the AY-IOI fluid. These options included: 1) sluicing with AY-101 supernatant, 2) sluicing with 2.5 molar hydroxide solution, 3 ) sluicing with other dilute or concentrated wastes such as AY-102 or AN-106, respectively, and 4) sluicing with corrosion inhibited raw water.

In addition to the results of the compatibility analyses, which indicated that any four of the options were satisfactory from a compatibility standpoint, programmatic drivers were included in the evaluation. At that time, Westinghouse Hanford Company (WHC) Tank Farm Transition Projects East Tank Farm Operations held discussions with project management staff in which it was requested that 102-AY supernatant be made available for future 242-A Evaporator campaigns. The conclusion was therefore reached that the $W-320$ sluicing fluid be changed to corrosion inhibited water. Concurrence was received from the WHC organization responsible for waste volume projections, which assessed that tank space was available to support this change. Other sluicing fluid options, such as the use of Liquid Effluent Retention Facility (LERF) waste for recycle back to AY-102, were evaluated and rejected due to an ammonia content similar to that of $A Y-101$.

Up to this point, project environmental and safety documentation had not specified a particular sluicing fluid. Rather, documentation referenced the compatibility study and stated that one of the "compatible" fluids would be used as the sluicing medium. Comments received during the second tier review of the project's Safety Assessment (SA) Document (WHC-SD-WM-SAD-024) requested specificity regarding the sluicing fluid. The SA text was modified to denote corrosion inhibited water (the baseline) as the sluicing fluid. 
Page 3

June 10,1996

Following the SA modification, East Tank Farm Operations informed project management staff that $A Y-102$ supernatant was no longer required as an Evaporator feed, and requested that the use of AY-102 supernatant be evaluated as a sluicing fluid. This fluid had already been evaluated in Reference 2 and found to be compatible, and its use would dramatically improve the waste minimization aspects of the retrieval activity. Also, the use of the existing AY-102 supernatant would greatly simplify the preparatory steps for the sluicing retrieval in that a decant and refill of AY-102 with corrosion inhibited water would no longer be required.

Because of the foregoing, it was agreed within WHC that the use of AY-102 supernatant was now the optimal choice, and the technical baseline for the project was changed. The discussion of the sluicing fluid in the project Safety Assessment Document has been modified to reflect the new baseline. Revised pages will be submitted to RL for the document's Tier III reviewers during the next scheduled update (to incorporate completion of comment resolutions) in June, 1996.

If you have any questions on this subject, please contact $K$. W. Leliefeld at 373-2759.

Very truly yours,

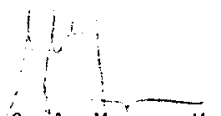

G. A. Meyer, Manager

Waste Retrieval Project

Tank Waste Remediation System

j]d

$\mathrm{RL}=\quad$ W. Abdu]

A. H. Wirkkala

W. R. Wrzesinski 
HNF-SD-WM-RPT-293 REV 0

This page intentionally left blank. 
From: Materials and Corrosion Engineering

Phone: $373-6296$ R1-30

Date: April 16, 1996

Subject: EVALUATION OF CORROSION STATUS OF 241-AY-102

To:

R2-11

$c c$ :

$\begin{array}{ll}\text { T. M. Blaak } & \text { S5-13 } \\ \text { K. G. Carothers } & \text { RI-5I } \\ \text { J. M. Jones } & \text { S5-13 } \\ \text { N. W. Kirch } & \text { R2-11 } \\ \text { P. C. Oh] } & \text { RI-30 }\end{array}$

D. A. Reynolds

W. E. Ross

$\mathrm{R} 2-11$

J. P. Sloughter

$\mathrm{S} 5-07$

M. J. Sutey

$\mathrm{R} 2-54$

P. C. Oh?

JLN LB/File

$\mathrm{T} 4-07$

References: (1) Internal Memo, D. L. Herting to J. M. Jones,

"Characterization of Sludge Sample from Tank 241-AY102," 75764-PCS-96-021, dated April 3, 1996.

(2) Meeting Minutes, L. A. Tusler to Distribution, "Get-We]l Plan on Low $\mathrm{pH}$, "meeting date March 4; 1996.

(3) Internal Memo, L: A. Tusler to N. W. Kirch, "Double Shell Tank Composition Status - Quarterly Report," 74A30-96-008, dated February 27, 1996.

In response to action item 1 of Reference 2, a corrosion evaluation of the chemistry conditions in 241-AY-101 has been completed. The evaluation is based on the analytical results from a December 6,1994 sludge sample plus that for the current estimate of the tank waste composition from mass balance calculations (Reference 3). This tank has most recently been corrected from a low hydroxide condition by the addition of 1,700 gallons of 19 molar sodium hydroxide in January, 1996. There are currentiy no jdentifiable disqualifying conditions for continued storage of this waste.

The hydroxide, nitrite, and nitrate concentrations used in the corrosion evaluation are shown in the table below. The relative concentrations of these species are prescribed in the double-shell tank corrosion control specifications. The concentrations of other reactive species are used in the evaluation of uniform corrosion rates, but are not reported here. These are available in Reference 1. 


\begin{tabular}{|l||c|c|c|}
\hline & $\begin{array}{l}\text { AY-102 } \\
\text { Supernate } \\
\text { Calculated }\end{array}$ & $\begin{array}{l}\text { AY-102 } \\
\text { Supernate } \\
\text { from 12/6/94 } \\
\text { Sample }\end{array}$ & $\begin{array}{l}\text { AY-102 Sludge } \\
\text { ISL from } \\
12 / 6 / 94 \\
\text { Sample }\end{array}$ \\
\hline Hydroxide (M) & 0.05 & $0^{*}$ & $0^{*}$ \\
\hline Nitrite (M) & 0.02 & 0.0222 & 0.0217 \\
\hline Nitrate (M) & 0.01 & 0.0093 & 0.0093 \\
\hline Corrosivity Factor & 0.14 & 0.42 & 0.43 \\
\hline Minimum Nitrite (M) & 0.017 & 0.015 & 0.015 \\
\hline$\%$ Elongation & $>20$ & $>20$ & $>20$ \\
\hline Uniform Corrosion, mpy & $<1$ & $<1$ & $<1$ \\
\hline
\end{tabular}

* Hydroxide concentration below detection limit of $0.00225 \mathrm{M}$ calculations based on waste at $40^{\circ} \mathrm{C}$

In the table above, "Supernate Calculated" refers to the estimated bulk supernate waste composition based on a combination of analytical results and a running mass balance of waste transfer activity in the tank, as reported in Reference 3. This represents the best estimate of current supernate waste composition. The column "Supernate from 12/6/94 Sample" reports the analytical results for the supernate waste from a sample taken December 6 , 1994 , as reported in Reference 1. It is beljeved that the "Supernate Calculated" data more accurately represent the current actual supernate composition, since nearly 15 months have elapsed from the time the sample was taken. The tank has been receiving new waste during this time and has had the previous caustic deficiency corrected by the direct addition of sodium hydroxide.

The column "Sludge ISL from $12 / 6 / 94$ Sample" reports the analytical results for the sludge interstitial liquid (ISL), as reported in Reference 1. The ISL composition is used for the corrosion evaluation because it is believed to provide the controlling chemistry for the corrosion reaction, rather than the bulk sludge chemical composition. The relationship between changes in sludge ISL chemistry and changes in bulk supernate chemistry from waste additions is unknown. However, it is expected that changes in the sludge ISL chemistry will lag behind changes in the supernate chemistry because such changes will be governed more by diffusion through the sludge layer than by mixing. Thus the sludge ISL sample analytical results may still most accurately represent the current corrosion conditions at the tank bottom, even though the supernate chemistry has changed significantly from the time of sampling.

The Corrosivity factor utilizes the ratio of nitrate to nitrite and hydroxide concentrations to estimate the tendency to stress corrosion crack the tank walls. Based on an assessment of single shell tank fajlures, corrosivity factors of greater than 2.5 are cause for concern and immediate corrective action. There are no corrosivity factors greater than 2.5 calculated above. 
L. A. Tusler

$74 A 40-96-J L N-006$

Page 3

ApriT 16, 1996

The Minimum Nitrite calculation estimates the lowest nitrite concentration required to inhibit nitrate induced pitting. This estimation is based on an algorithm developed from laboratory studies at the Savannah River Site (SRS). There are no nitrite values below the minimum. Moreover, the published algorithm includes a $50 \%$ factor of safety for the recommended 1 imits, i.e. the calculated minimum nitrite values are $50 \%$ higher than the estimated critical value to preclude pitting.

The Percent Elongation evaluation utilizes a regression fit of recent Pacific Northwest National Laboratory (Pacific Northwest) laboratory test results on stress corrosion cracking in dilute waste systems. Previous laboratory studies at the SRS have identified elongations of less than $13 \%$ as indication of stress corrosion cracking. Application of the Pacific Northwest data to the SRS criterion does not indicate stress corrosion cracking for the above waste systems. The Pacific Northwest data were generated at a significantly higher temperature $\left(92^{\circ} \mathrm{C}\right)$ than found in this waste tank. Nonetheless the results provide a useful independent corroboration to the corrosivity factor calculation.

The estimated uniform corrosion rates lie within acceptable ranges. The uniform corrosion rate model is highly dependent on temperature and hydroxide concentration. In the case where hydroxide is reported conservatively as 0 (below detection limit), the model cannot accept this concentration as an input. Extrapolation of the model output for hydroxide concentrations below the $0.0001 \mathrm{M}$ input limit indicates an acceptable uniform corrosion rate through at most one order of magnitude decrease in hydroxide concentration $(0.0000 \mathrm{I} M)$. Reliable estimations of corrosion rates below this limit are not possible without further study. Reference 1 reports an average supernate $\mathrm{pH}$ of 10.4 . For dilute solutions this would calculate to a hydroxide concentration of $0.00025 \mathrm{M}$. This is greater than the above estimating limit, indicating the output of the model may still have some validity. A temperature of $40^{\circ} \mathrm{C}$ was used as a conservative upper limit for the corrosion calculations.

Attached are the worksheets for the above evaluation. If you have any questions, please feel free to call me on 373-6296.

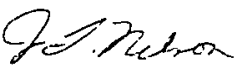

J. L. Nelson, Senior Principal Engineer

Materials and Corrosion Engineering vmm

Attachment 
PINL Uniform Corosion Rate Model

Estimated uniform corrosion rates at $40 \mathrm{C}$ mpy vs. $\mathrm{OH}$ concentration

\begin{tabular}{|r|r|r|r|}
\cline { 2 - 4 } \multicolumn{1}{c|}{$\mathrm{OH}(\mathrm{M})$} & $\begin{array}{r}\text { Supernate } \\
\text { Calculated }\end{array}$ & $\begin{array}{l}\text { Supernate } \\
\text { Sample }\end{array}$ & $\begin{array}{l}\text { Siudge ISL } \\
\text { Sample }\end{array}$ \\
\hline 0.1 & 0.1 & 0.1 & 0.1 \\
\hline 0.01 & 0.15 & 0.15 & 0.15 \\
\hline 0.001 & 0.27 & 0.27 & 0.27 \\
\hline 0.0001 & 0.46 & 0.46 & 0.46 \\
\hline
\end{tabular}
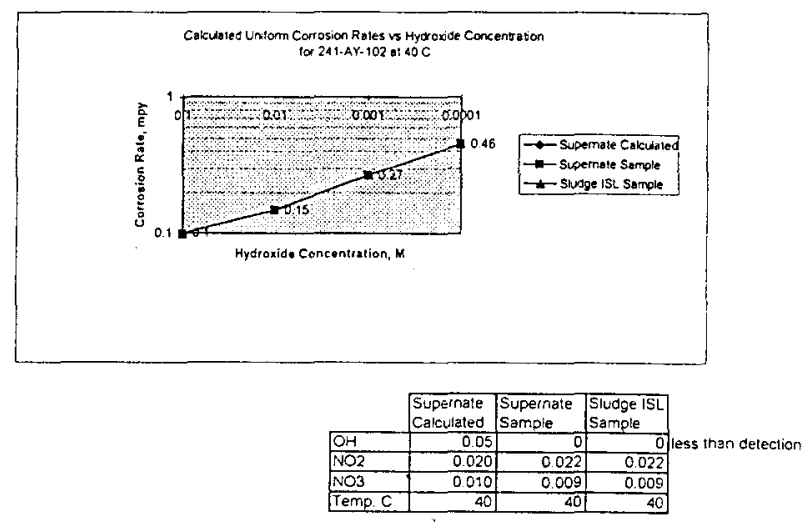

\begin{tabular}{|c|c|c|c|}
\hline Corrosivity Factor: & 0.14 & 0.42 & 0.43 \\
\hline Minimum $\mathrm{NO}_{2}$ required 10 inhibis $\mathrm{NO}_{3}$ induced pitting: & 0.017 & 0.015 & 0.015 \\
\hline \multirow{2}{*}{$\begin{array}{l}\text { Maximum temperature to inhibit NO3 induced pitting: } \\
\text { (from SRL pitting modei) }\end{array}$} & 42 & 44 & 44 \\
\hline & & & \\
\hline
\end{tabular}

PNL Sludge Washing Study

\begin{tabular}{|c|c|c|c|}
\hline $\mathrm{OH}$ & $\begin{array}{l}\text { \% Elongation } \\
\text { Supernate } \\
\text { Calculated }\end{array}$ & $\begin{array}{l}\text { \% Elongasion } \\
\text { Superrate } \\
\text { Sample }\end{array}$ & $\begin{array}{l}\text { \% Elongavon } \\
\text { Sludge ISL } \\
\text { Sample }\end{array}$ \\
\hline 0.01 & $21.1 \%$ & $21.2 \%$ & $21.2 \%$ \\
\hline 0.05 & $21.6 \%$ & $21.6 \%$ & $216 \%$ \\
\hline 0.1 & $22.0 \%$ & $22.0 \%$ & $22.0 \%$ \\
\hline 0.3 & $23.0 \%$ & $23.0 \%$ & $23.0 \%$ \\
\hline 0.5 & $23.6 \%$ & $23.6 \%$ & $23.6 \%$ \\
\hline 1 & $23.7 \%$ & $23.7 \%$ & $23.7 \%$ \\
\hline
\end{tabular}

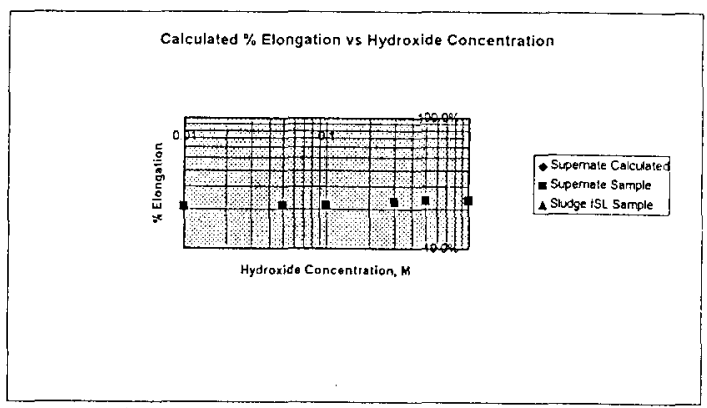


PNL Uniform Corosion Rate Model Estimated uniform corrosion rates at $40 \mathrm{C}$ mpy vs. $\mathrm{OH}$ concentration

\begin{tabular}{|r|r|r|r|}
\cline { 2 - 4 } \multicolumn{1}{c|}{$\mathrm{OH}(M)$} & $\begin{array}{l}\text { Supemate } \\
\text { Calculated }\end{array}$ & $\begin{array}{l}\text { Supermate } \\
\text { Sample }\end{array}$ & $\begin{array}{l}\text { Sludge 1SL } \\
\text { Sample }\end{array}$ \\
\hline 0.1 & 0.1 & 0.1 & 0.1 \\
\hline 0.01 & 0.15 & 0.15 & 0.15 \\
\hline 0.001 & 0.27 & 0.27 & 0.27 \\
\hline 00001 & 0.46 & 0.46 & 0.46 \\
\hline
\end{tabular}

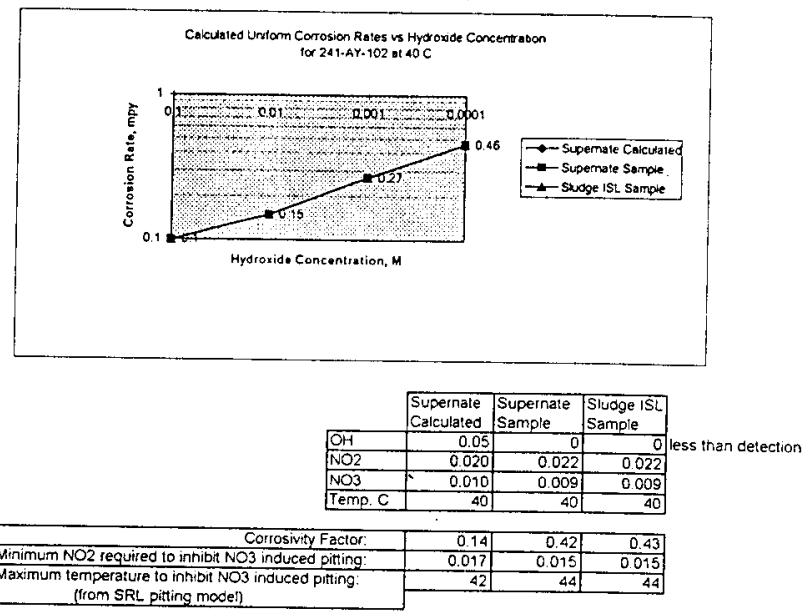

PNl Siudge Washing Study

\begin{tabular}{|c|c|c|c|}
\hline $\mathrm{OH}$ & $\begin{array}{l}\text { SErongston } \\
\text { Supernate } \\
\text { Calculated }\end{array}$ & $\begin{array}{l}\text { * Elongaton } \\
\text { Supernate } \\
\text { Sample }\end{array}$ & $\begin{array}{l}\text { Elongation } \\
\text { Sludge ISL } \\
\text { Sample }\end{array}$ \\
\hline 0.01 & $21.1 \%$ & $21.2 \%$ & $\frac{4}{21.2 \%}$ \\
\hline 0.05 & $21.6 \%$ & $21.6 \%$ & $21.6 \%$ \\
\hline 0.1 & $220 \%$ & $22.0 \%$ & $22.0 \%$ \\
\hline 0.3 & $23.0 \%$ & $23.0 \%$ & $23.0 \%$ \\
\hline 0.5 & $23.6 \%$ & $23.6 \%$ & $23.6 \%$ \\
\hline 1 & $237 \%$ & $23.7 \%$ & $23.7 \%$ \\
\hline
\end{tabular}

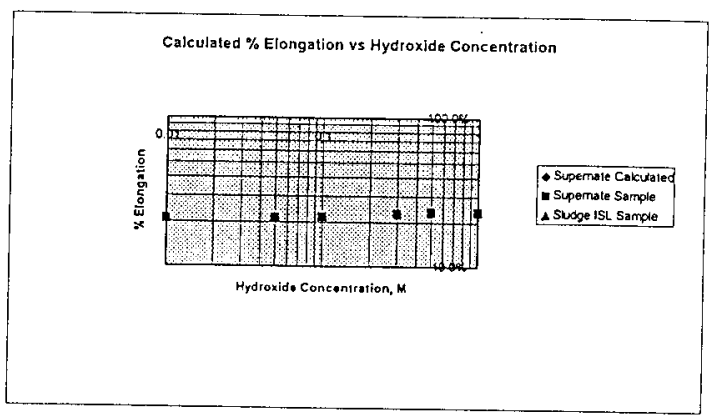


HNF-SD-WM-RPT-293 REV O

This page intentionally left blank. 


\section{DON'T SAY IT --- Write It! DATE June 25, 1996}

TO: John Bailey

cc: Dean Jones
FROM: D. Nguyen

$373-2398$

\section{SUBJECT: W-320 Pressure Pulse}

John,

I found some information on the mechanical properties of HEPA filter that I believe will answer the question that you have regard to the 2 psi. overpressure. Please review the attached document and let me know if you would like anymore information. Thank you

Danny 


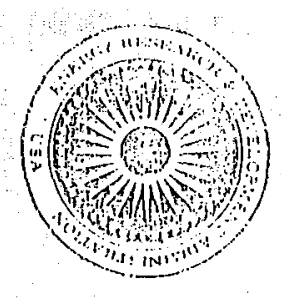

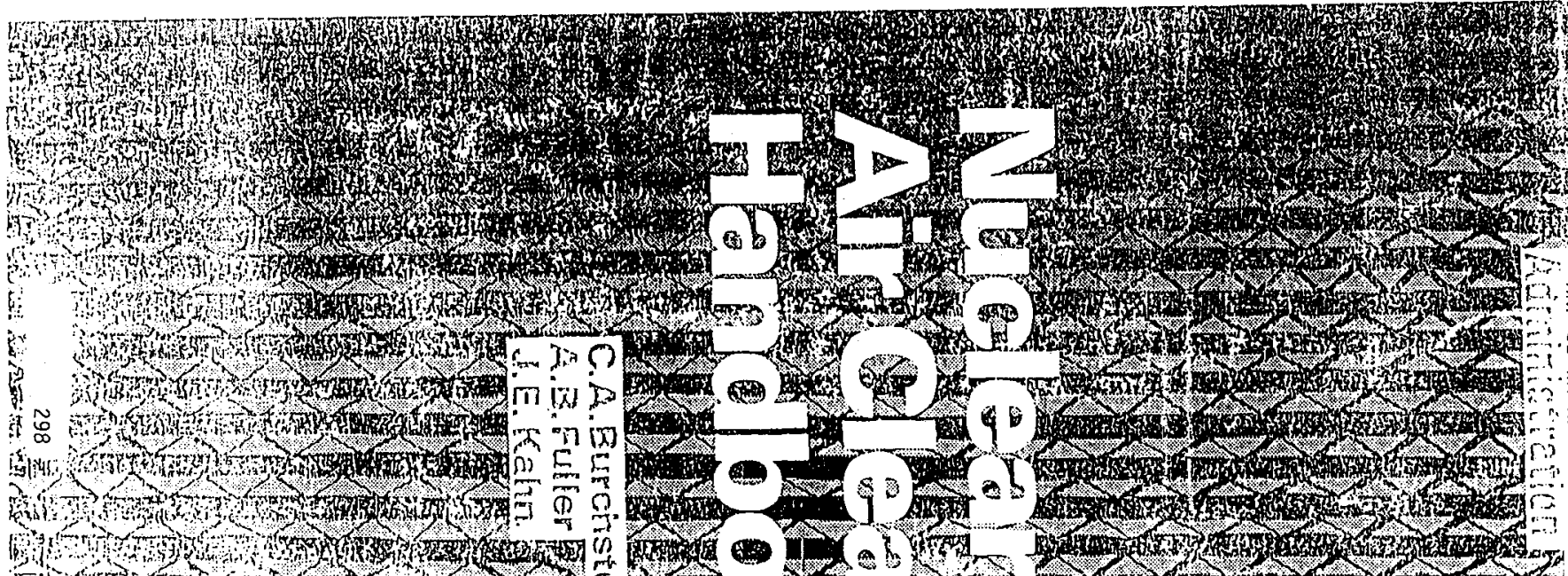
Hom rim,

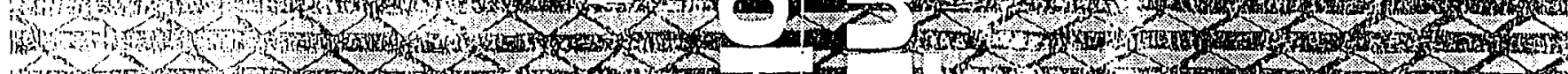
W. (5)

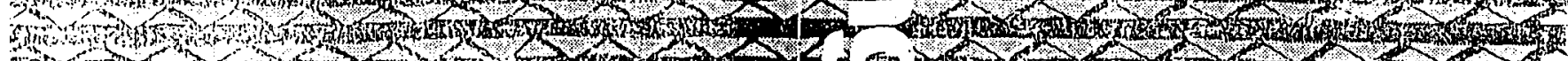

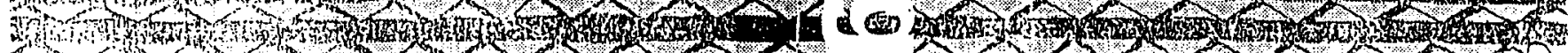

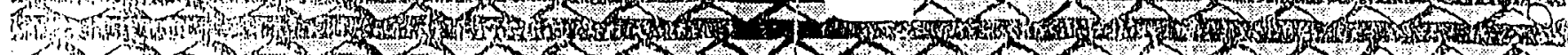
1) 作, 


\title{
NUGLEAR \\ AIR GLEANING \\ HAKDBOOK
}

DESIGN, CONSTRUCTION, AND TESTING OF HIGH-EFFICIENCY AIR CLEANING SYSTEMS FOR NUCLEAR AFPLICATION
C. A. Burchsted
J. E. Kehn

A. 3. Fuller

\author{
Contreet No. W.7405-eng-26 \\ OAK RIDGE NATIONAL LABORATORY \\ Ock Ridge, Tennessee 37330 \\ OPERATED BY UNION CARSIDE CORPORATION
}

FOR THE ENERGY RESEARCH AND DEYELOPMENT ADMINISTRATION

PROPETI OE US GOVERTIVETT 


\subsubsection{Weight of HEPA Filters}

The weight of filter elements is an important factor in design and maintenance. rable $\$ .2$ gives the cieunlilter weight of open-face and enclosed reciangular models. Uirty-tilter weights, for design purposes, are approximately 4 ib more per $1000 \mathrm{cfm}$ of rared capacity.

\subsubsection{Mechanical Properies'}

Uther factors (heat. moisture) being equal. woodcased hilters are preierred to steel-cased filters because of their greater rigidity. superior vibrationdamping characteristics. greater corrosion resistance. and greater comer strength." Common pracice in nuclear plant exhausi systems is to compress fiter gaskets by bute or more. This amount of gasket compression reyuires a clamping force of at least $1 \mathrm{~s}$ lb per square inch of gasket surface, or a total load of 1250 lb or more on the frame of a 1000 -cim filter unit. Because its section modulus is nearly 20 times that of a stee! c. se, the wood case is betier able to withsiand such high compressive, axial loads on the case pane!s. The wood case, with properly construcied (rabbeted) comers, also has about twice the comer strength of a steel case of the same size and is therefore better able to withsiand racking or skewing when subjected to a force couple. Racking, which frequently occurs during handling, shipping, and installation, can damage either the filter medium or the seal between the core and case, or both. Face guards, consisting of hardware cloth or expanded-metal screens fastened to each face of the filter, increase the resistance to racking or skewing.
Resistance to shock pressures is important in a HEPA filter because it is often the final barrier between the contaminated space and the atmosphere. The shock overpressure resistance of open-face rectangular niters, based on tesis by the U.S. Navy, ${ }^{12}$ is given in Table 3.3 and Fig. 3.4. The recommended values are the maximum shock overpressure that the filters should withstand without visible damage or loss in filtration efficiency when exposed to a shock of approximately $50 \mathrm{msec}$ duration. Filters with face guards on both faces have about $40 \%$ greater shock resistance than those without. Dirt-loaded filters in the Navy tests exhibited about $15 \%$ less shock resistance than clean nilters. At overpressures of 0.5 to 1.0 psi greaier than the failure value, the filter medium burst on the downstream side of the pieats; at overpressure of 2 psi greater than the failure value, extensive damage to the core occurred; and at 5 psi, blowout of the entire filter core occurred. 12 The greater shock resistance of filters with face guards is significant. The AEC, and more recsntly ERDA and NRC, has long advocated face guards on HEPA filters to minimize damage to the fragile core during handling and installation. The additional factor of higher shock overpressure resistance gives added weight to this recommendation. The shock overpressure resistance of enclosed filters is probably less than that of open-face filters, because the shock loading wiil be concentrated at the enter of the core. However, no tests have been made to verify this phenomenon.

Another important property of HEPA filters is theirability to withstand continuous overpressure. By

Table 3.2. Weight of unused REPA filtes

\begin{tabular}{|c|c|c|c|}
\hline \multirow{2}{*}{$\begin{array}{l}\text { Filler } \\
\text { size } \\
\text { (in.) }\end{array}$} & \multirow{2}{*}{$\begin{array}{l}\text { Nominal airtow } \\
\text { eapacity } \\
\text { (cim) }\end{array}$} & \multicolumn{2}{|c|}{$\begin{array}{l}\text { Approximate weight (ib) } \\
\text { of filters with - }\end{array}$} \\
\hline & & Wood case & Sterl case \\
\hline \multicolumn{4}{|c|}{ Open-iace } \\
\hline $8 \times 8 \times 3_{10}^{1}$ & 25 & $?$ & 3 \\
\hline $8 \times 8 \times s^{i}$ & 50 & 3.6 & 5.8 \\
\hline $12 \times 12 \times 5$ & 125 & 2.3 & 7.3 \\
\hline$=4 \times 24 \times 5$ & 500 & 17 & 22 \\
\hline $24 \times 24 \times 11^{1}=$ & 1000 & 32 & $\because 0$ \\
\hline \multicolumn{4}{|c|}{ Enclosed } \\
\hline$\checkmark \times \checkmark$ cross section & 25 & 5 & 9 \\
\hline$\gamma \times 8$ cross section & 50 & 7 & 10.5 \\
\hline $12 \times 12$ cross section & 125 & 17 & 20 \\
\hline 24 < 24 cross section & 500 & $6-1$ & 77 \\
\hline $24 \times 24$ eross section & 1000 & is & 95 \\
\hline
\end{tabular}


Tabie 3.3. Shock overpressure resistance of open-face HEP A fiters

\begin{tabular}{|c|c|c|c|c|}
\hline \multirow{3}{*}{\multicolumn{2}{|c|}{$\begin{array}{c}\text { Filter } \\
\text { dimensions (in.) }\end{array}$}} & \multicolumn{3}{|c|}{ Overpressure (psig) } \\
\hline & & \multirow{3}{*}{$\begin{array}{c}\text { Overpressure } \\
\text { at } \\
\text { Jailure }\end{array}$} & \multicolumn{2}{|c|}{$\begin{array}{c}\text { Recommended } \\
\text { design limic for used filters }\end{array}$} \\
\hline & & & \multirow{2}{*}{$\begin{array}{l}\text { With face } \\
\text { guards }\end{array}$} & \multirow{2}{*}{$\begin{array}{c}\text { Without face } \\
\text { guasds }\end{array}$} \\
\hline Face & Depih & & & \\
\hline $8 \times 8$ & $31 \mathrm{il6}$ & 3.7 & - & 2.0 \\
\hline $8 \times 8$ & $s^{3}$ & 4.5 & " & 2.5 \\
\hline $12 \times 12$ & $s_{i}^{\prime}$ & 3.6 & $\wedge$ & 7.0 \\
\hline $24 \times 24$ & $s_{i t}^{*}$ & 2.2 & 1.7 & i.2 \\
\hline $24 \times 24$ & $11:=$ & 3.2 & 2.7 & 1.8 \\
\hline
\end{tabular}

"Clean Jilter with 4- by 4-mesh face guards on both faces.

"Face guards not available.

Source: W. L. Anderson and T. Anderson, -Effec: of Shosk Overpressure on High Etficiency Filter Units." Proc 9th AEC Air Clean. Conj.. LSAEC Repor CONF-660904, 1966.

specilication. new HEPA filters must have sufficient structural strength to wihstand a continuously applied overpressure of 10 in.wg. or higher. For at least $15 \mathrm{~min}$ without visible damage or loss of efticiency. For used fillers. a value of $\mathrm{g}$ in. $\mathrm{wg}$ is recommended for design or planning purposes. In addition. the filter should be able to withstand the considerably higher, but short duration. overpressures that might be encountered in a tornudo or when a damper inadvertenlly slams shut in the duct sytem. Although the design basis cornudo speciries an overpressure of 3 psi for a period of $3 \mathrm{sec}$." it is unlikely that the HEPA filters would be subject 10 such a condition because of the attenuating effects of the stack. ductwork. and fans. Tests at Los Alumos showed that in $8 \times 8 \times 3 \%$ in. HEPA filter could withstand a $y$-sec pressure pulse during which the maximum pressure of 3 psi uas held lor 3 sec without visible damage or reduction in efficiency. ${ }^{4}$ Comparison of these results with the data of Fable 3.3 indicates that the $24 \times 24 \times 11$ : in. Titer can probably withsiand a y-sec pressure pulse of 2.5 psi. Which is probably substantially worse than what the filict would experience in the event of a tornado.

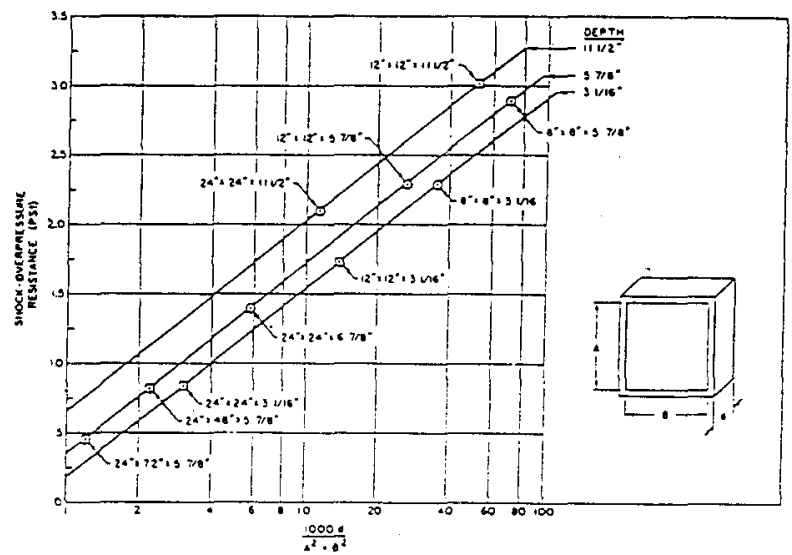

Fig. 3.4. Shock-overpressure resistance of elean HEP.A fiters (separator type) as a function of size. frum (6. 1. 13urchistud.

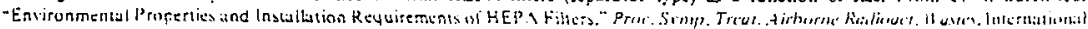
Alumic Enery segney. Visnnd. 19os. 
HNF-SD-WM-RPT-293 REV 0

This page intentionally left blank. 


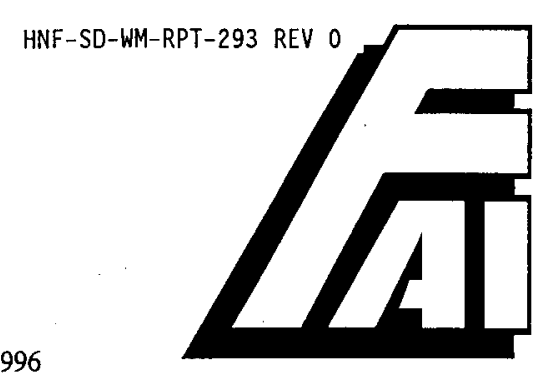

TO: John Harris, WHC

FROM: $\quad$ Marty Plys

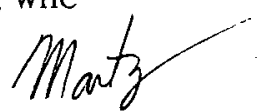

SUBJECT: Hypothetical AY-102 Burn Analysis

\subsection{SUMMARY}

A hypothetical flammable gas burn in AY-102 is analyzed here to illustrate the potential consequences. The key feature of the analysis is that combustion would be incomplete, and the pressure rise is calculated for bounding combustion completeness fraction, assumed here to be $10 \%$. This yields a pressure rise of $1.4 \mathrm{psig}$, well below the 4.3 psig HEPA failure threshold.

\subsection{DATA}

From an electronic mail communication, the AY-102 headspace is at $25 \%$ of the LFL, i.e. $1 \%$ hydrogen, when 1000 SCF of gas containing $50 \%$ hydrogen are released, and therefore the headspace volume is 49,500 SCF or 1400 cubic meters. Also from the communication, the HEPA filter can withstand a headspace pressure of 4.3 psig. From other personal communications, there are 500 SCF of stored gas per inch of pressure rise, so 1000 SCF is equivalent to a 2 inch rise.

Per my previous memorandum, gas from $\mathrm{C}-106$ has a nominal composition of $54 \%$ hydrogen, $31 \%$ methane, and $15 \%$ ammonia, and the corresponding heat of reaction is 426.8 $\mathrm{MJ} / \mathrm{kg}$-mole; pure hydrogen has a heat of reaction of $241.8 \mathrm{MJ} / \mathrm{kg}$-mole, so clearly the C-106 case is limiting. From my previous work also, a good heat capacity for the gas is $30 \mathrm{~kJ} / \mathrm{kg}$ mole-K. Finally, also from my previous work, incomplete combustion is expected when the gas concentration falls below $7 \%$.

\subsection{INCOMPLETE COMBUSTION}

Gas would be stored in a rather even distribution in the sludge in AY-102, and released incoherently over a time interval of minutes and over much of the supernatant surface area, per the physical phenomena of rollovers commoniy observed. This means that the released gas 
would $\mathrm{mix}$ intimately with headspace air to form a flammable cloud near the waste surface, but further mixing would reduce the gas concentration in the cloud. The physical picture of gas mixing is not that of a well-defined plume released at a particular, limited area which entrains surrounding gases, but rather a very large number of bubbles acting as sources for tiny plumes distributed over much of the waste surface. In particular, for a release of $1000 \mathrm{SCF}$ of pure flammable gas corresponding to a 2 inch level rise, dilution to the LFL would occur within $(1000 / 35.29) /(0.04 * 411)=1.7 \mathrm{~m}$ if the gas were emitted over the entire waste surface, or within about $3 \mathrm{~m}$ if the gas were emitted over a little over half the waste surface.

The flammable gas cloud thus would have a pancake shape, i.e. its height of no greater than about $3 \mathrm{~m}$ is much less than its diameter of about $22 \mathrm{~m}$. A flammable gas cloud of higher gas concentration would of course be commensurately shorter, so its aspect ratio would be more skewed. Note that it is conservative to assume that all the gas would be present in one coherent cloud, because over a release time of about one minute the gas can travel farther upward than the cloud layer thickness assumed here. In fact, the presence of a cloud of lean gas is guaranteed by the finite release interval. The real configuration of the "cloud" could just as likely be set of small clouds of flammable mixtures over individual release areas separated by nonflammable gas, and thus again incomplete combustion is the only physically possible phenomena.

It is experimentally observed that the combustion completeness is lower for systems with smaller aspect ratios (height to diameter ratios) than for spheres or vertically oriented cylinders, and physical models can adequately account for the effect of geometry [Plys, 1988A and B].

Based on the experience of this author, a combustion completeness of only several percent would be expected for the proposed flammable gas configuration, and ten percent is a bounding figure. Thus, a bounding estimate for the amount of gas that could actually burn is $10 \%$ of 1000 SCF, or 2.83 cubic meters. A better estimate could be obtained by using the model described in the references.

\subsection{METHOD}

A simple method is used here to relate post-combustion pressure to the volume burned. From an energy balance,

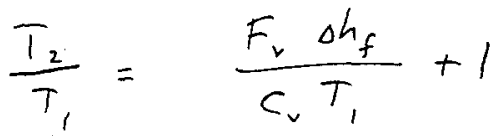

where

$$
\begin{array}{ll}
C_{\checkmark}= & \text { Average beat capacity, } \mathrm{J} / \mathrm{kg} \text {-mole- } \mathrm{K} \\
T_{2}= & \text { Post-burn temperature, } \mathrm{K} \\
T_{1}= & \text { Initial temperature, } \mathrm{K} \\
F_{V}= & \text { Fraction of volume occupied gas that burns }
\end{array}
$$




$$
\Delta h_{f}=\quad \text { Heat of reaction, } \mathrm{J} / \mathrm{kg}-\mathrm{mole}
$$

For the gases of interest, the pre-burn number of gas moles is nearly equal to the post-burn number of gas moles, allowing the expression above. Using the ideal gas law then yields

$$
\frac{\Delta P}{P}=\frac{F_{v} \Delta h_{f}}{C_{v} T_{1}}
$$

where

$$
\begin{array}{ll}
\Delta P= & \text { Pressure rise, } \mathrm{Pa} \\
P_{1}= & \text { Initial pressure, } \mathrm{Pa}
\end{array}
$$

\subsection{RESULTS}

Burning the specified amount of gas yields a pressure rise of:

$$
\frac{\Delta P}{P}=\left(\frac{2.83 \mathrm{~m}^{3}}{1400 \mathrm{~m}^{3}}\right) \frac{424.8 \times 10^{\mathrm{L}} \mathrm{J} / \mathrm{kg} \cdot \mathrm{mol}}{\left(30 \mathrm{es} \mathrm{J} / \mathrm{kgmol}_{\mathrm{j}}\right)(300 \mathrm{~K})}=0.096
$$

or about 1.4 psig.

\subsection{REFERENCES}

Martin G. Plys, memorandum to John Harris and John Conner, Westinghouse Hanford Company, Hypothetical C-106 Retrieval-Induced Gas Release and Combustion, June 18, 1996.

Martin G. Plys et al, “A Flammability and Combustion Model for Integrated Accident Analysis," Proc. Int. Conf. Thermal Reactor Safety, Avignon, France, Oct. 2-7, 1988 (A).

Martin G. Plys and Robert D. Astleford, Modifications for the Development of the MAAP-DOE Code, Volume III: A Mechanistic Model for Combustion in Integrated Accident Analysis, DOE/ID-10216 Vol. III, November, 1988 (B). 
HNF-SD-WM-RPT-293 REV O

This page intentionally left blank. 


\subsection{METHOD}

The post-combustion pressure rise in the headspace may be shown to be given by:

(1)

$$
\frac{\Delta P}{P}=\frac{F_{v} \Delta h}{C_{v} T_{1}}
$$

where

$$
\begin{array}{rll}
\Delta P & =\text { Pressure rise, } \mathrm{Pa} \\
P & =\text { Initial pressure, } \mathrm{Pa} \\
C_{v} & =\text { Average heat capacity, } \mathrm{J} / \mathrm{kg} \text {-mole- } \mathrm{K} \\
T_{1} & =\text { Initial temperature, } \mathrm{K} \\
F_{v} & =\text { Fraction of volume occupied gas that burns } \\
\Delta h & =\text { Heat of reaction, } \mathrm{J} / \mathrm{kg} \text {-mole }
\end{array}
$$

For the gases of interest, the pre-burn number of gas moles is nearly equal to the post-burn number of gas moles, allowing the expression above, and for the moderate temperature change a constant specific heat is appropriate.

\subsection{RESULTS}

Allowing a pressure rise of $4.3 \mathrm{psig}$ yields a burned flammable gas volume fraction:

$$
F_{v}=\left(\frac{4.3}{14.5}\right) \frac{(30 \mathrm{e} 3)(300)}{(426.8 \mathrm{e} 6)}=6.25 \mathrm{e}-3
$$

Multiplying by the headspace volume of 1400 cubic meters and by 3 for the combustion completeness yields a total release volume of 26.3 cubic meters or about $927 \mathrm{SCF}$, which at 500 $\mathrm{SCF} /$ inch is equivalent to a level rise of 1.85 inches. 


\section{采}

Fauske \& Assuciates, Inc.

DATE: $\quad$ August 9, 1996

TO: Jolnn Harris \& John Conner - WHC

FROM: Martin G. Plys \& Boro Malinosic MNAty

SUBJECT: Incomplete Combustion Model

This memorandum discusses the FAI incomplete combustion model and its application to C-106 and AY-102. The model and its validation are described in detail in the references.

\subsection{FaI Incomplete Combustion Model}

The FAI incomplete combustion model is strictly applicable for premixed gases. It accounts for:

Combustion morphology - experimental observation of the behavior of the bumed gases, which form a fireball that grows and accelerates upward from the ignition point,

Gas composition - which affects the tlame speed,

Geometry - which affects the distance a flame front travels before quenching, and includes the effect of the height/diameter aspect ratio,

Turbulence - which affects the burning rate by increasing entrainment, and Temperature - which affects the flame speed but is unimportant for this application.

Mathematical details of the model are contained in the references.

The model was validated for experimental data on a variety of scales in order to determine appropriate coefficient values for reactor safety application. The key finding was 
that turbulent gases required larger values of the flame flux multiplier than quiescent gases in order to match the combustion completeness.

Recall that incomplete combustion is expected when the well-mixed hydrogen concentration is below about $8 \%$. In the discussion below, it is assumed that the gas release volume is low enough that the well-mixed concentration is below the lean flammability limit of $4 \%$, so that flammability is only possible in the first place in a fraction of the tank headspace where released gases initially mix with headspace gases.

\subsection{Tank Applicatlon Versus Experiments}

The most important aspects of Hanford tank application are:

1. Geometry. Tank headspaces have relatively small height/diameter aspect ratios. This leads to a low combustion completeness because a growing, accelerating fireball will only occupy a small fraction of a volume with large radial extent, whereas it could occupy most of a volume whose radial extent equals the fireball radius. During incomplete combustion, quenching occurs at the tank walls and dome.

2. Turbulence. Some turbulence is expected as lighter flammable gases mix with and rise upward into heavier headspace gases; this promotes greater combustion completeness.

3. Nonuniform concentration. Concentrations are clearly nonuniform in the mixing region, with the largest concentrations of flammable gas being at the waste surface. If the release is over a non-trivial fraction of the tank surface area, as with a rollover GRE, then mixing of the rising gases occurs with overlying headspace gases and entrainment from the perimeter is negligiblc; a discrete plune where perineter entrainment is important is not applicable for a rollover GRE case. The flammable gas concentration is fairly uniform at any given axial elevation, and is basically only a function of height. This implies that a fireball originating from an ignition source near the waste surface would rise by buoyancy and eventually attain elevations where the average concentration lies bejow the LFL, unless the dome were encountered first; quenching would occur in either case.

Compared to the experiments used to validate the model, the Hanford tank aspect ratio implies lower combustion completeness than observed. The nonunifonn concentration wherc fuel content declines with elevation has a similar implication. Turbulence due to 
mixing implies that experiments with quiescent atmospheres would provide a lower bound on combustion completeness, and experiments with fan-induced turbulence would provide an upper bound on combustion completeness.

\subsection{Tank Calculations}

The FAI model was applied for various headspace heights and a uniformly mixed hydrogen concentration of $6 \%$ with results as shown in the table. The turbulent results were calculated using a flame flux multiplier of 10 , the value recommended to account for intense turbulence induced by large fans or spray systems. The highest combustion completeness was just under $11 \%$, for a turbulent, well-mixed headspace and a 5 meter vertical distance between the ignition point and dome.

\subsection{References}

Plys, M.G., et al, "A Flammability and Combustion Model for Integrated Accident Analysis," Proc. Int. Conf. Thermal Reaclor Safely, Avignon, France, Oct. 2-7.

Plys, M.G. and Astleford, R.D., "Modifications for the Development of the MAAP-DOE Code Volume III: A Mechanistic Model for Combustion in Integrated Accident Analysis," U.S. Department of Energy Advanced Reactor Severe Accident Program, DOE/ID-10215, Vol. MII, November 1988.

\section{MGP/BM:vdI}

cc: M. Epstein

H. Fauske

R.E. Henry 


\begin{tabular}{|c|c|c|c|c|c|c|c|c|c|c|c|c|}
\hline Case & $\begin{array}{c}\text { Conceolration } \\
\text { (S) }\end{array}$ & Flume & $\begin{array}{l}\text { Height } \\
\text { (m) }\end{array}$ & $\begin{array}{c}\text { Valume } \\
\left(\mathrm{m}^{3}\right)\end{array}$ & $\begin{array}{c}T_{\text {start }} \\
\text { (s) }\end{array}$ & $\begin{array}{c}T_{\text {end }} \\
(5)\end{array}$ & $\begin{array}{c}\text { Initial } \mathrm{H}_{2} \\
(\mathrm{~kg})\end{array}$ & $\begin{array}{c}\text { Finsl } I_{2} \\
\left(\mathrm{~K}_{\mathrm{b}}\right)\end{array}$ & $\begin{array}{l}\text { Inllial P } \\
(x \in E S P a)\end{array}$ & $\begin{array}{c}\text { Final } \mathrm{P} \\
(\mathrm{x} \mid \mathrm{ES} \mathrm{Pa})\end{array}$ & $\begin{array}{l}\text { Combustion } \\
\text { Completeness } \\
\text { (\$) }\end{array}$ & $\begin{array}{l}\text { Pressure } \\
\text { (x1Es Pa) }\end{array}$ \\
\hline 1 & 6 & Laminar & 3 & 1233 & 6.22 & 7.28 & 6.21 & 6.02 & 1.098 & 1.159 & 3.0 & 0.061 \\
\hline 2 & 6 & Laminas & 4 & 1644 & 8.29 & 9.59 & 8.28 & 7.85 & 1.097 & 1.205 & 52 & 0.108 \\
\hline 3 & 6 & Laminar & 5 & 2055 & 10.36 & 11.86 & 10.35 & 9.54 & 1.097 & 1259 & 7.8 & 2.162 \\
\hline 4 & 6 & Turbulen1 & 3 & 1233 & 6.22 & 6.92 & 6.21 & 5.96 & 1.099 & 1.179 & 3.9 & 0.08 \\
\hline 5 & 6 & Turbulen: & 4 & 1644 & 8.29 & 9.15 & 8.28 & 7.72 & 1.097 & 1.237 & 6.8 & 0.14 \\
\hline 6 & 6 & Turbujent & 5 & 2055 & 10.36 & 11.37 & 10.35 & 0.24 & 1.097 & 1.318 & 10.8 & 0.221 \\
\hline
\end{tabular}


From: Process Engineering Analys is

Phone: $\quad 376-2527$ HO-34

Date: July 12, 1996

Subject: $W-320$ AND $W-030$ DESIGN INTEGRATION

To:

J. P. Harris

$\begin{array}{ll}\text { cc: W. Abdui } & 57-53 \\ \text { J. W. Bailey } & 52-48 \\ \text { R. J. Cash } & S 7-15 \\ \text { J. C. Conner } & \text { A2-25 } \\ \text { R. L. Fritz } & \text { S2-12 } \\ \text { J. R. Kriskovich } & 52-24 \\ \text { G. A. Meyer } & \text { S2-48 }\end{array}$

S7-15
D. M. Ogden

$\mathrm{H} 0-34$

H5- 49

G3-I2

R1-56

RI-56

R2-54

HO- 34

References: (I) Internal Memo, K. Sathyanarayana to J. C. Conner, "Current Status of Thermal Hydraulics Analysis and results in support of the safety documentation for Project W-320," dated September 20, 1995.

(2) Sathyanarayana, K., and Brent C. Fryer, 1996, "Thermal Hydraul ic Evaluation of Consolidating Tank C-106 Waste into Tank AY-102," WHC-SD-WM-ER-534, Rev.0, Westinghouse Hanford Company, Richland, Washington.

(3) cc:Mail, J. P. Harris, III to K. Sathyanarayana, "Re: AY-102 Ventilation Questions/Answers," dated July 3, 1996.

Purpose:

The purpose of the analysis is to provide a technical basis for using the Project $W-030$ ventilation system under Project $W-320$ conditions to 1 imit peak sludge temperatures below ISOR limits.

\section{Problem Description:}

The previous thermal-hydraulic analysis was performed to provide a technical basis supporting the transfer of tank C-106 waste into tank AY-102 (Ref. 1). It has been assumed, based on the project assurances, that the project $\mathrm{W}-030$ ventilation system can provide up to about $600 \mathrm{cfm}$ of primary ventilation flow with ambient inlet air temperature and humidity conditions when operated in the once-through mode. Using the same volumetric flow rate, safety analysis calculations (Ref. 2) were also performed for accident conditions such as loss of ventilation and to estimate the floor cooling channel effectiveness. However, now we have been informed (Ref.3) that the W-030 system at best can only provide a total of $500 \mathrm{cfm}$ with $200 \mathrm{cfm}$ of ambient air and $300 \mathrm{cfm}$ of recirculation air flow. The operation of the $W-030$ system in recirculation or in once-through mode, as pointed out in Reference 2 is less effective in providing cooling compared to the current 
J. P. Harris, III

Page 2

July 12,1996

702-A system since air flow rates are lower and the tank inlet air conditions are worse than for the current system. For the same heat and sludge loading conditions, it should be expected that the operation of the $W-030$ system would increase the sludge peak temperatures and reduce the thermal safety margins available. In order to assess the magnitude of the increase to the earlier estimates of peak sludge temperatures for the consolidated waste in tank $A Y-102$ and to provide data for making engineering judgements to mitigate this problem, several parametric calculations were performed using expected normal and best inlet air flow conditions for the tank (Ref. 3) with the operation of the W-030 system and using increased secondary ventilation air flows for tank floor cooling.

\section{Results:}

Steady-state temperature distribution calculations for the consolidated sludge in tank $A Y-102$ were performed assuming that $4.8 \mathrm{ft}$ of $\mathrm{C}-106$ sludge with a heat load of $92,400 \mathrm{Btu} / \mathrm{h}$ has been transferred to tank $A Y-102$, and the transferred sludge will settle to twice its original thickness (Fluffiness Factor $=2$ ). This transfer will leave $1.2 \mathrm{ft}$ of bottom sludge having a heat load of less than $40,000 \mathrm{Btu} / \mathrm{h}$ in tank $\mathrm{C}-106$. The details of other parameters of the current waste in tank AY-102, tank C-106, and the estimated parameters of the consolidated waste in tank AY-102 are given in Table 1. For a given set of inlet air flow conditions of the primary ventilation system and specified air flow rate of tank floor cooling, the combined waste temperature distribution in tank AY-102 is estimated using cooling channel effectiveness as a parameter. For 2000 and $3000 \mathrm{cfm}$ air flow rates, the floor cooling channel effectiveness values (Ref. 2) were estimated to be about $37 \%$ and $32.5 \%$, respectively. For the $2500 \mathrm{cfm}$ flow, it is assumed that the effectiveness will be $35 \%$. The waste saturation temperatures were calculated assuming vapor pressure characteristics of waste as that of water. The Interim 0perational Safety Requirements (IOSR) document for the tank farms specifies the limits on sludge peak temperature based on the local saturation temperature/boiling point to eliminate the potential for a tank bump. The peak sludge temperature must be $17^{\circ} \mathrm{C}$ $\left(30^{\circ} \mathrm{F}\right)$ less than the local saturation temperature.

The results of the calculations are summarized in the Table 2 . The table provides the estimated peak sludge temperatures and the corresponding margin available for each case of air inlet flow conditions of both the primary ventilation flow to the tank dome and the secondary ventilation flow for tank floor cooling. The sludge temperature distribution for average summer inlet flow conditions of $630 \mathrm{cfm}$ flow for the primary ventilation system and 2000,2500 and $3000 \mathrm{cfm}$ air flow through the tank floor cooling channels is shown in Figures 1 through 3 with cooling effectiveness as a parameter. These air flow inlet conditions correspond to the current 702-A ventilation system or what the new system is supposed to provide if operated in oncethrough mode. For the W-030 new ventilation system operation, assuming that the primary ventilation air entering the tank will be at $83{ }^{\circ} \mathrm{F}$ and $100 \%$ relative humidity with a flow rate of $500 \mathrm{cfm}$ and the secondary ventilation flow of 2000,2500 , and $3000 \mathrm{cfm}$, the results of sludge temperature distribution is shown in Figures 4 through 6 , respectively. The s] udge peak temperature vaiues have increased by about 7 to $10^{\circ} \mathrm{F}$ and therefore, 
J. P. Harris, III

$74 A 50-96-K S-018$

Page 3

JuTy 12, 1996

Table 1. Tank Waste Parameters of AY-102 and C-106.

1. Current Waste in Tank AY-102

Waste Volume: $\quad 812,000$ gallons $(24.57 \mathrm{ft})$

Sludge Volume: 32,000 gallons $(0.97 \mathrm{ft})$

Supernatant Volume: $780,000 \mathrm{gallons}(23.6 \mathrm{ft})$

Waste Surface Level: 295 inches

Tank Heat Load: $33,000 \mathrm{Btu} / \mathrm{h}$

2. Current Waste in Tank C-106

Waste Volume: $219,000 \mathrm{gall}$ ons $(6.64 \mathrm{ft})$

Sludge Volume: 197,000 gallons $(5.97 \mathrm{ft})$

Supernatant Volume: 22,000 gallons $(0.67 \mathrm{ft})$

Insoluble Solids Concentration: 48 wt\%

Density of Insoluble Solids: $100.31 \mathrm{bm} / \mathrm{ft}^{3}$

Tank Heat load: 132,400 Btu/h $(\sim 110,000+20 \%)$.

Heat Load Distribution:

Top Layer: $2.78 \mathrm{ft}, 22,147 \mathrm{Btu} / \mathrm{h}$

Middle Layer: $1.32 \mathrm{ft}, 45,738 \mathrm{Btu} / \mathrm{h}$

Bottom Layer: $1.87 \mathrm{ft}, 64,515 \mathrm{Btu} / \mathrm{h}$

3. Consolidated Waste in Tank AY-102

Sludge

Bottom Layer: AY-102 Sludge

Sludge Height: $1 \mathrm{ft}$

heat Load: $33,000 \mathrm{Btu} / \mathrm{h}$

Thermal Conductivity: $0.35 \mathrm{Btu} / \mathrm{hr}-\mathrm{ft}-{ }^{\circ} \mathrm{R}$

Top Layer: Transferred $\mathrm{C}-106$ Sludge

Sludge Height: $9.62 \mathrm{ft}$

Fluffiness Factor: 2

Heat Load: $92,400 \mathrm{Btu} / \mathrm{h}$ (Heat load remained in $\mathrm{C}-106=40,000 \mathrm{Btu} / \mathrm{h}$

Thermal Conductivity: $0.43 \mathrm{Btu} / \mathrm{hr}-\mathrm{ft}-{ }^{\circ} \mathrm{R}$

Total Waste Volume: $10^{6}$ gallons $(30.0 \mathrm{ft})$ 
Table 2. Tank AY-102 Consolidated Sludge Peak Temperatures and Potentiai Margin from Local Saturation Temperature.

\begin{tabular}{|c|c|c|c|c|c|c|}
\hline \multirow{2}{*}{$\begin{array}{c}\text { Floor } \\
\text { cool ing } \\
\text { channel } \\
\text { flow } \\
\text { (cu } \mathrm{ft} / \mathrm{min} \text { ) }\end{array}$} & \multicolumn{2}{|c|}{$\begin{array}{c}\text { Primary vent } f \text { low } 630 \mathrm{cfm} \text { at } \\
70 \% \mathrm{ond} 50 \% \text { relative } \\
\text { humidity }\end{array}$} & \multicolumn{2}{|c|}{$\begin{array}{l}\text { Primary vent flow of } 500 \\
\text { cfm at } 83 \text { o f and } 100 \% \\
\text { relative humidity }\end{array}$} & \multicolumn{2}{|c|}{$\begin{array}{l}\text { Primary vent flow of } 500 \\
\text { cfm at } 76 \text { of and } 75 \% \\
\text { relative humidity }\end{array}$} \\
\hline & $\begin{array}{c}\text { Peak sludge } \\
\text { temperature } \\
\left({ }^{\circ} \mathrm{F}\right) \\
\end{array}$ & $\begin{array}{l}\text { Margin from } \\
\text { loca! Tsat } \\
\text { ( } F)\end{array}$ & $\begin{array}{c}\text { Peak sludge } \\
\text { temperature } \\
(\mathrm{F}) \\
\end{array}$ & $\begin{array}{c}\text { Margin from } \\
\text { local Isat } \\
(\mathrm{F})\end{array}$ & $\begin{array}{l}\text { Peak sludge } \\
\text { temperature } \\
\left({ }^{\circ} \mathrm{F}\right)\end{array}$ & $\begin{array}{l}\text { Margin from } \\
\text { Local Tsat } \\
(\text { O } F)\end{array}$ \\
\hline 2000 & 201 & 42 & 209 & 32 & 206 & 36 \\
\hline 2500 & 195 & 48 & 202 & 40 & 199 & 43 \\
\hline 3000 & 190 & 53 & 199 & 42 & 196 & 46 \\
\hline
\end{tabular}

correspondingly reduced the margin for example, with $2000 \mathrm{cfm}$ tank floor cooling flow from 42 to $32^{\circ} \mathrm{F}$. Under these primary air flow conditions, it requires that the cooling air flow through the tank floor channels has to be increased up to $3000 \mathrm{cfm}$ to maintain the same margin.

Due to features of the evaporative tower control system, it is reported (Ref. 3) that the $W-030$ recirculation ventilation air supply to the tank can be as low as $75^{\circ} \mathrm{F}$ (saturated). If the recirculation loop is operated at its design flow of $500 \mathrm{cfm}$ with $300 \mathrm{cfm}$ supplied to the tank through the recirculation loop and $200 \mathrm{cfm}$ ambient air flow, then the effective mixed air flow conditions (Ref. 3) will be $500 \mathrm{cfm}$ flow rate at $76^{\circ} \mathrm{F}$ and $75 \%$ relative humidity. Using these tank inlet air flow conditions for the primary ventilation system, the sludge temperature distribution calculations were performed for 2000,2500 , and $3000 \mathrm{cfm}$ secondary ventilation flow rates, and the results are shown in Figures 7 through 9 , respectively. As summarized in Table 2, the peak sludge temperatures were reduced by $3{ }^{\circ} \mathrm{F}$ and the corresponding improvement in the margin compared to normal operating conditions of the $W-030$ system. Based on these results, if the $W-030$ system can be operated to provide these effective inlet flow conditions for the primary air flow, then to maintain the same temperature margin of $42{ }^{\circ} \mathrm{F}$ for the peak sludge temperature, the secondary ventilation flow for tank floor cooling should be increased to at least $2500 \mathrm{cfm}$.

Conclusions:

The peak temperature in the consolidated sludge of tank AY-102 will be about $209{ }^{\circ} \mathrm{F}$ with the normal operation of the $\mathrm{W}-030$ new primary ventilation system at design conditions with $100 \mathrm{cfm}$ ambient air flow and $400 \mathrm{cfm}$ recirculation flow having effectively tank inlet flow conditions of $83^{\circ} \mathrm{F}$ and $100 \%$ relative humidity. This peak temperature corresponds to $2000 \mathrm{cfm}$ secondary ventilation flow for tank floor cooling and the temperature margin from local saturation will be very close to the IOSR requirement of $30^{\circ} \mathrm{F}$. This margin can be improved either by increasing the secondary flow rate and/or operating the $W-030$ system at best conditions to provide lower temperature 
HNF-SD-WM-RPT-293 REV 0

J. P. Harris, III

$74 A 50-96-K S-018$

Page 5

JuTy 12,1996

and relative humidity conditions for the tank inlet air flow. Based on the results of these calculations, it is recommended that the secondary ventilation air flow rate be increased from $2000 \mathrm{cfm}$ to $2500 \mathrm{cfm}$ to maintain the same margin for the peak sludge temperature from the saturation value.

L Saltutinaray $\cdot 7 / 12 / 96$

K. Sathyanarayana, Fellow Engineer

Process Engineering Analysis

bab

Attachment

CONCURRENCE:

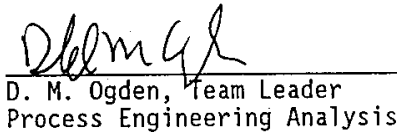

Date: $7 / 12196$ 
HNF-SD-WM-RPT-293 REV 0

This page intentionally left blank. 
HNF-SD-WM-RPT-293 REV O

74A50-96-KS-018

ATTACHMENT

Figures 1 - 9

Consisting of 10 pages, including cover page 
Figure 1. Temperature Distribution in S1udge Layer of Tank AY-102 with Annulus Ventilation Flow Effectiveness as a Parameter for Secondary Ventilation Flow of $2000 \mathrm{cfm}$.

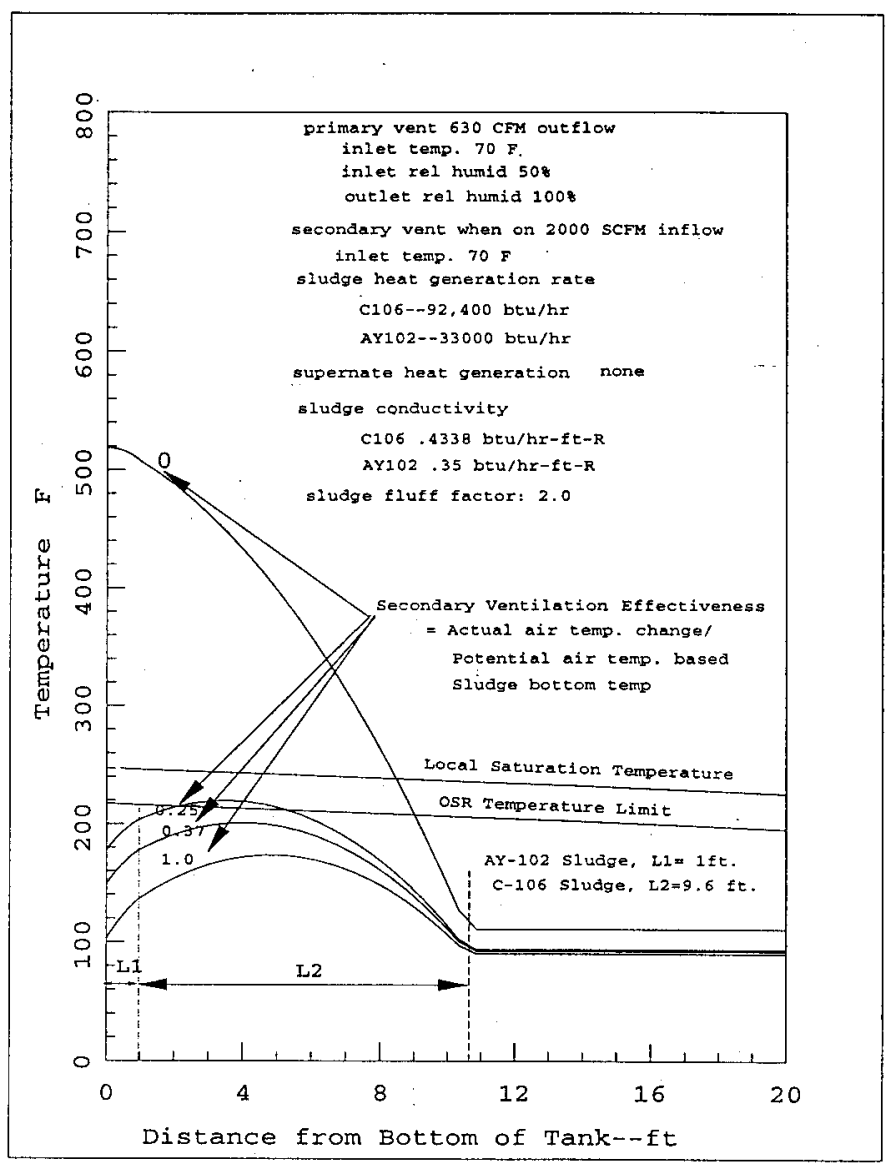


Figure 2. Temperature Distribution in Sludge Layer of Tank AY-102 with Annulus Ventilation Flow Effectiveness as a Parameter for Secondary Ventilation Flow of $2500 \mathrm{cfm}$.

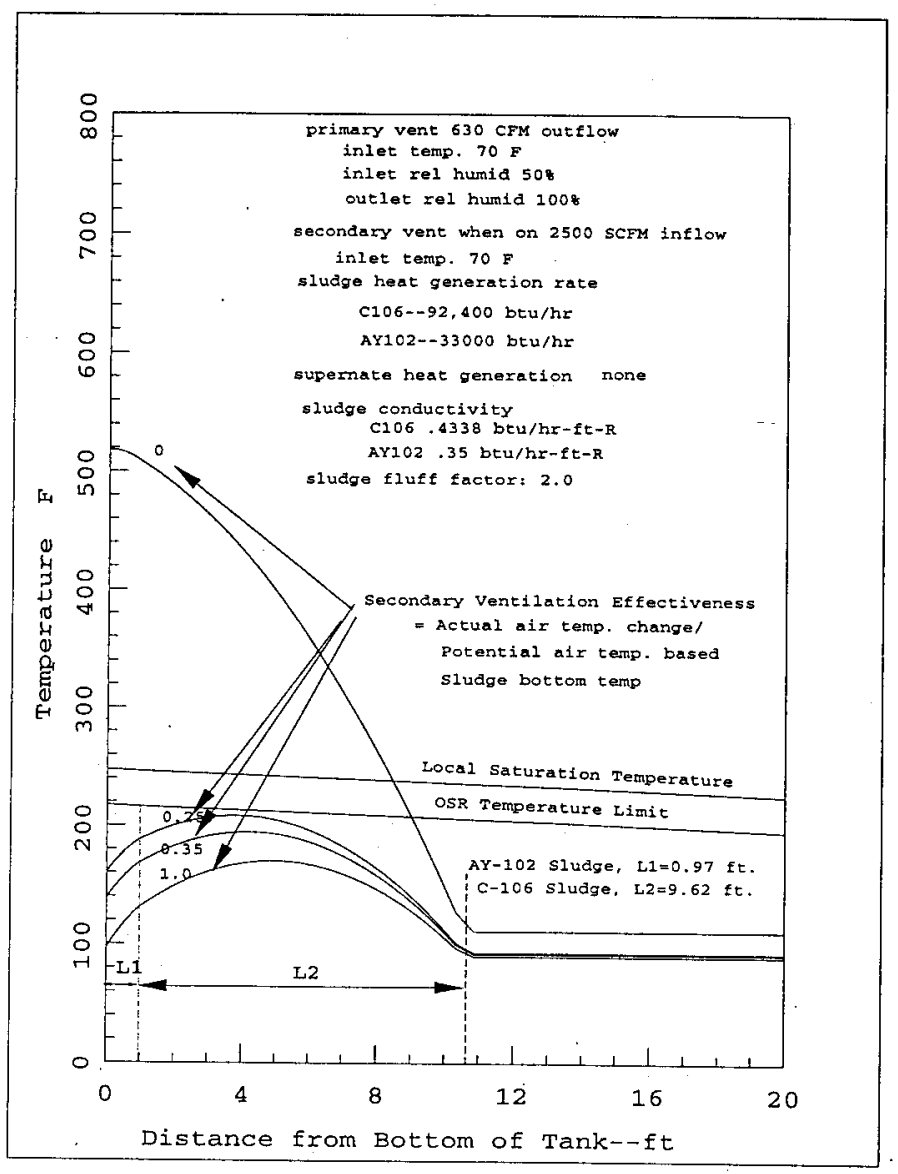


Figure 3. Temperature Distribution in Sludge Layer of Tank AY-102 with Annulus Ventilation Flow Effectiveness as a Parameter for Secondary Ventilation Flow of $3000 \mathrm{cfm}$.

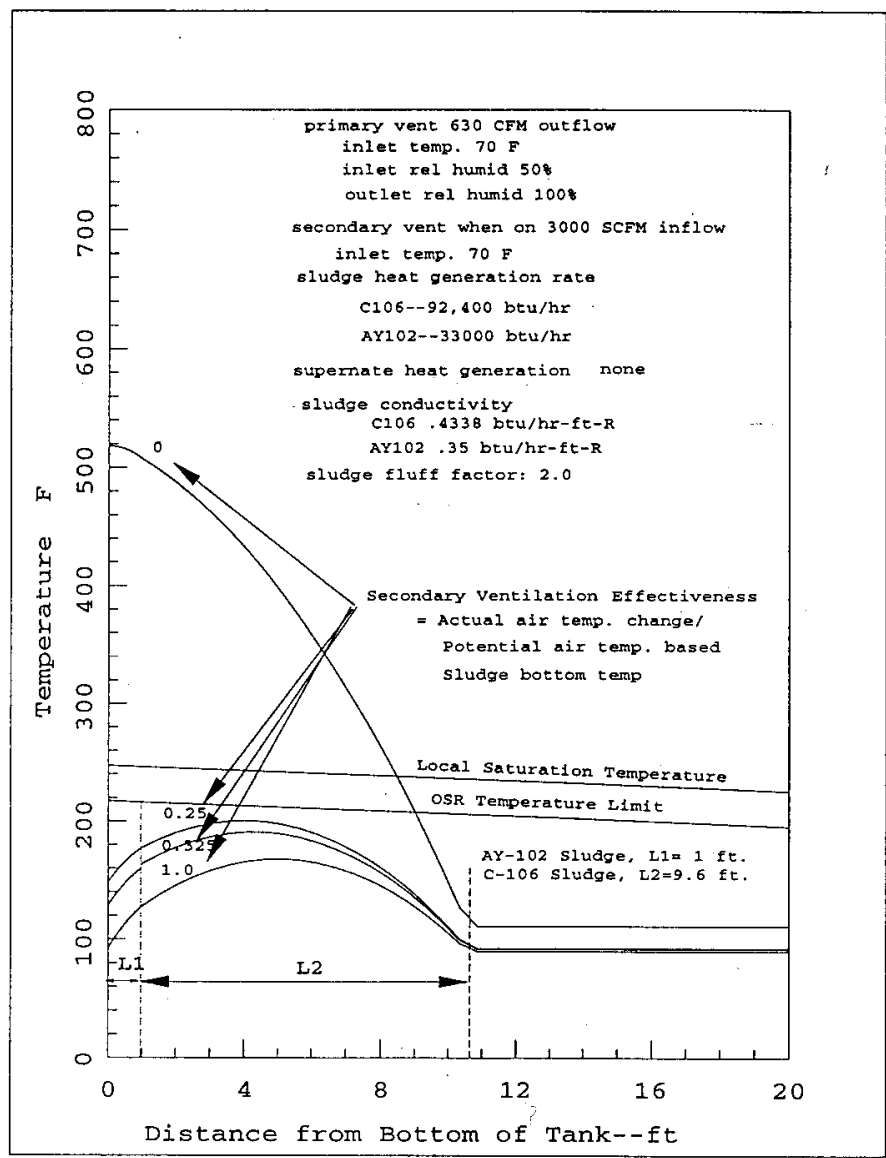


Figure 4. Temperature Distribution for the Combined Siudge of AY-102 and c-106 Using $500 \mathrm{cfm}$ Primary and $2000 \mathrm{cfm}$ Annulus Ventilation Flow.

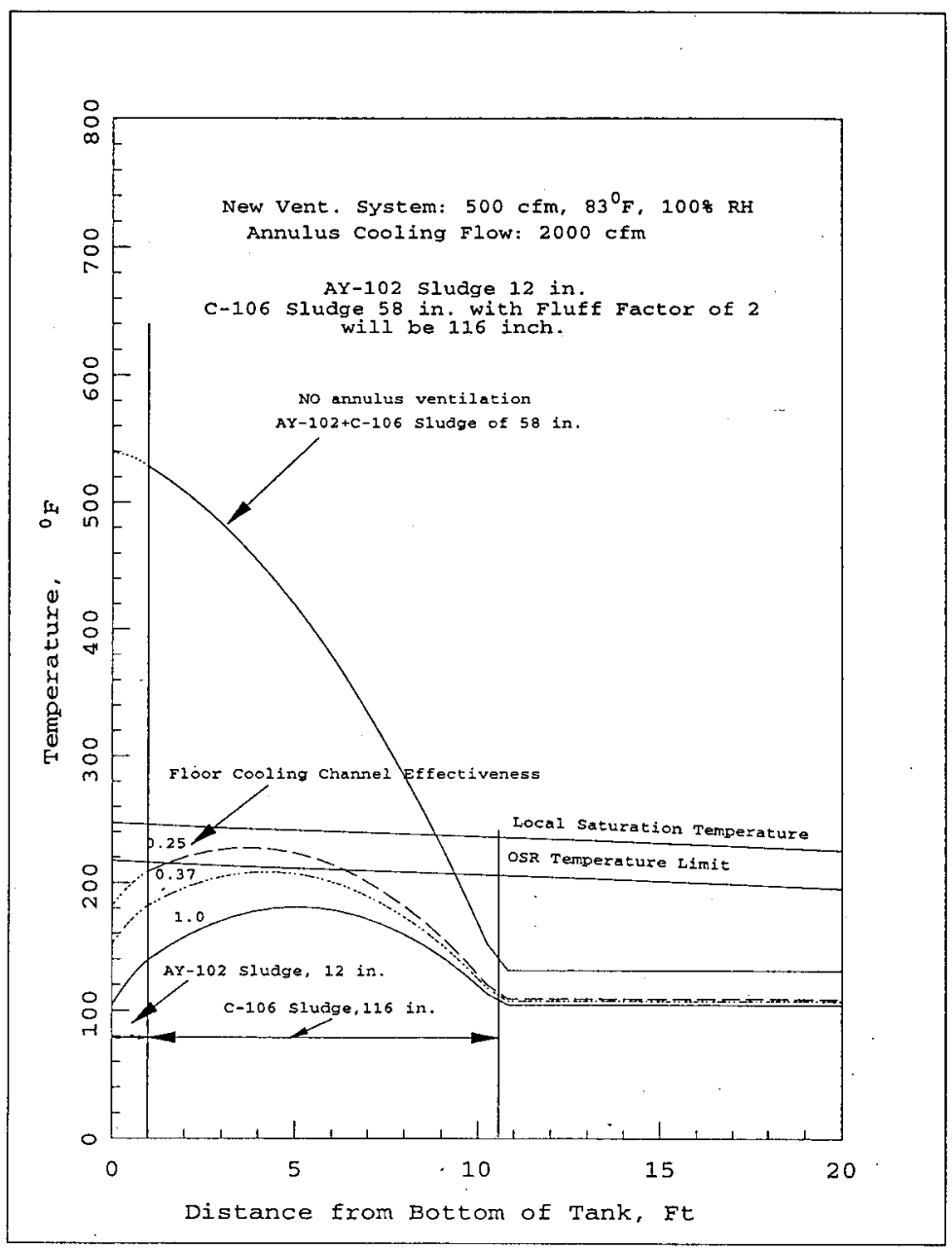


Figure 5. Temperature Distribution for the Combined sludge of $A Y-102$ and C-106 Using $500 \mathrm{cfm}$ Primary and $2500 \mathrm{cfm}$ Annulus Ventilation Flow.

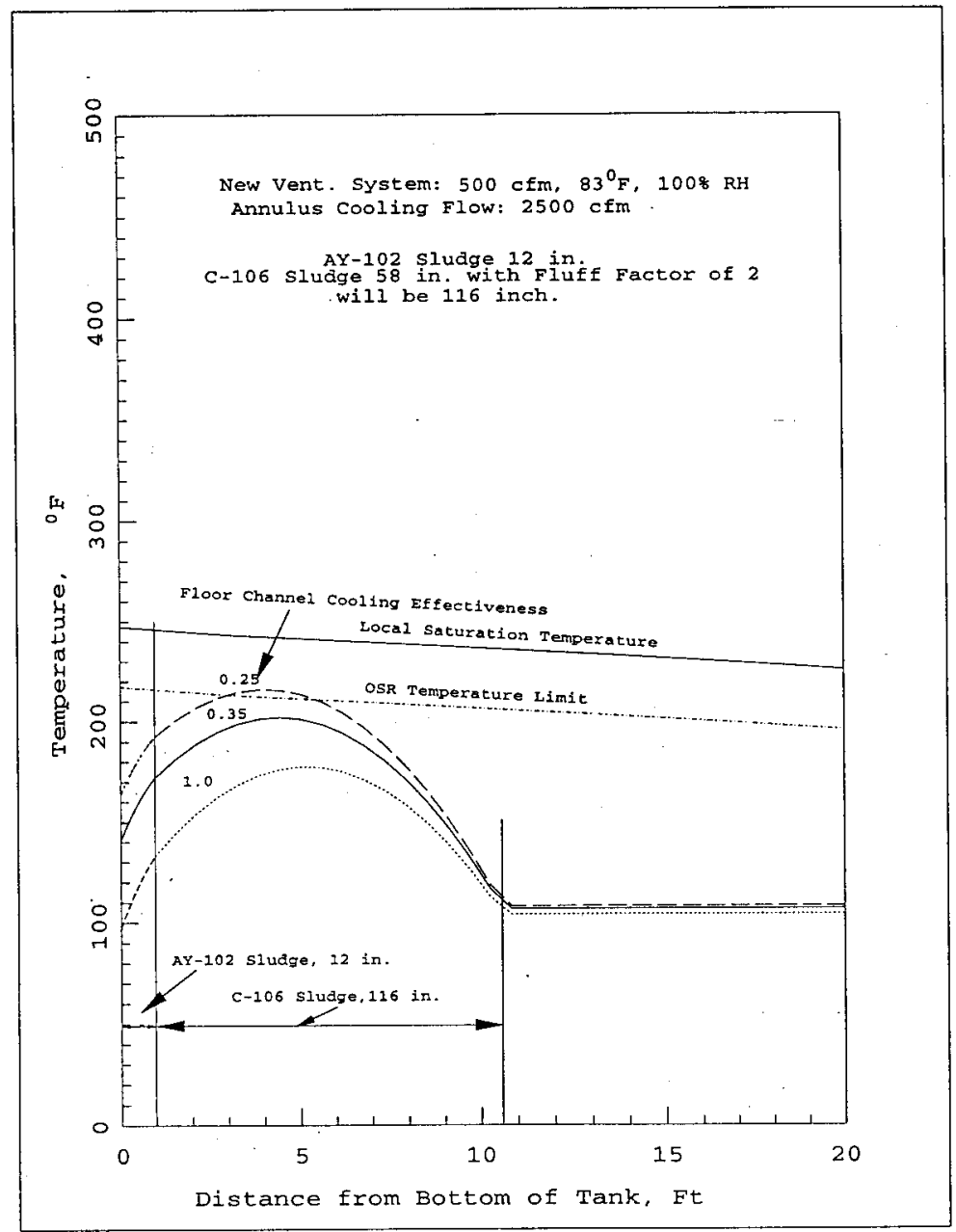


Figure 6. Temperature Distribution for the Combined Siudge of $A Y-102$ and C-106 Using $500 \mathrm{cfm}$ Primary and $3000 \mathrm{cfm}$ Annulus Ventilation Flow.

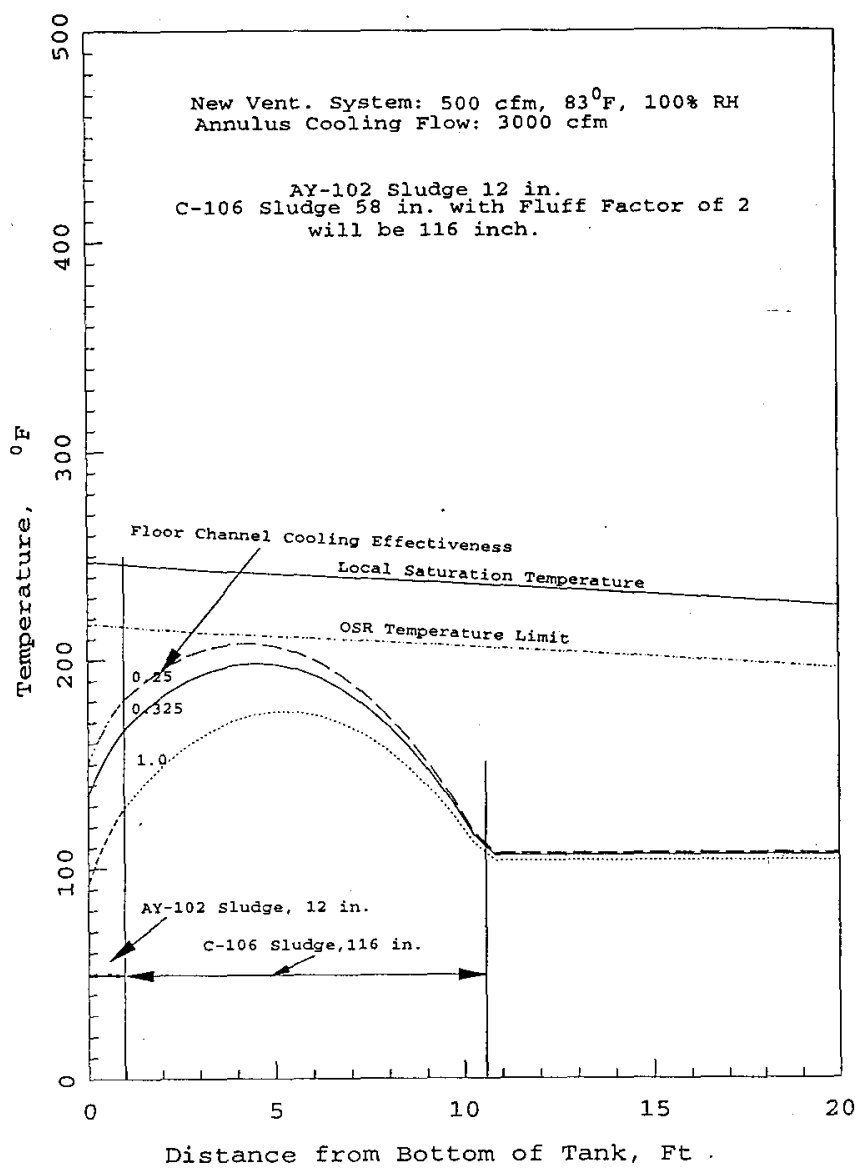


Figure 7. Temperature Distribution for the Combined Sludge of AY-102 and C-106 Using $500 \mathrm{cfm}$ Primary and $2000 \mathrm{cfm}$ Annulus Ventilation Flow.

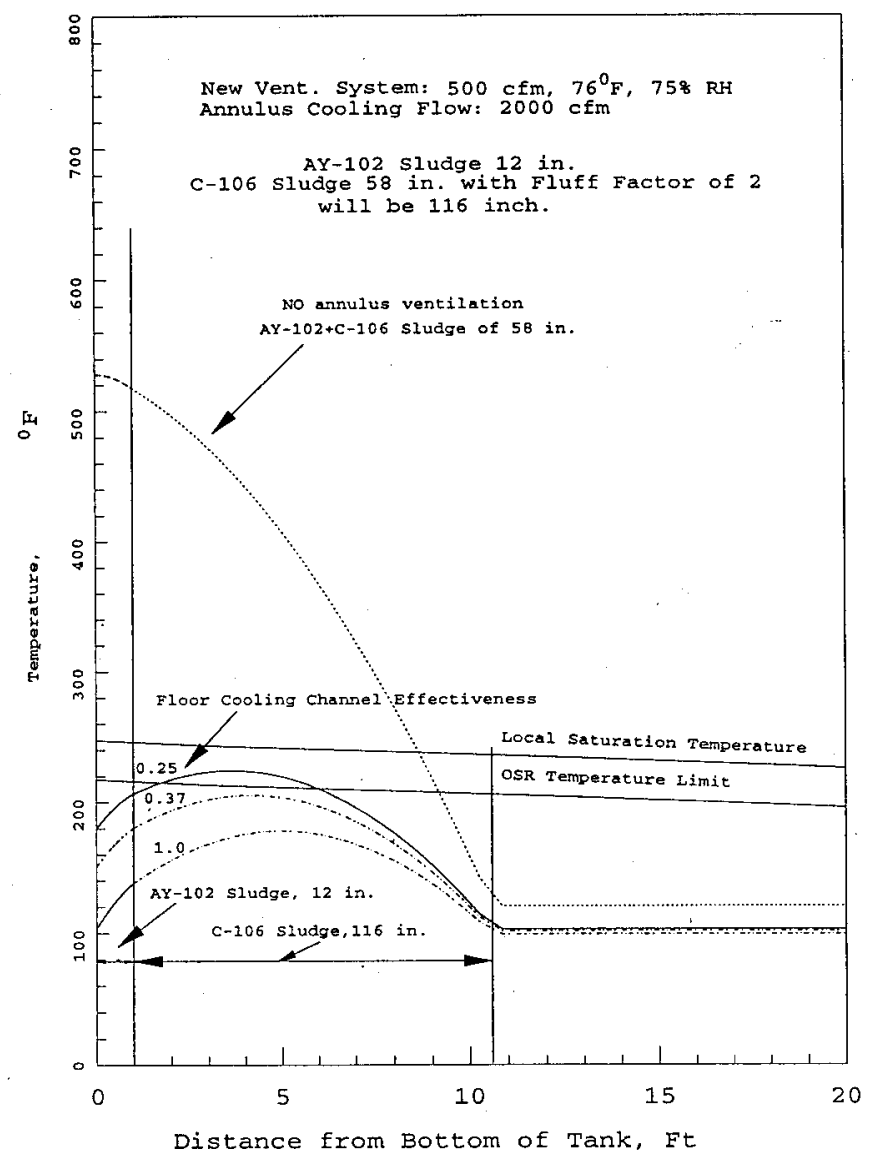


Figure 8. Temperature Distribution for the Combined Sludge of $A Y-102$ and c-106 Using $500 \mathrm{cfm}$ Primary and $2500 \mathrm{cfm}$ Annulus Ventilation Flow.

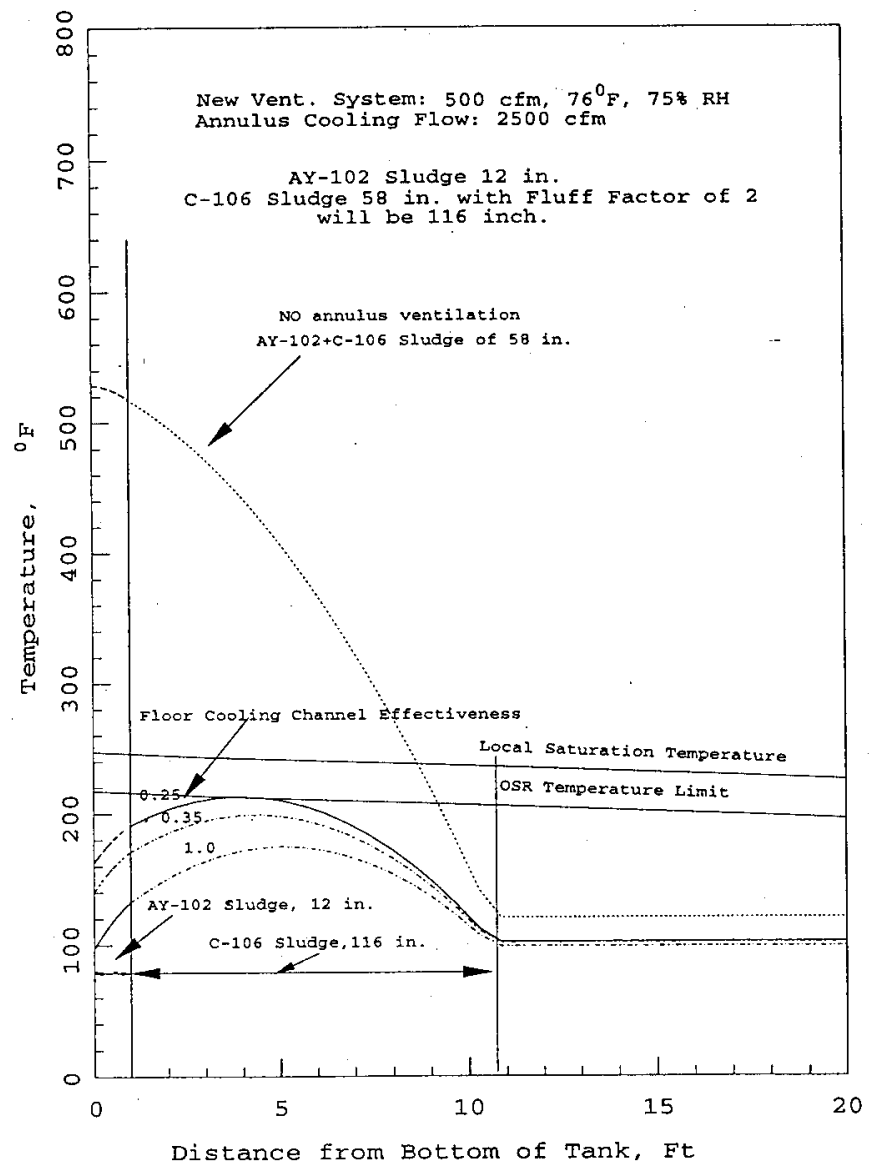


Figure 9. Temperature Distribution for the Combined Sludge of AY-102 and C-106 Using $500 \mathrm{cfm}$ Primary and $3000 \mathrm{cfm}$ Annulus Ventilation Flow.

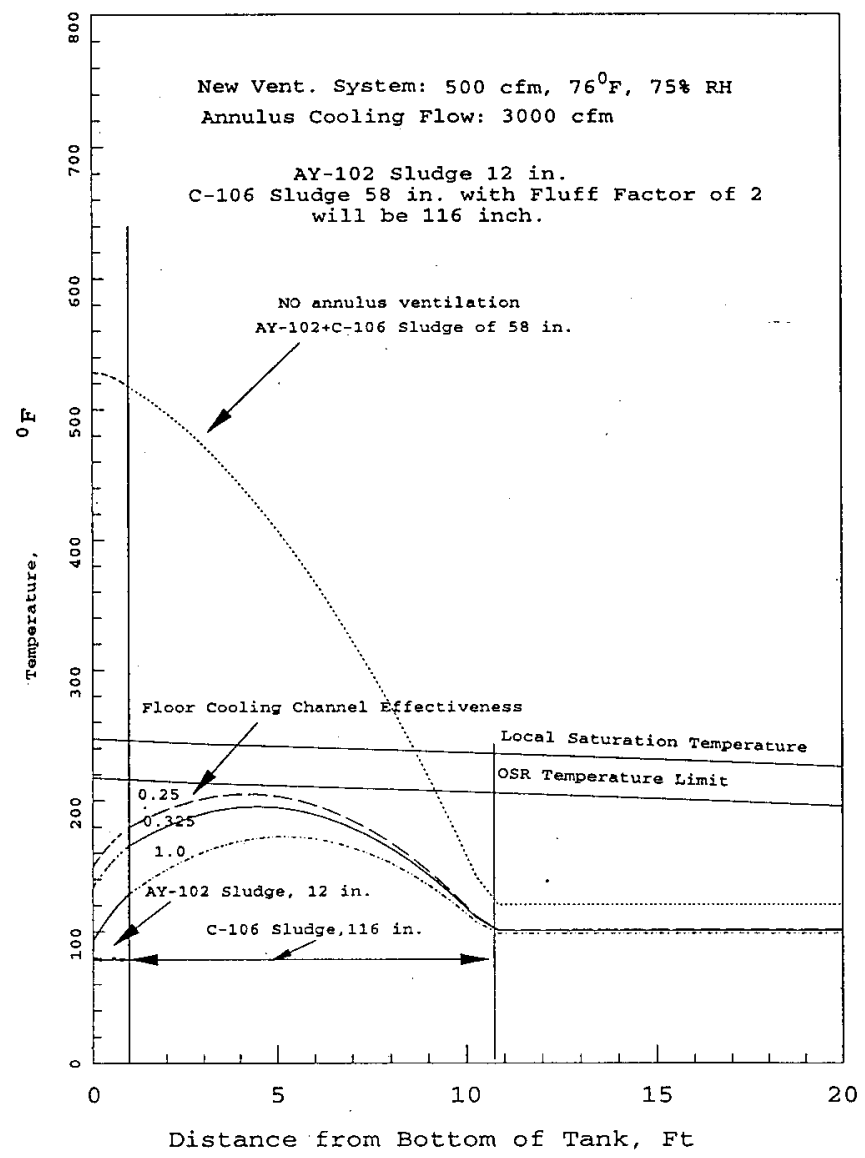


From: Double-Shell Tank Safety Analysis

Phone: $\quad 376-2613$ H4-63

Date: January 11,1994

Subject: SAFETY CLASSIFICATION OF THE STANDARD HYDROGEN MONITORING SYSTEM FOR FLAMMABLE GAS WATCH LIST TANKS

To:

R. E. Clayton

$\begin{array}{llll}\text { R. E. Clayton } & \text { S1-54 } & & \\ \text { cC: K. O. Fein } & H 4-63 & \text { R. J. Kidder } & H 4-61 \\ \text { K. O. Gibson } & H 4-61 & \text { D. T. Lott } & R 3-49 \\ \text { J. M. Grigsby } & H 4-62 & \text { R. H. Reed } & R 1-51 \\ \text { J. A. Hurley } & \text { R3-49 } & \text { T. C. Schneider } & \text { L7-04 } \\ \text { M. N. Islam } & \text { R3-08 } & \text { M. H. Shannon } & H 4-61 \\ \text { RJVV File/LB } & & & \end{array}$

29140-94-001

This letter provides the safety classification of the standard hydrogen monitoring system. This is a piece of monitoring equipment to be instalied on both single-shell and double-shell flammable gas watch list tanks.

To date, a controversy exists for safety classification of monitoring equipment. It is well recognized that the failure of the equipment itself usually does not create an immediate consequence. However, if the failed monitoring equipment is not fixed, potential changes in the tank (waste level, temperature, or in this case flammable gas generation) could lead to an unsafe condition that potentially could cause a safety class 2 or possibly safety class 1 consequence to occur. This issue is currentiy under negotiation with the U.S. Department of Energy.

The first standard hydrogen monitoring systems were installed on Tank 241-SY-101 (101-SY). The safety basis documentation for this is contained in the following places.

WHC-SD-WM-SAD-003, Rev. 3, Safety Assessment for Window $B$ Activities in Tank 101-SY, describes installation of probe assembities into the tank (these will be used for single-shell tanks) and installation of instrumentation in the exhaust header (the approach to be used for double-shell tanks).

\footnotetext{
WHC-SD-WM-SAD-007, Rev. 1, Safety Assessment for Operation of the Temporary GaS Monitoring System in Tank 101-SY, describes the components used to make up the temporary gas monitoring system. The same or similar components were used to make the standard hydrogen monitoring system.
}

External letter 9255759, "Safety Documentation for Non-Pump Work in Tank 241-SY-101, Window G," from D. C. Richardson to R. E. Gerton, dated July 31,1993 , contained an attachment entitled 
removal of the standard hydrogen monitoring system. The U.S. Department of Energy (both $\mathrm{HQ}$ and RL) authorized installation for Tank 101-SY.

External letter 9308225B R1, "PLANNED WORK ACTIVITIES FOR TANK 24I-SY-103," from H. D. Harmon to J. H. Anttonnen, dated November 24, 1993, contained an attachment entitled "8asis for Installation, Operation, and Repair of Standard Hydrogen Monitoring Systems in the SY Tank Farm." The U.S. Department of Energy, Richland Field office, authorized the installation for Tank 103-SY.

The standard hydrogen monitoring systems to be installed on the other flammable gas watch list tanks present no new irazards that have not already. been analyzed in the above mentioned document. All components of the system meet the specifications of the National Fire. Protection Association National Electric lode for use in Class 1. Uivision 1, Group 8 (hydrogen) atmospheres. No credible accident initiating events were determined to exist in the above documentation. The drilling of the sample hole and the return hole in the ventilation system was also analyzed. In fact, it was determined by a laboratory demonstration that the autoignition temperature for hydrogen could not be reached during the drilling operation.

If the standard hydrogen monitoring system failed, flamable gases accumulated in concentrations that could be igniced, and an ignition source was introduced, a fire/deflagration could occur in the tank. This is a highly unlikely situation. since all tanks are ventilated (active or passive), the tanks on the flammable gas watich list require a sampling of the tank vapor space to ensure that concentrations are below $25 \%$ of the lower flammable limit before and during any activity in the dome space and/or ventilation system and measures are taken to eliminate spark sources (e.g., electrical grounding and bonding, spark resistant toois and materials, and slow and deliberate insertion or removal of equipment).

However, the consequences of an ignition, of a larqe quantity of flammable gas have been calculated ror lank iol-SY. This calculation assumed that a $34.3 \mathrm{~cm}$ (13.5 inch) level drop occurred and when the peak hydrogen concentration was reached, an ignition source was introduced. This resulted in a fire/deflagration with an associated pressure pulse. The pressure pulse propagated through the ventilation system and blew out the HEPA filters. The HEPA filtors were at their maximum loading. There was also material picked up from the waste surface that was entrained in the gases leaving the tank. The nnsite receptor received an effective dose equivalient of $3.9 \mathrm{mSv}(0.39 \mathrm{rem})$ and the offsite receptor received an effective dose equivalent of $1.05 \mathrm{msv}(0.105 \mathrm{rem})$. The majority of the dose consequence is due to the fitter loading. Therefore, even if other tanks have entrained material from the waste surface that contributes more to the dose consequences, they will not change significantly. Thus, these consequences are representative of consequences on other tanks.

These consequences do not support the classification of the standard hydrogen monitoring system as safety class 1 or safety class 2 . None of the 
R. E. Clayton

Page 3

January 11, 1994

other criteria for safety class 1 or 2 (see MRP 5.46) are satisfied either. It is felt that the failure of the standard hydrogen monitoring system could preclude the implementation of the as low as reasonably achievable principals for exposure to radioactive or nonradiological hazardous materials.

The following tabie presents the various components of the standard hydrogen monitoring system and gives their safety classification.

Table 1. Safety Classification of Standard Hydrogen Monitoring System

\begin{tabular}{|c|c|}
\hline System, Item, or Component & Safety Class \\
\hline Standard Hydrogen Monitoring System & 3 \\
\hline - concrete pad & 4 \\
\hline - tubing & 3 \\
\hline - heat tracing & 3 \\
\hline $\begin{array}{l}\text { - saddle clamp (DSTs) } \\
\text { - water jacketed probe } \\
\text { assemblies (SSTs) }\end{array}$ & $\begin{array}{l}3 \\
3\end{array}$ \\
\hline - electric tie-ins & 3 \\
\hline $\begin{array}{l}\text { - environmentally controlled } \\
\text { instrumentation cabinet }\end{array}$ & 3 \\
\hline - gas rack and bottles & 3 \\
\hline
\end{tabular}

a Note that the exhaust header is safety class 2 while the SHMS is safety class 3 .

If you have any questions, please feel free to contact me on $376-2613$ or via cc:Maj1. Thank you very much.

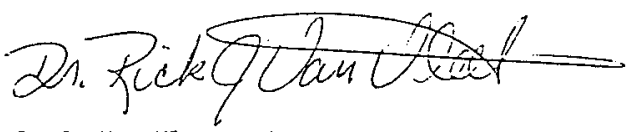

R..J. Van V1eet, Ph.D.

Principal Engineer

Double-She 11 Tank Safety Analys is

gjr 
HNF-SD-WM-RPT-293 REV 0

This page intentionally left blank. 


\begin{tabular}{|c|c|c|c|c|c|c|}
\hline \multicolumn{7}{|c|}{ DISTRIBUTION SHEET } \\
\hline To & \multirow{2}{*}{\multicolumn{4}{|c|}{$\begin{array}{l}\text { From } \\
\text { J. C. Conner }\end{array}$}} & \multicolumn{2}{|l|}{ Page 1 of 1} \\
\hline Distribution & & & & & \multicolumn{2}{|l|}{ Date $4 / 15 / 97$} \\
\hline \multicolumn{5}{|l|}{ Project Title/Work Order } & \multicolumn{2}{|c|}{ EDT No. 616290} \\
\hline \multicolumn{5}{|c|}{$\begin{array}{l}\text { Repository of Not Readily Available Documents for Project } W-320 \\
/ \text { E09120 }\end{array}$} & \multicolumn{2}{|l|}{ ECN No. $\quad \mathrm{N} / \mathrm{A}$} \\
\hline Name & & MSIN & $\begin{array}{c}\text { Text } \\
\text { With All } \\
\text { Attach. }\end{array}$ & Text Only & $\begin{array}{l}\text { Attach./ } \\
\text { Appendix } \\
\text { Only }\end{array}$ & $\begin{array}{l}\text { EDT/ECN } \\
\text { Only }\end{array}$ \\
\hline $\begin{array}{l}\text { JW Bailey } \\
\text { SE Chalk } \\
\text { JC Conner } \\
\text { SK Farnsworth } \\
\text { GW Gault } \\
\text { LE Johnson } \\
\text { RG Stickney } \\
\text { Central Files (2 copies) } \\
\text { Docket Files ( } 2 \text { copies) } \\
\text { Official Project Files } \\
\text { Official Field File, Person (KB }\end{array}$ & Ferlan) & $\begin{array}{l}\text { S2-48 } \\
\text { A2-25 } \\
\text { A2-25 } \\
\text { H5-57 } \\
\text { R1-44 } \\
\text { A2-25 } \\
\text { R1-49 } \\
\text { A3-88 } \\
\text { B } 1-17 \\
\text { R1-28 } \\
\text { S6-12 }\end{array}$ & $\begin{array}{l}X \\
X \\
X \\
X \\
X\end{array}$ & & & $\begin{array}{l}X \\
X \\
X \\
X \\
X\end{array}$ \\
\hline
\end{tabular}

